\title{
AGR-1 Irradiated Compact 6-1-1 PIE Report: Evaluation of As-Irradiated Fuel Performance Using Leach Burn Leach, IMGA, Materialography, and X-ray Tomography
}

\author{
John D. Hunn, Robert N. Morris, Charles A. Baldwin, \\ Fred C. Montgomery, G.W. Chinthaka Silva, and Tyler J. Gerczak
}

ORNL/TM-2012/233

Revision 0

June 2012

Prepared for the United States Department of Energy -

Office of Nuclear Energy under the

Next Generation Nuclear Plant

Fuel Development and Qualification Program 
This report was prepared as an account of work sponsored by an agency of the United States Government. Neither the United States Government nor any agency thereof, nor any of their employees, makes any warranty, express or implied, or assumes any legal liability or responsibility for the accuracy, completeness, or usefulness of any information, apparatus, product, or process disclosed, or represents that its use would not infringe privately owned rights. Reference herein to any specific commercial product, process, or service by trade name, trademark, manufacturer, or otherwise, does not necessarily constitute or imply its endorsement, recommendation, or favoring by the United States Government or any agency thereof. The views and opinions of authors expressed herein do not necessarily state or reflect those of the United States Government or any agency thereof. 


\title{
AGR-1 Irradiated Compact 6-1-1 PIE Report: Evaluation of As-Irradiated Fuel Performance Using Leach Burn Leach, IMGA, Materialography, and X-ray Tomography
}

\author{
J.D. Hunn, R.N. Morris, C.A. Baldwin, F.C. Montgomery, G.W.C. Silva, and T.J. Gerczak
}

Irradiated Compact 6-1-1 from AGR-1 Baseline fuel lot, LEU01-46T-Z, was examined in the asirradiated state to evaluate the irradiation performance of the fuel compact and as a shakedown of the PIE methods and procedures. The compact was electrolytically deconsolidated to recover the individual triisotropic (TRISO) coated particles for examination using the Advanced Irradiated Microsphere Gamma Analyzer (IMGA). IMGA analysis was performed on every particle in the compact to determine the ${ }^{137} \mathrm{Cs}$ and ${ }^{144} \mathrm{Ce}$ isotope inventories. This analysis will detect particles with defective $\mathrm{SiC}$ layers, of which none were found. IMGA analysis using longer collection times was performed on a subset of particles to determine additional gamma-emitting isotope inventories. The IMGA measured a reduced inventory for

${ }^{110 \mathrm{~m}} \mathrm{Ag}$. Leach-burn-leach (LBL) analysis was also performed. After electrolytic deconsolidation, particles and matrix residue were leached twice in nitric acid before the TRISO particles were separated out for the IMGA analysis. Pre-burn leach analysis will detect uranium from kernels that have been exposed due to total failure of the TRISO coatings. Given the fact that no gaseous fission product release indicative of a failed TRISO coating was detected in the irradiation test sweep gas monitors, no exposed kernels were expected, and none were found. After separating out the particles, the matrix residue was burned and the remaining oxide ash was leached twice. After IMGA analysis, about $90 \%$ of the particles were also burned to remove exposed carbon and leached twice to detect exposed uranium and other fission products. This particle burn-leach will also detect particles with defective $\mathrm{SiC}$, and none were found, in agreement with the IMGA result. The pre- and post-burn leach results were summed to obtain an inventory of fission products released by the $\mathrm{SiC}$, but retained in the compact. The LBL analyses detected significant amounts of $\mathrm{Ag}, \mathrm{Eu}$, and $\mathrm{Pd}$ outside of the $\mathrm{SiC}$. Less significant but measurable amounts of $\mathrm{Sr}$, $\mathrm{Ce}$, and Sm were also detected. Several other elements (e.g., Tc, La, Pr, and Nd) were detected by the ICP-MS, but the results were inconclusive because of the possible levels of background contamination in the hot cell. Materialographic analysis was performed on particles selected using the IMGA. Analysis of cross-sectioned particles showed $\mathrm{Pd}$ and U coalesced in regions near the SiC layer, possibly in the form of a silicide. There were also indications that some Pd and U were trapped within the SiC. Significant shrinking of the buffer layer was observed and it was common for buffer layers to detach from the inner pyrocarbon (IPyC). Some of the buffer layers were fractured and portions of the kernels had extruded into the open gap, in some cases protruding all the way out to the IPyC layer. In general, there were no indications of physical irradiation-induced defects in the pyrocarbon or SiC layers. However, one particle was observed to have a cracked IPyC layer where a buffer crack had apparently propagated across the interface. This particle also showed delamination at the IPyC/SiC interface, resulting in a crack in the $\mathrm{SiC}$ that propagated a short distance into the $\mathrm{SiC}$ without penetrating the layer. Because of difficulties encountered with the method for grinding and polishing samples for materialographic inspection, a new method was developed using a Buehler Minimet. This new method was able to produce better planar polishes, allowing for much better imaging using the optical and scanning electron microscopes. An x-ray imaging technique was also demonstrated. The x-ray method showed great promise for non-destructive, three dimensional analysis of the internal microstructure of the irradiated fuel particles. 


\section{Table of Contents}

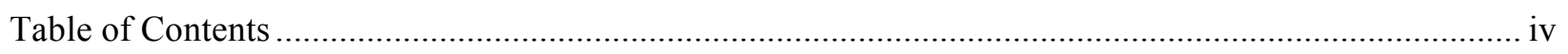

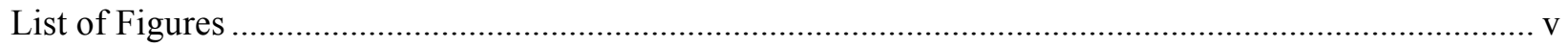

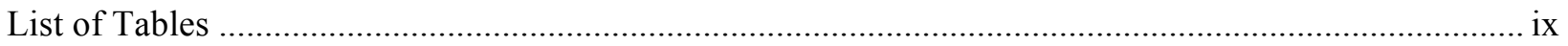

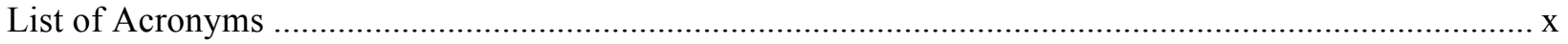

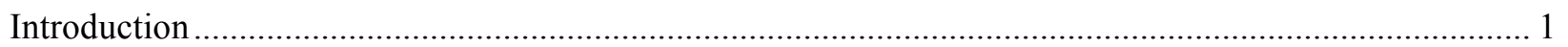

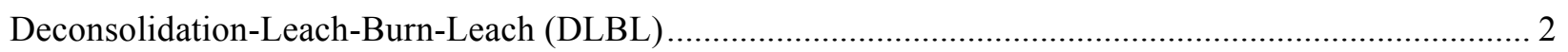

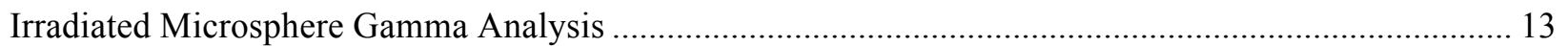

Materialography on Individual Particles: Sample Preparation and Optical Imaging ............................... 34

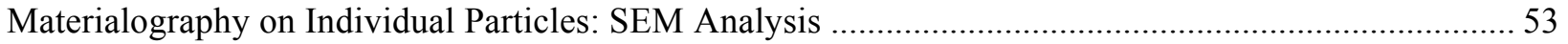

Materialography on Individual Particles: Introduction of the Minimet ............................................... 70

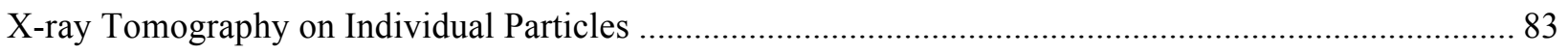

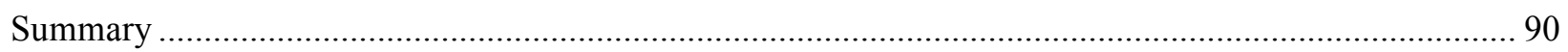

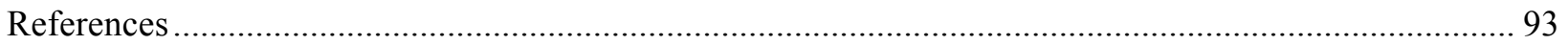




\section{List of Figures}

Figure 1. Flow diagram of Compact DLBL processing. 2

Figure 2. a) Deconsolidation apparatus, b) deconsolidating into the thimble, c) Soxhlet apparatus, d) deconsolidated material and thimble in Soxhlet extractor.

Figure 3. Deconsolidated particles. Two stainless steel calibration spheres provide a visual size reference.

Figure 4. Fully coated TRISO particle diameter measured by shadowscopy on sample of preirradiated particles. Average diameter $=800 \mu \mathrm{m}$, standard deviation $=14 \mu \mathrm{m}[\mathrm{Hunn}$ and Lowden 2006].

Figure 5. Full spectrum gamma scan of pre-burn deconsolidation-leach aliquot..................................... 5

Figure 6. Advanced-IMGA hot cell cubicle in ORNL Building 3525 ........................................... 13

Figure 7. Advanced Irradiated Microsphere Gamma Analyzer........................................................ 14

Figure 8. Advanced-IMGA in cell (left). Carousel for sample vials with Particle Micromanipulator in background (right).

Figure 9. IMGA operating in batch mode operation. Images from left to right: acquiring a particle from a source vial, removing a single particle, positioning the particle in gamma counting location, and returning particle to a selected destination vial.

Figure 10. IMGA operating in vial mode operation. Images from left to right: selecting a vial, transporting vial containing single particle, positioning vial in counting location, and

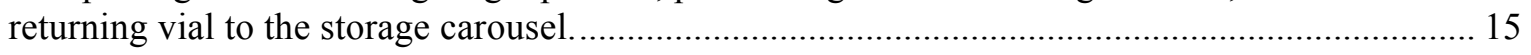

Figure 11. Detector 1 efficiency over the course of AGR-1 Compact 6-1-1 analysis.............................. 17

Figure 12. Average detector 1 efficiency for IMGA 50-cm geometry.................................................. 17

Figure 13. Detector 1 variation in energy peak full-width half-maximum over time. This increase

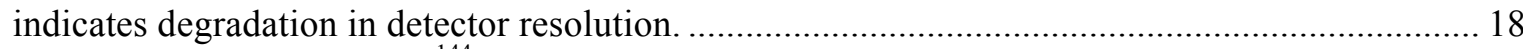

Figure 14. Particle distribution for ${ }^{144} \mathrm{Ce}$ activity (decay corrected to EOL +1 day), normalized to the

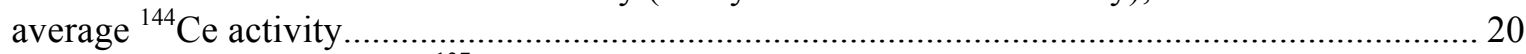

Figure 15. Particle distribution for ${ }^{137} \mathrm{Cs}$ activity (decay corrected to EOL +1 day), normalized to the

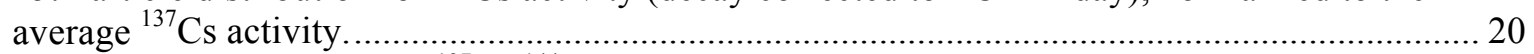

Figure 16. Particle distribution for ${ }^{137} \mathrm{Cs} /{ }^{144} \mathrm{Ce}$ activity ratio (decay corrected to $\mathrm{EOL}+1$ day), normalized to the average ratio.

Figure 17. Estimated fraction of ${ }^{137} \mathrm{Cs}$ retained in particles based on calculated inventory and adjusted for variation in fissionable material and burn-up using the measured ${ }^{144} \mathrm{Ce}$ activity. Results suggest low Cs release and good accuracy in calculated inventory.

Figure 18. Ratio of ${ }^{154} \mathrm{Eu}$ retained in 120 particles versus calculated inventory, adjusted for variation in fissionable material and burn-up using the measured ${ }^{144} \mathrm{Ce}$ activity. Ratio of measured versus calculated value is lower than expected from Eu release measured by other methods, implying the calculated inventory was too high.

Figure 19. Ratio of ${ }^{154} \mathrm{Eu}$ retained in 120 particles versus calculated inventory, adjusted for variation in fissionable material and burn-up using the measured ${ }^{137} \mathrm{Cs}$ activity. ....................................... 23

Figure 20. Ratio of ${ }^{110 \mathrm{~m}} \mathrm{Ag}$ retained in 120 particles versus calculated inventory, adjusted for variation in fissionable material and burn-up using the measured ${ }^{137} \mathrm{Cs}$ activity.

Figure 21. Ratio of ${ }^{154} \mathrm{Eu}$ retained in 73 particles without detectable silver versus calculated inventory, adjusted for variation in fissionable material and burn-up using the measured ${ }^{144} \mathrm{Ce}$ activity.

Figure 22. Ratio of ${ }^{154}$ Eu retained in 47 particles with detectable silver versus calculated inventory, adjusted for variation in fissionable material and burn-up using the measured ${ }^{144} \mathrm{Ce}$ activity........ 25

Figure 23. Ratio of ${ }^{154} \mathrm{Eu}$ retained in 73 particles without detectable silver versus calculated inventory, adjusted for variation in fissionable material and burn-up using the measured ${ }^{137}$ Cs activity.

Figure 24. Ratio of ${ }^{154}$ Eu retained in 47 particles with detectable silver versus calculated inventory, adjusted for variation in fissionable material and burn-up using the measured ${ }^{137} \mathrm{Cs}$ activity....... 26 
Figure 25. Ratio of ${ }^{137} \mathrm{Cs}$ retained in 73 particles without detectable silver versus calculated inventory, adjusted for variation in fissionable material and burn-up using the measured ${ }^{144} \mathrm{Ce}$ activity

Figure 26. Ratio of ${ }^{137} \mathrm{Cs}$ retained in 47 particles with detectable silver versus calculated inventory, adjusted for variation in fissionable material and burn-up using the measured ${ }^{144} \mathrm{Ce}$ activity........ 27

Figure 27. Results of a 6 hour counting time re-analysis of particles that had detectable ${ }^{110 \mathrm{~m}} \mathrm{Ag}$ in the 1 hour gamma scan. Histogram shows the ratio of ${ }^{110 \mathrm{~m}} \mathrm{Ag}$ retained in 49 particles versus calculated inventory, adjusted for variation in fissionable material and burn-up using the measured ${ }^{137} \mathrm{Cs}$ activity. Note that this figure does not represent a random sampling of the ${ }^{110 \mathrm{~m}} \mathrm{Ag}$ distribution because it does not include particles sorted out as having no detectable ${ }^{110 \mathrm{~m}} \mathrm{Ag}$ in the 1 hour scan.

Figure 28. Results of a 6 hour counting time re-analysis of particles that had detectable ${ }^{110 \mathrm{~m}} \mathrm{Ag}$ in the 1 hour gamma scan. Histogram shows the ratio of ${ }^{154} \mathrm{Eu}$ retained in 47 particles versus calculated inventory, adjusted for variation in fissionable material and burn-up using the measured ${ }^{137} \mathrm{Cs}$ activity.

Figure 29. Ratio of ${ }^{110 \mathrm{~m}} \mathrm{Ag}$ retained in 122 particles versus calculated inventory, adjusted for variation in fissionable material and burn-up using the measured ${ }^{137} \mathrm{Cs}$ activity. Solid bars indicated measured values from 6 hour gamma scan. Hollow bars indicate estimated distribution for remaining particles with undetectable ${ }^{110 \mathrm{~m}} \mathrm{Ag}$ in 1 hour gamma scan................... 30

Figure 29. Variation in SiC surface appearance of particles after burn back to remove the OPyC

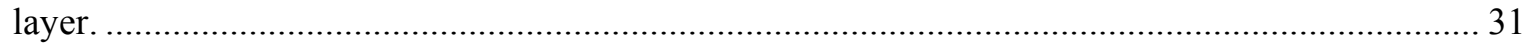

Figure 30. Assembly for mounting particles in a fixed array. .......................................................... 35

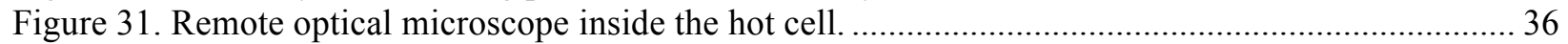

Figure 32. Workstation for remote optical microscope adjacent to hot cell cubicle................................. 36

Figure 33. Rough polish of unirradiated particle mixed in with IMGA sample (Mount 6350)................. 38

Figure 34. Rough polish of unirradiated particle mixed in with IMGA sample (Mount 6351)................. 38

Figure 35. Rough polish of particle with low ${ }^{144} \mathrm{Ce}$, but normal ${ }^{137} \mathrm{Cs} /{ }^{144} \mathrm{Ce}$ ratio (Mount 6349).............. 39

Figure 36. Rough polish of particle with low ${ }^{144} \mathrm{Ce}$, but normal ${ }^{137} \mathrm{Cs} /{ }^{144} \mathrm{Ce}$ ratio (Mount 6349)............... 39

Figure 37. Rough polish of particle with low ${ }^{144} \mathrm{Ce}$, but normal ${ }^{137} \mathrm{Cs} /{ }^{144} \mathrm{Ce}$ ratio (Mount 6349).............. 40

Figure 38. X-ray image of pre-irradiated fuel particles from AGR-1 Baseline compact showing small diameter kernel

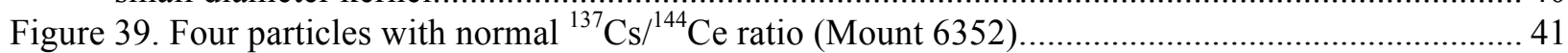

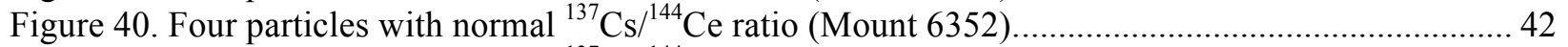

Figure 41. Four particles with normal ${ }^{137} \mathrm{Cs} /{ }^{144} \mathrm{Ce}$ ratio (Mount 6353). The radial cracks in the SiC are artifacts of a non-optimized grinding process.

Figure 42. Four particles with normal ${ }^{137} \mathrm{Cs} /{ }^{144} \mathrm{Ce}$ ratio (Mount 6353). The radial cracks in the SiC are artifacts of a non-optimized grinding process. The buffer and kernel were pulled out of the particle in the lower right during sample preparation...

Figure 43. Particle from Mount 6353. Buffer and IPyC appear to have cracked simultaneously and separation of IPyC from $\mathrm{SiC}$ appears to have cracked SiC.

Figure 44. Four general kernel surface types observed in AGR-1 fuel particles. Relative populations of the various types was 30\% Type $1,40 \%$ Type $2,15 \%$ Type 3 , and $15 \%$ Type $4 .$.

Figure 45. Six general kernel microstructure types observed in AGR-1 Baseline fuel particles.

Rough estimate of relative populations of the various types was 44\% Type A, 14\% Type B, 25\% Type C, 2\% Type D, 10\% Type E, and 5\% Type F.

Figure 46. Irradiated kernels from Mounts 6352 and 6353 with two regions of different porosity, possibly related to kernels with a symmetric microstructure and thick, well-defined oxide rind (Types A and B).

Figure 47. Irradiated kernels from Mount 6353 with less obvious demarcation between fine porosity and coarse porosity, possibly related to kernels with thin, less well-defined oxide rind (Type C).

Figure 48. Irradiated kernels from Mount 6353 with asymmetric porosity, possibly related to kernels with asymmetric carbide content (Type E). 
Figure 49. Irradiated kernel from Mount 6353 with possible aspherical shape, similar to Type F kernels.

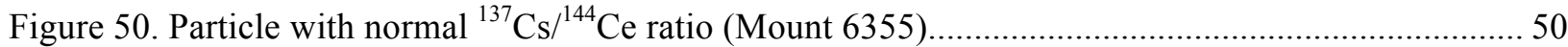

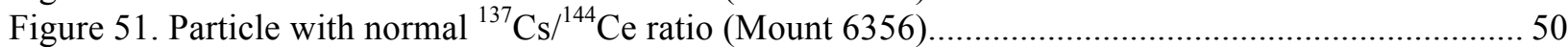

Figure 52. Particle Ag-14 with below average ${ }^{110 \mathrm{~m}} \mathrm{Ag}$ inventory (Mount 6357) .................................... 51

Figure 53. Particle Ag-18 with below average ${ }^{110 \mathrm{~m}} \mathrm{Ag}$ inventory (Mount 6357)................................... 52

Figure 54. Particle Ag-51 with no detectable ${ }^{110 \mathrm{~m}} \mathrm{Ag}$ inventory (Mount 6359) ......................................... 52

Figure 55. SEM with WDS/EDS in position in the CCCTF hot cell cubicle. ........................................ 54

Figure 56. BSE image of Particle Ag-14 with below average ${ }^{110 \mathrm{~m}} \mathrm{Ag}$ inventory (Mount 6357)................ 55

Figure 57. BSE image of Particle Ag-18 with below average ${ }^{110 \mathrm{~m}} \mathrm{Ag}$ inventory (Mount 6357)............... 56

Figure 58. BSE image of Particle Ag-51 with less than detectable ${ }^{110 \mathrm{~m}} \mathrm{Ag}$ inventory (Mount 6359)........ 56

Figure 59. BSE image of Particle Ag-18 IPyC/SiC interface (Mount 6357) showing embedded FP

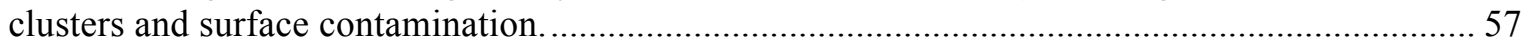

Figure 60. SE image of the same area on Particle Ag-18 shown in Figure 59 showing different appearance for embedded FP clusters and surface contamination. ..............................................5 57

Figure 61. BSE image of Particle Ag-14 with below average ${ }^{110 \mathrm{~m}} \mathrm{Ag}$ inventory (Mount 6357)

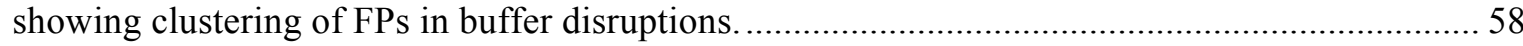

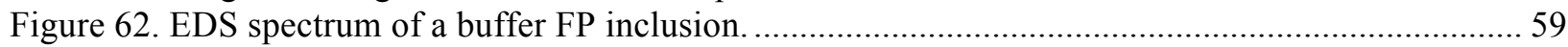

Figure 63. WDS wavescan on PET crystal from 2.48-2.94 $\AA$ indicating there was no Ce present in

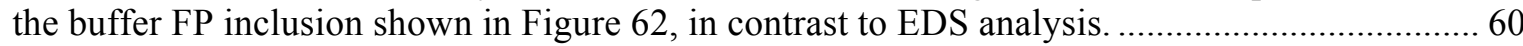

Figure 64. Regions of interest used for Cs distribution analysis, conducted on Particle Ag-18.............. 61

Figure 65. BSE image indicating embedded FP cluster at IPyC/SiC interface in Particle Ag-14, analyzed by WDS (wavescan in Figure 62).

Figure 66. WDS wavescan on PET crystal from 3.65-4.41 $\AA$ of Particle Ag-14 indicating Pd and U

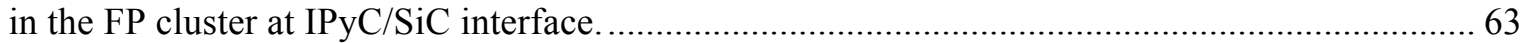

Figure 67. WDS wavescans on LiF crystal from 2.32-2.42 $\AA$ and PET crystal from 2.51-2.61 $\AA$ of the normal particle in Mount 6355 indicating Ce and Nd.

Figure 68. BSE image indicating embedded FP cluster in Particle Ag-51 analyzed by WDS (wavescan in Figure 65).

Figure 69. WDS wavescans on PET crystal from 3.65-4.01 $\AA$ and 4.10-4.41 $\AA$ of Particle Ag-51 indicating $\mathrm{Pd}$ and $\mathrm{U}$ in the $\mathrm{FP}$ cluster.

Figure 70. Example of unirradiated $\mathrm{SiC}$ microstructure from LEU01-27T representative of three of the four coater batches in the AGR-1 Baseline fuel composite ( $71 \%$ of the composite).

Figure 71. Example of unirradiated $\mathrm{SiC}$ microstructure from LEU01-45T representative of one of the four coater batches in the AGR-1 Baseline fuel composite ( $29 \%$ of the composite).

Figure 72. High contrast BSE image of Particle Ag-14 with below average ${ }^{110 \mathrm{~m}} \mathrm{Ag}$ inventory (Mount 6357).

Figure 73. High contrast BSE image of Particle Ag-18 with below average ${ }^{110 \mathrm{~m}} \mathrm{Ag}$ inventory (Mount 6357)......

Figure 74. High contrast BSE image of Particle Ag-51 with no detectable ${ }^{110 \mathrm{~m}} \mathrm{Ag}$ inventory (Mount 6359).

Figure 75. High contrast BSE image of SiC layer near kernel extrusion of Particle Ag-14 (Mount 6357).

Figure 76. Buehler Minimet 1000 with precision thinning attachment.

Figure 77. Mounts for polishing particles have been made using Garolite and aluminum (left).

Image at right shows an aluminum mount loaded on the underside of the thinning attachment

Figure 78. Particle Ag-16 from Compact 6-1-1 (Mount MM-C) polished on Minimet............................ 72

Figure 79. Higher magnification image of particle from Figure 78 (Particle Ag-16)............................ 73

Figure 80. Higher magnification image of particle from Figure 78 (Particle Ag-16)............................ 73

Figure 81. Higher magnification image of particle from Figure 78 (Particle Ag-16)........................... 74

Figure 82. Higher magnification image of particle from Figure 78 (Particle Ag-16). ............................ 74

Figure 83. Higher magnification image of particle from Figure 78 (Particle Ag-16). ............................ 75

Figure 84. Digital zoom of image in Figure 83 (Particle Ag-16)....................................................... 75 
Figure 85. Particle Ag-02 from Compact 6-1-1 (Mount MM-A) polished on Minimet........................... 76

Figure 86. Higher magnification image of particle from Figure 85 (Particle Ag-02) ........................... 77

Figure 87. Higher magnification image of particle from Figure 85 (Particle Ag-02) ............................ 77

Figure 88. Higher magnification image of particle from Figure 85 (Particle Ag-02). ........................... 78

Figure 89. Particle Ag-54 from Compact 6-1-1 (Mount MM-D) polished on Minimet............................ 78

Figure 90. Higher magnification image of particle from Figure 89 (Particle Ag-54). ............................ 79

Figure 91. Higher magnification image of particle from Figure 89 (Particle Ag-54). ........................... 79

Figure 92. Higher magnification image of particle from Figure 89 (Particle Ag-54). ............................ 80

Figure 93. Particle Ag-15 from Compact 6-1-1 (Mount MM-B) polished on Minimet............................ 80

Figure 94. Higher magnification image of particle from Figure 93 (Particle Ag-15). .......................... 81

Figure 95. Higher magnification image of particle from Figure 93 (Particle Ag-15).......................... 81

Figure 96. Higher magnification image of particle from Figure 93 (Particle Ag-15) ........................... 82

Figure 97. Shielded enclosure for $x$-ray tomography of irradiated fuel particles................................... 84

Figure 98. Shielded enclosure in position in x-ray tomography instrument. The x-ray source is shown on the left and the detector on the right of the shield enclosure. ....................................... 84

Figure 99. Xradia x-ray tomography system for coated particle imaging. .............................................. 85

Figure 100. X-ray tomograph near mid-plane of particle in Mount XR-1 . ............................................. 86

Figure 101. X-ray tomograph near mid-plane of particle in Mount XR-1 (orthogonal to tomograph

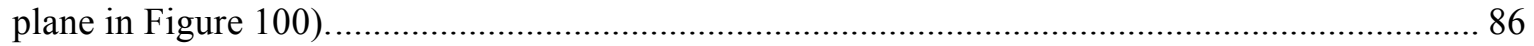

Figure 102. Enhanced resolution tomographic reconstruction of upper region of particle in Mount

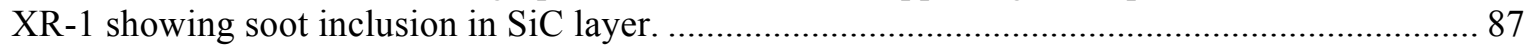

Figure 103. X-ray tomograph of an irradiated TRISO particle showing cracking in the buffer layer and kernel extrusion

Figure 104. X-ray tomograph of an irradiated TRISO particle showing fission products coalesced at

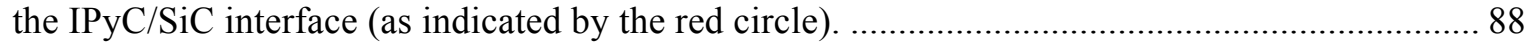

Figure 105. Three dimensional visualization of the extruded kernel from Particle Ag-19.................... 88

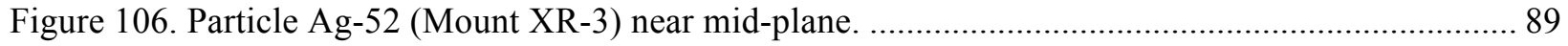




\section{List of Tables}

Table 1. Compact inventory fractions for $U$ and Pu detected by LBL of irradiated Compact 6-1-1 (analyzed by mass spectrometric method). None of the measured values are significantly above background....

Table 2. Compact inventory fractions of important gamma emitting fission products detected by LBL of AGR-1 irradiated Compact 6-1-1 (analyzed by gamma spectrometric method).... 10

Table 3. Compact inventories of stable isotopes of interest in leach solutions from LBL of irradiated Compact 6-1-1 (analyzed by mass spectrometric method) 11

Table 4. Comparison of the compact fraction of isotopes in leach solutions measured by GS and ICP-MS 12

Table 5. Parameters used in analysis of IMGA examination results (key peaks highlighted). 16

Table 6. Summary of results from 6 hour IMGA analysis. 32

Table 7. Results of 6 hour gamma scanning showing measured activity (Bq/particle decay-corrected to EOL+1day) for key peaks from Table 5 . 32

Table 8. List of materialographic mounts of particles from Compact 6-1-1 …...................................... 37

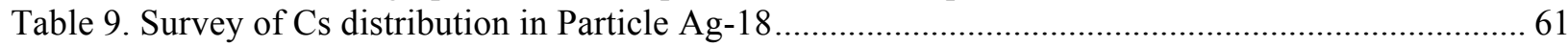

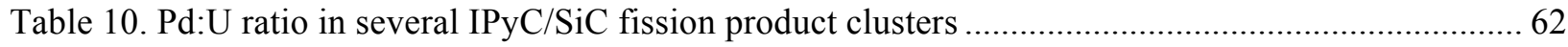

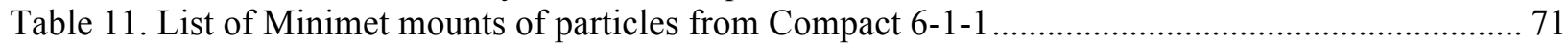

Table 12. Particles from Compact 6-1-1 imaged by x-ray tomography 85 


\section{List of Acronyms}

$\begin{array}{ll}\text { AGR } & \text { Advanced Gas Reactor } \\ \text { ATR } & \text { Advanced Test Reactor } \\ \text { BSE } & \text { Backscattered Electron } \\ \text { CCCTF } & \text { Core Conduction Cool-down Test Facility } \\ \text { DLBL } & \text { Deconsolidation Leach-Burn-Leach } \\ \text { EDS } & \text { Energy Dispersive Spectrometry } \\ \text { FIMA } & \text { Fissions per Initial Metal Atom } \\ \text { FP } & \text { Fission Product } \\ \text { GS } & \text { Gamma Spectrometry } \\ \text { ICP-MS } & \text { Inductively Coupled Plasma Mass Spectrometry } \\ \text { IFEL } & \text { Irradiated Fuels Examination Laboratory } \\ \text { IMGA } & \text { Irradiated Microsphere Gamma Analyzer } \\ \text { INL } & \text { Idaho National Laboratory } \\ \text { IPyC } & \text { Inner Pyrocarbon (layer) } \\ \text { LBL } & \text { Leach-Burn-Leach } \\ \text { LEU } & \text { Low Enriched Uranium } \\ \text { MCA } & \text { Multi-Channel Analyzer } \\ \text { OPyC } & \text { Outer Pyrocarbon (layer) } \\ \text { ORNL } & \text { Oak Ridge National Laboratory } \\ \text { PET } & \text { Pentaerythritol } \\ \text { PyC } & \text { Pyrocarbon (layer) } \\ \text { SE } & \text { Secondary Electron } \\ \text { SEM } & \text { Scanning Electron Microscope } \\ \text { SiC } & \text { Silicon Carbide (layer) } \\ \text { TAP } & \text { Thallium Acid Pthalate } \\ \text { TEM } & \text { Transmission Electron Microscope } \\ \text { TRISO } & \text { Tri-Isotropic (coated particles) } \\ \text { UCO } & \text { Uranium oxide/uranium carbide (kernels) } \\ \text { WDS } & \text { Wavelength Dispersive Spectrometry } \\ & \end{array}$




\section{Introduction}

The AGR-1 irradiation test train consisted of six independently monitored capsules. All capsules contained twelve compacts in three stacks of four compacts each [Pope 2010]. Compact 6-1-1 was located in capsule 6, at the top of the test train. The compact was in stack 1 (one of the two stacks closest to the core) in position 1 (at the bottom of the 4 compact stack). Compact 6-1-1 was identified in the fabrication data package as LEU01-46T-Z32 [Hunn et al. 2006]. Details of the compact fabrication and measured properties can be found in that data package. The compact lot was made using TRISO-coated particles designated as AGR-1 Baseline fuel. These particles contained 19.7\% enriched mixed uranium oxideuranium carbide (UCO) kernels with a $\mathrm{O} / \mathrm{U}$ atomic ratio of $\sim 1.36$ and a $\mathrm{C} / \mathrm{U}$ atomic ratio of $\sim 0.33$ [Pope 2010]. Details of the coated particle fabrication and measured properties can be found in the data package for the AGR-1 Baseline particles [Hunn and Lowden 2006]. The compact was irradiated at the INL Advanced Test Reactor (ATR) to an average calculated burn-up of 15.1\% fissions per initial metal atom (FIMA) and an average calculated fast fluence of $3.0 \times 10^{25} \mathrm{n} / \mathrm{m}^{2}$ [Sterbentz 2011] at a calculated volume averaged and time averaged temperature of approximately $1111^{\circ} \mathrm{C}$ [Hawkes 2012]. Capsules were disassembled and preliminary compact and graphite holder inspection was performed [Demkowicz et al. 2011]. Compact 6-1-1 was shipped to ORNL and post-irradiation examination (PIE) was performed according to examination plan PLN-3624 [Demkowicz 2010-2]. All the examination plan objectives listed below were completed except item 6 , which was deleted due to limited funding.

1. Determine the inventory of fission products retained in the compact matrix, but not contained by the $\mathrm{SiC}$ and determine the number of exposed kernels or particles with defective $\mathrm{SiC}$ layers using the deconsolidation-leach-burn-leach method.

2. Gamma count all particles to quantify ${ }^{137} \mathrm{Cs}$ inventory for comparison with calculated values and gamma spectrometric measurements made on the whole compact. Also, attempt to quantify the inventory of any other fission products for which gamma emissions are observed.

3. Characterize each particle based on the ${ }^{137} \mathrm{Cs} /{ }^{144} \mathrm{Ce}$ ratio to identify particles with low Cs retention that may be the result of a failed $\mathrm{SiC}$ coating.

4. Gamma count a subset of particles to determine the ${ }^{110 \mathrm{~m}} \mathrm{Ag}$ inventory for comparison with calculated values and gamma spectrometric measurements made on the whole compact. Also, attempt to quantify the inventory of other fission products observed.

5. Microscopically inspect selected particles to determine the condition of the kernels and coatings. This could include kernel migration, coating microstructures and defects, fission product attack of the $\mathrm{SiC}$ layer, and fission product migration in the coating layers.

6. Perform high temperature fission product release tests on a subset of particles in order to calibrate the collection efficiency of the Core Conduction Cooldown Test Facility (CCCTF) deposition cup for selected fission products. Gamma count particles before and after the heating test to quantify the released fission product fractions.

7. Archive remaining particles for later use.

Compact 6-1-1 LBL began with compact deconsolidation in the Building 3525 hot cell, followed by two nitric acid leaches of the particles and matrix residue using a Soxhlet extraction apparatus. The matrix residue was then burned and the ash was leached twice with boiling nitric acid. The deconsolidated particles underwent an IMGA analysis to determine gamma-emitting isotope inventories for individual particles; the most conspicuous elements with reduced inventories, indicating fission product release, were silver and europium. During the IMGA analysis, particles with low silver were identified and a subset of these was set aside for materialography and x-ray. After the completion of the IMGA study, about $10 \%$ of the particles (421) were set aside as an archive and the remainder burned back and leached twice in the Soxhlet apparatus. Figure 1 shows a flow chart detailing the PIE of Compact 6-1-1. 


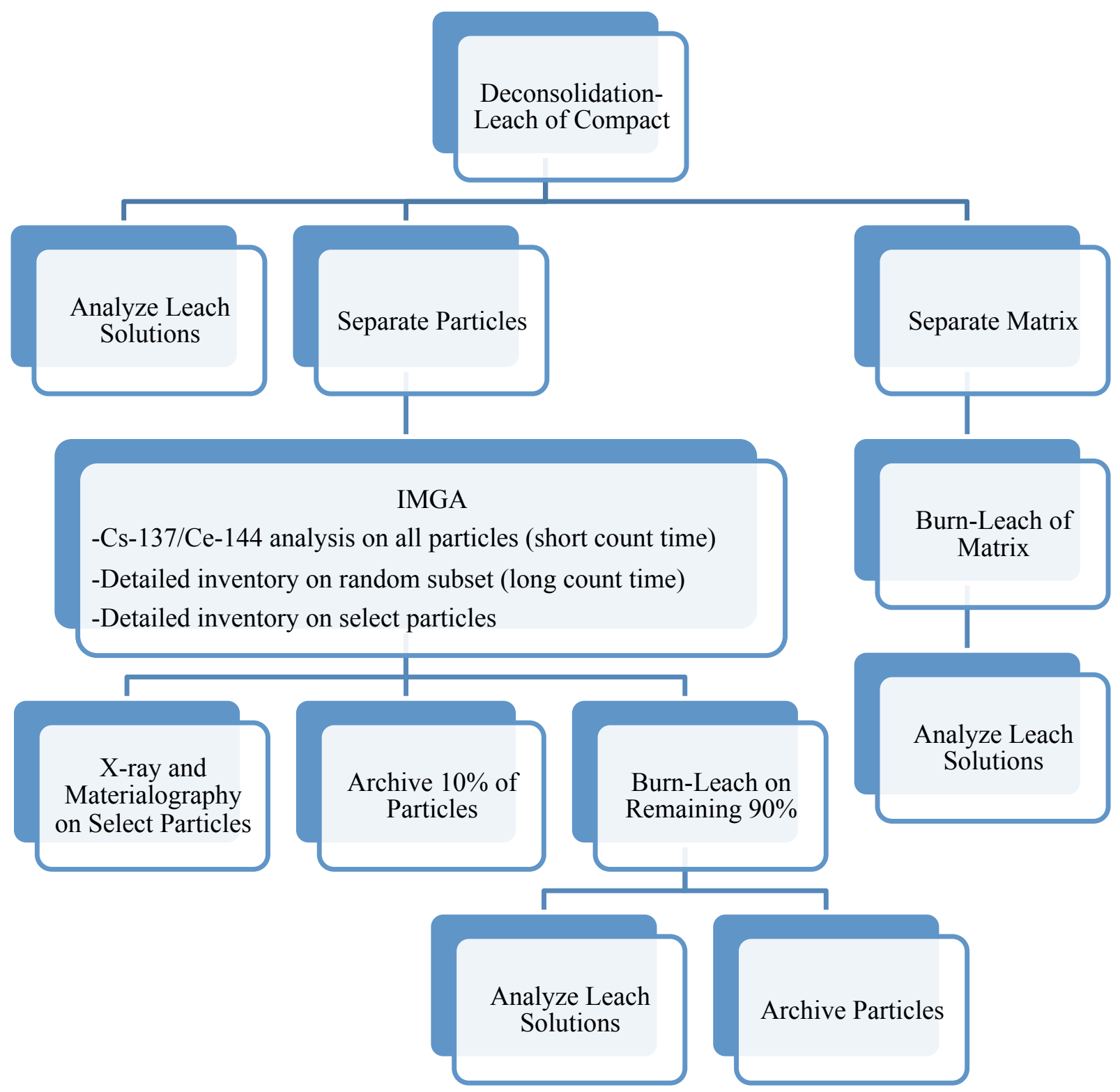

Figure 1. Flow diagram of Compact DLBL processing.

\section{Deconsolidation-Leach-Burn-Leach (DLBL)}

A photo sequence of the deconsolidation and leaching process is shown in Figure 2. Deconsolidation of the compact was done at room temperature by applying 0.62 amperes through the length of the compact with the bottom of the compact submersed in concentrated nitric acid (EMD, OmniTrace, 69$70 \%$ ). The applied potential was about 2.5 volts. The deconsolidation required about 5 hours. As the compact deconsolidated, the particles and matrix residue were collected in a medium porosity quartz frit Soxhlet extraction thimble. After deconsolidation, the thimble was placed into the Soxhlet apparatus and the deconsolidation solution was added to the Soxhlet boiling flask. During extraction, nitric acid vapor from the boiling flask at the bottom was collected by the condenser at the top and returned to the extractor in the middle. The particles and matrix residue in the thimble were leached by extraction with hot nitric acid for about 24 hours. After the $24 \mathrm{hr}$ extraction, the leach solution was removed, the volume measured, and a sample was taken for analysis. Clean nitric acid was then added to the boiling flask and the extraction was repeated for an additional 24 hours. 

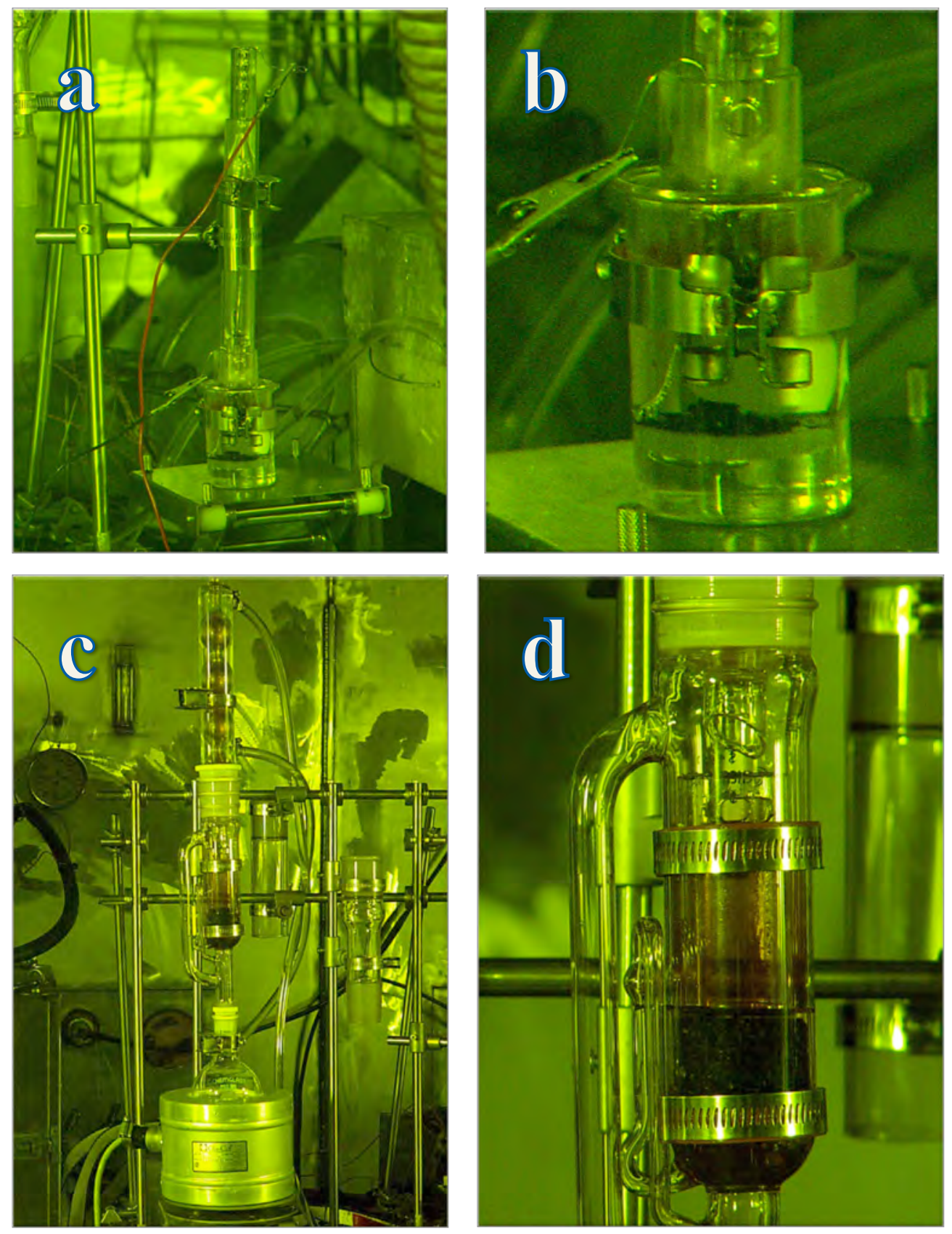

Figure 2. a) Deconsolidation apparatus, b) deconsolidating into the thimble, c) Soxhlet apparatus, d) deconsolidated material and thimble in Soxhlet extractor.

The deconsolidated particles and matrix residue from the thimble were further digested in boiling concentrated nitric acid for about $24 \mathrm{hr}$ to remove any remaining matrix overcoat from the outer pyrocarbon $(\mathrm{OPyC})$ layer of the particles. The particles were then collected by pouring the digested slurry through a nominally $500 \mu \mathrm{m}$ square opening stainless steel sieve to separate out the particles and pass the acid and fine matrix material through to a stainless steel pan. The deconsolidated particles are shown in Figure 3. The particles appeared to be mostly free of any graphite matrix with no apparent damage to the OPyC. The recovered particle size was in good agreement with the average TRISO particle diameter of $800 \mu \mathrm{m}$ (Figure 4) measured on the unirradiated particles [Hunn and Lowden 2006]. 


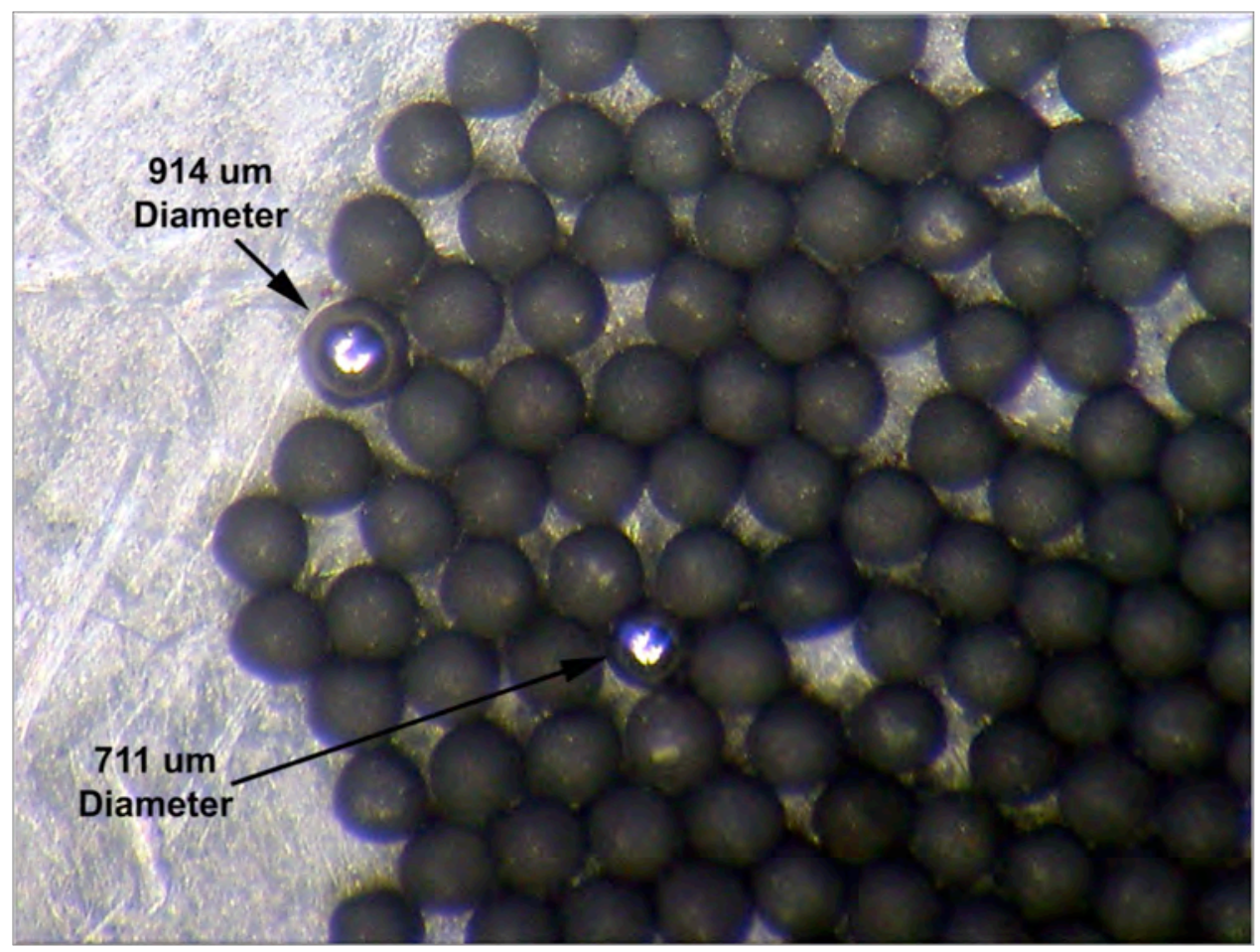

Figure 3. Deconsolidated particles. Two stainless steel calibration spheres provide a visual size reference.

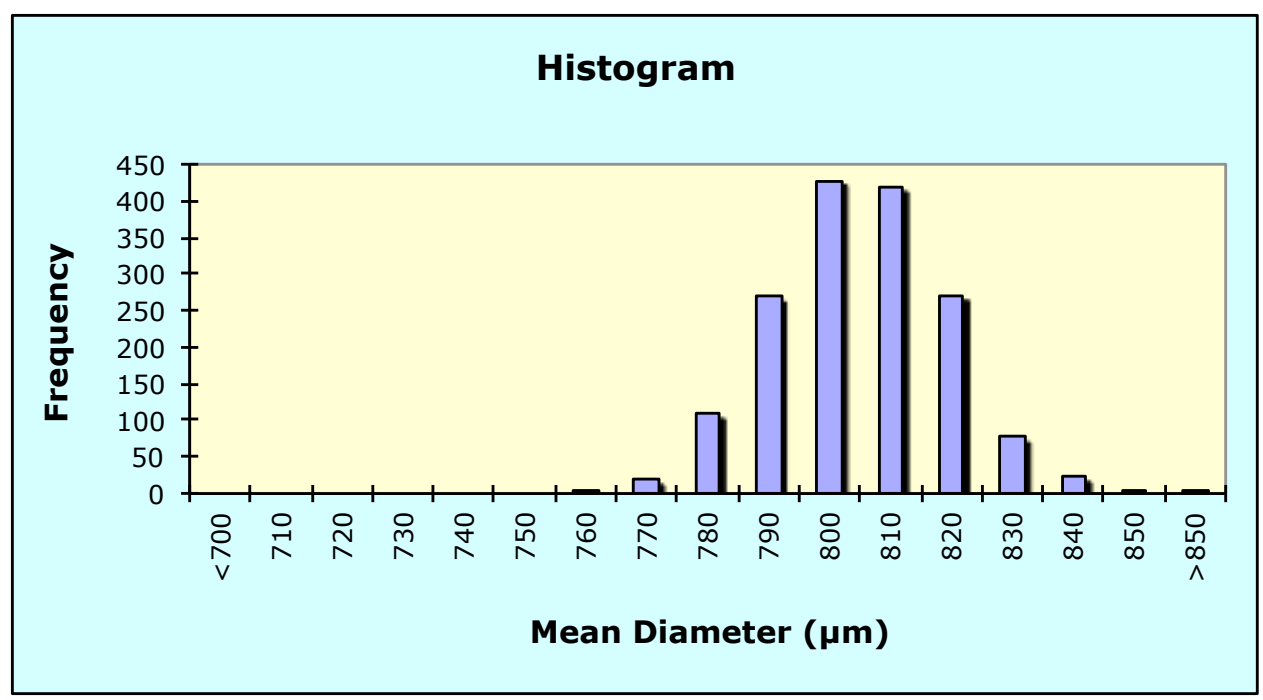

Figure 4. Fully coated TRISO particle diameter measured by shadowscopy on sample of preirradiated particles. Average diameter $=800 \mu \mathrm{m}$, standard deviation $=14 \mu \mathrm{m}$ [Hunn and Lowden 2006].

The nitric acid slurry from the sieve pan, containing the compact matrix material, was placed into a quartz $250 \mathrm{ml}$ round bottom flask and the acid was distilled from the suspension by heating. The resulting dry matrix carbon residue was burned in a box furnace (modified Neytech Vulcan 3-550) at $750^{\circ} \mathrm{C}$ in air for 24 hours. There appeared to be a considerable amount of white oxide ash left after the burn. The ash was leached twice for $24 \mathrm{hr}$ with boiling concentrated $\mathrm{HNO}_{3}$ and a sample of each leachant was transferred to analytical radiochemistry for analysis. There was a small amount of white residue remaining on the inside of the quartz vessel after the two leaches. 
The TRISO coated particles that were separated out were transferred to the IMGA cubicle for analysis (discussed in the next section). After IMGA analysis, $421(\sim 10 \%)$ of the particles were set aside for additional analysis, while the remaining particles were returned for completion of the DLBL analysis. Particles were returned to the Soxhlet thimble and burned in air at $750^{\circ} \mathrm{C}$ for 72 hours. After the burn, two more $24 \mathrm{hr}$ nitric acid leaches by extraction were completed, similar to the pre-burn phase.

Aliquots from the 2 pre-burn leaches, the 2 post-burn matrix leaches, and the 2 post-burn particle leaches were taken for analysis. The aliquots from each leach solution were analyzed using Gamma Spectrometry (GS) and Inductively Coupled Mass Spectrometry (ICP-MS). For the GS analysis, a full spectrum gamma scan was performed to identify any significant gamma-emitting isotopes (Figure 5). Based on the results of this scan, quantitative analysis was performed on selected isotopes. The gamma activity from each selected isotope in an aliquot was measured and this result was used to determine the total activity $(A)$ of that isotope in the associated leach solution. From this total activity, the number of atoms leached could be estimated as $N=A / \lambda$, where the decay constant $\lambda=\ln (2) / t_{1 / 2}$ was calculated for each isotope using the half-life $\left(t_{1 / 2}\right)$ reported at http://www.matpack.de/Info/index.html. The number of atoms leached was then decay-corrected using the equation, $N(t)=N_{0} e^{-\lambda t}$, to estimate the number of atoms $\left(N_{0}\right)$ that would have been leached 24 hours after completion of the last irradiation cycle (i.e., end of life, $\mathrm{EOL}=11 / 06 / 2009$ at 0500 hours MST), where $t$ was the time elapsed in seconds from EOL +1 day to the time the gamma scan analysis was performed. Final results for each of the selected isotopes are reported in terms of compact inventory fraction and equivalent particle inventory. The compact inventory fraction was calculated from the number of atoms that would have been leached at EOL +1 day divided by the calculated EOL +1 day inventory for that isotope [Sterbentz 2011 or Parry 2009]. The equivalent particle inventory was calculated by multiplying the compact inventory fraction by the average number of particles in the compact.

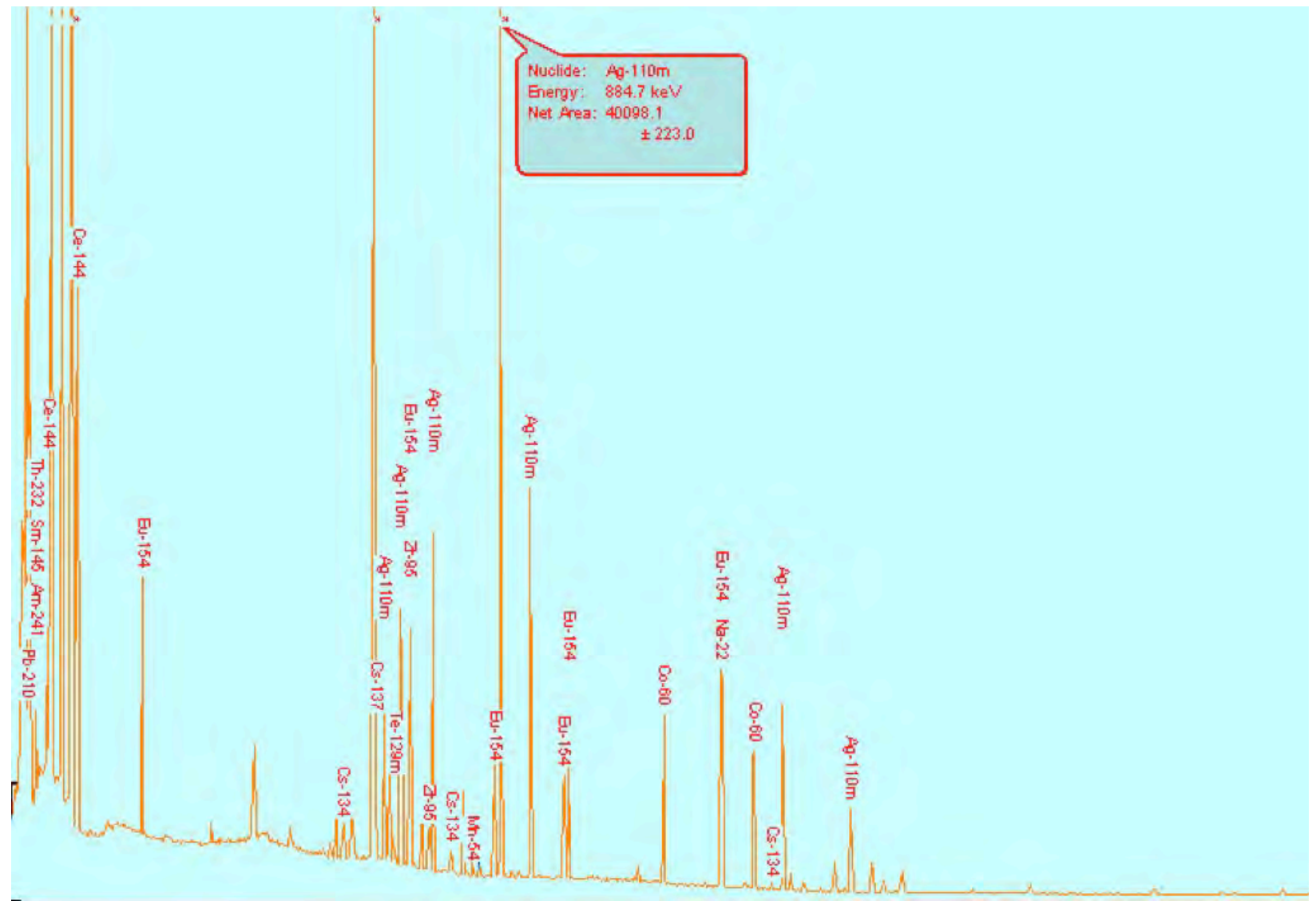

Figure 5. Full spectrum gamma scan of pre-burn deconsolidation-leach aliquot. 
For the ICP-MS analysis, a full spectrum mass scan was performed to identify any significant stable isotopes in the leachant aliquots. Based on the results of this scan, quantitative analysis was performed on selected isotopes. Using calibrated standard solutions, the concentration of each isotope in an aliquot was determined. This was used to calculate the total amount of each isotope in the leach solution. Again, final results are reported in terms of compact inventory fraction and equivalent particle inventory, as described above.

Results of the LBL analysis are shown in Table 1, Table 2, and Table 3. Results are presented in terms of compact inventory and equivalent particle inventory, as discussed above. The compact inventory fractions were based on calculations by [Sterbentz 2011], except for those isotopes noted in Table 3, where EOL compact inventories from [Parry 2009] were used in the absence of available data from the more recent Sterbentz calculations. The average inventory in one particle is equivalent to a compact fraction of $2.4 \cdot 10^{-4}$, based on a measured average of 4145 particles per AGR-1 Baseline fuel compact [Hunn et al. 2006]. Values below the analytical threshold for the GS or ICP-MS analysis are noted by a $<$ symbol and reported totals at the bottom of each table do not include these values. It is important to consider possible uncertainties and contributing factors when drawing conclusions from the data presented in these tables. Summation of values near the threshold limits of the analysis, background contributions from hot cell contamination, and error in the calculated inventories used to derive the compact inventory fractions can lead to apparent release values equivalent to the inventory of several particles. In addition to recognizing these possible contributions to an over-estimation of the fission product release, it is also important to note that the LBL analysis only detects fission products released through the $\mathrm{SiC}$ but still retained in the compact. Analysis is being performed at INL to measure the release of some elements from the compacts to the irradiation capsule components, and this additional information is important in understanding the overall fission product release behavior. Large amounts of silver and traces of europium, cesium, cerium and strontium have been detected [Harp et al. 2012].

From the data in Table 1, it can be concluded that there were no exposed kernels at any stage of analysis. If any kernels had been exposed due to broken TRISO coatings in the pre-burn analysis or due to defective $\mathrm{SiC}$ in the post-burn analysis, then the equivalent particle inventory detected for uranium would have been, at a minimum, close to one. It cannot be concluded from the current analysis if the detected uranium or plutonium levels reported in Table 1 come from actual heavy metal release or from background contamination in the hot cell. In fact, it is very likely that the detected plutonium did not come from actual heavy metal release. Prior to the first Soxhlet extraction, acid cleaning of the apparatus and analysis of the cleaning solutions indicated high levels of uranium and plutonium contamination from the surrounding hot cell area. Even during subsequent acid cleaning of the Soxhlet apparatus before the post-burn leaching, uranium and plutonium levels were still often at similar levels to those detected in the leach solutions. Acid cleaning of the Soxhlet apparatus immediately prior to leaching was used to reduce contamination in the glassware, but particle handling may have resulted in pick-up of additional contamination from the hot cell area. The most significant fraction of the total detected $\mathrm{Pu}$ was found in the post-burn particle leach. This is probably related to the fact that comparatively more particle handling (e.g., sieving, sample transfer, and IMGA analysis) occurred prior to the post-burn particle leach. There was also a significant disagreement between the measured fraction for the two $\mathrm{Pu}$ isotopes, indicating the source of the observed plutonium was probably not from the compact being analyzed. In Table 1, an estimated range for the amount of background contamination that may have gotten into the leach solutions is provided based on the results of the pre-leach acid rinses of the extraction apparatus. Comparison of the measured values for each leach to this estimated range indicates a high probability that the amounts detected in the leaches could have come from background contamination.

Table 2 summarizes the measured inventories for those isotopes that could be analyzed by gamma spectrometry (or by chemical separation and beta analysis, in the case of ${ }^{90} \mathrm{Sr}$ ). As was done for Table 1, background contamination was estimated from analysis of the acid solutions used to clean the Soxhlet extractor at the start of each leaching series. Values that primarily contributed to the total for each isotope are highlighted by shading the table cell in gray. Values which are low compared to possible background contributions are presented as gray text. The values measured in the leach solutions for ${ }^{106} \mathrm{Ru}$ can be discounted. These results appear to be dominated by contributions from hot cell contamination; reported 
values are close to background and the value from the second leach in each series was higher than the first leach. The values for cesium, if they are real, are too low to measure with confidence. Relative concentrations in first and second leaches at each stage are consistent, but the only results that are high enough to not have been dominated by possible background contamination are for the first post-burn matrix leach and possibly the first pre-burn leach. The fact that the ${ }^{137} \mathrm{Cs}$ is consistently higher than the ${ }^{134} \mathrm{Cs}$ is probably related to the higher background contamination for ${ }^{137} \mathrm{Cs}$. In contrast, the measured values for ${ }^{154} \mathrm{Eu},{ }^{155} \mathrm{Eu}$, and ${ }^{110 \mathrm{~m}} \mathrm{Ag}$ were clearly significant and correspond to relatively high fractions of the calculated compact inventories. The first leach in each of the pre-burn and post-burn analyses for europium was well above background and there was excellent agreement between the two isotopes for all leaches. The ${ }^{110 \mathrm{~m}} \mathrm{Ag}$ analyses were also well above background. The fractional release of silver was, by far, the highest for all the isotopes measured. Results for ${ }^{144} \mathrm{Ce}$ and ${ }^{90} \mathrm{Sr}$ also appear to be real when compared to background contamination, but the compact inventory fractions were not as significant as for silver and europium. These isotopes should be monitored in future tests.

The results for ${ }^{95} \mathrm{Zr}$ were complicated by an interference with ${ }^{154} \mathrm{Eu}$. The two main energy peaks from the gamma decay of ${ }^{95} \mathrm{Zr}$ are $724.2 \mathrm{keV}$ (with a branching ratio of 0.442 ) and $756.7 \mathrm{keV}$ (with a branching ratio of 0.548 ). These overlap with two energy peaks from the gamma decay of ${ }^{154} \mathrm{Eu}$ at $724 \mathrm{keV}$ (with a branching ratio of 0.197 ) and $756 \mathrm{keV}$ (with a branching ratio of 0.043 ). This interference becomes worse with time because the ${ }^{95} \mathrm{Zr}$ (with a half-life of 64 days) decays much faster than the ${ }^{154} \mathrm{Eu}$ (with a half-life of 8.6 years). Because the ${ }^{154} \mathrm{Eu}$ interference is smaller for the $756 \mathrm{keV}$ peak, ${ }^{95} \mathrm{Zr}$ activity was estimated using a corrected value for the $756.7 \mathrm{keV}$ peak. The measured activity from the $756.7 \mathrm{keV}{ }^{95} \mathrm{Zr}$ peak was corrected by subtracting the measured activity from the $756 \mathrm{keV}{ }^{154} \mathrm{Eu}$ peak, where the appropriate branching ratios were used to determine what these individual peak activities would be, based on the total activities for each isotope reported in the gamma analysis data. The corrected activity for the $756.7 \mathrm{keV}$ ${ }^{95} \mathrm{Zr}$ peak was then divided by the branching ratio (0.548) to calculate the total activity for the ${ }^{95} \mathrm{Zr}$ isotope.

Table 3 lists the measured compact inventory fractions detected in leach solutions using ICP-MS. The isotopes listed in the table are those whose peaks could be isolated and for which the values appeared to be above the mass spectrometry measurement threshold for at least some of the leaches. As for the preceding tables, a range was estimated for possible background contamination. Values that primarily contributed to the total for each isotope are highlighted by shading the cell in gray; and values which are low compared to possible background contributions are presented as gray text. Background contamination in the hot cell appeared to be more of an issue for the isotopes monitored by the mass spectrometry analysis. All measured values for ${ }^{99} \mathrm{Tc}$ and ${ }^{133} \mathrm{Cs}$ were well below what might come from hot cell contamination. In the case of ${ }^{99} \mathrm{Tc}$, the equivalent particle fraction appeared high, at 6.9 particles, but background levels make it likely that this is a false indicator for significant technetium release. For several of the isotopes $\left({ }^{91} \mathrm{Zr},{ }^{139} \mathrm{La},{ }^{141} \mathrm{Pr},{ }^{146} \mathrm{Nd}\right)$, one or two of the leach solutions showed concentrations that were equivalent to what might come from background contamination, making these results inconclusive. The results for ${ }^{140} \mathrm{Ce}$ were slightly more than what would be expected from background contamination. Comparison of the ${ }^{140} \mathrm{Ce}$ mass spectrometry analysis to the gamma spectrometry results for ${ }^{144} \mathrm{Ce}$ indicates that at least some of the ${ }^{140} \mathrm{Ce}$ was probably coming from the fuel compact.

The ${ }^{105} \mathrm{Pd}$ and ${ }^{156} \mathrm{Gd}$ detected in the first leach solution of each series appear to be clearly significant compared to background contamination. ${ }^{156} \mathrm{Gd}$ is a decay product of ${ }^{156} \mathrm{Eu}$ and the detected inventory is in fair agreement, but slightly higher than the europium results from the gamma spectrometry. Palladium is of interest because it reacts with and forms compounds with SiC. Palladium has been seen at the interface between the inner pyrocarbon and the $\mathrm{SiC}$, and some islands of $\mathrm{Pd}$ were observed in the $\mathrm{SiC}$ itself (see materialography discussion later in this report). The amount of ${ }^{152} \mathrm{Sm}$ detected in the first leach of each series also appears to be above the expected background contamination level, although not as significantly as the ${ }^{105} \mathrm{Pd}$ and ${ }^{156} \mathrm{Gd}$. A beta analysis for ${ }^{151} \mathrm{Sm}$ may be useful as a verification of the ${ }^{152} \mathrm{Sm}$ ICP-MS result.

The ${ }^{88} \mathrm{Sr},{ }^{109} \mathrm{Ag}$, and ${ }^{153} \mathrm{Eu}$ also appear to be present at levels above background contamination in the first leach solution of each series. However, the analysis results for these isotopes are still questionable. Table 4 compares the mass spectrometry and gamma spectrometry results for these elements. The only 
good agreement for strontium is for the first pre-burn leach. This, incidentally, is where most of the ${ }^{90} \mathrm{Sr}$ was detected. The first post-burn matrix leach for ${ }^{88} \mathrm{Sr}$ appeared to yield significant values compared to the estimated background. However, ${ }^{86} \mathrm{Sr}$, which is not a fission product, was also detected in significant quantities, suggesting that a large fraction of the detected ${ }^{88} \mathrm{Sr}$ may come from a natural strontium contamination. The fact that the ${ }^{88} \mathrm{Sr}$ was higher for the post-burn leaches may indicate contamination during particle sieving or burn back. There are also some inconsistencies in the results for ${ }^{109} \mathrm{Ag}$. The first pre-burn leach and first post-burn particle leach for ${ }^{109} \mathrm{Ag}$ agree reasonably well with the results for ${ }^{110 \mathrm{~m}} \mathrm{Ag}$. The higher ${ }^{109} \mathrm{Ag}$ results for the second pre-burn leach and second post-burn matrix leach can probably be explained by the high background contamination level for ${ }^{109} \mathrm{Ag}$. However, the fact that the second post-burn particle leach for ${ }^{109} \mathrm{Ag}$ is higher than the previous leach cannot be explained and the first post-burn matrix leach for ${ }^{109} \mathrm{Ag}$ is a factor of 10 lower than expected from the ${ }^{110 \mathrm{~m}} \mathrm{Ag}$ determination. There is some indication that the inconsistencies in the results for ${ }^{109} \mathrm{Ag}$ stem from issues with the ICPMS radioanalytical chemistry analysis rather than issues in the hot cell.

Results for ${ }^{153} \mathrm{Eu}$ were mostly consistent with the results for ${ }^{154} \mathrm{Eu}$ and ${ }^{155} \mathrm{Eu}$. There was good agreement between the mass spectrometer and gamma spectrometer results except for the first post-burn matrix leach, where the ${ }^{153} \mathrm{Eu}$ was inexplicably low. Unfortunately, this resulted in the total detected value for ${ }^{153} \mathrm{Eu}$ being similarly under measured because $78 \%$ of the europium detected in the gamma spectrometry was in the post-burn matrix leach. This anomaly of the first post-burn matrix leach being comparatively low was also observed for ${ }^{109} \mathrm{Ag},{ }^{133} \mathrm{Cs},{ }^{140} \mathrm{Ce}$, and ${ }^{156} \mathrm{Gd}$. This is a serious issue because gamma spectrometry results indicate that a significant fraction of the released fission products for these isotopes should be detected in the first post-burn matrix leach. In fact, more than $70 \%$ of the detected concentrations of ${ }^{144} \mathrm{Ce},{ }^{154} \mathrm{Eu}$, and ${ }^{155} \mathrm{Eu}$ were found in the GS analysis of the first post-burn matrix leach. Further study is needed to determine if the ICP-MS analysis procedure is sufficient for detection of these isotopes after the burn.

In summary, several conclusions can be drawn from the deconsolidation leach-burn-leach analysis of AGR-1 irradiated Compact 6-1-1. Low values for uranium indicated that there were no exposed kernels, either due to total failure of the TRISO coating layers or due to defective SiC. However, retention of silver, europium, and palladium by the intact $\mathrm{SiC}$ shells was relatively poor. More than $10 \%$ of the expected ${ }^{110 \mathrm{~m}} \mathrm{Ag}$ generated during irradiation was detected outside of the $\mathrm{SiC}$ and this represents an unknown fraction of the total silver release because it is known that silver diffused into the graphite holder during irradiation. Europium and palladium were detected at about $1 \%$ of the expected fission product concentration. A similar amount of gadolinium was also detected outside of the $\mathrm{SiC}$, but it is unclear if the detected ${ }^{156} \mathrm{Gd}$ passed through the $\mathrm{SiC}$ as gadolinium or as ${ }^{156} \mathrm{Eu}$ prior to beta decay. At less than $0.1 \%$ of expected fission product inventories, smaller, but apparently measurable releases of ${ }^{90} \mathrm{Sr}$, ${ }^{144} \mathrm{Ce}$, and ${ }^{152} \mathrm{Sm}$ were also detected by the LBL analysis. In general, gamma or beta spectrometry analysis for the radioactive isotopes appeared to be more reliable than mass spectrometry of the stable isotopes. This was mostly due to the higher relative background observed for the stable isotopes. Palladium and samarium were the only elements detected by ICP-MS in significant quantities that could not be analyzed for using a radioactive isotope. Several other elements (e.g., technetium, lanthanum, praseodymium, and neodymium) were detected by the ICP-MS, but the results were inconclusive because of the possible levels of background contamination.

For future leach-burn-leach analysis of irradiated compacts, quantitative analysis should be performed for the radioisotopes appearing in Table 2. Quantitative mass spectrometry should be performed for ${ }^{105} \mathrm{Pd}$, ${ }^{152} \mathrm{Sm}$, and ${ }^{235} \mathrm{U}$. There is no real advantage in performing quantitative mass spectrometry for elements that can be measured by gamma spectrometry. Attempts to measure the other stable isotopes by quantitative mass spectrometry should only be made if a broad range mass spectrum indicates a more significant concentration than observed in the analysis of Compact 6-1-1. 
Table 1. Compact inventory fractions for $U$ and Pu detected by LBL of irradiated Compact 6-1-1 (analyzed by mass spectrometric method). None of the measured values are significantly above background

\begin{tabular}{|c|c|c|c|c|c|}
\hline Sample ID & ${ }^{235} \mathbf{U}$ & ${ }^{236} \mathbf{U}$ & ${ }^{238} \mathrm{U}$ & ${ }^{239} \mathrm{Pu}$ & ${ }^{240} \mathrm{Pu}$ \\
\hline $\begin{array}{l}\text { Possible background } \\
\text { contamination levels }\end{array}$ & $1 \mathrm{E}-6$ to $1 \mathrm{E}-4$ & $5 \mathrm{E}-7$ to $1 \mathrm{E}-4$ & $5 \mathrm{E}-6$ to $1 \mathrm{E}-3$ & $3 \mathrm{E}-6$ to $5 \mathrm{E}-4$ & $4 \mathrm{E}-6$ to $5 \mathrm{E}-4$ \\
\hline $\begin{array}{l}\text { Deconsolidation followed by } \\
\text { Pre-burn leach } 1\end{array}$ & $1.25 \mathrm{E}-5$ & $7.08 \mathrm{E}-6$ & $2.02 \mathrm{E}-5$ & $1.40 \mathrm{E}-5$ & $2.43 \mathrm{E}-5$ \\
\hline Pre-burn leach 2 & $2.23 \mathrm{E}-6$ & $1.63 \mathrm{E}-6$ & $3.83 \mathrm{E}-6$ & $2.43 \mathrm{E}-5$ & $5.08 \mathrm{E}-5$ \\
\hline Post-burn particle leach $1^{\text {(a) }}$ & $2.53 \mathrm{E}-5$ & $1.76 \mathrm{E}-5$ & $1.91 \mathrm{E}-5$ & $1.93 \mathrm{E}-4$ & $5.12 \mathrm{E}-4$ \\
\hline Post-burn particle leach $2^{(a)}$ & $1.28 \mathrm{E}-6$ & $4.35 \mathrm{E}-7$ & $2.38 \mathrm{E}-6$ & $5.07 \mathrm{E}-6$ & $1.21 \mathrm{E}-5$ \\
\hline Post-burn matrix leach 1 & $8.60 \mathrm{E}-6$ & $4.52 \mathrm{E}-6$ & $4.02 \mathrm{E}-5$ & $4.63 \mathrm{E}-5$ & $9.86 \mathrm{E}-5$ \\
\hline Post-burn matrix leach 2 & $4.39 \mathrm{E}-7$ & $1.14 \mathrm{E}-6$ & $8.18 \mathrm{E}-6$ & $4.03 \mathrm{E}-6$ & $5.51 \mathrm{E}-6$ \\
\hline Totals & $5.03 \mathrm{E}-5$ & $3.24 \mathrm{E}-5$ & $9.38 \mathrm{E}-5$ & $2.86 \mathrm{E}-4$ & $7.03 \mathrm{E}-4$ \\
\hline Equivalent particle inventory & 0.21 & 0.13 & 0.39 & 1.2 & 2.9 \\
\hline
\end{tabular}

(a) The measured post-burn particle data was multiplied by $4145 / 3724$ to account for 421 particles held out of the sample after IMGA analysis. 
Table 2. Compact inventory fractions of important gamma emitting fission products detected by LBL of AGR-1 irradiated Compact 6-1-1 (analyzed by gamma spectrometric method)

\begin{tabular}{|c|c|c|c|c|c|c|c|c|c|}
\hline Sample ID & ${ }^{90} \mathbf{S r}^{(b)}$ & ${ }^{95} \mathbf{Z r}^{(\mathrm{c})}$ & ${ }^{106} \mathbf{R u}$ & ${ }^{110 m} \mathrm{Ag}$ & ${ }^{134} \mathrm{Cs}$ & ${ }^{137} \mathrm{Cs}$ & ${ }^{144} \mathrm{Ce}$ & ${ }^{154} \mathrm{Eu}$ & ${ }^{155} \mathrm{Eu}$ \\
\hline $\begin{array}{l}\text { Possible background } \\
\text { contamination levels }\end{array}$ & n.d. & $\sim 1 \mathrm{E}-6$ & $\sim 5 \mathrm{E}-7$ & $\sim 2 \mathrm{E}-5$ & $\begin{array}{c}4 \mathrm{E}-7 \\
\text { to } \\
4 \mathrm{E}-6\end{array}$ & $\begin{array}{c}1 \mathrm{E}-6 \\
\text { to } \\
1 \mathrm{E}-4\end{array}$ & $\sim 1 \mathrm{E}-7$ & $\begin{array}{c}3 \mathrm{E}-6 \\
\text { to } \\
5 \mathrm{E}-5\end{array}$ & $\begin{array}{c}2 \mathrm{E}-6 \\
\text { to } \\
2 \mathrm{E}-5\end{array}$ \\
\hline $\begin{array}{l}\text { Deconsolidation followed by } \\
\text { Pre-burn leach } 1\end{array}$ & $4.43 \mathrm{E}-4$ & $1.19 \mathrm{E}-6$ & n.d. & $7.91 \mathrm{E}-2$ & $3.70 \mathrm{E}-6$ & $6.66 \mathrm{E}-6$ & $1.38 \mathrm{E}-5$ & $2.45 \mathrm{E}-3$ & $2.59 \mathrm{E}-3$ \\
\hline Pre-burn leach 2 & $6.18 \mathrm{E}-6$ & n.d. & $3.13 \mathrm{E}-6$ & $1.19 \mathrm{E}-4$ & $2.02 \mathrm{E}-7$ & $6.57 \mathrm{E}-7$ & $9.16 \mathrm{E}-6$ & $6.15 \mathrm{E}-5$ & $5.98 \mathrm{E}-5$ \\
\hline Post-burn particle leach $1^{(a)}$ & $4.64 \mathrm{E}-5$ & $3.05 \mathrm{E}-5$ & n.d. & $6.41 \mathrm{E}-4$ & $2.30 \mathrm{E}-7$ & $3.10 \mathrm{E}-6$ & $2.26 \mathrm{E}-4$ & $4.23 \mathrm{E}-4$ & $3.91 \mathrm{E}-4$ \\
\hline Post-burn particle leach $2^{(a)}$ & $6.68 \mathrm{E}-7$ & n.d. & $5.84 \mathrm{E}-7$ & n.d. & $1.49 \mathrm{E}-7$ & 6.90E-7 & $1.86 \mathrm{E}-6$ & $3.45 \mathrm{E}-6$ & $2.97 \mathrm{E}-6$ \\
\hline Post-burn matrix leach 1 & $9.84 \mathrm{E}-5$ & $4.68 \mathrm{E}-5$ & n.d. & $3.75 \mathrm{E}-2$ & $1.44 \mathrm{E}-5$ & $6.77 \mathrm{E}-5$ & $4.39 \mathrm{E}-4$ & $1.01 \mathrm{E}-2$ & $1.15 \mathrm{E}-2$ \\
\hline Post-burn matrix leach 2 & $1.93 \mathrm{E}-6$ & n.d. & n.d. & $1.11 \mathrm{E}-4$ & $1.43 \mathrm{E}-7$ & $1.92 \mathrm{E}-6$ & $5.26 \mathrm{E}-7$ & $1.53 \mathrm{E}-5$ & $1.43 \mathrm{E}-5$ \\
\hline Totals & $5.97 \mathrm{E}-4$ & $7.84 \mathrm{E}-5$ & $3.71 \mathrm{E}-6$ & $1.18 \mathrm{E}-1$ & $1.88 \mathrm{E}-5$ & $8.07 \mathrm{E}-5$ & $6.91 \mathrm{E}-4$ & $1.30 \mathrm{E}-2$ & $1.45 \mathrm{E}-2$ \\
\hline Equivalent particle inventory & 2.5 & 0.33 & 0.015 & 487 & 0.078 & 0.34 & 2.9 & 54 & 60 \\
\hline
\end{tabular}

"n.d." = not determined because measure value was below detection threshold.

Values that primarily contributed to the total for each isotope are highlighted. Numbers in gray are low compared to possible background.

(a) The measured post-burn particle data was multiplied by $4145 / 3724$ to account for 421 particles held out of the sample after IMGA analysis.

(b) The ${ }^{90} \mathrm{Sr}$ was measured by chemical separation and beta analysis.

(c) The ${ }^{95} \mathrm{Zr}$ data is based on $756.7 \mathrm{keV}$ peak after subtraction of ${ }^{154} \mathrm{Eu}$ interference. 
Table 3. Compact inventories of stable isotopes of interest in leach solutions from LBL of irradiated Compact 6-1-1 (analyzed by mass spectrometric method)

\begin{tabular}{|c|c|c|c|c|c|c|c|c|c|c|c|c|c|}
\hline Sample ID & ${ }^{88} \mathrm{Sr}$ & ${ }^{91} \mathbf{Z r}^{(\mathbf{b})}$ & ${ }^{99} \mathrm{Tc}$ & ${ }^{105} \mathrm{Pd}$ & ${ }^{109} \mathrm{Ag}$ & ${ }^{133} \mathrm{Cs}$ & ${ }^{139} \mathbf{L a}$ & ${ }^{140} \mathrm{Ce}$ & ${ }^{141} \operatorname{Pr}^{(b)}$ & ${ }^{146} \mathrm{Nd}^{(\mathrm{b})}$ & ${ }^{152} \mathrm{Sm}$ & ${ }^{153} \mathbf{E u}$ & ${ }^{156} \mathbf{G d}^{(\mathrm{b})}$ \\
\hline $\begin{array}{l}\text { Possible background } \\
\text { contamination levels }\end{array}$ & $\begin{array}{l}6 \mathrm{E}-5 \\
\text { to } \\
4 \mathrm{E}-4\end{array}$ & $\begin{array}{c}1 \mathrm{E}-4 \\
\text { to } \\
3 \mathrm{E}-4\end{array}$ & $\begin{array}{c}1 \mathrm{E}-3 \\
\text { to } \\
3 \mathrm{E}-3\end{array}$ & $\sim 3 \mathrm{E}-4$ & $\begin{array}{c}1 \mathrm{E}-3 \\
\text { to } \\
3 \mathrm{E}-3\end{array}$ & $\begin{array}{l}2 \mathrm{E}-6 \\
\text { to } \\
2 \mathrm{E}-4\end{array}$ & $\begin{array}{l}2 \mathrm{E}-6 \\
\text { to } \\
2 \mathrm{E}-4\end{array}$ & $\begin{array}{l}2 \mathrm{E}-5 \\
\text { to } \\
2 \mathrm{E}-4\end{array}$ & $\begin{array}{l}2 \mathrm{E}-6 \\
\text { to } \\
2 \mathrm{E}-4\end{array}$ & $\begin{array}{l}2 \mathrm{E}-6 \\
\text { to } \\
2 \mathrm{E}-4\end{array}$ & $\begin{array}{c}1 \mathrm{E}-5 \\
\text { to } \\
1 \mathrm{E}-4\end{array}$ & $\begin{array}{c}2 \mathrm{E}-5 \\
\text { to } \\
5 \mathrm{E}-4\end{array}$ & $\begin{array}{c}7 \mathrm{E}-5 \\
\text { to } \\
1 \mathrm{E}-3\end{array}$ \\
\hline $\begin{array}{l}\text { Deconsolidation } \\
\text { followed by } \\
\text { Pre-burn leach } 1\end{array}$ & $5.01 \mathrm{E}-4$ & 4.97E-4 & $4.21 \mathrm{E}-4$ & $5.99 \mathrm{E}-3$ & $5.55 \mathrm{E}-2$ & 7.91E-6 & $4.80 \mathrm{E}-5$ & $1.74 \mathrm{E}-4$ & $2.41 \mathrm{E}-5$ & $2.19 \mathrm{E}-5$ & $2.85 \mathrm{E}-4$ & $2.02 \mathrm{E}-3$ & $1.01 \mathrm{E}-2$ \\
\hline Pre-burn leach 2 & $7.22 \mathrm{E}-5$ & $<8.44 \mathrm{E}-5$ & $<3.48 \mathrm{E}-5$ & $<2.53 \mathrm{E}-4$ & 4.36E-4 & $1.03 \mathrm{E}-6$ & $1.81 \mathrm{E}-5$ & 4.96E-5 & $1.45 \mathrm{E}-5$ & $1.19 \mathrm{E}-5$ & $2.16 \mathrm{E}-5$ & $7.31 \mathrm{E}-5$ & 3.97E-4 \\
\hline $\begin{array}{l}\text { Post-burn particle } \\
\text { leach } 1^{\text {(a) }}\end{array}$ & $2.77 \mathrm{E}-4$ & $1.26 \mathrm{E}-4$ & $1.71 \mathrm{E}-4$ & $2.62 \mathrm{E}-3$ & 7.64E-4 & $3.52 \mathrm{E}-6$ & $2.81 \mathrm{E}-4$ & 7.77E-4 & 2.99E-4 & 2.62E-4 & $5.36 \mathrm{E}-4$ & 4.03E-4 & $5.69 \mathrm{E}-3$ \\
\hline $\begin{array}{l}\text { Post-burn particle } \\
\text { leach } 2^{\text {(a) }}\end{array}$ & $<3.77 \mathrm{E}-5$ & $<9.40 \mathrm{E}-5$ & $5.19 \mathrm{E}-4$ & $<2.81 \mathrm{E}-4$ & 7.04E-3 & $1.15 \mathrm{E}-6$ & $3.38 \mathrm{E}-6$ & $2.28 \mathrm{E}-5$ & $3.11 \mathrm{E}-6$ & $2.88 \mathrm{E}-6$ & $<9.26 \mathrm{E}-6$ & $<1.48 \mathrm{E}-5$ & $<7.13 \mathrm{E}-5$ \\
\hline $\begin{array}{l}\text { Post-burn matrix } \\
\text { leach } 1\end{array}$ & $6.53 \mathrm{E}-3$ & $<3.67 \mathrm{E}-5$ & $3.13 \mathrm{E}-4$ & $2.73 \mathrm{E}-3$ & $3.92 \mathrm{E}-3$ & 7.51E-6 & 7.49E-5 & $2.81 \mathrm{E}-4$ & $5.39 \mathrm{E}-5$ & 4.24E-5 & $9.86 \mathrm{E}-5$ & 7.45E-4 & $1.71 \mathrm{E}-3$ \\
\hline $\begin{array}{l}\text { Post-burn matrix } \\
\text { leach } 2\end{array}$ & $3.56 \mathrm{E}-4$ & $<3.67 \mathrm{E}-5$ & $2.38 \mathrm{E}-4$ & $<1.10 \mathrm{E}-4$ & 4.12E-4 & $2.45 \mathrm{E}-6$ & $6.57 \mathrm{E}-6$ & $2.28 \mathrm{E}-5$ & $5.07 \mathrm{E}-6$ & 4.13E-6 & $<3.62 \mathrm{E}-6$ & $1.96 \mathrm{E}-5$ & $6.68 \mathrm{E}-5$ \\
\hline Totals & 7.74E-3 & $6.23 \mathrm{E}-4$ & $1.66 \mathrm{E}-3$ & $1.13 \mathrm{E}-2$ & $6.81 \mathrm{E}-2$ & $2.36 \mathrm{E}-5$ & 4.32E-4 & $1.33 \mathrm{E}-3$ & 4.00E-4 & $3.45 \mathrm{E}-4$ & $9.41 \mathrm{E}-4$ & $3.26 \mathrm{E}-3$ & $1.80 \mathrm{E}-2$ \\
\hline $\begin{array}{l}\text { Equivalent particle } \\
\text { inventories }\end{array}$ & 32 & 2.6 & 6.9 & 47 & 282 & 0.1 & 1.8 & 5.5 & 1.7 & 1.4 & 3.9 & 14 & 74 \\
\hline
\end{tabular}

A less than symbol $(<)$ indicates concentration was at the minimum detectable limit of the ICP-MS, these values are not included in totals. n.d. $=$ not determined because measure value was below detection threshold.

Values that primarily contributed to the total for each isotope are highlighted. Numbers in gray are low compared to possible background.

(a) The measured post-burn particle data was multiplied by 4145/3724 to account for 421 particles held out of the sample after IMGA analysis.

(b) Compact inventory fractions based on [Parry 2009] because isotopes not included in [Sterbentz 2011] calculations. 
Table 4. Comparison of the compact fraction of isotopes in leach solutions measured by GS and ICP-MS

\begin{tabular}{|c|c|c|c|c|c|c|c|c|c|}
\hline Sample ID & ${ }^{88} \mathrm{Sr}$ & ${ }^{90} \mathrm{Sr}^{(\mathbf{b})}$ & $\begin{array}{l}\text { Ratio } \\
\text { MS/GS }\end{array}$ & ${ }^{109} \mathrm{Ag}$ & ${ }^{110 m} \mathrm{Ag}$ & $\begin{array}{c}\text { Ratio } \\
\text { MS/GS }\end{array}$ & ${ }^{153} \mathbf{E u}$ & ${ }^{154} \mathrm{Eu}$ & $\begin{array}{l}\text { Ratio } \\
\text { MS/GS }\end{array}$ \\
\hline $\begin{array}{l}\text { Possible background } \\
\text { contamination levels }\end{array}$ & $\begin{array}{c}6 \mathrm{E}-5 \\
\text { to } \\
4 \mathrm{E}-4\end{array}$ & n.d. & & $\begin{array}{c}1 \mathrm{E}-3 \\
\text { to } \\
3 \mathrm{E}-3\end{array}$ & $\sim 2 \mathrm{E}-5$ & & $\begin{array}{c}2 \mathrm{E}-5 \\
\text { to } \\
5 \mathrm{E}-4\end{array}$ & $\begin{array}{c}3 \mathrm{E}-6 \\
\text { to } \\
5 \mathrm{E}-5\end{array}$ & \\
\hline $\begin{array}{l}\text { Deconsolidation followed by } \\
\text { Pre-burn leach } 1\end{array}$ & $5.01 \mathrm{E}-4$ & $4.43 \mathrm{E}-4$ & 1.1 & $5.55 \mathrm{E}-02$ & 7.91E-02 & 0.70 & $2.02 \mathrm{E}-03$ & $2.45 \mathrm{E}-3$ & 0.82 \\
\hline Pre-burn leach 2 & $7.22 \mathrm{E}-5$ & $6.18 \mathrm{E}-6$ & 12 & $4.36 \mathrm{E}-04$ & $1.19 \mathrm{E}-04$ & 3.7 & 7.31E-05 & $6.15 \mathrm{E}-5$ & 1.2 \\
\hline Post-burn particle leach $1^{\text {(a) }}$ & $2.77 \mathrm{E}-4$ & 4.64E-5 & 6.0 & 7.64E-04 & $6.41 \mathrm{E}-04$ & 1.2 & 4.03E-04 & 4.23E-4 & 0.95 \\
\hline Post-burn particle leach $2^{(a)}$ & $<3.77 \mathrm{E}-5$ & $6.68 \mathrm{E}-7$ & & $7.04 \mathrm{E}-3$ & n.d. & & $<1.48 \mathrm{E}-5$ & $3.45 \mathrm{E}-6$ & \\
\hline Post-burn matrix leach 1 & $6.53 \mathrm{E}-3$ & $9.84 \mathrm{E}-5$ & 66 & $3.92 \mathrm{E}-03$ & $3.75 \mathrm{E}-02$ & 0.10 & $7.45 \mathrm{E}-04$ & $1.01 \mathrm{E}-2$ & 0.07 \\
\hline Post-burn matrix leach 2 & $3.56 \mathrm{E}-4$ & $1.93 \mathrm{E}-6$ & 184 & 4.12E-04 & $1.11 \mathrm{E}-04$ & 3.7 & $1.96 \mathrm{E}-05$ & $1.53 \mathrm{E}-5$ & 1.3 \\
\hline Totals & $7.74 \mathrm{E}-3$ & $5.97 \mathrm{E}-4$ & 13 & $6.81 \mathrm{E}-02$ & $1.18 \mathrm{E}-01$ & 0.58 & $3.26 \mathrm{E}-03$ & $1.30 \mathrm{E}-2$ & 0.25 \\
\hline Equivalent particle inventory & 32 & 2.5 & 13 & 282 & 487 & 0.58 & 14 & 54 & 0.25 \\
\hline
\end{tabular}

A less than symbol $(<)$ indicates concentration was at the minimum detectable limit of the ICP-MS, these values are not included in totals. n.d. $=$ not determined because measure value was below detection threshold.

(a) The measured post-burn particle data was multiplied by $4145 / 3724$ to account for 421 particles held out of the sample after IMGA analysis.

${ }^{\text {(b) }} \mathrm{The}{ }^{90} \mathrm{Sr}$ was measured by chemical separation and beta analysis. 


\section{Irradiated Microsphere Gamma Analysis}

TRISO-coated particles were deconsolidated from AGR-1 irradiated Compact 6-1-1 as described in the previous section. With the matrix graphite removed, the clean particles (Figure 3 ) were then transferred to the IMGA cubicle (Figure 6) for analysis using the Advanced-IMGA system. The Advanced Irradiated Microsphere Gamma Analyzer is an automated system designed to evaluate large numbers of individual coated fuel particles. Part of this evaluation involves determining the integrity or permeability of the particle coating based on the coating's ability to retain volatile fission products. The ratio of a volatile to a non-volatile fission product (e.g., ${ }^{137} \mathrm{Cs}$ versus ${ }^{144} \mathrm{Ce}$ ) is used to determine the retention characteristics of the coating. Low retention or damaged coatings will show a drop in the relative concentration of the more volatile species. The system also provides the capability to determine each particles inventory of various gamma-emitting isotopes.

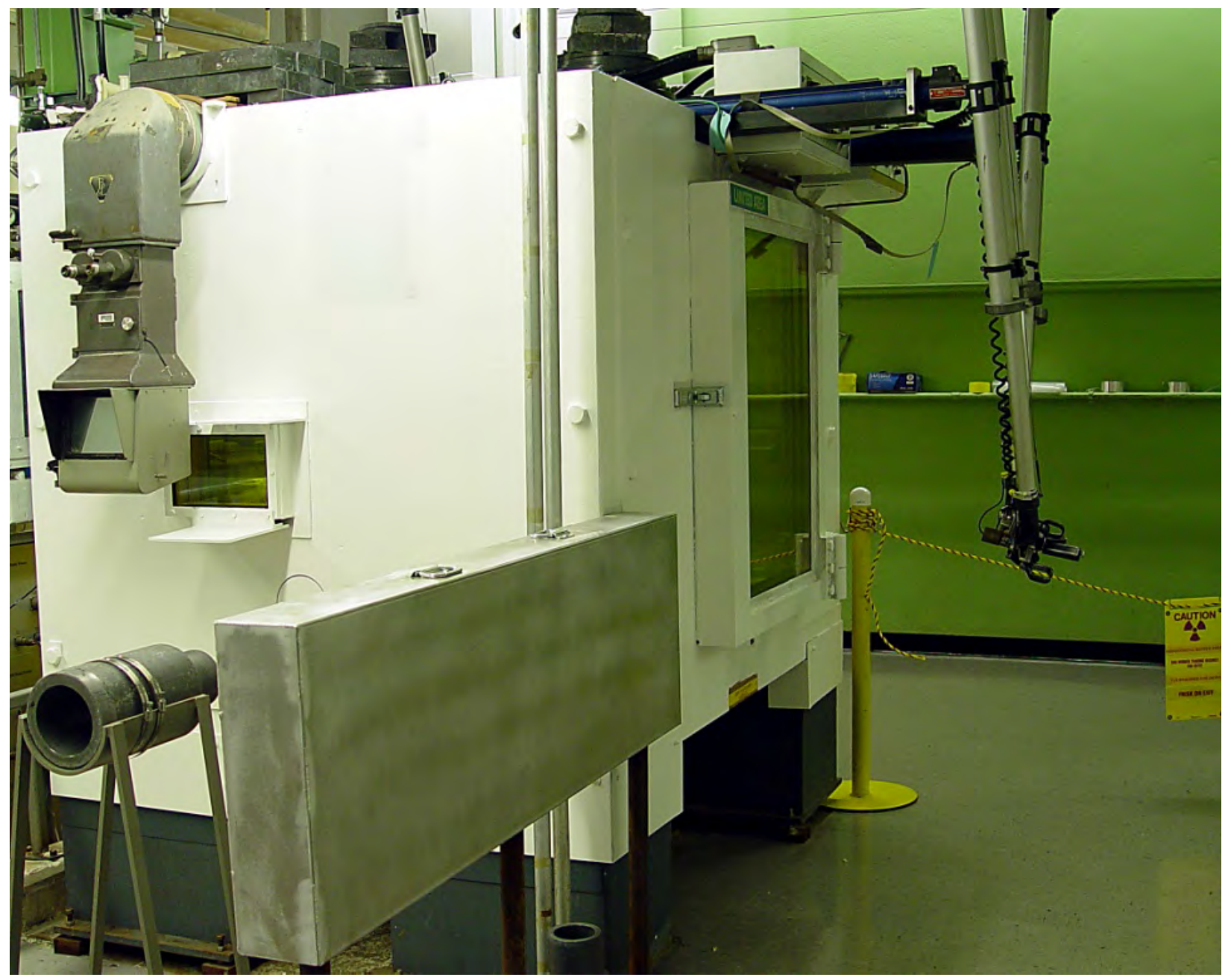

Figure 6. Advanced-IMGA hot cell cubicle in ORNL Building 3525.

The Advanced-IMGA system is composed of 2 highly integrated sub-systems. The first sub-system is a standard Multi-Channel Analyzer (MCA) that is used to acquire and analyze the gamma-ray spectrum produced from the decay of fission products in the coated fuel particle. The second sub-system is an incell particle handler (Figure 7 and Figure 8) designed to transport individual particles from the storage carousel on one side of an integral shield to the gamma counting position on the other side of the shield. The integral shield isolates the particle analysis area from the other particles in the storage carousel. The particle handling system uses a vacuum needle to pick up particles and computer controlled stepping motors on two linear stages (to move the needle) and one rotary stage (to move the carousel). 

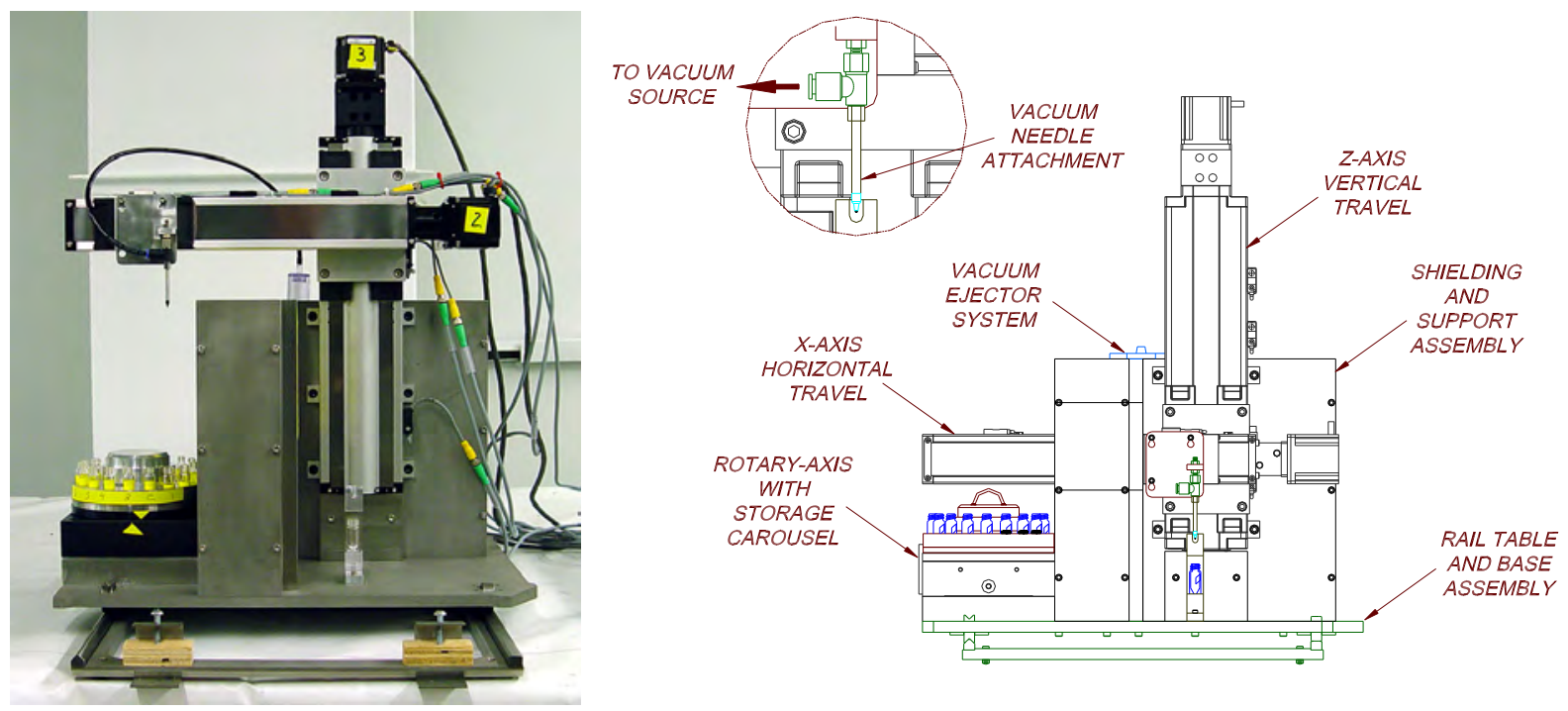

Figure 7. Advanced Irradiated Microsphere Gamma Analyzer.
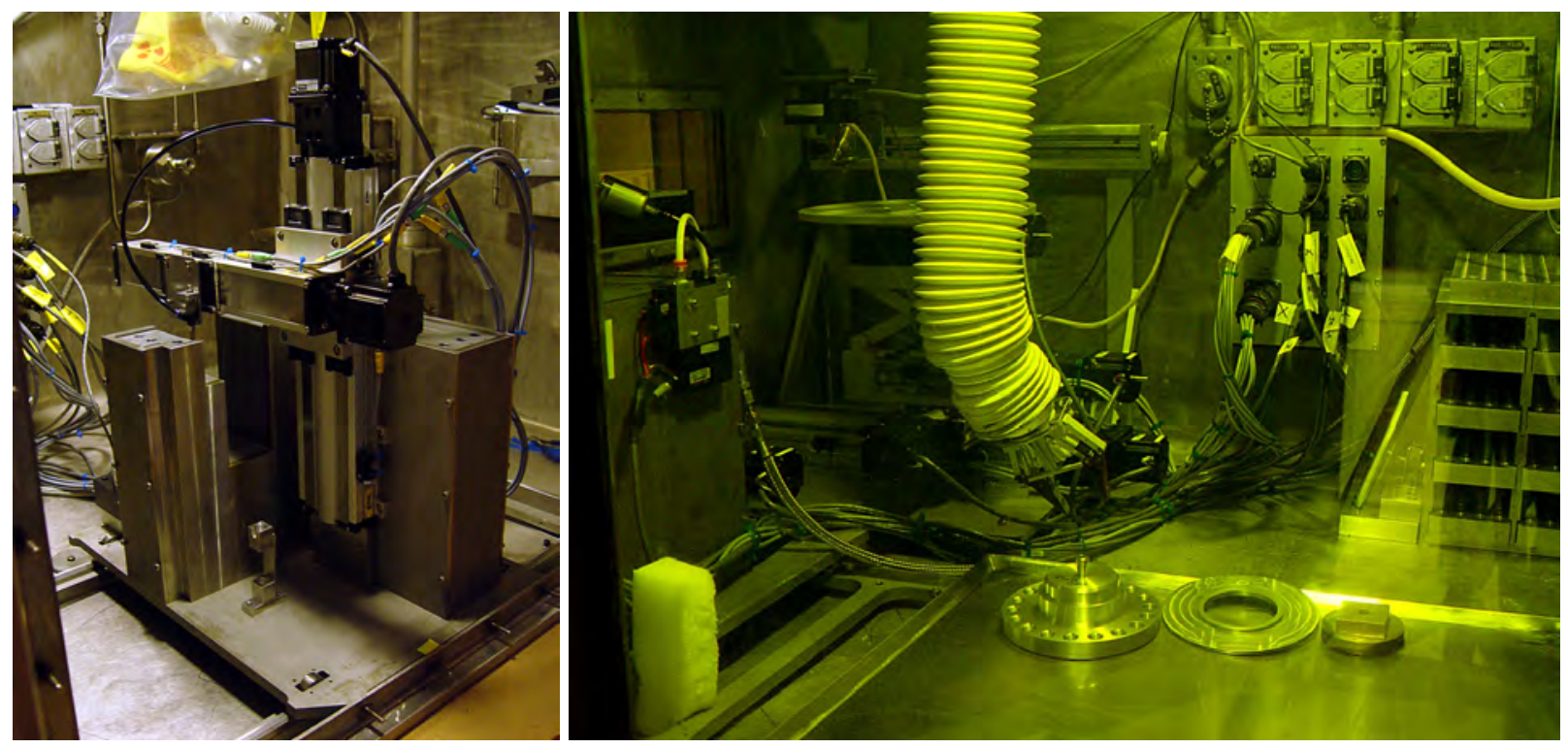

Figure 8. Advanced-IMGA in cell (left). Carousel for sample vials with Particle Micromanipulator in background (right).

Two modes of operation for the Advanced-IMGA system are supported. In the standard mode of operation, a single coated fuel particle is selected from a batch of particles located in taper-bottomed "vvials" stored in the sample carousel (Figure 9). The particle is picked up by a vacuum transport system, which has a feedback signal to the control program allowing the program to "know" that a particle has been successfully acquired. The transport system lifts the particle up and over the integral shielding and positions it in front of the counting port where the gamma-ray spectrum is acquired. A real time analysis is then performed to evaluate the measured gamma signals against user-defined sorting criteria. Based on this criteria a new location in the storage carousel is selected for each particle. A secondary mode of operation is also supported where individual fuel particles are pre-loaded into vials (with caps on), one particle per vial (Figure 10). In this mode of operation the entire loaded vial is picked up from the storage carousel using a small vacuum pad and positioned in front of the counting port. A gamma-ray spectrum is then acquired and saved for later off-line analysis. The vial is then returned to its original location in the storage carousel. This process continues until all the vials in the carousel have been examined. This mode 
of operation has the advantage of maintaining the unique identity of each individual fuel particle and is commonly used when particles are to be used in a test where pre- and post-test measurements are desired.
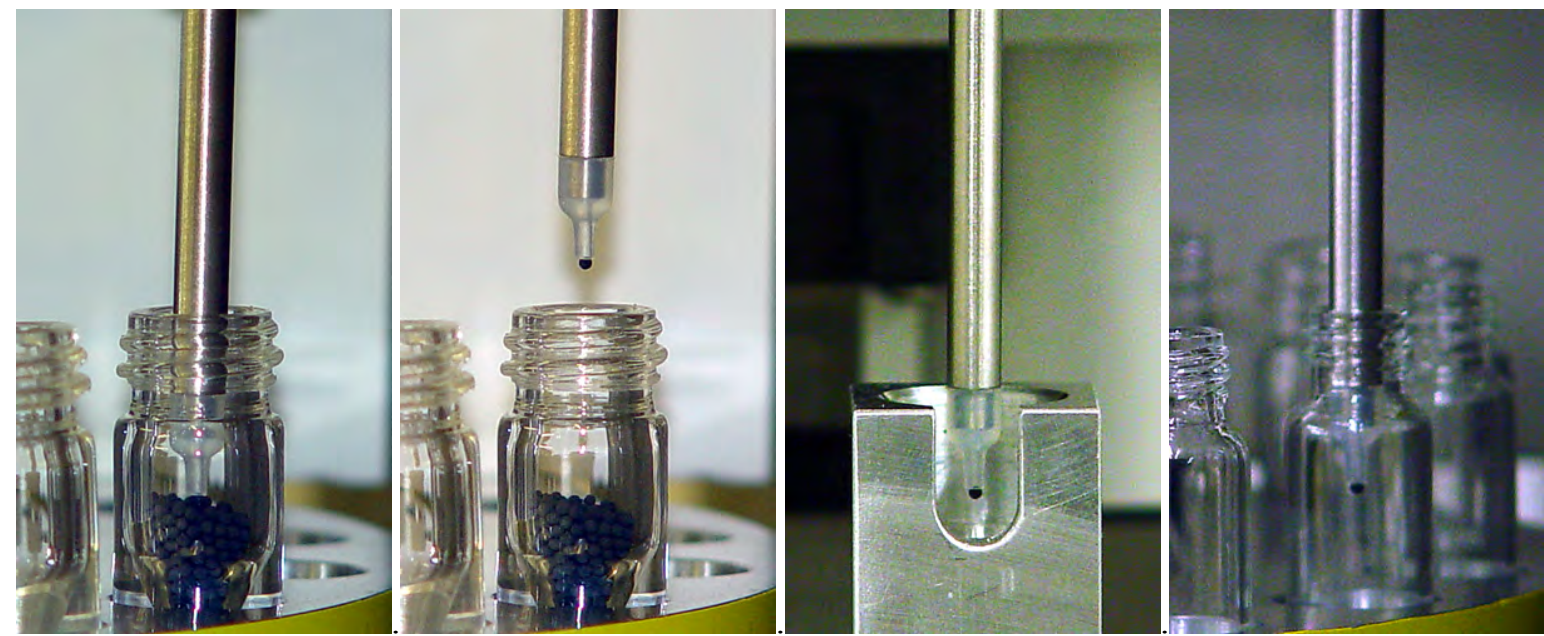

Figure 9. IMGA operating in batch mode operation. Images from left to right: acquiring a particle from a source vial, removing a single particle, positioning the particle in gamma counting location, and returning particle to a selected destination vial.
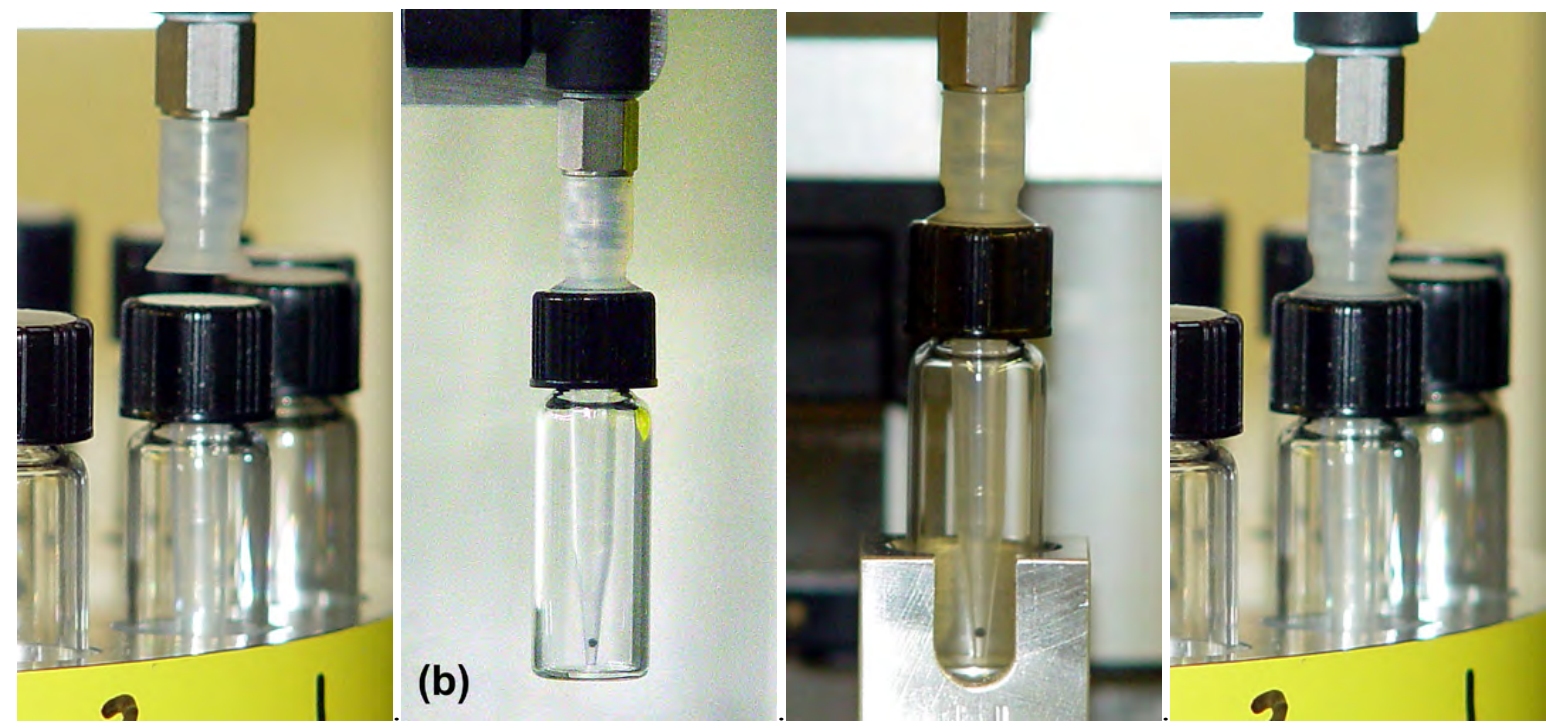

Figure 10. IMGA operating in vial mode operation. Images from left to right: selecting a vial, transporting vial containing single particle, positioning vial in counting location, and returning vial to the storage carousel.

An Ortec Gamma-X germanium detector and Canberra DSA100 digital spectrum analyzer coupled to a Genie-2000 multi channel analyzer (MCA) were used to obtain the raw gamma collection data. The MCA provided data on the live counting time (LT) and the number of counts under each designated energy peak $\left(\mathrm{PA}_{\mathrm{n}}\right)$. The MCA also recorded the time of analysis for each particle so that the elapsed time (t) since EOL +1 day could be calculated. This allowed for direct comparison between particles and to the calculated isotope inventories. For each energy peak, the number of gammas escaping from the particle per second was estimated as GPS $=\left(\mathrm{PA}_{n} / \mathrm{LT}-\mathrm{EBR}_{\mathrm{n}}\right) / \mathrm{GDE}_{\mathrm{n}}$, where $\mathrm{EBR}_{\mathrm{n}}$ was the environmental background count rate and $\mathrm{GDE}_{\mathrm{n}}$ was the gamma detection efficiency for that energy and detector geometry. The environmental background rate and gamma detection efficiency were determined as part of the system calibration. Two gamma detectors were used for the IMGA analysis of Compact 6-1-1. Figure 11 shows 3 measurements of the gamma detector efficiency performed on detector 1 over the course of the IMGA analysis of the Compact 6-1-1 particles. The average of these calibration results was used 
(Figure 12). Table 5 lists the energy peaks included in the analysis and the detector efficiencies for each peak, as well as additional parameters used in the data refinement. In determining the gamma detector efficiency, standard gamma sources were used in representative counting geometries. Because of the effect of vial shielding for the low energy gammas, it was important to also simulate these vials during calibration. The total gamma decay activity in each particle that would produce each detected gamma signal at time $t$ was calculated by the equation $\mathrm{A}_{\mathrm{n}}(\mathrm{t})=\mathrm{GPS}_{\mathrm{n}} /\left(\mathrm{BR}_{\mathrm{n}} \cdot \mathrm{SS}_{\mathrm{n}}\right)$. $\mathrm{BR}_{\mathrm{n}}$ was the branching ratio, or fraction of gammas of that energy emitted from the gamma decay. $\mathrm{SS}_{\mathrm{n}}$ was the estimated fraction of gammas of that energy expected to escape the particle due to self-shielding. Branching ratio was obtained from tables of radioactive decay data [Kocher 1981]. Particle self-shielding was estimated using an approach described in [Valentine and Kania 1979] and data from [Roussin et al. 1983]. Finally, the activity was decayed back to the activity at $\mathrm{EOL}+1$ day $\left(\mathrm{A}_{0}\right)$ using the equation, $A(t)=A_{0} e^{-\lambda t}$, where the decay constant $\lambda=\ln (2) / t_{1 / 2}$ was calculated using the half-life $\left(t_{1 / 2}\right)$ reported in [Kocher 1981] for each isotopic gamma decay. In the results reported below, the activity is reported for the key peaks highlighted in Table 5. In cases where multiple gamma energies were measured for a given isotopic gamma decay, activities determined from the additional peaks were compared to the key peak to check for self consistency in the data and to refine self shielding estimates for the lower energy gammas (e.g., ${ }^{144} \mathrm{Ce}$ at $\left.133 \mathrm{keV}\right)$.

Table 5. Parameters used in analysis of IMGA examination results (key peaks highlighted).

\begin{tabular}{|c|c|c|c|c|c|c|}
\hline Isotope & $\begin{array}{l}\text { Decay } \\
\text { Constant } \\
\left(\sec ^{-1}\right)\end{array}$ & $\begin{array}{c}\text { Peak } \\
\text { Energy } \\
(\mathrm{keV})\end{array}$ & $\begin{array}{c}\text { Branching } \\
\text { Ratio } \\
\text { (emitted/decay) }\end{array}$ & $\begin{array}{c}\text { Self-Shielding } \\
\text { Factor } \\
\text { (escaped/emitted) }\end{array}$ & $\begin{array}{c}\text { Detector } 1 \\
\text { Efficiency with } \\
\text { Bare Particles } \\
\text { (counts/gamma) } \\
\end{array}$ & $\begin{array}{c}\text { Detector } 2 \\
\text { Efficiency with } \\
\text { Particles in Vials } \\
\text { (counts/gamma) } \\
\end{array}$ \\
\hline Ce-144 & $2.82 \mathrm{E}-08$ & 133.54 & 1.09E-01 & 0.841 & $2.52 \mathrm{E}-04$ & $2.87 \mathrm{E}-04$ \\
\hline $\mathrm{Ce}-141$ & $2.46 \mathrm{E}-07$ & 145.44 & $4.84 \mathrm{E}-01$ & 0.880 & $2.39 \mathrm{E}-04$ & $2.72 \mathrm{E}-04$ \\
\hline Sb- 125 & $7.93 \mathrm{E}-09$ & 427.89 & $2.93 \mathrm{E}-01$ & 0.975 & $8.61 \mathrm{E}-05$ & $1.15 \mathrm{E}-04$ \\
\hline $\mathrm{Ru}-103$ & $2.04 \mathrm{E}-07$ & 497.08 & $8.95 \mathrm{E}-01$ & 0.980 & $7.09 \mathrm{E}-05$ & $9.98 \mathrm{E}-05$ \\
\hline Ru-106(Rh-106) & 2.19E-08 & 511.85 & $2.07 \mathrm{E}-01$ & 0.981 & $6.90 \mathrm{E}-05$ & $9.71 \mathrm{E}-05$ \\
\hline $\mathrm{Sb}-125$ & 7.93E-09 & 600.56 & $1.78 \mathrm{E}-01$ & 0.984 & $6.00 \mathrm{E}-05$ & $8.33 \mathrm{E}-05$ \\
\hline Cs-134 & $1.07 \mathrm{E}-08$ & 604.70 & $9.76 \mathrm{E}-01$ & 0.984 & $5.92 \mathrm{E}-05$ & $8.30 \mathrm{E}-05$ \\
\hline Ru-106(Rh-106) & 2.19E-08 & 621.84 & $9.85 \mathrm{E}-02$ & 0.985 & $5.78 \mathrm{E}-05$ & $8.08 \mathrm{E}-05$ \\
\hline $\mathrm{Sb}-125$ & 7.93E-09 & 635.89 & $1.13 \mathrm{E}-01$ & 0.985 & $5.68 \mathrm{E}-05$ & 7.91E-05 \\
\hline Cs-137 & $7.28 \mathrm{E}-10$ & 661.65 & $8.52 \mathrm{E}-01$ & 0.986 & $5.49 \mathrm{E}-05$ & $7.62 \mathrm{E}-05$ \\
\hline Ce-144(Pr-144) & $2.82 \mathrm{E}-08$ & 696.49 & $1.46 \mathrm{E}-02$ & 0.986 & $5.25 \mathrm{E}-05$ & 7.29E-05 \\
\hline Zr-95 & $1.25 \mathrm{E}-07$ & 724.18 & $4.38 \mathrm{E}-01$ & 0.987 & $5.08 \mathrm{E}-05$ & $7.05 \mathrm{E}-05$ \\
\hline $\mathrm{Zr}-95$ & $1.25 \mathrm{E}-07$ & 756.72 & $5.53 \mathrm{E}-01$ & 0.988 & $4.89 \mathrm{E}-05$ & $6.78 \mathrm{E}-05$ \\
\hline $\mathrm{Nb}-95$ & $2.29 \mathrm{E}-07$ & 765.79 & $9.98 \mathrm{E}-01$ & 0.988 & $4.84 \mathrm{E}-05$ & $6.71 \mathrm{E}-05$ \\
\hline Cs-134 & $1.07 \mathrm{E}-08$ & 795.85 & $8.54 \mathrm{E}-01$ & 0.988 & $4.65 \mathrm{E}-05$ & $6.49 \mathrm{E}-05$ \\
\hline Eu-154 & $2.50 \mathrm{E}-09$ & 873.19 & $1.16 \mathrm{E}-01$ & 0.989 & $4.22 \mathrm{E}-05$ & $6.02 \mathrm{E}-05$ \\
\hline $\mathrm{Ag}-110 \mathrm{~m}$ & $3.21 \mathrm{E}-08$ & 884.67 & $7.26 \mathrm{E}-01$ & 0.989 & $4.17 \mathrm{E}-05$ & $5.96 \mathrm{E}-05$ \\
\hline $\mathrm{Ag}-110 \mathrm{~m}$ & $3.21 \mathrm{E}-08$ & 937.48 & $3.42 \mathrm{E}-01$ & 0.990 & $4.00 \mathrm{E}-05$ & $5.70 \mathrm{E}-05$ \\
\hline Eu-154 & $2.50 \mathrm{E}-09$ & 1004.76 & $1.80 \mathrm{E}-01$ & 0.991 & $3.73 \mathrm{E}-05$ & $5.36 \mathrm{E}-05$ \\
\hline Ru-106(Rh-106) & $2.19 \mathrm{E}-08$ & 1050.48 & $1.73 \mathrm{E}-02$ & 0.991 & $3.57 \mathrm{E}-05$ & $5.13 \mathrm{E}-05$ \\
\hline Eu-154 & $2.50 \mathrm{E}-09$ & 1274.45 & $3.55 \mathrm{E}-01$ & 0.992 & $2.93 \mathrm{E}-05$ & $4.27 \mathrm{E}-05$ \\
\hline Ag-110m & $3.21 \mathrm{E}-08$ & 1384.27 & $2.43 \mathrm{E}-01$ & 0.993 & $2.71 \mathrm{E}-05$ & $4.04 \mathrm{E}-05$ \\
\hline Ce-144(Pr-144) & $2.82 \mathrm{E}-08$ & 1489.15 & $2.96 \mathrm{E}-03$ & 0.993 & $2.56 \mathrm{E}-05$ & $3.77 \mathrm{E}-05$ \\
\hline
\end{tabular}




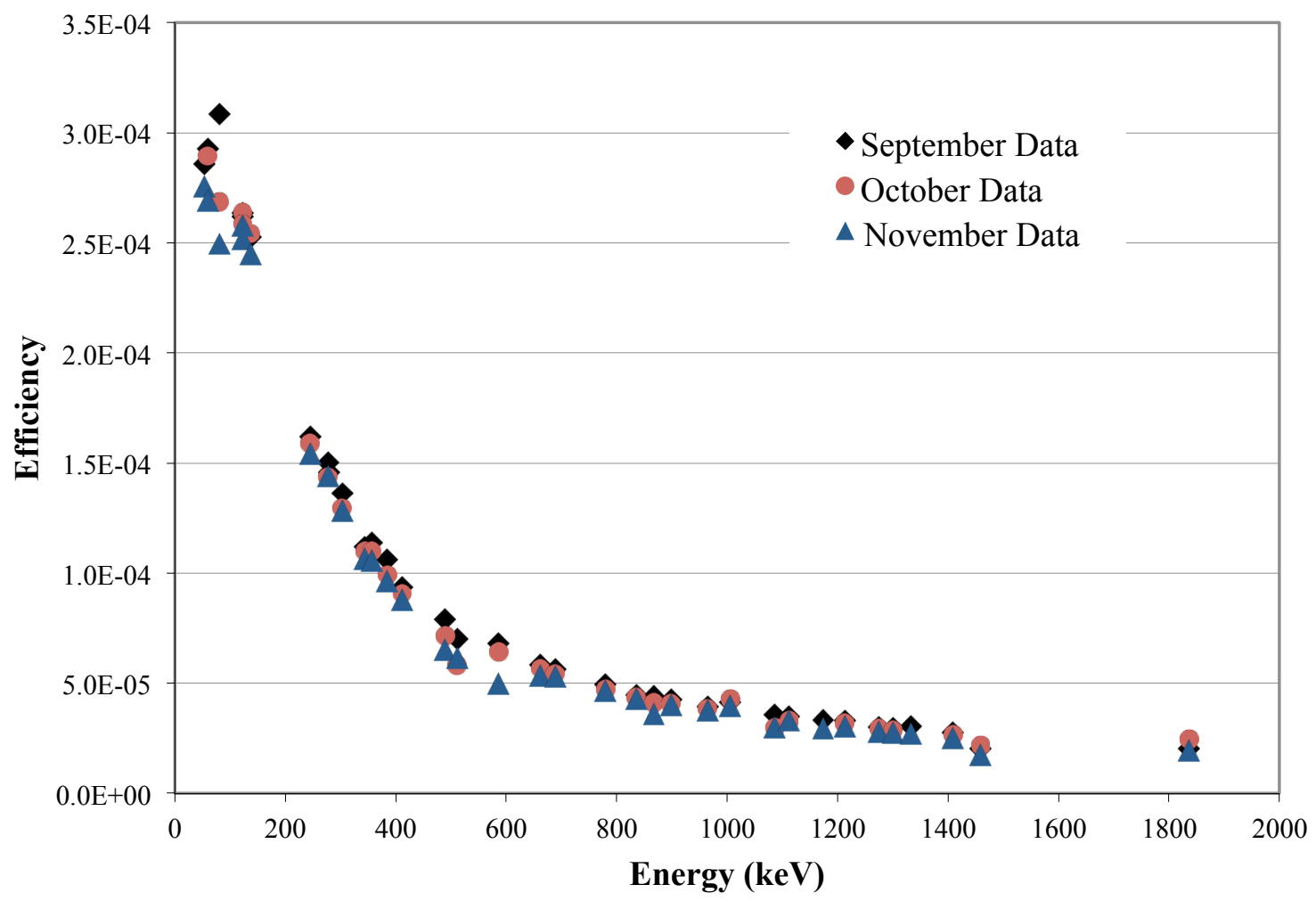

Figure 11. Detector 1 efficiency over the course of AGR-1 Compact 6-1-1 analysis.

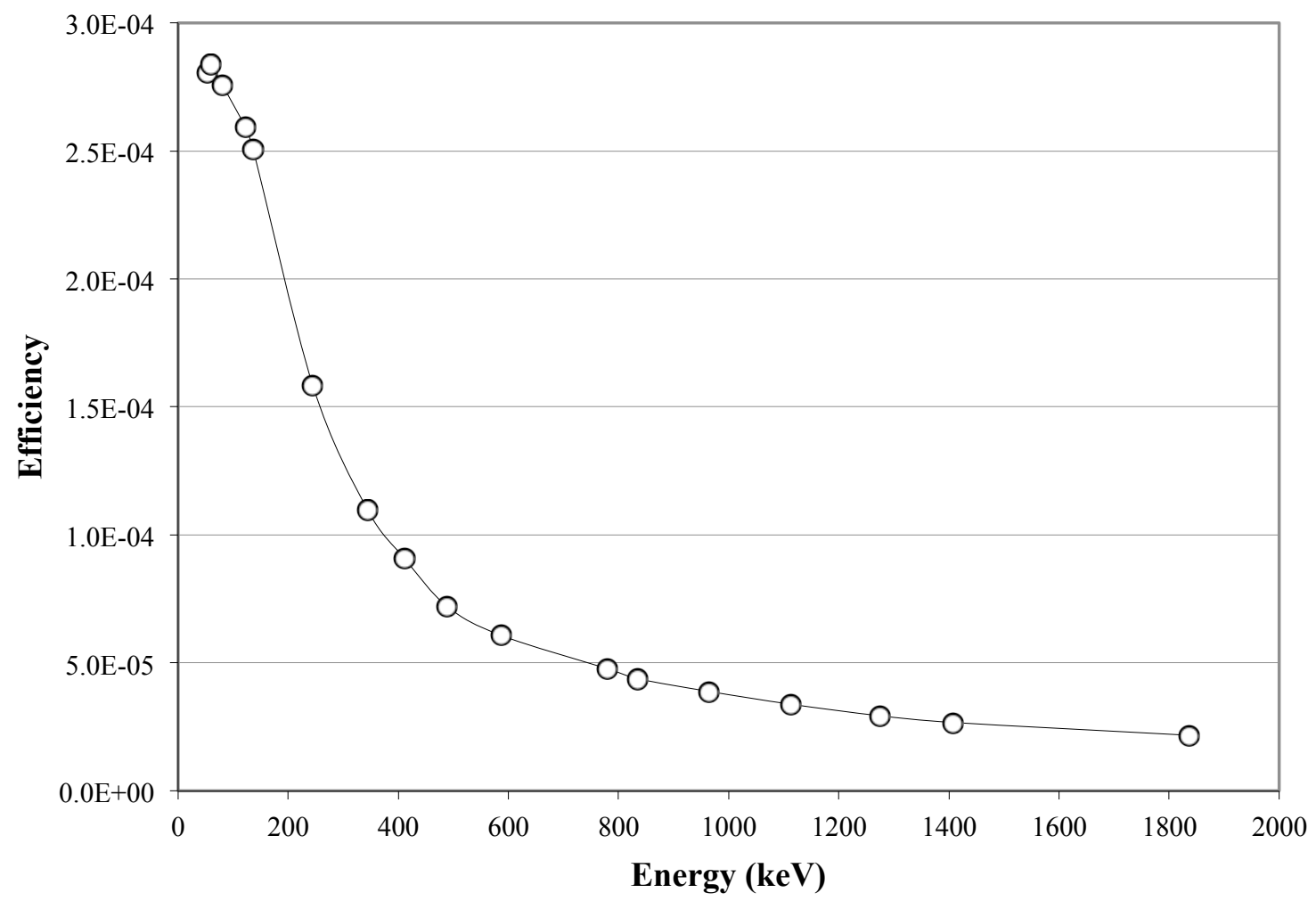

Figure 12. Average detector 1 efficiency for IMGA 50-cm geometry. 
TRISO-coated particles deconsolidated from AGR-1 irradiated Compact 6-1-1 were analyzed using both Advanced-IMGA modes of operation. Using the standard batch mode of operation, all particles were gamma counted for at least 100 seconds each to determine their Cs and Ce inventories. In agreement with the LBL results, there was no indication from this survey that any particles had defective SiC layers. Also using standard batch mode operation, 123 particles were counted for 1 hour each to measure ${ }^{110 \mathrm{~m}} \mathrm{Ag}$ and ${ }^{154} \mathrm{Eu}$ content. Based on the results of this 1 hour scan, 60 of these particles were placed in individual labeled vials and gamma counted in the vials for 6 hours to better determine their ${ }^{110 \mathrm{~m}} \mathrm{Ag}$ inventory. Detector 1 was used for the two batch mode operations, but was replaced by detector 2 for the 6 hour invial scans due to indications that detector 1 resolution was degrading (Figure 13).

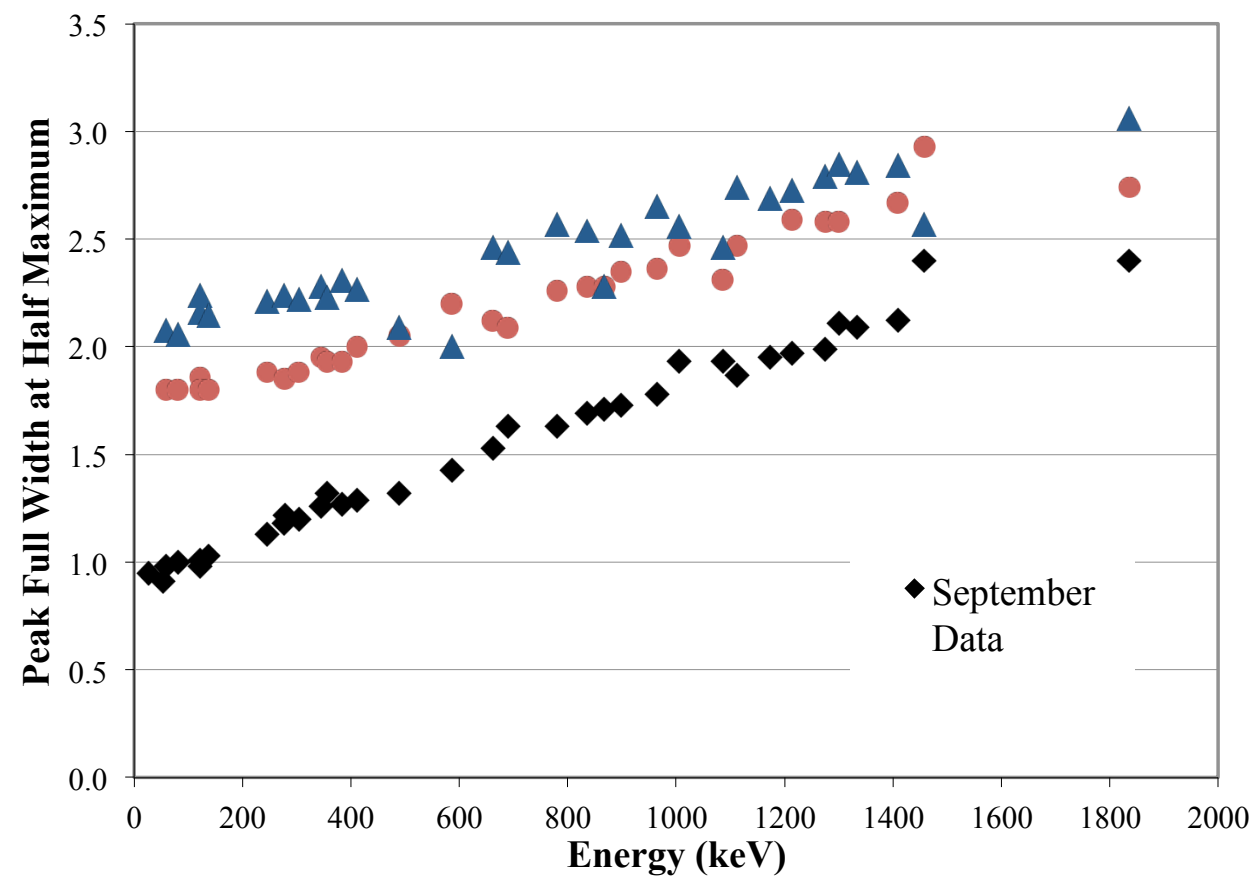

Figure 13. Detector 1 variation in energy peak full-width half-maximum over time. This increase indicates degradation in detector resolution.

During the 100 second scanning, particles were sorted according to their ${ }^{137} \mathrm{Cs} /{ }^{144} \mathrm{Ce}$ ratio with an additional sorting according to the total ${ }^{144} \mathrm{Ce}$ signal. This additional sorting by ${ }^{144} \mathrm{Ce}$ content was used to identify events where more than one particle was picked up by the vacuum needle or where the particle's ${ }^{144} \mathrm{Ce}$ content was abnormally low compared to an average particle. A total of 4079 particles were scanned. This total does not include 4 unirradiated particles that were found mixed in with the 6-1-1 particles. Unirradiated particles had previously been sieved during an LBL shakedown test and it is believed that these 4 particles were temporarily stuck in the sieve and later came out during sieving of the 6-1-1 particles. A total of 4079 particles is less than the measured average for the AGR-1 Baseline fuel of 4145 particles per compact. It is possible that some particles remained in the sieve. It is also known that some particles were lost during particle transport between the storage bottles and the gamma counting station. About 150 particles were involved in multiple pick up events. In the case where these particles were transported to the gamma counting station, the automatic sorting routine placed the particles in a designated vial and they were later recounted singly. However, a number of particles must have fallen off during multiple particle transport from one side of the IMGA to the other. Subsequent modification to the particle pick up routine has reduced the likelihood for multiple particle pick up.

The overall results of the 100 second gamma scans for ${ }^{144} \mathrm{Ce}$ and ${ }^{137} \mathrm{Cs}$ are shown in Figure 14 through Figure 17. Figure 14 and Figure 15 are histograms plotting the variation in the EOL +1 day ${ }^{144} \mathrm{Ce}$ and ${ }^{137} \mathrm{Cs}$ activity for each particle $i$ normalized by dividing by the average EOL +1 day activities for all $n=4079$ particles analyzed, 


$$
\frac{A_{i}\left({ }^{144} C e\right)}{\sum_{i=1}^{n}\left(\frac{1}{n}\right) A_{i}\left({ }^{144} C e\right)}=\frac{A_{i}\left({ }^{144} C e\right)}{\overline{A\left({ }^{144} C e\right)}} \text { and } \frac{A_{i}\left({ }^{137} C s\right)}{\sum_{i=1}^{n}\left(\frac{1}{n}\right) A_{i}\left({ }^{137} C s\right)}=\frac{A_{i}\left({ }^{137} C s\right)}{\overline{A\left({ }^{137} C s\right)}} \text {. }
$$

In Figure 16, the ${ }^{137} \mathrm{Cs}$ activity for each particle was divided by the ${ }^{144} \mathrm{Ce}$ activity for that same particle and then normalized by dividing by the average of this ratio to show the variation of the ratio from particle to particle,

$$
\frac{A_{i}\left({ }^{137} C s\right) / A_{i}\left({ }^{144} C e\right)}{\sum_{i=1}^{n}\left(\frac{1}{n}\right)\left[A_{i}\left({ }^{137} C s\right) / A_{i}\left({ }^{144} C e\right)\right]} .
$$

The fact that there are no outliers in the ${ }^{137} \mathrm{Cs} /{ }^{144} \mathrm{Ce}$ ratio in Figure 16 indicates that $\mathrm{Cs}$ was not preferentially escaping from any particle, as might occur if there were particles with defective SiC layers. Figure 16 also illustrates that some variation in the individual ${ }^{144} \mathrm{Ce}$ and ${ }^{137} \mathrm{Cs}$ activities seen in the previous figures is due to variation in the initial content of fissionable material and burn-up during irradiation. This can be concluded from the fact that the distribution of the ratio is narrower than the individual distributions, the tails in the distribution are removed, and most notably, the two outliers are moved into the main distribution. These two outlier particles exhibited abnormally low inventories for both ${ }^{144} \mathrm{Ce}$ and ${ }^{137} \mathrm{Cs}$ (Figure 14 and Figure 15). However, the ${ }^{137} \mathrm{Cs} /{ }^{144} \mathrm{Ce}$ ratio for these two particles (Figure 16) fell within the distribution band for the whole compact. This indicates that these two particles simply had less fissionable material at the start of irradiation. These two particles are discussed in the materialography sections below, where it is evident that the observed inventory can be at least partially explained by the particles having undersized kernels. However, there was also some indication from the kernel microstructure and inventory of other fission products that the initial ${ }^{235} \mathrm{U}$ content of these kernels may also have been abnormally low. Further analysis is required to fully characterize these kernels.

As discussed above, Figure 16 illustrates that it is useful to adjust for variation in the initial content of fissionable material and burn-up when considering fission product release from a particle. Without this correction, it might appear from the distribution for ${ }^{137} \mathrm{Cs}$ in Figure 15, that some particles lost significantly more $\mathrm{Cs}$ than others. The variation in the ${ }^{144} \mathrm{Ce}$ activity, $A_{i}\left({ }^{144} \mathrm{Ce}\right) / \overline{A\left({ }^{144} \mathrm{Ce}\right)}$, could be considered as one possible correction factor that would approximately scale with the variation in the initial content of fissionable material and burn-up, assuming that ${ }^{144} \mathrm{Ce}$ is uniformly retained in the particles. The gamma spectrometry LBL results (Table 2) indicated that a small fraction of the ${ }^{144} \mathrm{Ce}$ is escaping from the particles, but this should not significantly affect the correction. There is a difference in the build-up of ${ }^{144} \mathrm{Ce}$ and ${ }^{137} \mathrm{Cs}$ as a function of burn-up that can affect the accuracy of this correction, but it is still a reasonable approach to capture the variation in kernel size and uranium density that is probably the dominant factor.

An estimate of the fraction of ${ }^{137} \mathrm{Cs}$ retained in the particles was plotted in Figure 17 using the following approach. The calculated average compact inventory at EOL +1 day, $\left(\overline{N_{\text {calc }}\left({ }^{137} C s\right)}\right)$, was first converted to a calculated average particle activity,

$$
\overline{A_{\text {calc }}\left({ }^{137} \mathrm{Cs}\right)}=(\lambda / 4145) \times \overline{N_{\text {calc }}\left({ }^{137} \mathrm{Cs}\right)} \text {. }
$$

This calculated average particle activity was then adjusted for variation in the initial content of fissionable material and burn-up in each particle $i$ by multiplying by the variation in the ${ }^{144} \mathrm{Ce}$ activity to obtain an estimate of the ${ }^{137} \mathrm{Cs}$ activity expected in each particle $i$ at EOL +1 day,

$$
A_{\text {calc }, i}\left({ }^{137} C s\right)=\overline{A_{\text {calc }}\left({ }^{137} C s\right)} \times \frac{A_{i}\left({ }^{144} C e\right)}{\overline{A\left({ }^{144} C e\right)}} .
$$

Note that by multiplying by the variation in the ${ }^{144} \mathrm{Ce}$ activity for each particle, the calculated inventory for the ${ }^{137} \mathrm{Cs}$ is increased slightly for "larger" kernels and decreased slightly for "smaller" ones. Finally, the measured activity for each particle was divided by the expected activity for each particle to obtain the fraction of ${ }^{137} \mathrm{Cs}$ retained in each particle,

$$
\frac{A_{i}\left({ }^{137} C s\right)}{\overline{A_{\text {calc }, l}\left({ }^{137} C s\right)}}=\frac{A_{i}\left({ }^{137} C s\right)}{\overline{A_{\text {calc }}\left({ }^{137} C s\right)}} / \frac{A_{i}\left({ }^{144} C e\right)}{\overline{A\left({ }^{144} C e\right)}} .
$$




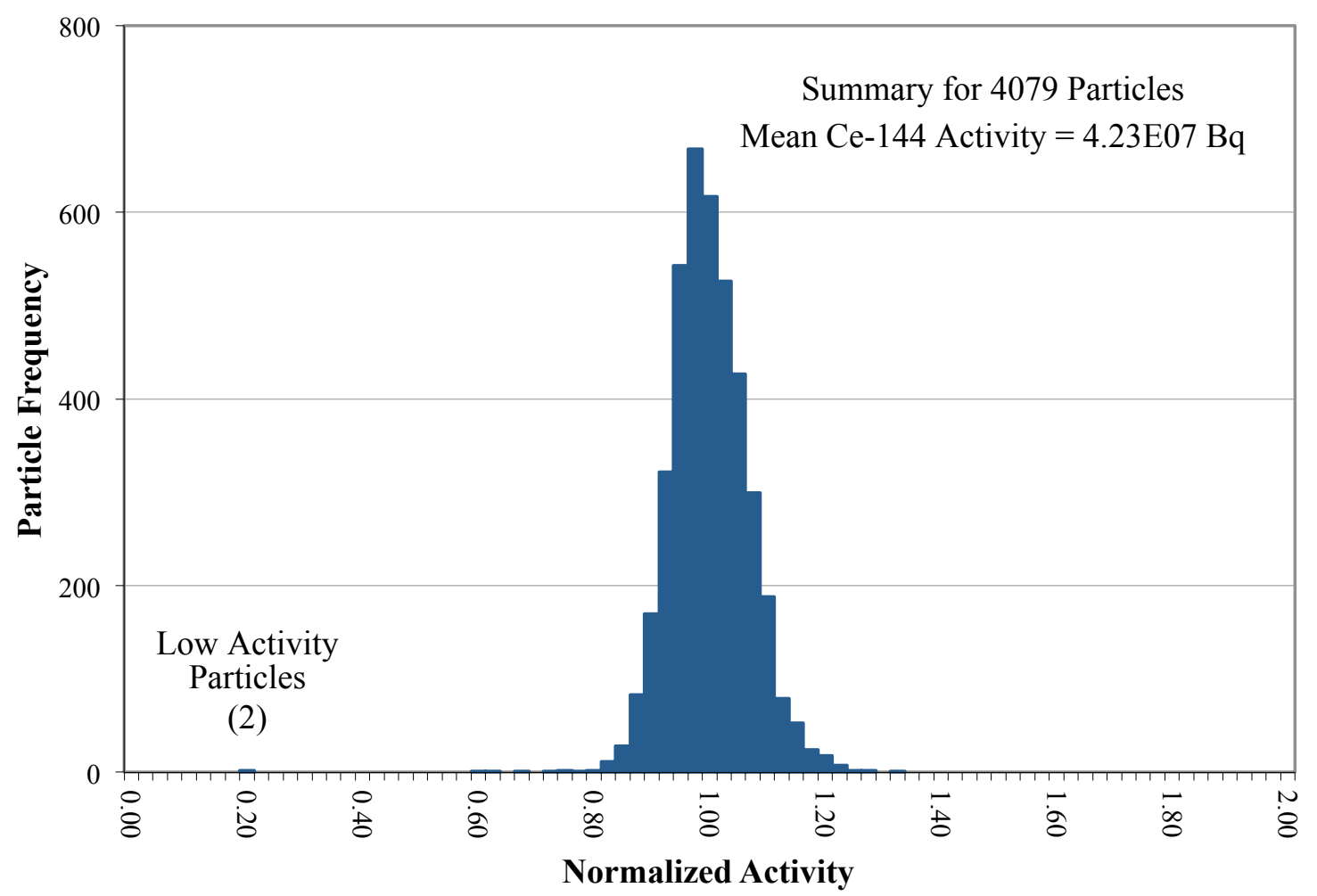

Figure 14. Particle distribution for ${ }^{144} \mathrm{Ce}$ activity (decay corrected to EOL +1 day), normalized to the average ${ }^{144}$ Ce activity.

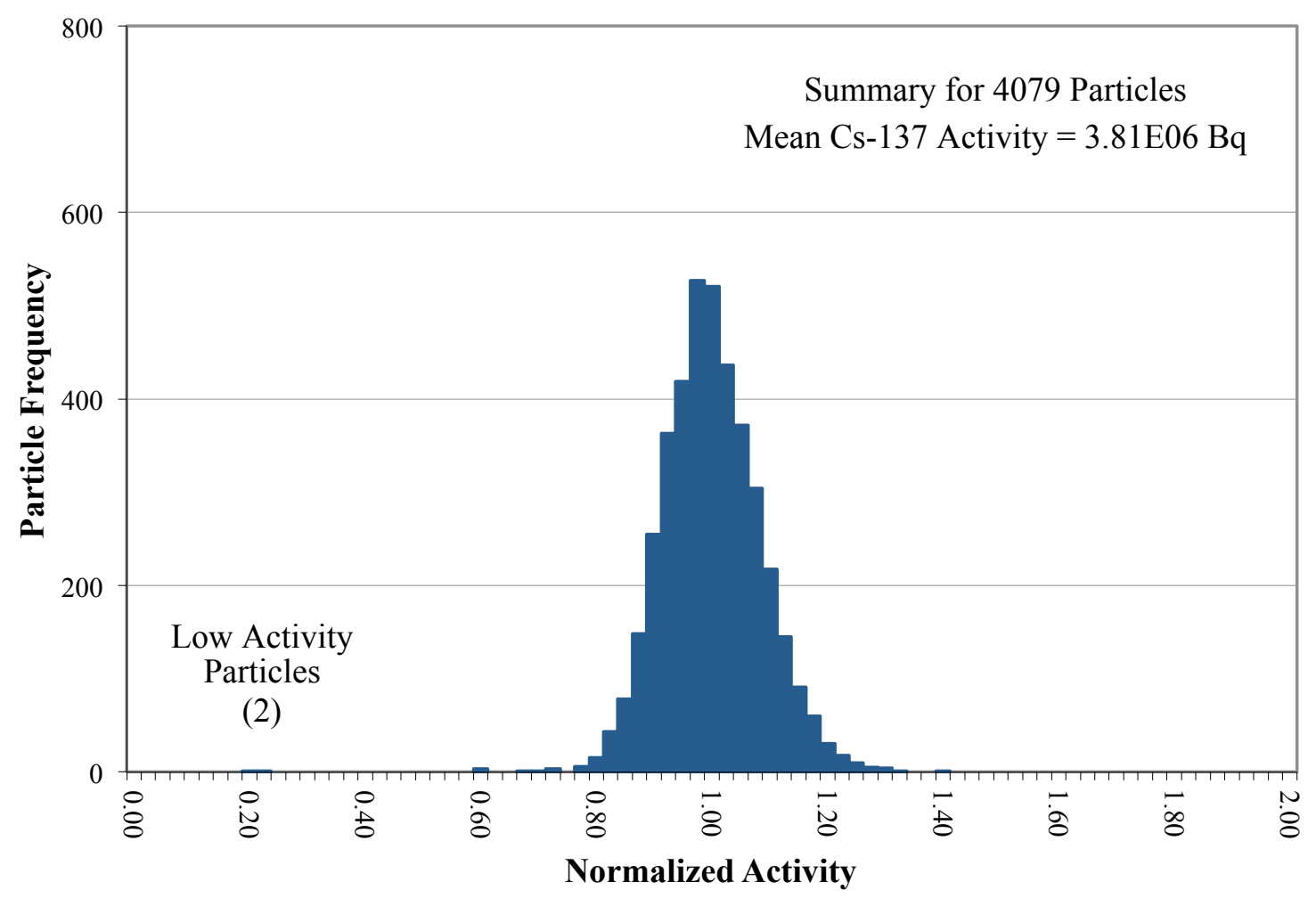

Figure 15. Particle distribution for ${ }^{137} \mathrm{Cs}$ activity (decay corrected to EOL +1 day), normalized to the average ${ }^{137}$ Cs activity. 


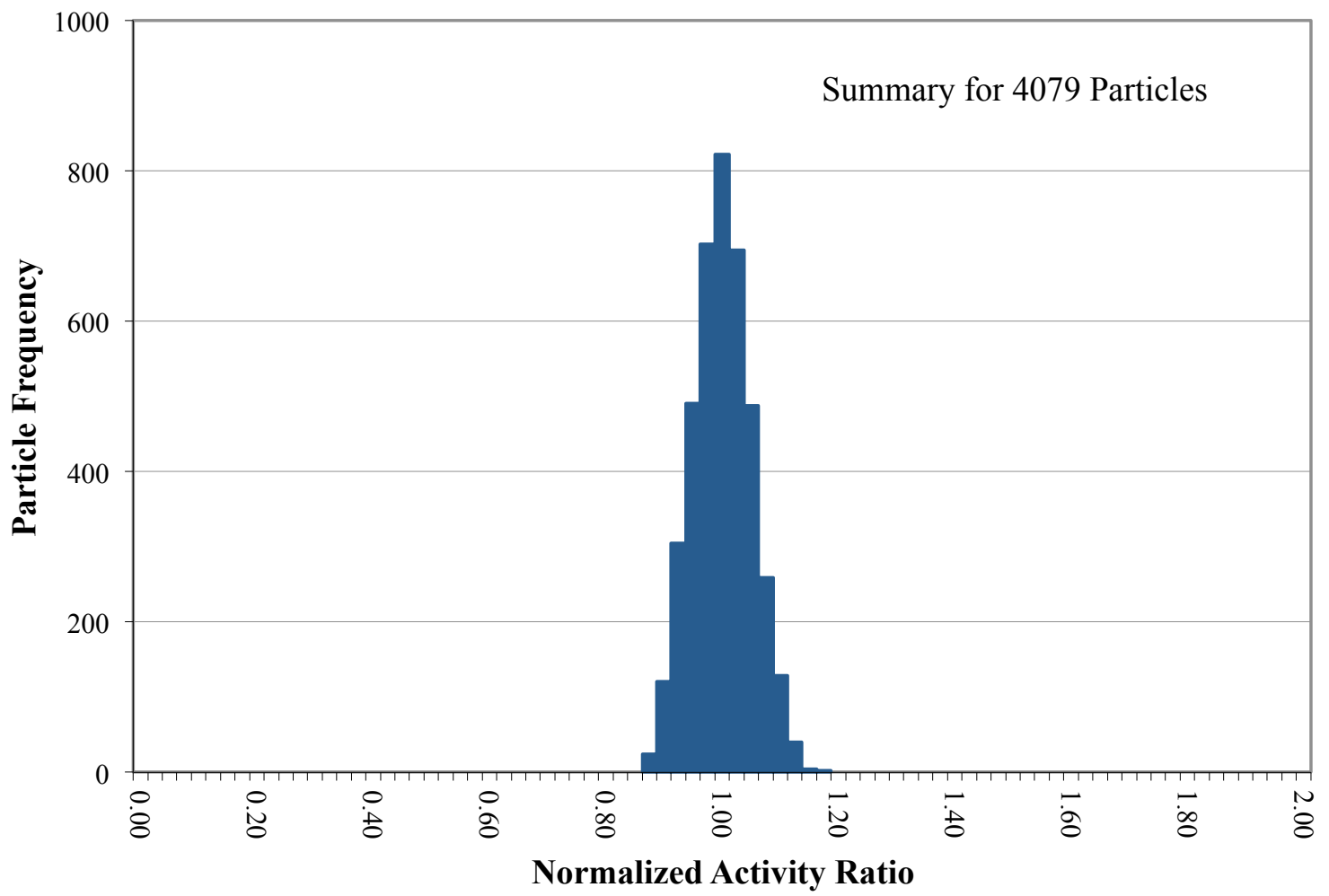

Figure 16. Particle distribution for ${ }^{137} \mathrm{Cs} /{ }^{144} \mathrm{Ce}$ activity ratio (decay corrected to EOL+1 day), normalized to the average ratio.

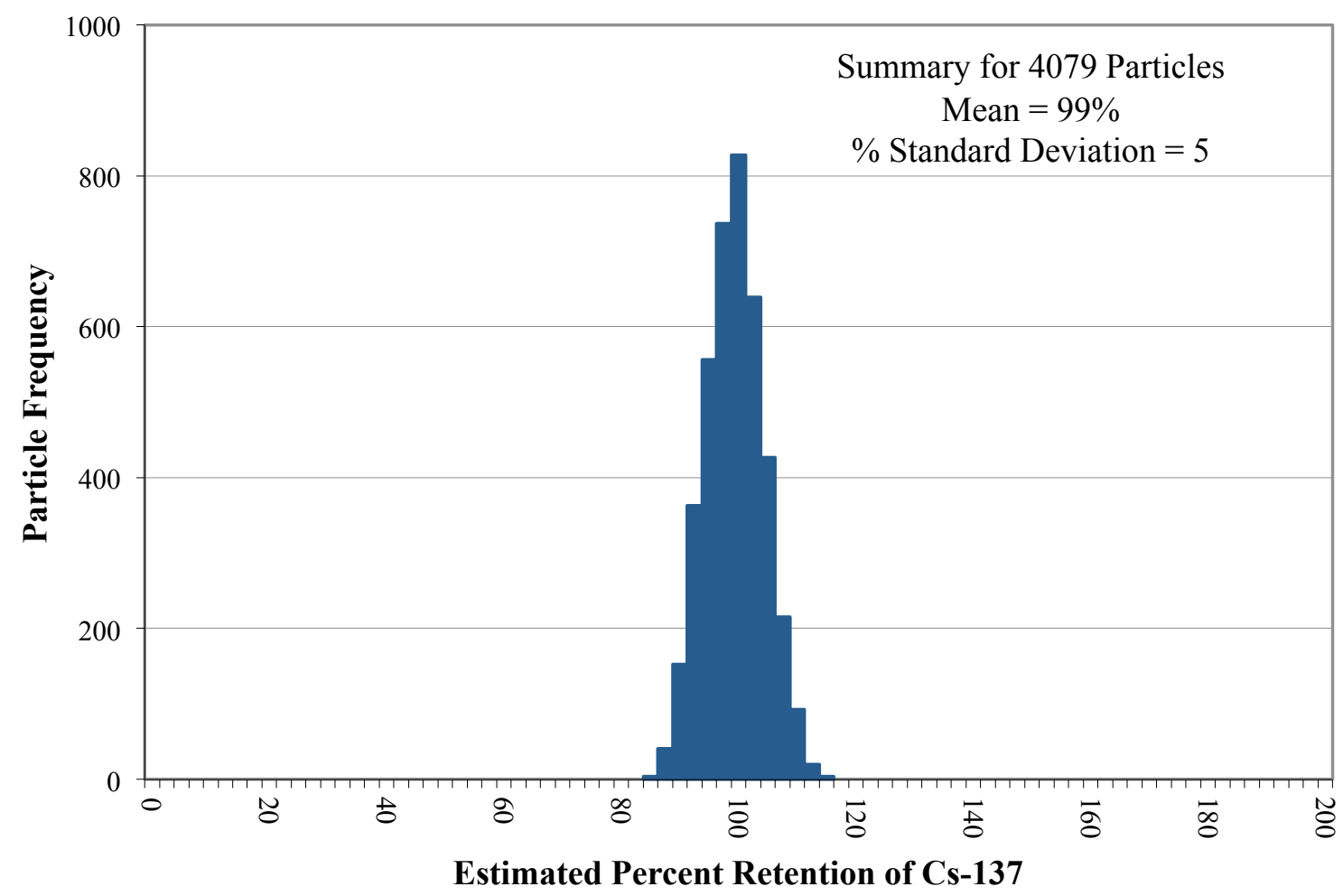

Figure 17. Estimated fraction of ${ }^{137} \mathrm{Cs}$ retained in particles based on calculated inventory and adjusted for variation in fissionable material and burn-up using the measured ${ }^{144} \mathrm{Ce}$ activity. Results suggest low $\mathrm{Cs}$ release and good accuracy in calculated inventory. 
The distribution shown in Figure 17 of ${ }^{137} \mathrm{Cs}$ estimated to have been retained in the particles is centered around $99 \%$ with a standard deviation of $\sim 5 \%$. This indicates good Cs retention and is in agreement with the LBL results, where negligible Cs was found in the matrix, as well as preliminary results from analysis of the AGR-1 capsules, which indicate very low quantities of cesium were released from the compacts in Capsule 6 [Harp et al. 2012]. The narrow and symmetric variation of the values around $99 \%$ is most likely due to uncertainty in the analysis. Again, there is no indication that any individual particles lost an unusual amount of cesium.

A set of 120 particles was counted for 1 hour each to determine their silver and europium inventories. These particles were chosen at random prior to the 100 second scanning and sorting by ${ }^{144} \mathrm{Ce}$ and ${ }^{137} \mathrm{Cs}$ inventory. For these 120 particles, results for ${ }^{144} \mathrm{Ce}$ and ${ }^{137} \mathrm{Cs}$ from this 1 hour scan were used in the summary figures above in lieu of 100 second scanning results. The 120 particles were sorted by ${ }^{110 \mathrm{~m}} \mathrm{Ag}$ activity into 7 bins.

Figure 18 is a histogram comparing the measured inventory of ${ }^{154}$ Eu retained in the particles versus the calculated inventory at EOL +1 day [Sterbentz 2011]. The data in this figure was adjusted for variation in the initial content of fissionable material and burn-up in each particle $i$ using the variation in the ${ }^{144} \mathrm{Ce}$ activity, as was done for ${ }^{137} \mathrm{Cs}$ in Figure 17,

$$
\frac{A_{i}\left({ }^{154} \mathrm{Eu}\right)}{\overline{A_{\text {calc }}\left({ }^{154} \mathrm{Eu}\right)}} / \frac{A_{i}\left({ }^{144} \mathrm{Ce}\right)}{\overline{\overline{A\left({ }^{144} \mathrm{Ce}\right)}}} \text {. }
$$

However, the distribution for ${ }^{154} \mathrm{Eu}$ was not labeled as an estimate of the percent retention because it is evident that the ratio of the measured inventory versus the calculated inventory is lower than expected from other analyses. The ${ }^{154} \mathrm{Eu}$ distribution is centered around 0.84 . Some Eu release was detected by the LBL analysis, but it was only $1.3-1.5 \%$ of the calculated inventory. The graphite holder surrounding the compact was found to have some $\mathrm{Eu}$, indicating a loss of Eu from the compact, but this would only account for an additional fraction of a percent. Therefore, the average ratio of the measured inventory versus the calculated inventory should be above 0.98 . This discrepancy is most likely due to an overestimation of the calculated Eu inventory. A similar issue was observed for the ${ }^{144} \mathrm{Ce}$ IMGA data, where the mean activity was about $89 \%$ of what was expected based on the EOL +1 day inventory calculations [Sterbentz 2011]. An overestimation of the ${ }^{154}$ Eu inventory was also indicated by gamma spectrometry performed on the AGR-1 compacts [Harp 2011], which consistently showed less ${ }^{154} \mathrm{Eu}$ than predicted, in spite of very low quantities found outside of the compacts.

Figure 19 is another histogram comparing the measured inventory of ${ }^{154} \mathrm{Eu}$ retained in the particles versus the calculated inventory, but rather than adjusting for variation in the initial content of fissionable material and burn-up in each particle $i$ using the ${ }^{144} \mathrm{Ce}$ activity, data in this figure was adjusted using the variation in the ${ }^{137} \mathrm{Cs}$ activity.

$$
\frac{A_{i}\left({ }^{154} \mathrm{Eu}\right)}{\overline{A_{\text {calc }}\left({ }^{154} \mathrm{Eu}\right)}} / \frac{A_{i}\left({ }^{137} \mathrm{Cs}\right)}{\overline{\left.A^{137} \mathrm{Cs}\right)}} .
$$

Observations of correlation between $\mathrm{Eu}, \mathrm{Ce}$, and $\mathrm{Cs}$ activities indicate that the ${ }^{137} \mathrm{Cs}$ activity has a stronger correlation to the ${ }^{154} \mathrm{Eu}$ activity. This is reflected in the narrower distribution of the Eu in Figure 19 compared to Figure 18. Historically, Ce has been used to adjust for variation in the initial content of fissionable material and burn-up because Ce is stable in oxide fuel kernels. However, analysis of the AGR-1 fuel indicates that cesium retention was at least as good as cerium. In addition, the build-up of ${ }^{137} \mathrm{Cs}$ was much more linear than ${ }^{144} \mathrm{Ce}$ as a function of burn-up throughout the course of the AGR-1 irradiation, because the irradiation test extended over several ${ }^{144} \mathrm{Ce}$ half-lives and there is a neutron spectrum dependency in the production of ${ }^{144} \mathrm{Ce}$. For these reasons, ${ }^{137} \mathrm{Cs}$ may be the better choice for adjusting for variation in the initial content of fissionable material and burn-up.

It is interesting to note that, although the general distribution of the ${ }^{154} \mathrm{Eu}$ activity narrowed in Figure 19 compared to Figure 18, the two particles located around 0.5 remained. It is possible that these particles do not lie in the tail of a normal distribution, but rather contain an abnormally lower ${ }^{154} \mathrm{Eu}$ inventory. This might indicate that the $1.3-1.5 \%$ Eu release detected by the LBL analysis is due to a small fraction of particles releasing large fractions of their inventory, rather than uniform release of Eu from all particles. 


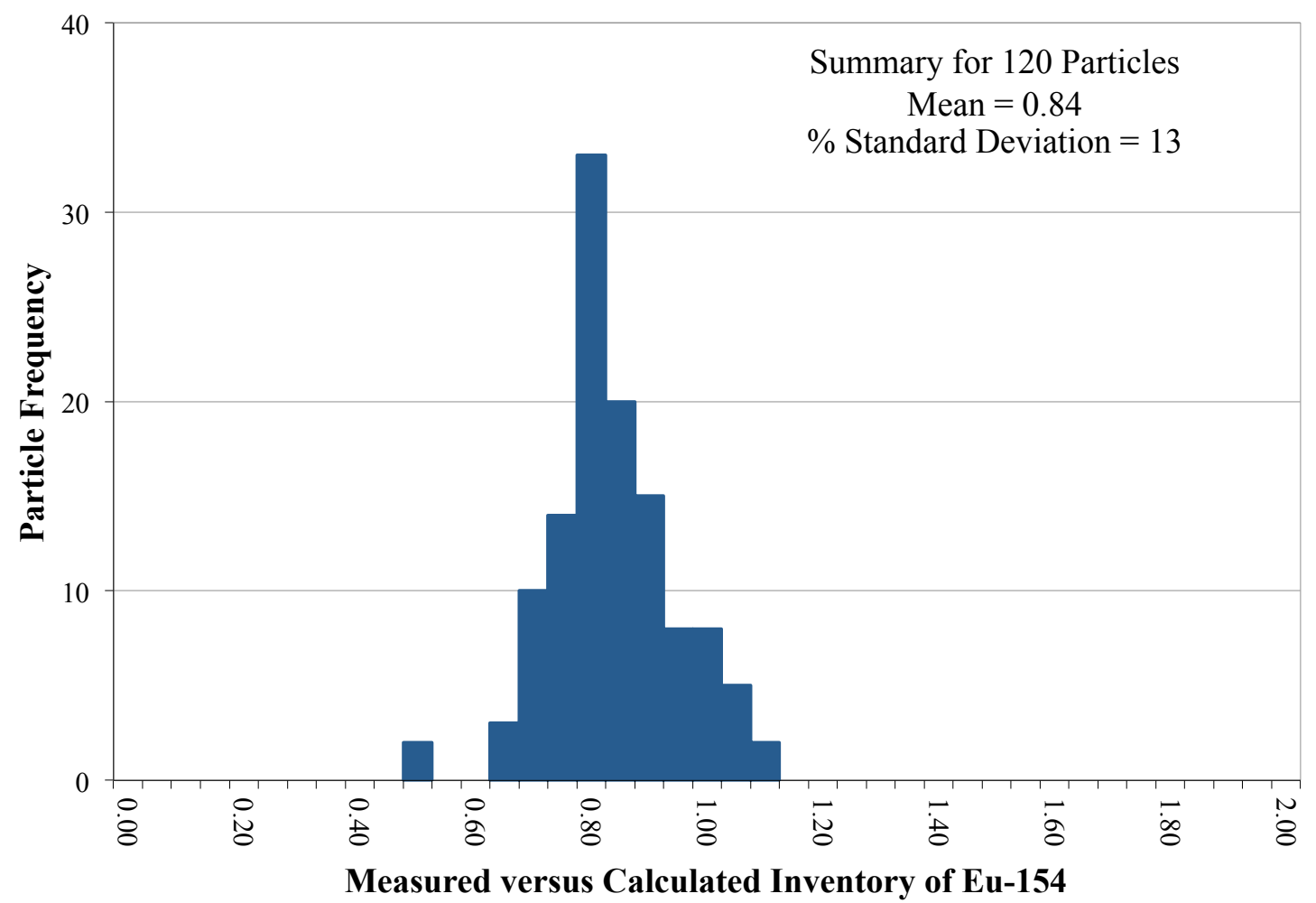

Figure 18. Ratio of ${ }^{154}$ Eu retained in 120 particles versus calculated inventory, adjusted for variation in fissionable material and burn-up using the measured ${ }^{144} \mathrm{Ce}$ activity. Ratio of measured versus calculated value is lower than expected from Eu release measured by other methods, implying the calculated inventory was too high.

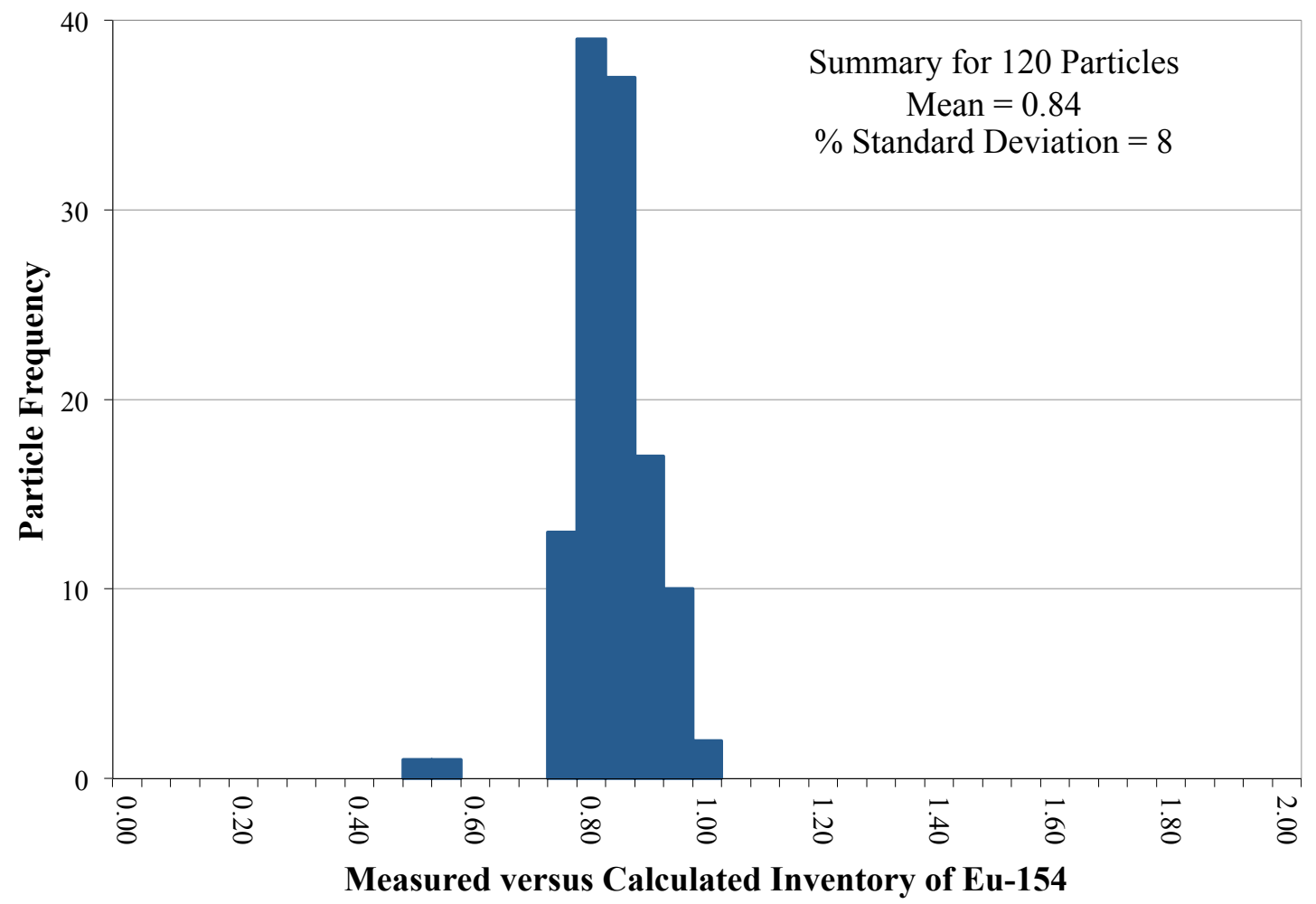

Figure 19. Ratio of ${ }^{154} \mathrm{Eu}$ retained in 120 particles versus calculated inventory, adjusted for variation in fissionable material and burn-up using the measured ${ }^{137} \mathrm{Cs}$ activity. 
Figure 20 plots the ratio of the measured inventory of ${ }^{110 \mathrm{~m}} \mathrm{Ag}$ retained in the particles versus the calculated inventory, again adjusted for variation in the initial content of fissionable material and burn-up in each particle $i$ using the variation in the ${ }^{137} \mathrm{Cs}$ activity.

$$
\frac{A_{i}\left({ }^{110 \mathrm{~m}} \mathrm{Ag}\right)}{\overline{A_{\text {calc }}\left({ }^{110 \mathrm{~m}} \mathrm{Ag}\right)}} / \frac{A_{i}\left({ }^{137} \mathrm{Cs}\right)}{\overline{\left.A^{137} C s\right)}} \text {. }
$$

The ${ }^{110 \mathrm{~m}} \mathrm{Ag}$ distribution is very broad and asymmetric, with only 47 of the 120 particles having ${ }^{110 \mathrm{~m}} \mathrm{Ag}$ inventories that could be measured by the 1 hour count. This bimodal distribution indicates a variable silver retention. For the 47 particles that had measurable ${ }^{110 \mathrm{~m}} \mathrm{Ag}$ inventories, the center of the distribution is close to 1 (0.94), but the standard deviation is high (28\%). The fact that the ${ }^{110 \mathrm{~m}} \mathrm{Ag}$ fraction goes as high as 1.4 may indicate that the calculated EOL +1 day inventory for this isotope is lower than the actual inventory or it may just indicate a large variation in the ${ }^{110 \mathrm{~m}} \mathrm{Ag}$ production. Because of the large spread and bimodal distribution in the ${ }^{110 \mathrm{~m}} \mathrm{Ag}$ distribution, it is difficult to draw conclusions as to the accuracy of the calculated inventory or the interpretation of the plotted data as a quantitative estimate of the retention.

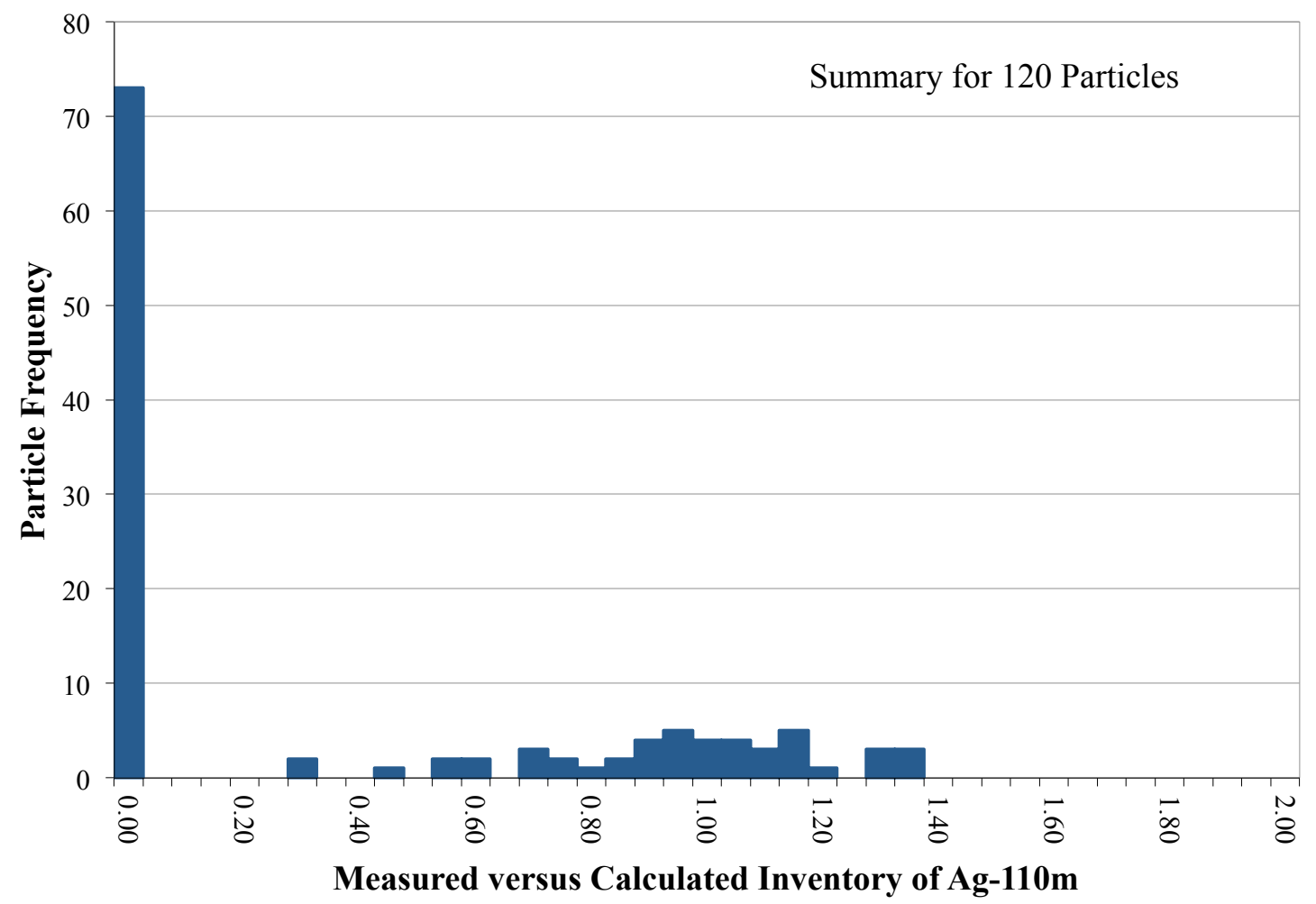

Figure 20. Ratio of ${ }^{110 \mathrm{~m}} \mathrm{Ag}$ retained in 120 particles versus calculated inventory, adjusted for
variation in fissionable material and burn-up using the measured ${ }^{137} \mathrm{Cs}$ activity.

Figure 21 and Figure 22 compare the measured inventory of ${ }^{154}$ Eu retained in the particles versus the calculated inventory, as was done in Figure 18, except the data has been plotted separately for those particles with detectable silver and those without. Similarly, Figure 23 and Figure 24 subdivide the ${ }^{137} \mathrm{Cs}$ adjusted data from Figure 19. These figures show that the particles that retained more silver also appear to have retained more europium. The source of this correlation is not known, but it does not appear to be an artifact of the data analysis. The raw data for the measured ${ }^{154} \mathrm{Eu}$ activity also shows the same correlation. A correlation in the retention of these elements would not necessarily imply that the Ag and Eu moved through the $\mathrm{SiC}$ together, but it may suggest that $\mathrm{Ag}$ and $\mathrm{Eu}$ release could be related by a common driving factor, such as temperature. A similar correlation can be seen in the ${ }^{137} \mathrm{Cs}$ distribution (Figure 25 and Figure 26). 


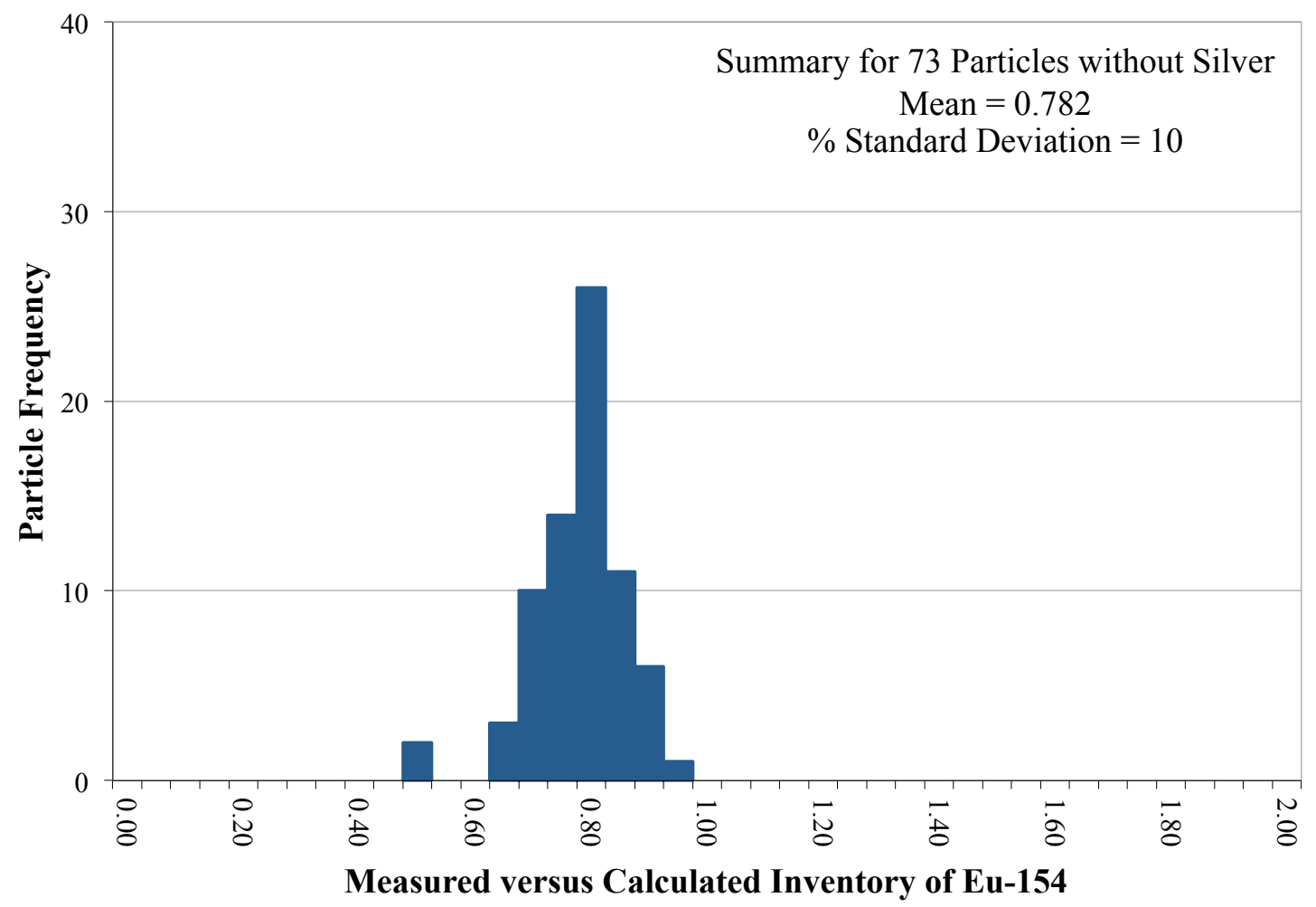

Figure 21. Ratio of ${ }^{154}$ Eu retained in 73 particles without detectable silver versus calculated inventory, adjusted for variation in fissionable material and burn-up using the measured ${ }^{144} \mathrm{Ce}$ activity.

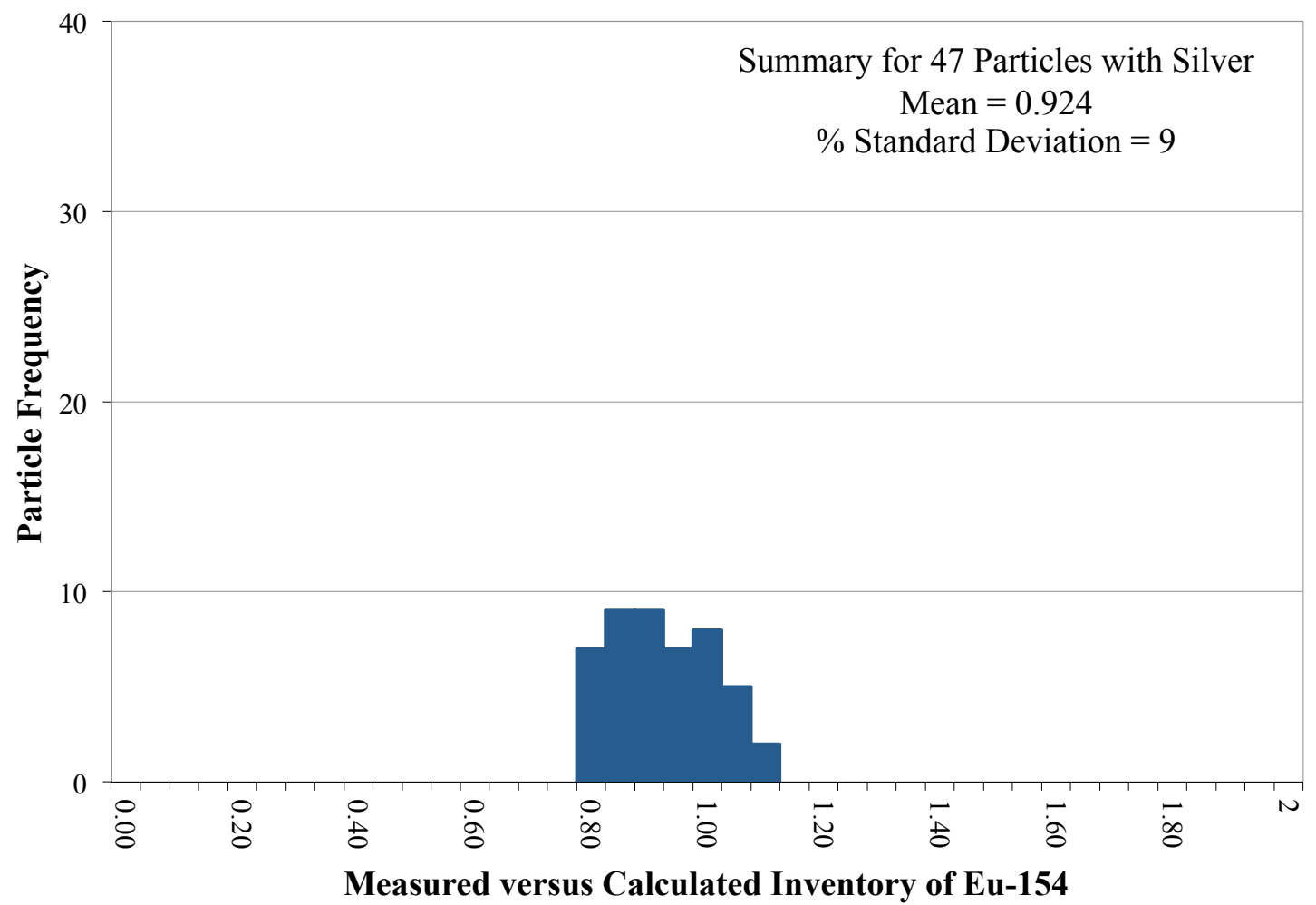

Figure 22. Ratio of ${ }^{154} \mathrm{Eu}$ retained in 47 particles with detectable silver versus calculated inventory, adjusted for variation in fissionable material and burn-up using the measured ${ }^{144} \mathrm{Ce}$ activity. 


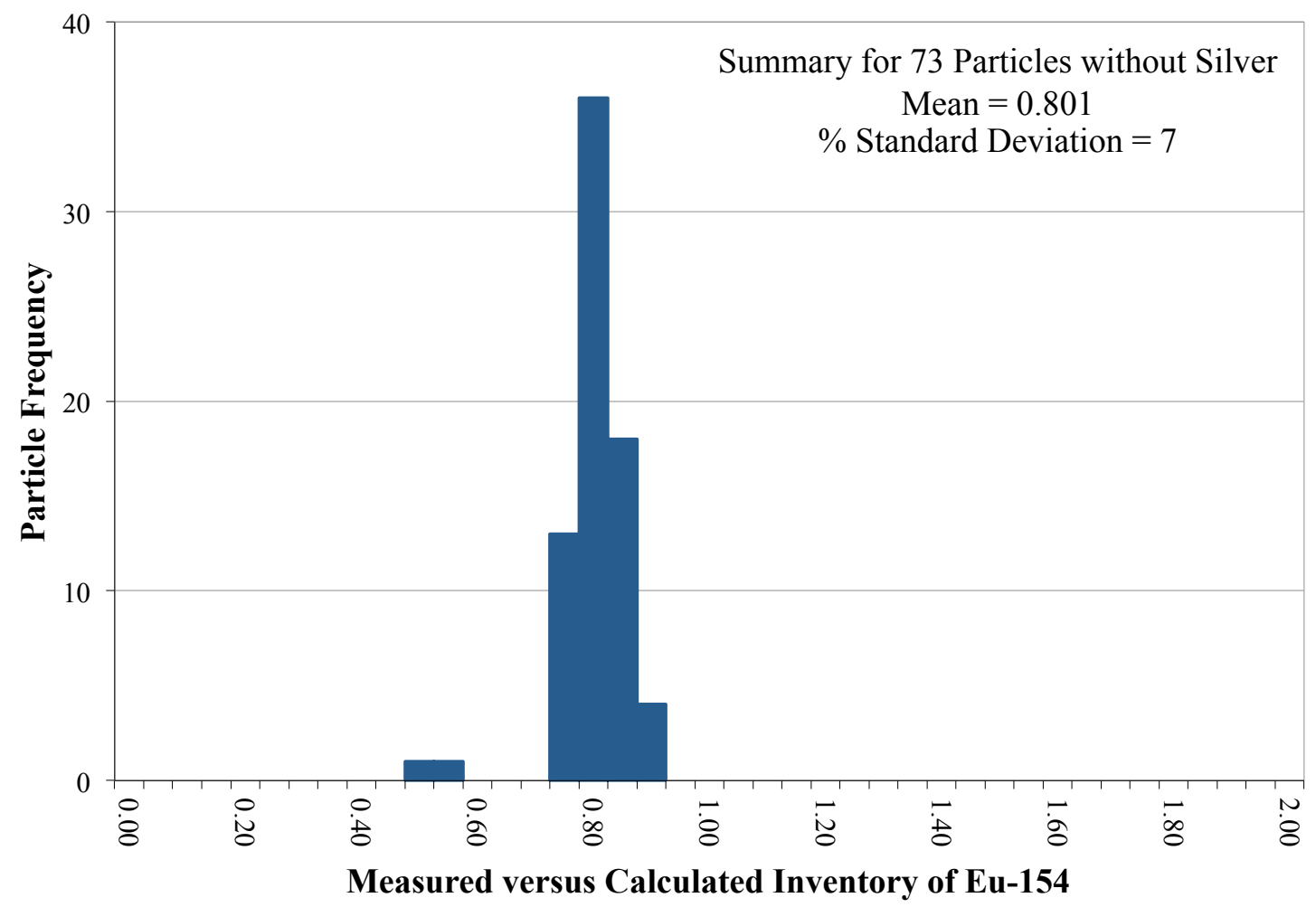

Figure 23. Ratio of ${ }^{154}$ Eu retained in 73 particles without detectable silver versus calculated inventory, adjusted for variation in fissionable material and burn-up using the measured ${ }^{137} \mathrm{Cs}$ activity.

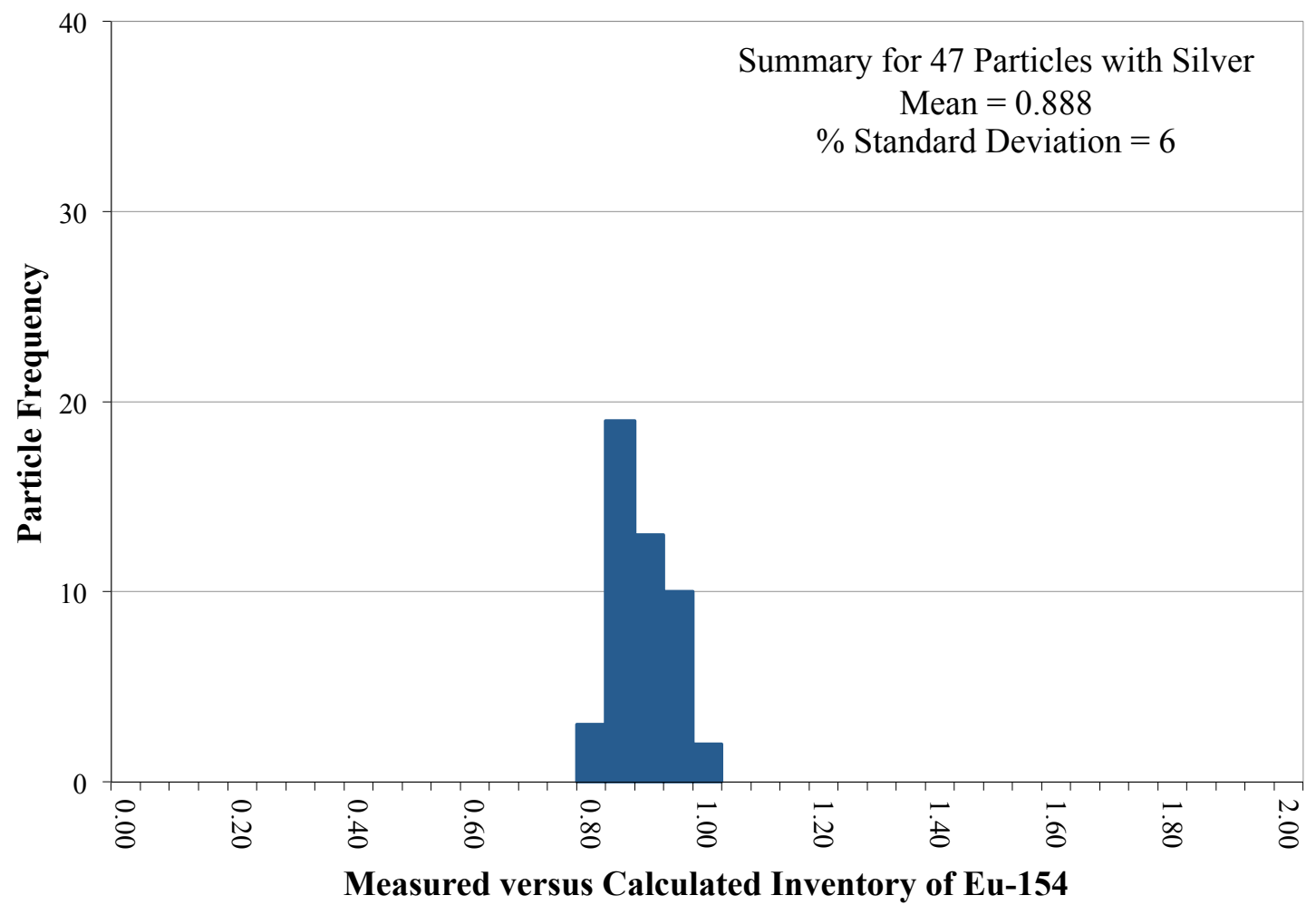

Figure 24. Ratio of ${ }^{154} \mathrm{Eu}$ retained in 47 particles with detectable silver versus calculated inventory, adjusted for variation in fissionable material and burn-up using the measured ${ }^{137} \mathrm{Cs}$ activity. 


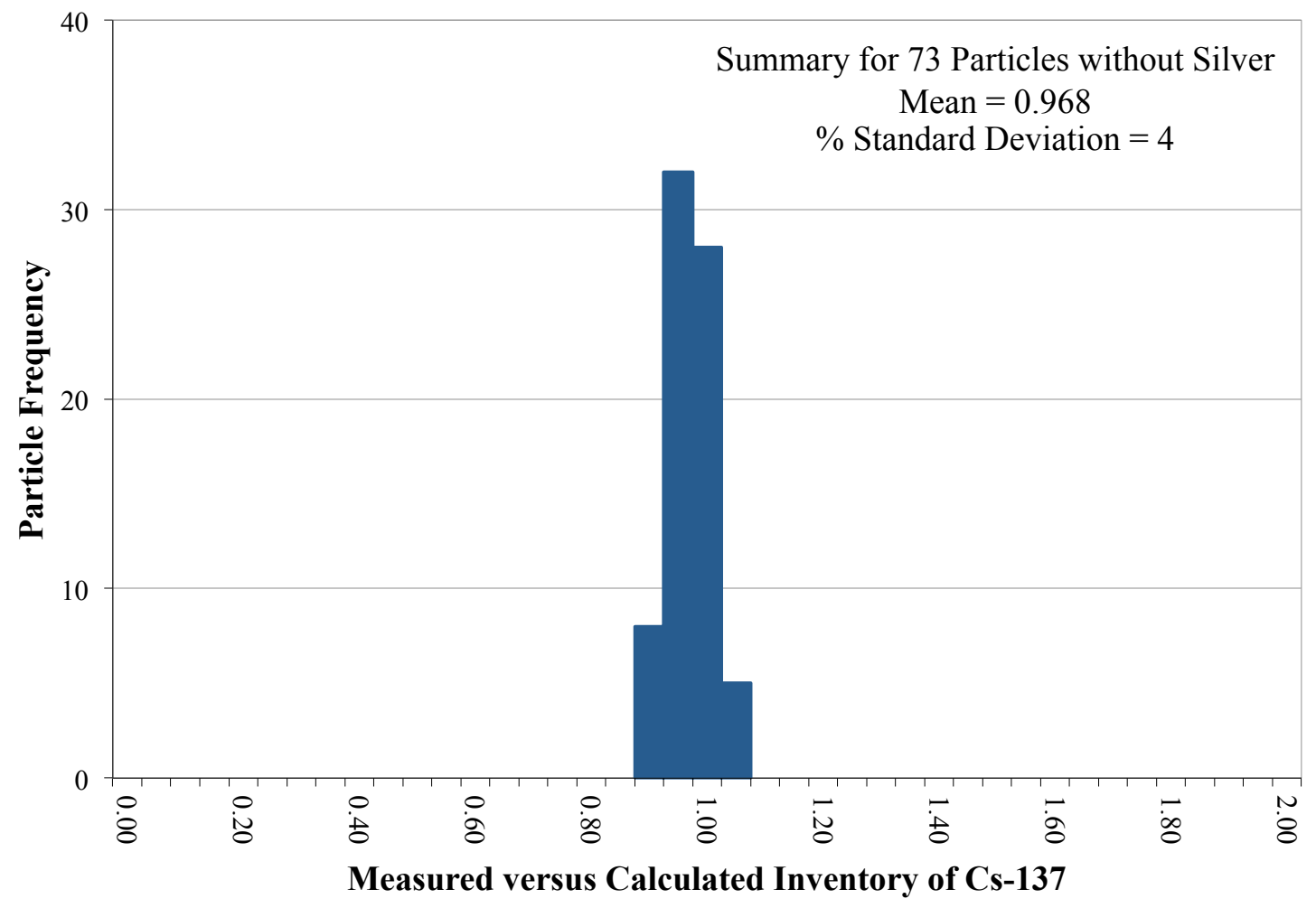

Figure 25. Ratio of ${ }^{137} \mathrm{Cs}$ retained in 73 particles without detectable silver versus calculated inventory, adjusted for variation in fissionable material and burn-up using the measured ${ }^{144} \mathrm{Ce}$ activity.

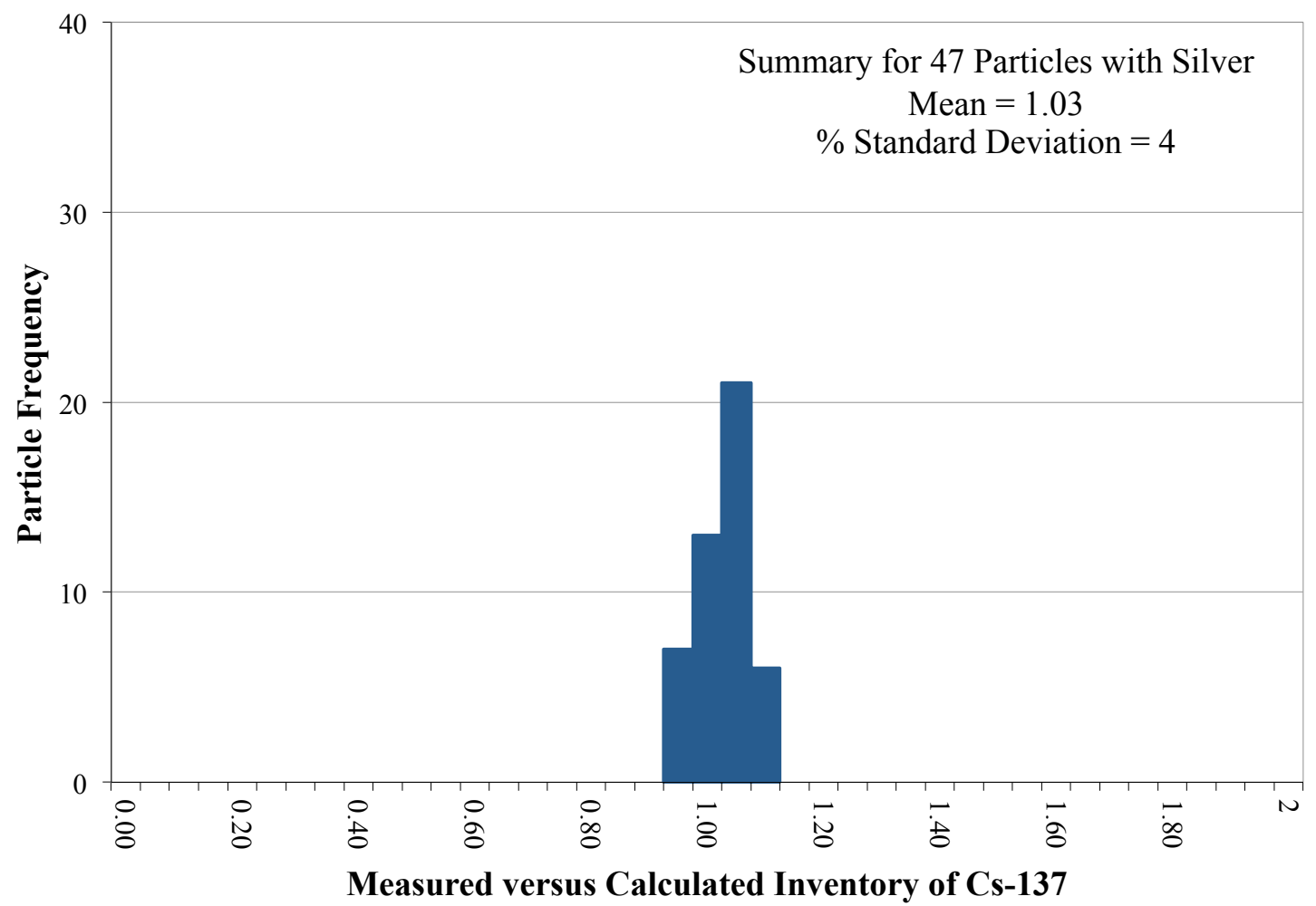

Figure 26. Ratio of ${ }^{137} \mathrm{Cs}$ retained in 47 particles with detectable silver versus calculated inventory, adjusted for variation in fissionable material and burn-up using the measured ${ }^{144} \mathrm{Ce}$ activity. 
To further analyze the variation in the ${ }^{110 \mathrm{~m}} \mathrm{Ag}$ distribution, the 47 particles analyzed to have measurable silver in the 1 hour counting were re-analyzed using a 6 hour gamma scanning time. Two additional particles had been binned with these 47 particles, but not included in the 1 hour analysis results because they had been picked up together and measured simultaneously. These were also included in the 6 hour re-analysis, for a total of 49 particles re-analyzed. Each particle was placed in an individual vial and the IMGA was operated in its vial mode. This allowed for further analysis by materialographic crosssectioning or x-ray tomography of particles where the relative silver retention was known. Figure 27 shows the ${ }^{110 \mathrm{~m}} \mathrm{Ag}$ distribution obtained from this re-analysis, adjusted using the ${ }^{137} \mathrm{Cs}$ activity as was done for Figure 20. The distribution is essentially similar to the data from the 1 hour counting time for these particles. Figure 28 shows the ratio of ${ }^{154}$ Eu measured in the 6 hour counting versus the calculated inventory, adjusted for variation in fissionable material and burn-up using the measured ${ }^{137} \mathrm{Cs}$ activity. The data compares well with the 1 hour data in Figure 24.

A question was also raised as to whether the 73 particles with no detectable ${ }^{110 \mathrm{~m}} \mathrm{Ag}$ inventory using the 1 hour counting time were simply part of the low inventory tail of the ${ }^{110 \mathrm{~m}} \mathrm{Ag}$ distribution. The lowest detected ${ }^{110 \mathrm{~m}} \mathrm{Ag}$ activity in the 1 hour counting was about $10^{4} \mathrm{~Bq}$. Eleven particles from this population were re-counted for 6 hours each to increase the sensitivity for ${ }^{110 \mathrm{~m}} \mathrm{Ag}$. Of these eleven particles, six still showed no detectable ${ }^{110 \mathrm{~m}} \mathrm{Ag}$. Four particles exhibited low ${ }^{110 \mathrm{~m}} \mathrm{Ag}$ activity between $0.5-1.3 \cdot 10^{4} \mathrm{~Bq}$. One particle had a measured ${ }^{110 \mathrm{~m}} \mathrm{Ag}$ activity of $2.6 \cdot 10^{4} \mathrm{~Bq}$, which should have been detectable with 1 hour of counting, but might possibly not have been detected if it was part of a multiple particle pick-up. With approximately half of the 73 out of 120 particles below $0.5 \cdot 10^{4} \mathrm{~Bq}$, a bimodal behavior is still indicated.

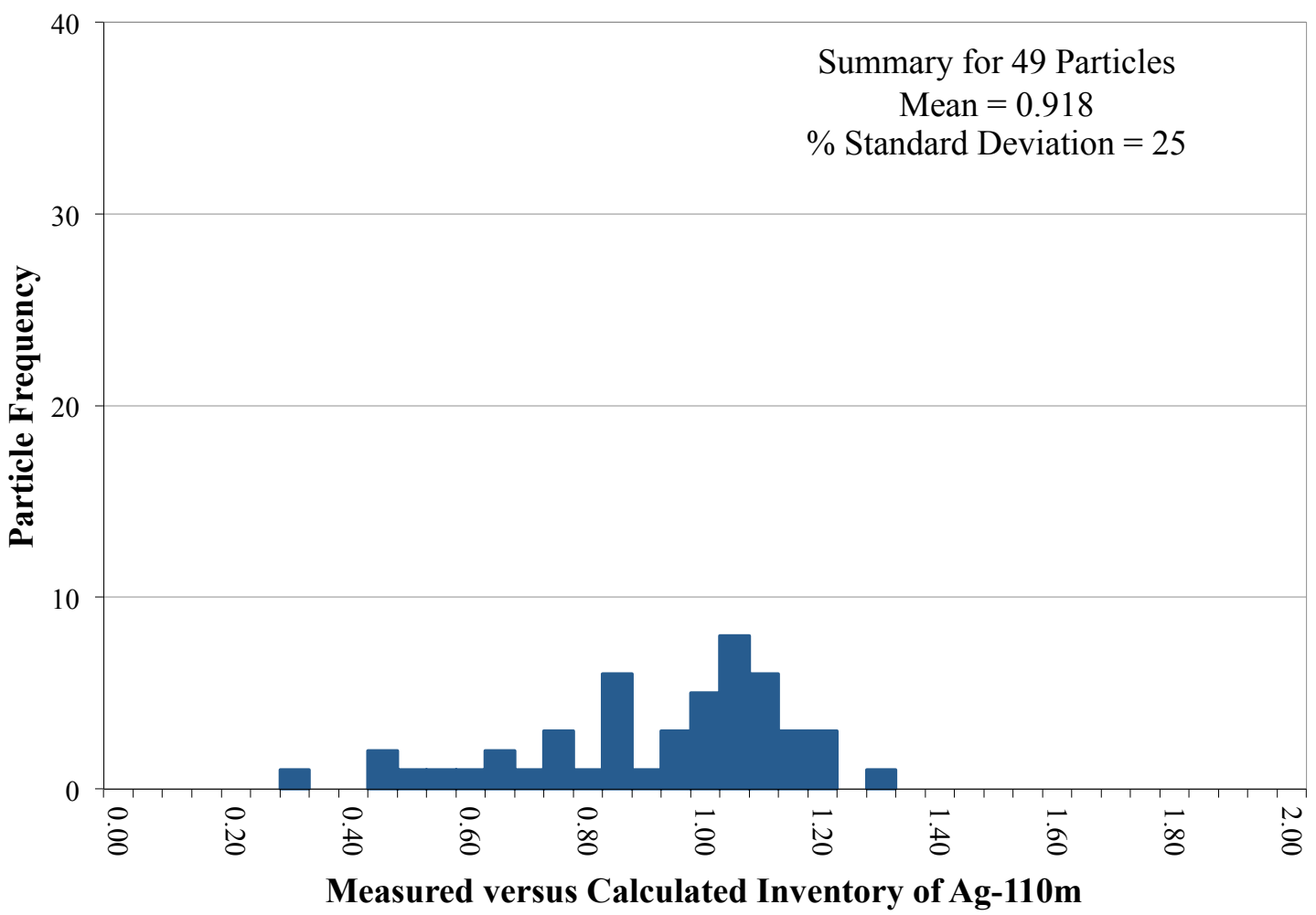

Figure 27. Results of a 6 hour counting time re-analysis of particles that had detectable ${ }^{110 \mathrm{~m}} \mathrm{Ag}$ in the 1 hour gamma scan. Histogram shows the ratio of ${ }^{110 \mathrm{~m}} \mathrm{Ag}$ retained in 49 particles versus calculated inventory, adjusted for variation in fissionable material and burn-up using the measured ${ }^{137} \mathrm{Cs}$ activity. Note that this figure does not represent a random sampling of the ${ }^{110 \mathrm{~m}} \mathrm{Ag}$ distribution because it does not include particles sorted out as having no detectable ${ }^{110 \mathrm{~m}} \mathrm{Ag}$ in the 1 hour scan. 


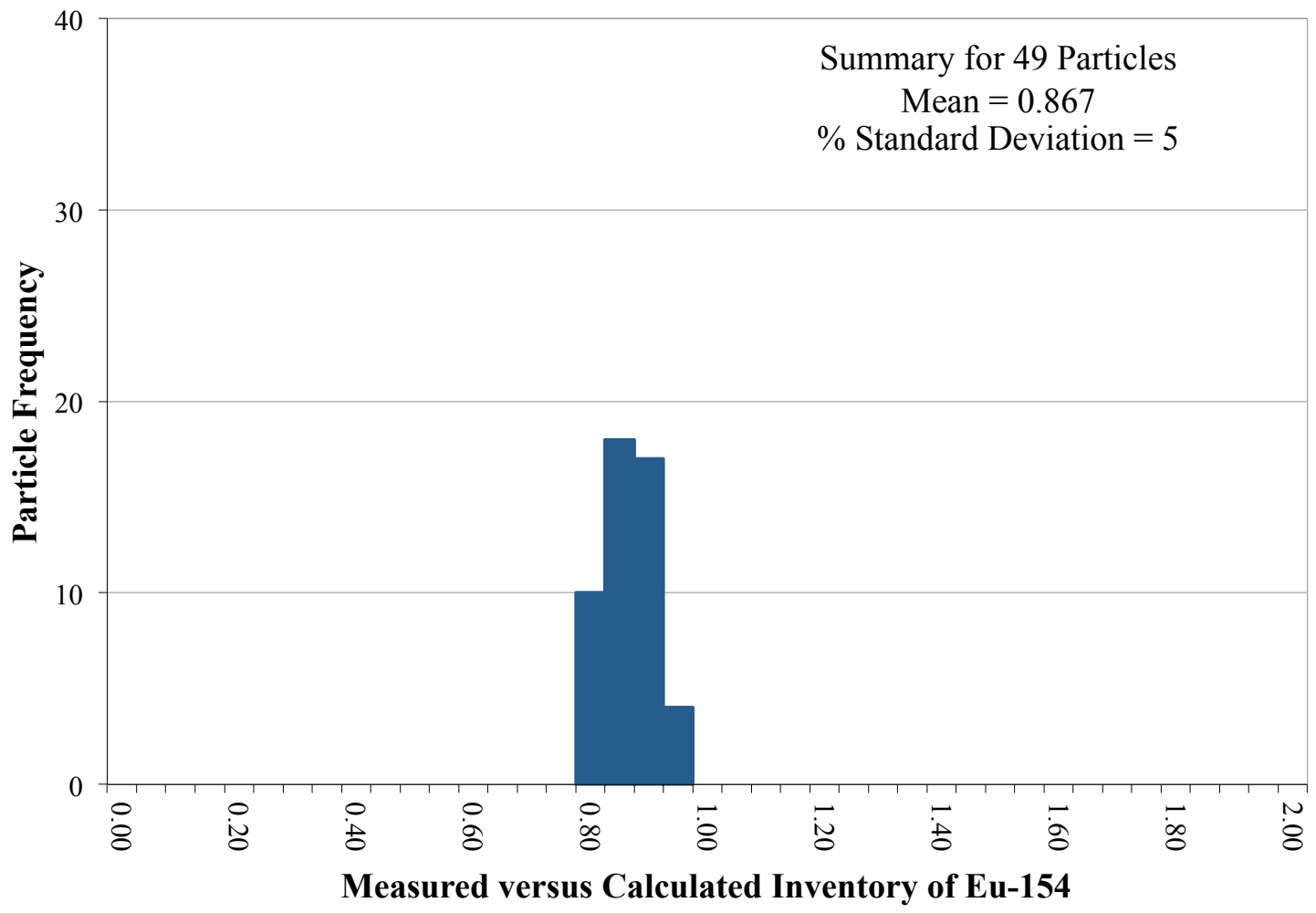

Figure 28. Results of a 6 hour counting time re-analysis of particles that had detectable ${ }^{110 \mathrm{~m}} \mathrm{Ag}$ in the 1 hour gamma scan. Histogram shows the ratio of ${ }^{154} \mathrm{Eu}$ retained in 47 particles versus calculated inventory, adjusted for variation in fissionable material and burn-up using the measured ${ }^{137}$ Cs activity.

The fact that the entire random sample of particles riffled out for gamma scanning over an extended period was not re-analyzed for 6 hours introduces the problem that the available 6 hour scan data does not represent the whole compact. Figure 27 is a plot of only those particles that had detectable silver in the 1 hour scan and does not show the bimodal distribution in the silver retention. An estimate of the possible distribution within the lower population of the bimodal distribution was made based on the 6 hour reanalysis discussed above of the 11 particles from the 73 particles sorted as having undetectable silver during the 1 hour scan. Figure 29 shows the measured data from the 6 hour gamma scan plotted with an estimation of the distribution for the remaining particles with low silver retention in the original random sample. This estimated distribution was extrapolated from the distribution of the low silver retention particles that were measured for 6 hours. This extrapolated plot illustrates that the particles in the lower peak contained more silver than is implied by Figure 20, which plots all 73 particles in the lowest bin of the histogram. Future IMGA analysis should be performed using count times sufficient to measure the full range of silver inventory, and if count times are extended, all particles in a random sample should be re-analyzed. 


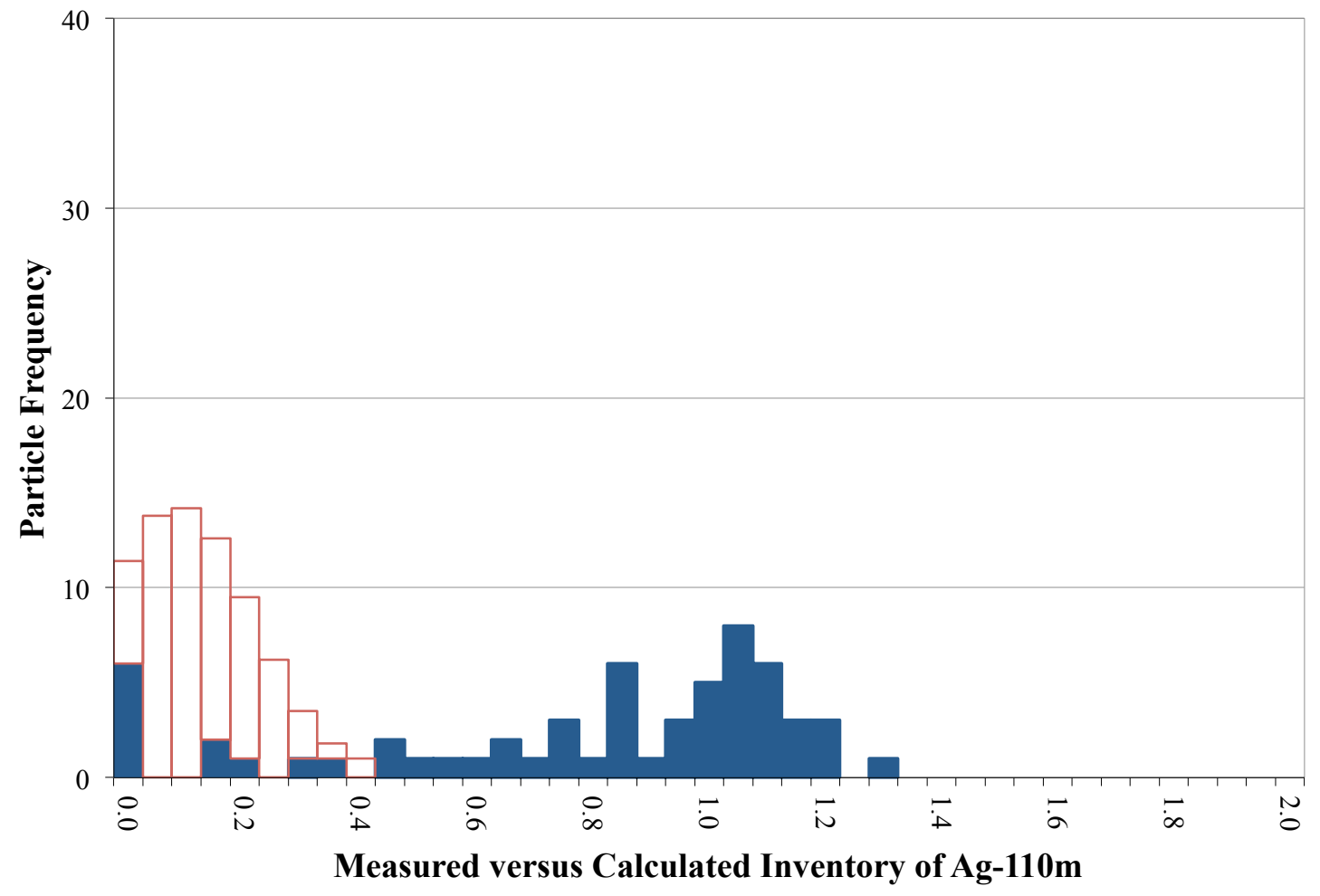

Figure 29. Ratio of ${ }^{110 \mathrm{~m}} \mathrm{Ag}$ retained in 122 particles versus calculated inventory, adjusted for variation in fissionable material and burn-up using the measured ${ }^{137} \mathrm{Cs}$ activity. Solid bars indicate measured values from 6 hour gamma scan. Hollow bars indicate estimated distribution for remaining particles with undetectable ${ }^{110 \mathrm{~m}} \mathrm{Ag}$ in 1 hour gamma scan.

Previous observation of the pre-irradiated fuel particles showed a variation in the $\mathrm{SiC}$ surface appearance for the four different coating batches used to make the AGR-1 Baseline fuel composite. This variation could be distinguished optically as either a dull or a shiny surface appearance, and was related to the $\mathrm{SiC}$ grain structure near the surface. Approximately $42.6 \%$ of the particles in the composite had a dull appearance and approximately $57.4 \%$ had a shiny appearance. This ratio is similar to that observed for the bimodal ${ }^{110 \mathrm{~m}} \mathrm{Ag}$ distribution. In order to investigate the possibility that this varying $\mathrm{SiC}$ microstructure might be related to the varying silver retention observed by IMGA, 20 particles with varied silver retention were placed in individual tubes and heated in air at $850^{\circ} \mathrm{C}$ for 8 hours to remove the OPyC layer. Close examination of the particles under the stereo microscope in the IMGA cell, both individually and side by side, did reveal differences in the surface quality ("shiny" versus "dull"), but there was no obvious correlation between the surface state and silver retaining ability of the particles for the small number examined. See Figure 30 for photos of the particles. The "No Ag" particles in the figure had no detectable ${ }^{110 \mathrm{~m}} \mathrm{Ag}$ inventory in the 1 hour gamma scans. Particles Ag-01 through Ag-08 had the highest measured ${ }^{110 \mathrm{~m}} \mathrm{Ag}$ inventories. The bright sphere in each photo is a $711 \mu \mathrm{m}$ diameter stainless steel calibration sphere shown for dimensional reference. Care was taken to process all images the same so the surface appearance of the particles could be compared. While difficult to see in the photos, some particles have a "shiny" appearance and some have a "satiny or dull" appearance. (The shiny particles tend to have a lighter shaded circle in the center due to reflected light.) 


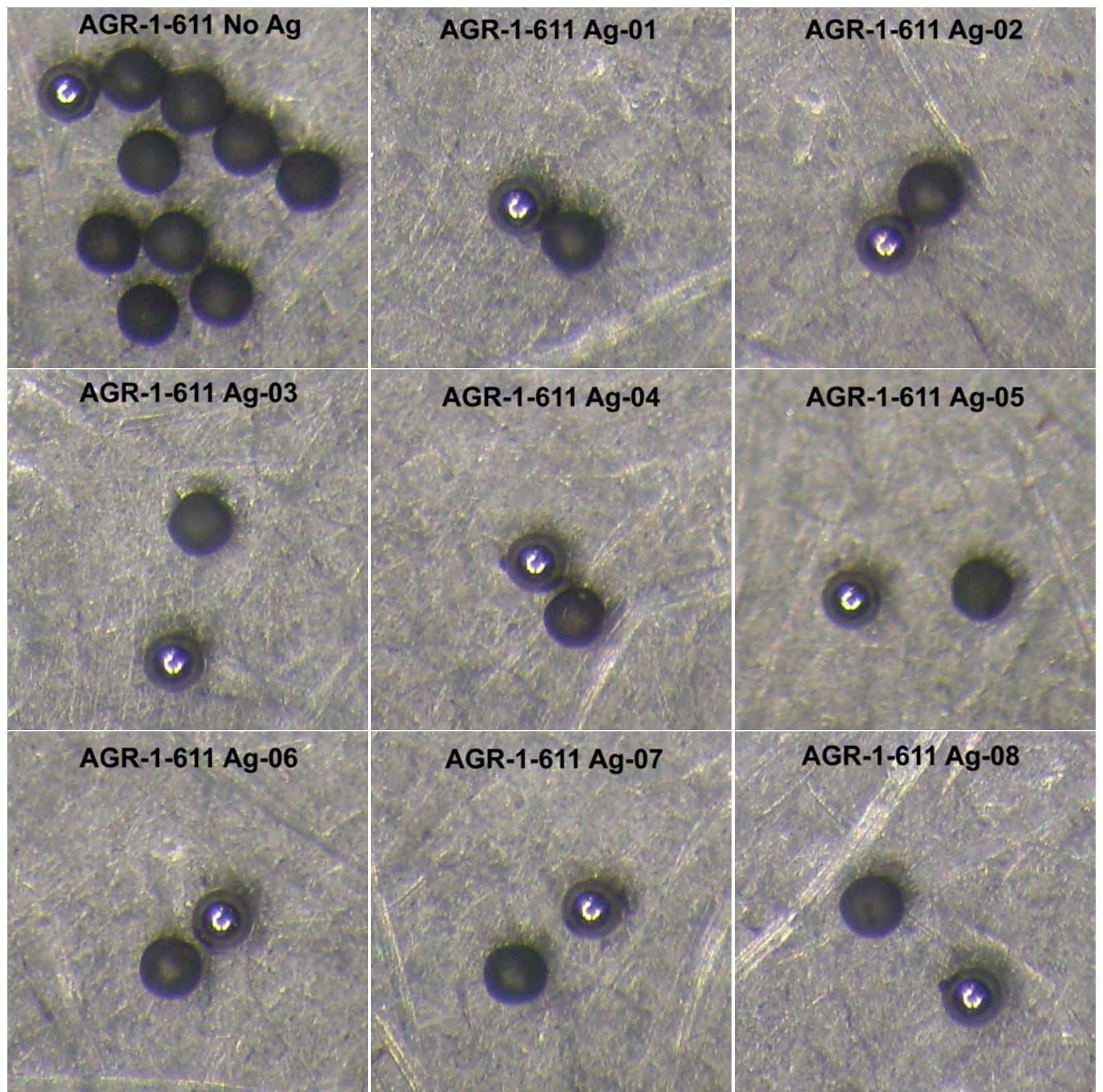

Figure 30. Variation in SiC surface appearance of particles after burn back to remove the OPyC layer.

Activity from several additional isotopes was detected during the 1 hour and 6 hour IMGA analysis (see discussion of key peaks for Table 5). The 6 hour scan results are summarized in Table 6. Data for ${ }^{95} \mathrm{Zr}$, ${ }^{106} \mathrm{Ru}$, and ${ }^{125} \mathrm{Sb}$ are not discussed in detail in this report because the LBL analysis indicated that release of these isotopes was too low to expect to be able to detect a variation in the inventory with IMGA. However, for completeness, Table 7 provides a record of the measured activity for each of the key peaks from all the particles scanned for 6 hours. Note that Table 6 also shows the values for the calculated average particle activity,

$$
\overline{A_{\text {calc }}(\text { Isotope X) }}=(\lambda / 4145) \times \overline{N_{\text {calc }}(\text { Isotope X })},
$$

derived from the calculated average compact inventory [Sterbentz 2011] and used in Figure 17 through Figure 28 to plot the IMGA data in terms of measured versus calculated inventory. 
Table 6. Summary of results from 6 hour IMGA analysis

\begin{tabular}{|c||c|c|c|c|}
\hline Isotope & $\begin{array}{c}\text { Calculated Inventory } \\
\text { at EOL+1 day } \\
\text { (Bq/particle) }\end{array}$ & $\begin{array}{c}\text { Average Measured Activity } \\
\text { Decay Corrected to EOL+1 day } \\
\text { (Bq/particle) }\end{array}$ & $\begin{array}{c}\text { \% Standard Deviation } \\
\text { in Measured Activity }\end{array}$ & $\begin{array}{c}\text { Measured / } \\
\text { Calculated } \\
\text { Inventory }\end{array}$ \\
\hline \hline Zr-95 & $5.92 \mathrm{E}+07$ & $5.48 \mathrm{E}+07$ & 8 & 0.93 \\
\hline Ru-106 & $1.06 \mathrm{E}+07$ & $1.08 \mathrm{E}+07$ & 10 & 1.02 \\
\hline Ag-110m & $3.28 \mathrm{E}+04$ & $3.08 \mathrm{E}+04$ & 35 & 0.94 \\
\hline Sb-125 & $2.68 \mathrm{E}+05$ & $2.11 \mathrm{E}+05$ & 8 & 0.79 \\
\hline Cs-134 & $3.85 \mathrm{E}+06$ & $4.17 \mathrm{E}+06$ & 11 & 1.08 \\
\hline Cs-137 & $3.84 \mathrm{E}+06$ & $4.08 \mathrm{E}+06$ & 8 & 1.06 \\
\hline Ce-144 & $4.75 \mathrm{E}+07$ & $4.36 \mathrm{E}+07$ & 7 & 0.92 \\
\hline Eu-154 & $1.31 \mathrm{E}+05$ & $1.20 \mathrm{E}+05$ & 10 & 0.92 \\
\hline
\end{tabular}

${ }^{1}$ Interference from ${ }^{154} \mathrm{Eu}$ has been subtracted out of ${ }^{95} \mathrm{Zr}$ peak.

${ }^{2}$ Mean and standard deviation for ${ }^{110 \mathrm{~m}} \mathrm{Ag}$ do not include particles with undetectable inventory.

Table 7. Results of 6 hour gamma scanning showing measured activity (Bq/particle decay-corrected to EOL+1day) for key peaks from Table 5

\begin{tabular}{|c|c|c|c|c|c|c|c|c|}
\hline Particle & Zr-95 & Ru-106 & Ag-110m & Sb-125 & Cs-134 & Cs-137 & Ce-144 & Eu-154 \\
\hline Ag-01 & $5.87 \mathrm{E}+07$ & $1.15 \mathrm{E}+07$ & $3.83 \mathrm{E}+04$ & $2.20 \mathrm{E}+05$ & $4.16 \mathrm{E}+06$ & $4.14 \mathrm{E}+06$ & $4.41 \mathrm{E}+07$ & $1.23 \mathrm{E}+05$ \\
\hline $\mathrm{Ag}-02$ & $5.17 \mathrm{E}+07$ & $1.23 \mathrm{E}+07$ & $4.48 \mathrm{E}+04$ & $2.27 \mathrm{E}+05$ & $4.72 \mathrm{E}+06$ & $4.31 \mathrm{E}+06$ & $4.34 \mathrm{E}+07$ & $1.35 \mathrm{E}+05$ \\
\hline $\mathrm{Ag}-03$ & $5.25 \mathrm{E}+07$ & $1.15 \mathrm{E}+07$ & $3.86 \mathrm{E}+04$ & $2.13 \mathrm{E}+05$ & $4.58 \mathrm{E}+06$ & $4.14 \mathrm{E}+06$ & $4.30 \mathrm{E}+07$ & $1.29 \mathrm{E}+05$ \\
\hline $\mathrm{Ag}-04$ & $6.25 \mathrm{E}+07$ & $1.08 \mathrm{E}+07$ & $1.88 \mathrm{E}+04$ & $2.19 \mathrm{E}+05$ & $4.19 \mathrm{E}+06$ & $4.41 \mathrm{E}+06$ & $4.85 \mathrm{E}+07$ & $1.19 \mathrm{E}+05$ \\
\hline $\mathrm{Ag}-05$ & $5.12 \mathrm{E}+07$ & $1.25 \mathrm{E}+07$ & $4.41 \mathrm{E}+04$ & $2.27 \mathrm{E}+05$ & $4.89 \mathrm{E}+06$ & $4.38 \mathrm{E}+06$ & $4.41 \mathrm{E}+07$ & $1.38 \mathrm{E}+05$ \\
\hline Ag-06 & $5.72 \mathrm{E}+07$ & $1.21 \mathrm{E}+07$ & $4.04 \mathrm{E}+04$ & $2.35 \mathrm{E}+05$ & $4.62 \mathrm{E}+06$ & $4.47 \mathrm{E}+06$ & $4.66 \mathrm{E}+07$ & $1.33 \mathrm{E}+05$ \\
\hline Ag-07 & $5.63 \mathrm{E}+07$ & $1.37 \mathrm{E}+07$ & $5.02 \mathrm{E}+04$ & $2.53 \mathrm{E}+05$ & $5.38 \mathrm{E}+06$ & $4.84 \mathrm{E}+06$ & $4.68 \mathrm{E}+07$ & $1.54 \mathrm{E}+05$ \\
\hline $\mathrm{Ag}-08$ & $5.47 \mathrm{E}+07$ & $1.20 \mathrm{E}+07$ & $4.28 \mathrm{E}+04$ & $2.29 \mathrm{E}+05$ & $4.74 \mathrm{E}+06$ & $4.30 \mathrm{E}+06$ & $4.46 \mathrm{E}+07$ & $1.37 \mathrm{E}+05$ \\
\hline $\mathrm{Ag}-09$ & $5.77 \mathrm{E}+07$ & $1.20 \mathrm{E}+07$ & $3.85 \mathrm{E}+04$ & $2.25 \mathrm{E}+05$ & $4.40 \mathrm{E}+06$ & $4.32 \mathrm{E}+06$ & $4.44 \mathrm{E}+07$ & $1.30 \mathrm{E}+05$ \\
\hline Ag-10 & $5.44 \mathrm{E}+07$ & $1.19 \mathrm{E}+07$ & $4.07 \mathrm{E}+04$ & $2.27 \mathrm{E}+05$ & $4.60 \mathrm{E}+06$ & $4.34 \mathrm{E}+06$ & $4.51 \mathrm{E}+07$ & $1.29 \mathrm{E}+05$ \\
\hline Ag-11 & $4.96 \mathrm{E}+07$ & $1.16 \mathrm{E}+07$ & $4.14 \mathrm{E}+04$ & $2.16 \mathrm{E}+05$ & $4.60 \mathrm{E}+06$ & $4.18 \mathrm{E}+06$ & $4.15 \mathrm{E}+07$ & $1.32 \mathrm{E}+05$ \\
\hline $\mathrm{Ag}-12$ & $4.92 \mathrm{E}+07$ & $1.19 \mathrm{E}+07$ & $4.37 \mathrm{E}+04$ & $2.24 \mathrm{E}+05$ & $4.70 \mathrm{E}+06$ & $4.22 \mathrm{E}+06$ & $4.18 \mathrm{E}+07$ & $1.33 \mathrm{E}+05$ \\
\hline Ag-13 & $5.99 \mathrm{E}+07$ & $1.10 \mathrm{E}+07$ & $2.47 \mathrm{E}+04$ & $2.21 \mathrm{E}+05$ & $4.39 \mathrm{E}+06$ & $4.43 \mathrm{E}+06$ & $4.65 \mathrm{E}+07$ & $1.27 \mathrm{E}+05$ \\
\hline Ag-14 & $5.12 \mathrm{E}+07$ & $9.46 \mathrm{E}+06$ & $1.03 \mathrm{E}+04$ & $1.91 \mathrm{E}+05$ & $3.82 \mathrm{E}+06$ & $3.80 \mathrm{E}+06$ & $4.24 \mathrm{E}+07$ & $1.10 \mathrm{E}+05$ \\
\hline Ag-15 & $5.69 \mathrm{E}+07$ & $1.02 \mathrm{E}+07$ & $1.50 \mathrm{E}+04$ & $2.08 \mathrm{E}+05$ & $4.09 \mathrm{E}+06$ & $4.04 \mathrm{E}+06$ & $4.37 \mathrm{E}+07$ & $1.18 \mathrm{E}+05$ \\
\hline Ag-16 & $4.90 \mathrm{E}+07$ & $1.18 \mathrm{E}+07$ & $4.66 \mathrm{E}+04$ & $2.16 \mathrm{E}+05$ & $4.55 \mathrm{E}+06$ & $4.11 \mathrm{E}+06$ & $4.18 \mathrm{E}+07$ & $1.32 \mathrm{E}+05$ \\
\hline Ag-17 & $5.52 \mathrm{E}+07$ & $9.28 \mathrm{E}+06$ & $1.94 \mathrm{E}+04$ & $1.96 \mathrm{E}+05$ & $3.84 \mathrm{E}+06$ & $3.84 \mathrm{E}+06$ & $4.19 \mathrm{E}+07$ & $1.11 \mathrm{E}+05$ \\
\hline $\mathrm{Ag}-18$ & $5.49 \mathrm{E}+07$ & $9.96 \mathrm{E}+06$ & $1.49 \mathrm{E}+04$ & $2.03 \mathrm{E}+05$ & $4.11 \mathrm{E}+06$ & $3.98 \mathrm{E}+06$ & $4.54 \mathrm{E}+07$ & $1.17 \mathrm{E}+05$ \\
\hline Ag-19 & $5.86 \mathrm{E}+07$ & $1.01 \mathrm{E}+07$ & $3.29 \mathrm{E}+04$ & $2.07 \mathrm{E}+05$ & $3.80 \mathrm{E}+06$ & $3.96 \mathrm{E}+06$ & $4.57 \mathrm{E}+07$ & $1.11 \mathrm{E}+05$ \\
\hline Ag-20 & $4.87 \mathrm{E}+07$ & $9.59 \mathrm{E}+06$ & $2.00 \mathrm{E}+04$ & $1.85 \mathrm{E}+05$ & $3.55 \mathrm{E}+06$ & $3.58 \mathrm{E}+06$ & $3.88 \mathrm{E}+07$ & $1.03 \mathrm{E}+05$ \\
\hline $\mathrm{Ag}-21$ & $6.01 \mathrm{E}+07$ & $1.17 \mathrm{E}+07$ & $2.08 \mathrm{E}+04$ & $2.22 \mathrm{E}+05$ & $4.34 \mathrm{E}+06$ & $4.25 \mathrm{E}+06$ & $4.86 \mathrm{E}+07$ & $1.20 \mathrm{E}+05$ \\
\hline Ag-22 & $5.35 \mathrm{E}+07$ & $1.11 \mathrm{E}+07$ & $3.85 \mathrm{E}+04$ & $2.10 \mathrm{E}+05$ & $4.24 \mathrm{E}+06$ & $3.97 \mathrm{E}+06$ & $4.18 \mathrm{E}+07$ & $1.27 \mathrm{E}+05$ \\
\hline Ag-23 & $5.11 \mathrm{E}+07$ & $9.58 \mathrm{E}+06$ & $2.89 \mathrm{E}+04$ & $1.93 \mathrm{E}+05$ & $4.06 \mathrm{E}+06$ & $3.88 \mathrm{E}+06$ & $4.14 \mathrm{E}+07$ & $1.10 \mathrm{E}+05$ \\
\hline $\mathrm{Ag}-24$ & $5.90 \mathrm{E}+07$ & $1.12 \mathrm{E}+07$ & $2.73 \mathrm{E}+04$ & $2.25 \mathrm{E}+05$ & $4.33 \mathrm{E}+06$ & $4.34 \mathrm{E}+06$ & $4.64 \mathrm{E}+07$ & $1.24 \mathrm{E}+05$ \\
\hline $\mathrm{Ag}-25$ & $5.47 \mathrm{E}+07$ & $1.05 \mathrm{E}+07$ & $3.00 \mathrm{E}+04$ & $2.05 \mathrm{E}+05$ & $4.12 \mathrm{E}+06$ & $4.08 \mathrm{E}+06$ & $4.23 \mathrm{E}+07$ & $1.22 \mathrm{E}+05$ \\
\hline $\mathrm{Ag}-26$ & $4.88 \mathrm{E}+07$ & $8.95 \mathrm{E}+06$ & $2.51 \mathrm{E}+04$ & $1.82 \mathrm{E}+05$ & $3.38 \mathrm{E}+06$ & $3.53 \mathrm{E}+06$ & $3.79 \mathrm{E}+07$ & $9.81 \mathrm{E}+04$ \\
\hline $\mathrm{Ag}-27$ & $5.90 \mathrm{E}+07$ & $9.81 \mathrm{E}+06$ & $2.70 \mathrm{E}+04$ & $2.02 \mathrm{E}+05$ & $3.65 \mathrm{E}+06$ & $3.93 \mathrm{E}+06$ & $4.31 \mathrm{E}+07$ & $1.08 \mathrm{E}+05$ \\
\hline
\end{tabular}


Table 7 (continued). Results of 6 hour gamma scanning showing measured activity (Bq/particle decay-corrected to EOL+1day) for key peaks from Table 5

\begin{tabular}{|c|c|c|c|c|c|c|c|c|}
\hline Particle & Zr-95 & Ru-106 & Ag-110m & Sb-125 & Cs-134 & Cs-137 & Ce-144 & Eu-154 \\
\hline Ag-28 & $6.36 \mathrm{E}+07$ & $1.15 \mathrm{E}+07$ & $2.60 \mathrm{E}+04$ & $2.31 \mathrm{E}+05$ & $4.27 \mathrm{E}+06$ & $4.47 \mathrm{E}+06$ & $4.99 \mathrm{E}+07$ & $1.26 \mathrm{E}+05$ \\
\hline Ag-29 & $5.71 \mathrm{E}+07$ & $1.12 \mathrm{E}+07$ & $2.61 \mathrm{E}+04$ & $2.19 \mathrm{E}+05$ & $4.22 \mathrm{E}+06$ & $4.11 \mathrm{E}+06$ & $4.75 \mathrm{E}+07$ & $1.22 \mathrm{E}+05$ \\
\hline $\mathrm{Ag}-30$ & $5.27 \mathrm{E}+07$ & $1.08 \mathrm{E}+07$ & $3.50 \mathrm{E}+04$ & $2.08 \mathrm{E}+05$ & $4.09 \mathrm{E}+06$ & $3.94 \mathrm{E}+06$ & $4.09 \mathrm{E}+07$ & $1.21 \mathrm{E}+05$ \\
\hline Ag-31 & $5.25 \mathrm{E}+07$ & $1.06 \mathrm{E}+07$ & $3.56 \mathrm{E}+04$ & $2.16 \mathrm{E}+05$ & $4.25 \mathrm{E}+06$ & $4.10 \mathrm{E}+06$ & $4.43 \mathrm{E}+07$ & $1.20 \mathrm{E}+05$ \\
\hline Ag-32 & $5.60 \mathrm{E}+07$ & $1.15 \mathrm{E}+07$ & $3.64 \mathrm{E}+04$ & $2.19 \mathrm{E}+05$ & $4.21 \mathrm{E}+06$ & $4.05 \mathrm{E}+06$ & $4.42 \mathrm{E}+07$ & $1.25 \mathrm{E}+05$ \\
\hline $\mathrm{Ag}-33$ & $5.76 \mathrm{E}+07$ & $1.12 \mathrm{E}+07$ & $3.14 \mathrm{E}+04$ & $2.25 \mathrm{E}+05$ & $4.39 \mathrm{E}+06$ & $4.37 \mathrm{E}+06$ & $4.55 \mathrm{E}+07$ & $1.28 \mathrm{E}+05$ \\
\hline Ag-34 & $5.17 \mathrm{E}+07$ & $1.08 \mathrm{E}+07$ & $3.58 \mathrm{E}+04$ & $2.07 \mathrm{E}+05$ & $3.92 \mathrm{E}+06$ & $3.81 \mathrm{E}+06$ & $4.02 \mathrm{E}+07$ & $1.16 \mathrm{E}+05$ \\
\hline Ag-35 & $5.59 \mathrm{E}+07$ & $1.06 \mathrm{E}+07$ & $3.25 \mathrm{E}+04$ & $2.09 \mathrm{E}+05$ & $4.36 \mathrm{E}+06$ & $4.20 \mathrm{E}+06$ & $4.41 \mathrm{E}+07$ & $1.28 \mathrm{E}+05$ \\
\hline $\mathrm{Ag}-36$ & $5.90 \mathrm{E}+07$ & $9.96 \mathrm{E}+06$ & $2.77 \mathrm{E}+04$ & $1.97 \mathrm{E}+05$ & $3.52 \mathrm{E}+06$ & $3.80 \mathrm{E}+06$ & $4.27 \mathrm{E}+07$ & $1.05 \mathrm{E}+05$ \\
\hline $\mathrm{Ag}-37$ & $5.06 \mathrm{E}+07$ & $1.13 \mathrm{E}+07$ & $3.92 \mathrm{E}+04$ & $2.15 \mathrm{E}+05$ & $4.61 \mathrm{E}+06$ & $4.14 \mathrm{E}+06$ & $4.21 \mathrm{E}+07$ & $1.31 \mathrm{E}+05$ \\
\hline Ag-38 & $5.18 \mathrm{E}+07$ & $1.12 \mathrm{E}+07$ & $3.92 \mathrm{E}+04$ & $2.13 \mathrm{E}+05$ & $4.39 \mathrm{E}+06$ & $4.06 \mathrm{E}+06$ & $4.16 \mathrm{E}+07$ & $1.30 \mathrm{E}+05$ \\
\hline Ag-39 & $5.36 \mathrm{E}+07$ & $1.08 \mathrm{E}+07$ & $3.62 \mathrm{E}+04$ & $2.12 \mathrm{E}+05$ & $4.13 \mathrm{E}+06$ & $4.09 \mathrm{E}+06$ & $4.39 \mathrm{E}+07$ & $1.19 \mathrm{E}+05$ \\
\hline Ag-40 & $7.03 \mathrm{E}+07$ & $1.35 \mathrm{E}+07$ & $3.31 \mathrm{E}+04$ & $2.67 \mathrm{E}+05$ & $4.90 \mathrm{E}+06$ & $5.15 \mathrm{E}+06$ & $5.40 \mathrm{E}+07$ & $1.42 \mathrm{E}+05$ \\
\hline Ag-41 & $5.24 \mathrm{E}+07$ & $1.10 \mathrm{E}+07$ & $3.58 \mathrm{E}+04$ & $2.13 \mathrm{E}+05$ & $4.17 \mathrm{E}+06$ & $4.08 \mathrm{E}+06$ & $4.26 \mathrm{E}+07$ & $1.18 \mathrm{E}+05$ \\
\hline Ag-42 & $5.21 \mathrm{E}+07$ & $1.15 \mathrm{E}+07$ & $3.88 \mathrm{E}+04$ & $2.22 \mathrm{E}+05$ & $4.80 \mathrm{E}+06$ & $4.34 \mathrm{E}+06$ & $4.35 \mathrm{E}+07$ & $1.36 \mathrm{E}+05$ \\
\hline Ag-43 & $5.55 \mathrm{E}+07$ & $1.13 \mathrm{E}+07$ & $3.74 \mathrm{E}+04$ & $2.22 \mathrm{E}+05$ & $4.75 \mathrm{E}+06$ & $4.45 \mathrm{E}+06$ & $4.56 \mathrm{E}+07$ & $1.34 \mathrm{E}+05$ \\
\hline Ag-44 & $4.61 \mathrm{E}+07$ & $9.74 \mathrm{E}+06$ & $3.22 \mathrm{E}+04$ & $1.92 \mathrm{E}+05$ & $3.94 \mathrm{E}+06$ & $3.70 \mathrm{E}+06$ & $3.80 \mathrm{E}+07$ & $1.13 \mathrm{E}+05$ \\
\hline Ag-45 & $5.50 \mathrm{E}+07$ & $1.01 \mathrm{E}+07$ & $3.20 \mathrm{E}+04$ & $2.01 \mathrm{E}+05$ & $3.92 \mathrm{E}+06$ & $3.90 \mathrm{E}+06$ & $4.22 \mathrm{E}+07$ & $1.13 \mathrm{E}+05$ \\
\hline Ag-46 & $4.88 \mathrm{E}+07$ & $9.58 \mathrm{E}+06$ & $3.22 \mathrm{E}+04$ & $1.85 \mathrm{E}+05$ & $3.58 \mathrm{E}+06$ & $3.59 \mathrm{E}+06$ & $3.84 \mathrm{E}+07$ & $1.04 \mathrm{E}+05$ \\
\hline Ag-47 & $5.05 \mathrm{E}+07$ & $1.02 \mathrm{E}+07$ & $3.25 \mathrm{E}+04$ & $2.05 \mathrm{E}+05$ & $4.25 \mathrm{E}+06$ & $4.02 \mathrm{E}+06$ & $4.14 \mathrm{E}+07$ & $1.21 \mathrm{E}+05$ \\
\hline Ag-48 & $6.13 \mathrm{E}+07$ & $1.21 \mathrm{E}+07$ & $3.16 \mathrm{E}+04$ & $2.38 \mathrm{E}+05$ & $4.27 \mathrm{E}+06$ & $4.43 \mathrm{E}+06$ & $4.78 \mathrm{E}+07$ & $1.23 \mathrm{E}+05$ \\
\hline Ag-49 & $5.44 \mathrm{E}+07$ & $1.04 \mathrm{E}+07$ & $3.41 \mathrm{E}+04$ & $2.01 \mathrm{E}+05$ & $4.04 \mathrm{E}+06$ & $3.89 \mathrm{E}+06$ & $4.19 \mathrm{E}+07$ & $1.17 \mathrm{E}+05$ \\
\hline Ag-50 & $5.20 \mathrm{E}+07$ & $1.03 \mathrm{E}+07$ & $1.27 \mathrm{E}+04$ & $2.08 \mathrm{E}+05$ & $4.19 \mathrm{E}+06$ & $4.02 \mathrm{E}+06$ & $4.48 \mathrm{E}+07$ & $1.17 \mathrm{E}+05$ \\
\hline Ag-51 & $5.86 \mathrm{E}+07$ & $1.10 \mathrm{E}+07$ & $5.79 \mathrm{E}+03$ & $2.14 \mathrm{E}+05$ & $4.30 \mathrm{E}+06$ & $4.19 \mathrm{E}+06$ & $4.64 \mathrm{E}+07$ & $1.22 \mathrm{E}+05$ \\
\hline $\mathrm{Ag}-52$ & $5.38 \mathrm{E}+07$ & $9.16 \mathrm{E}+06$ & $0.00 \mathrm{E}+00$ & $1.86 \mathrm{E}+05$ & $3.47 \mathrm{E}+06$ & $3.70 \mathrm{E}+06$ & $4.11 \mathrm{E}+07$ & $9.83 \mathrm{E}+04$ \\
\hline Ag-53 & $5.49 \mathrm{E}+07$ & $1.12 \mathrm{E}+07$ & $0.00 \mathrm{E}+00$ & $2.13 \mathrm{E}+05$ & $3.99 \mathrm{E}+06$ & $3.99 \mathrm{E}+06$ & $4.53 \mathrm{E}+07$ & $1.15 \mathrm{E}+05$ \\
\hline Ag-54 & $5.35 \mathrm{E}+07$ & $9.13 \mathrm{E}+06$ & $2.60 \mathrm{E}+04$ & $1.83 \mathrm{E}+05$ & $3.45 \mathrm{E}+06$ & $3.64 \mathrm{E}+06$ & $4.02 \mathrm{E}+07$ & $1.02 \mathrm{E}+05$ \\
\hline Ag-55 & $5.41 \mathrm{E}+07$ & $8.87 \mathrm{E}+06$ & $0.00 \mathrm{E}+00$ & $1.84 \mathrm{E}+05$ & $3.30 \mathrm{E}+06$ & $3.59 \mathrm{E}+06$ & $4.01 \mathrm{E}+07$ & $9.55 \mathrm{E}+04$ \\
\hline $\mathrm{Ag}-56$ & $5.41 \mathrm{E}+07$ & $9.37 \mathrm{E}+06$ & $0.00 \mathrm{E}+00$ & $1.83 \mathrm{E}+05$ & $3.37 \mathrm{E}+06$ & $3.53 \mathrm{E}+06$ & $4.13 \mathrm{E}+07$ & $9.66 \mathrm{E}+04$ \\
\hline Ag-57 & $5.24 \mathrm{E}+07$ & $9.28 \mathrm{E}+06$ & $0.00 \mathrm{E}+00$ & $1.77 \mathrm{E}+05$ & $3.29 \mathrm{E}+06$ & $3.44 \mathrm{E}+06$ & $3.98 \mathrm{E}+07$ & $9.43 \mathrm{E}+04$ \\
\hline Ag-58 & $5.76 \mathrm{E}+07$ & $1.13 \mathrm{E}+07$ & $6.91 \mathrm{E}+03$ & $2.20 \mathrm{E}+05$ & $4.14 \mathrm{E}+06$ & $4.27 \mathrm{E}+06$ & $4.69 \mathrm{E}+07$ & $1.22 \mathrm{E}+05$ \\
\hline Ag-59 & $5.65 \mathrm{E}+07$ & $1.08 \mathrm{E}+07$ & $4.90 \mathrm{E}+03$ & $2.13 \mathrm{E}+05$ & $3.99 \mathrm{E}+06$ & $4.16 \mathrm{E}+06$ & $4.40 \mathrm{E}+07$ & $1.16 \mathrm{E}+05$ \\
\hline Ag-60 & $5.49 \mathrm{E}+07$ & $9.59 \mathrm{E}+06$ & $0.00 \mathrm{E}+00$ & $1.97 \mathrm{E}+05$ & $3.86 \mathrm{E}+06$ & $3.91 \mathrm{E}+06$ & $4.29 \mathrm{E}+07$ & $1.09 \mathrm{E}+05$ \\
\hline Maximum & $7.03 \mathrm{E}+07$ & $1.37 \mathrm{E}+07$ & $5.02 \mathrm{E}+04$ & $2.67 \mathrm{E}+05$ & $5.38 \mathrm{E}+06$ & $5.15 \mathrm{E}+06$ & $5.40 \mathrm{E}+07$ & $1.54 \mathrm{E}+05$ \\
\hline Minimum & $4.61 \mathrm{E}+07$ & $8.87 \mathrm{E}+06$ & $4.90 \mathrm{E}+03$ & $1.77 \mathrm{E}+05$ & $3.29 \mathrm{E}+06$ & $3.44 \mathrm{E}+06$ & $3.79 \mathrm{E}+07$ & $9.43 \mathrm{E}+04$ \\
\hline Mean & $5.48 \mathrm{E}+07$ & $1.08 \mathrm{E}+07$ & $3.08 \mathrm{E}+04$ & $2.11 \mathrm{E}+05$ & $4.17 \mathrm{E}+06$ & $4.08 \mathrm{E}+06$ & $4.36 \mathrm{E}+07$ & $1.20 \mathrm{E}+05$ \\
\hline$\%$ St Dev & 8 & 10 & 35 & 8 & 11 & 8 & 7 & 10 \\
\hline
\end{tabular}

${ }^{1} \mathrm{Ag}-01$ through Ag-49 are all the particles that had detectable ${ }^{110 \mathrm{~m}} \mathrm{Ag}$ in the 1 hour gamma scan, Ag-50 through Ag-60 are 11 selected particles that did not have detectable ${ }^{110 \mathrm{~m}} \mathrm{Ag}$ in the 1 hour gamma scan.

${ }^{2}$ Interference from ${ }^{154} \mathrm{Eu}$ has been subtracted out of ${ }^{95} \mathrm{Zr}$ peak.

${ }^{3}$ Mean and standard deviation for ${ }^{110 \mathrm{~m}} \mathrm{Ag}$ do not include particles with undetectable inventory. 


\section{Materialography on Individual Particles: Sample Preparation and Optical Imaging}

After the deconsolidation leaching and IMGA measurements described in the preceding sections, individual particles from Compact 6-1-1 were selected for materialographic analysis. Samples were mounted in epoxy, ground and polished to reveal cross-sections close to the center of the particle, imaged using an optical microscope and a scanning electron microscope (SEM), and analyzed in the SEM using energy dispersive $\mathrm{x}$-ray spectrometry (EDS) and wavelength dispersive spectrometry (WDS).

Several methods were tested for materialographic sample preparation. A two-part room temperature epoxy, Struer's Epofix, was used as the mounting media. For some SEM sample mounts, $15 \mathrm{wt} \%$ graphite powder was thoroughly mixed into to the epoxy resin. This provided conducting pathways from the outer surface of the particle to the sides of the mount to reduce charging in the epoxy. For further reduction in surface charging across the polished particle cross-section, thin conductive coatings were also applied to the surface of some SEM sample mounts after polishing by evaporating gold in a vacuum coater. Carbon coating is preferred for this purpose, because the lower atomic mass results in reduced scattering of the electron beam. However, carbon coating was not available.

Epoxy molds where made using 1.25" diameter Garolite XX phenolic rod machined into various forms. One epoxy mold consisted of a Garolite rod with a funnel shaped bore sealed at the bottom with a temporary Lucite disc glued on with 5 minute epoxy. Particles could be poured into the funnel from the top and then epoxy added under vacuum using a Struer's Epovac system. The funnel mount assembly was used when individual particle identity did not need to be maintained. A second epoxy mold assembly was used when individual particle identity was being tracked; the steps for using this assembly are shown in Figure 31. Using the Particle Micromanipulator in the IMGA cubicle, particles were glued to specific positions in a dimple array machined into a re-usable puck and then vacuum potted with epoxy. Shim rings were used to help indicate when grinding approached the center of the particles.

Various grinding and polishing methods were investigated. In general, grinding was done using a Struer's RotoPol system similar to what was successfully used for grinding and polishing of unirradiated AGR-1 particles. This system uses $200 \mathrm{~mm}$ diameter discs intermittently dosed with diamond suspensions of various particulate size. Grinding was typically accomplished using $9 \mu \mathrm{m}$ diamond with a Struer's Allegro disk. This disc uses a hexagonal array of cast iron pads that produce a combined grinding/lapping effect which works well for the mixed material in the coated particle. Diamond particles rolling between the cast iron pad and the $\mathrm{SiC}$ or kernel surfaces provide the lapping that is appropriate for these brittle materials, while diamond particles momentarily trapped in the soft iron can grind away the ductile carbon layers. Tests on unirradiated particles showed that this Allegro-based process produced less damage than grinding with fixed abrasive discs, where impact could cause fracture in the SiC layer. Vacuum backpotting with Struer's Epofix was also used in most cases to fill in gaps between the buffer and IPyC and minimize layer fracture, especially grinding damage to $\mathrm{SiC}$.

Many methods were tested for achieving a final surface polish with varying success. In general, diamond suspensions were stepped down through $6 \mu \mathrm{m}, 3 \mu \mathrm{m}$, and finer. Various discs were used on the RotoPol in an attempt to produce a polished surface without excessive rounding at the interfaces or vertical relief between the materials with different hardness. In addition, some testing was done using a Syntron vibratory polisher. An optimum process was not achieved for the materialographic sample preparation of particles from this compact. Subsequent refinement of the process indicates that a Struer's Allegro disk on the RotoPol with $6 \mu \mathrm{m}$ diamond can provide a good fine grind while maintaining a flat surface. Subsequent polishes on a Struer's Plan disk using $3 \mu \mathrm{m}$ and $1 \mu \mathrm{m}$ diamond can achieve an effective polish without introducing excess relief or rounding at the interfaces.

Optical images of the polished surfaces were obtained using a Leica DMI-5000 inverted optical microscope (Figure 32 and Figure 33) operated in a small hot cell cubicle on the second floor of the ORNL Irradiated Fuels Examination Laboratory (IFEL). Samples were ground and polished in the main cell on the ground floor and transferred to the microscopy cell using a manual elevator. The DMI-5000 uses an 8 megapixel camera (3264 x 2448) to capture images in brightfield, darkfield, or with interference 
contrast and provides an imaging resolution down to $\sim 0.5 \mu \mathrm{m}$. Large area, high resolution images can be obtained using an automated mosaic capture/reconstruction routine.

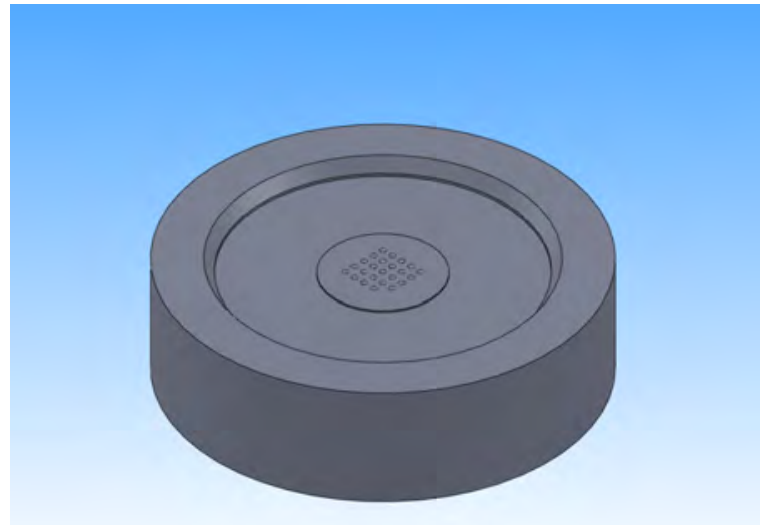

Step 1: Apply thin layer of epoxy to puck.

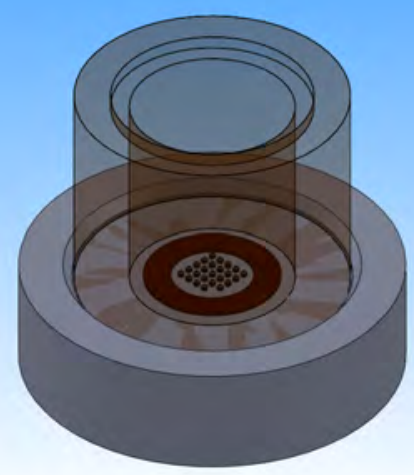

Step 3: Place phenolic blank around particles.

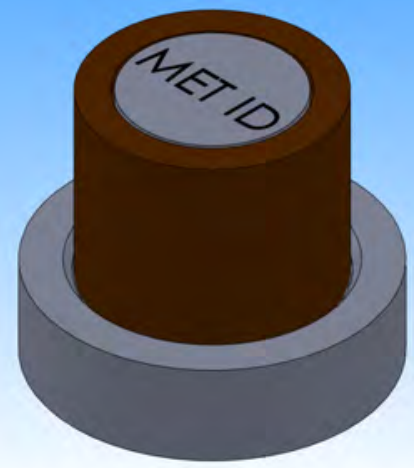

Step 5: Place ID tag on back of phenolic blank.

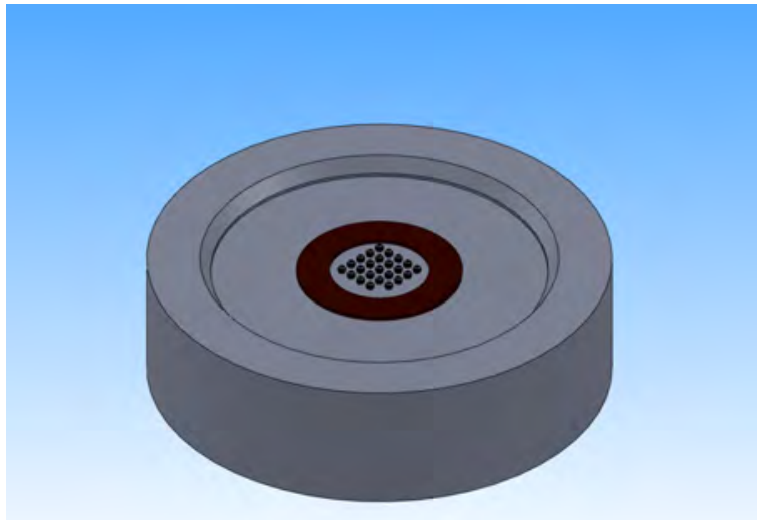

Step 2: Place shim washer and particles in position.

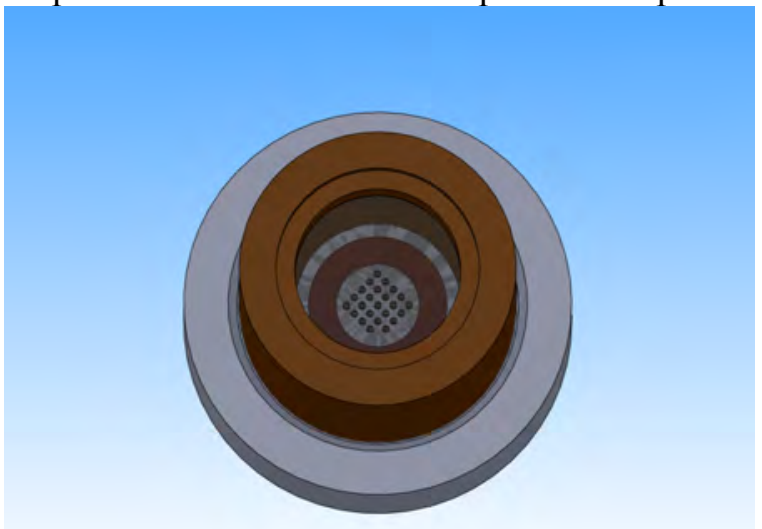

Step 4: Add Epofix epoxy through top.

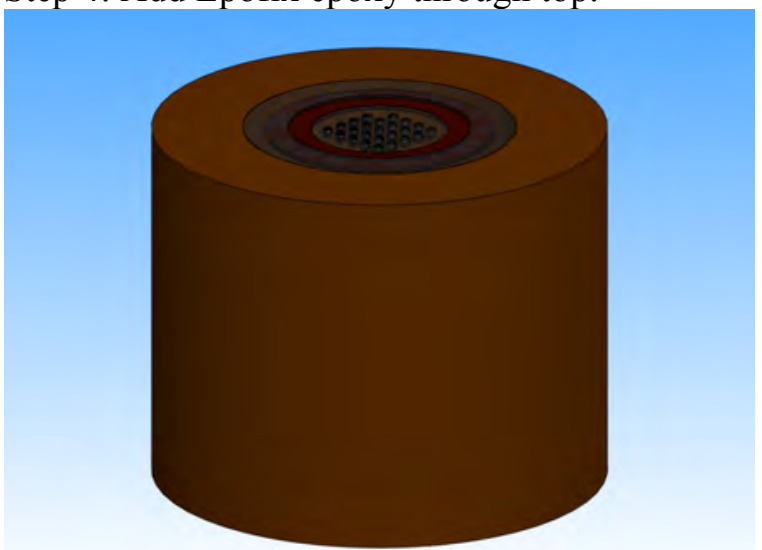

Step 6: Remove mounting puck after epoxy sets.

Figure 31. Assembly for mounting particles in a fixed array. 


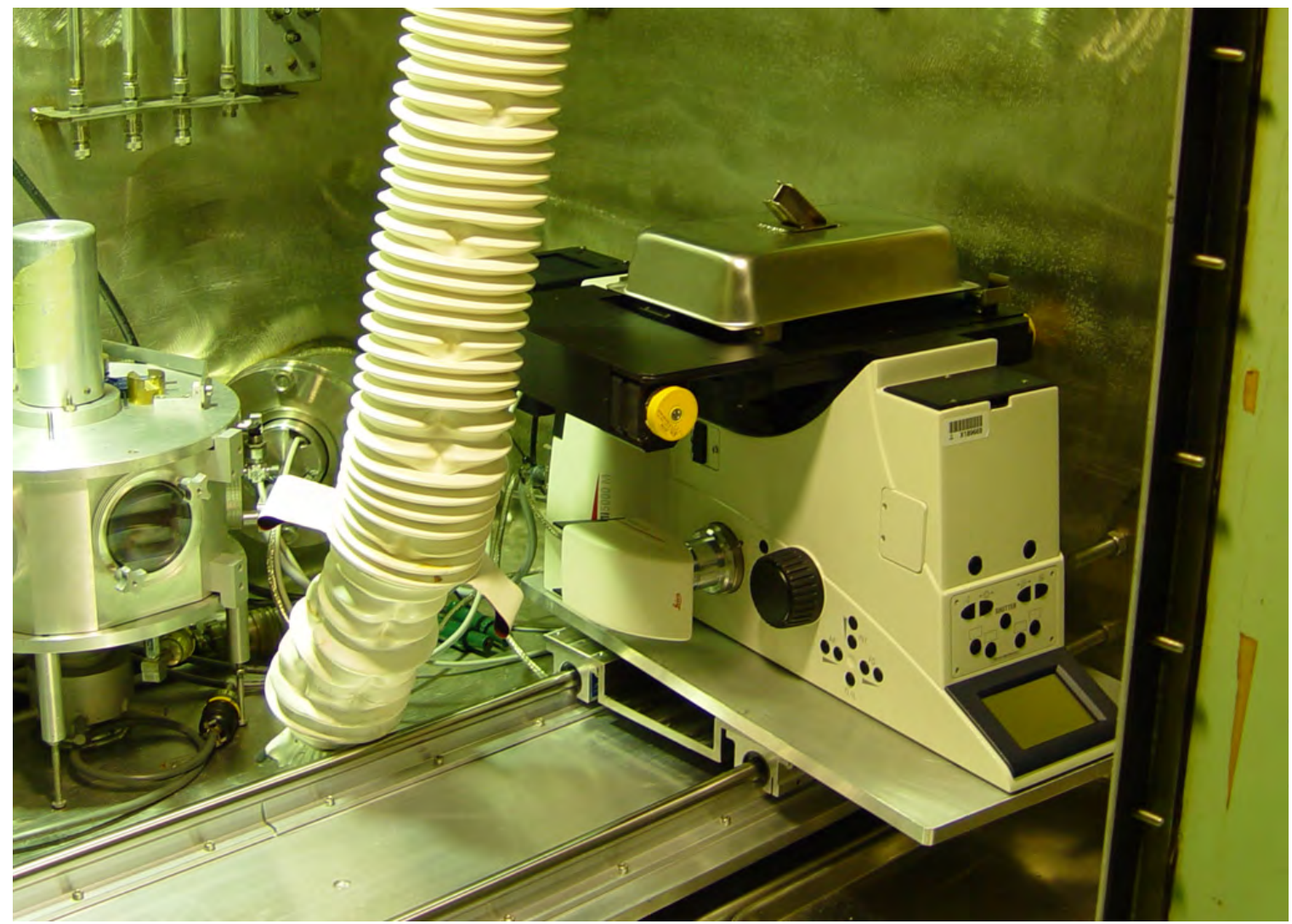

Figure 32. Remote optical microscope inside the hot cell.

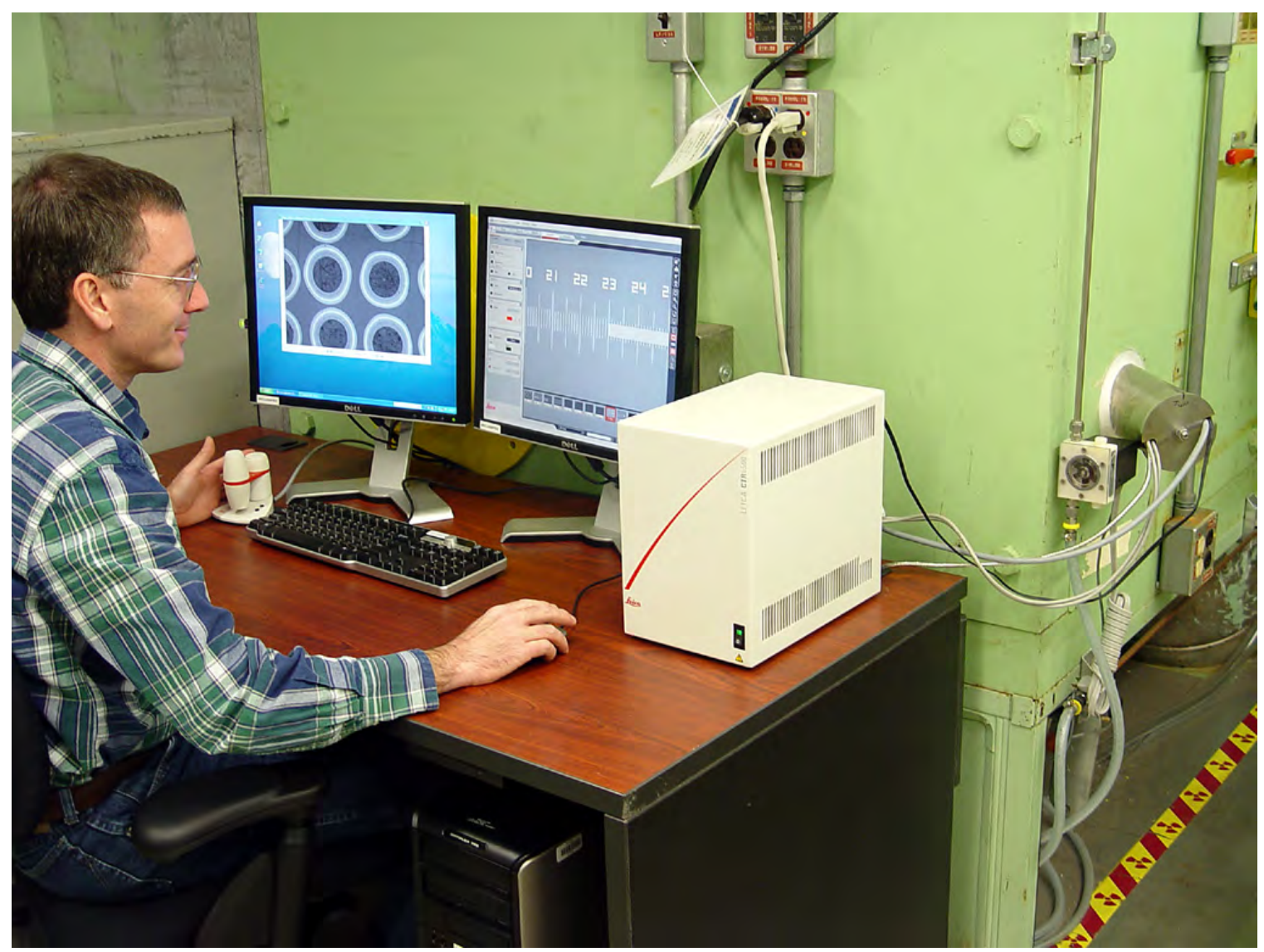

Figure 33. Workstation for remote optical microscope adjacent to hot cell cubicle. 
Table 8 is a list of materialographic mounts prepared using particles from Compact 6-1-1. Particles were selected based on IMGA sorting on ${ }^{144} \mathrm{Ce},{ }^{137} \mathrm{Cs} /{ }^{144} \mathrm{Ce}$ ratio, and ${ }^{110 \mathrm{~m}} \mathrm{Ag}$ inventory. As previously mentioned in the discussion of the IMGA results, 4 particles were discovered that appeared to be unirradiated material mixed in from previous sieving operations. Two of these particles were mounted and rough polished cross sections are shown in Figure 34 and Figure 35. From the clearly segregated uranium oxide (gray) and uranium carbide (white) regions in the kernel, it is obvious that these particles did not come from the irradiated compact (compare to irradiated kernels in the figures that follow).

Also mentioned in the IMGA discussion was the existence of two particles with low ${ }^{144} \mathrm{Ce}$ inventory, but normal ${ }^{137} \mathrm{Cs} /{ }^{144} \mathrm{Ce}$ ratio (Figure 14 through Figure 16), indicating that these two particles had less fissionable material at the start of irradiation. Images of a rough polished cross section of one of these particles are shown in Figure 36 through Figure 38. The buffer in this particle has fractured and allowed the kernel to swell (as evidenced by the large pores throughout the kernel). This buffer behavior is discussed further below. Even with the swelling, this kernel is still smaller than average, appearing in this near mid-plane cross-section as an oval measuring about $300 \mu \mathrm{m} \times 335 \mu \mathrm{m}$. Pre-irradiation characterization of the AGR-1 fuel compacts included x-ray analysis of approximately 50,000 particles deconsolidated from each compact composite. This analysis was performed to determine existence of particles exhibiting uranium dispersion, but also allowed for characterization of various anomalies. For the AGR-1 Baseline compacts, 25 out of 49735 particles were found to have undersized kernels. An example is shown in Figure 39 of a kernel with a diameter of about $210 \mu \mathrm{m}$. During coating, there is a natural tendency to deposit thicker buffer on undersized kernels, resulting in an average final particle size. At this defect population, 1 - 3 particles in each compact are expected to have undersized kernels. This expected population is in agreement with the observation of 2 particles with low inventory in Compact 61-1 (two particles with undersized kernels were also observed in Compact 4-4-2). The other low inventory particle from Compact 6-1-1 was analyzed by x-ray tomography and is discussed in the next section. Also note that the microstructure of the kernel in Mount 6349 was markedly different from the other irradiated kernels discussed below.

Table 8. List of materialographic mounts of particles from Compact 6-1-1

\begin{tabular}{|c|c|c|c|c|}
\hline $\begin{array}{l}\text { Mount } \\
\text { ID }\end{array}$ & $\begin{array}{c}\text { Number } \\
\text { of } \\
\text { Particles }\end{array}$ & $\begin{array}{l}\text { Mount } \\
\text { Type }\end{array}$ & Notes & Particle Description \\
\hline 6346 & 6 & array & grind destroyed $\mathrm{SiC}$ & $\mathrm{Cs} / \mathrm{Ce}$ ratio in the range of $0.6-0.9$ (tail of distribution) \\
\hline 6347 & 8 & funnel & grind destroyed $\mathrm{SiC}$ & $\mathrm{Cs} / \mathrm{Ce}$ ratio in the range of $0.9-1.2$ (center of distribution) \\
\hline 6348 & 8 & funnel & grind destroyed $\mathrm{SiC}$ & ${ }^{110 \mathrm{~m}} \mathrm{Ag}$ undetectable in 1 hour IMGA scan \\
\hline 6349 & 1 & funnel & stop at rough polish & Low Ce inventory, normal $\mathrm{Cs} / \mathrm{Ce}$ ratio \\
\hline 6350 & 1 & funnel & stop at rough polish & Suspected unirradiated particle (no activity) \\
\hline 6351 & 1 & funnel & stop at rough polish & Suspected unirradiated particle (no activity) \\
\hline 6352 & 8 & funnel & polished with OP-S & $\mathrm{Cs} / \mathrm{Ce}$ ratio in the range of $0.9-1.2$ (center of distribution) \\
\hline 6353 & 8 & funnel & polished with OP-S & $\mathrm{Cs} / \mathrm{Ce}$ ratio in the range of $0.9-1.2$ (center of distribution) \\
\hline 6354 & 1 & funnel & destroyed in grinding & $\mathrm{Cs} / \mathrm{Ce}$ ratio in the range of $0.9-1.2$ (center of distribution) \\
\hline 6355 & 1 & funnel & $\begin{array}{l}\text { typical particle } \\
\text { polished with OP-S }\end{array}$ & $\mathrm{Cs} / \mathrm{Ce}$ ratio in the range of $0.9-1.2$ (center of distribution) \\
\hline 6356 & 1 & funnel & $\begin{array}{l}\text { extruded kernel } \\
\text { polished with OP-S }\end{array}$ & $\mathrm{Cs} / \mathrm{Ce}$ ratio in the range of $0.9-1.2$ (center of distribution) \\
\hline 6357 & 6 & array & $\begin{array}{l}\text { conducting epoxy } \\
\text { polished with OP-S }\end{array}$ & $\begin{array}{l}\text { Varied measurable }{ }^{110 \mathrm{~m}} \mathrm{Ag} \text { inventory in } 6 \text { hour IMGA scan: } \\
\text { above average }(\mathrm{Ag}-11 \text { \& } \mathrm{Ag}-12 \text { from Table } 7) \\
\text { average (Ag-13 from Table } 7) \\
\text { below average (Ag-14, Ag-17 \& Ag-18 from Table 7) }\end{array}$ \\
\hline 6358 & 1 & funnel & $\begin{array}{l}\text { conducting epoxy } \\
\text { polish not completed }\end{array}$ & $\begin{array}{l}{ }^{110 m} \mathrm{Ag} \text { undetectable in } 6 \text { hour IMGA scan } \\
\text { (Ag-50 from Table } 7)\end{array}$ \\
\hline 6359 & 1 & funnel & $\begin{array}{l}\text { conducting epoxy } \\
\text { polished with OP-S }\end{array}$ & $\begin{array}{l}{ }^{110 \mathrm{~m}} \mathrm{Ag} \text { undetectable in } 6 \text { hour IMGA scan } \\
(\mathrm{Ag}-51 \text { from Table } 7)\end{array}$ \\
\hline
\end{tabular}




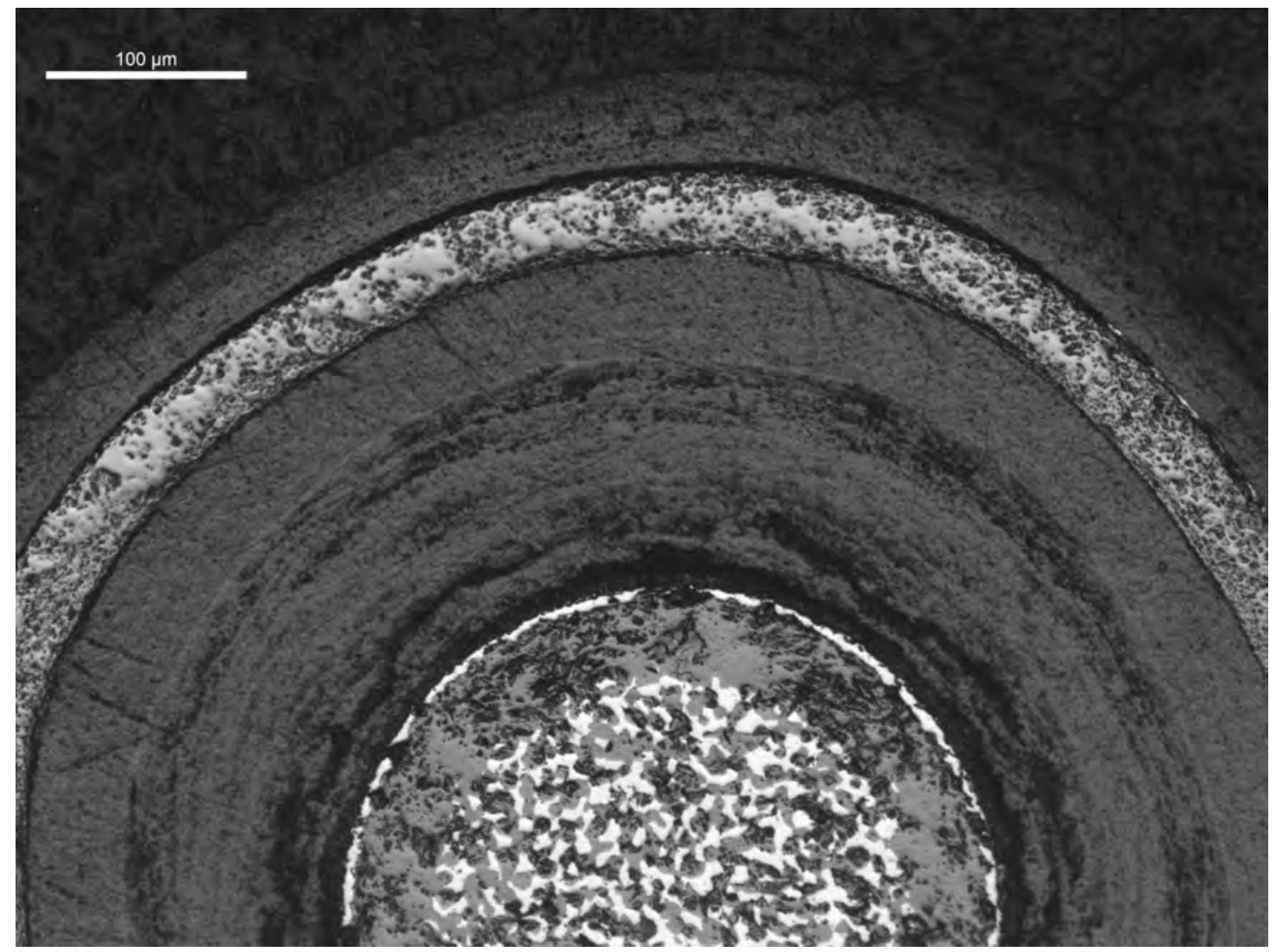

Figure 34. Rough polish of unirradiated particle mixed in with IMGA sample (Mount 6350).

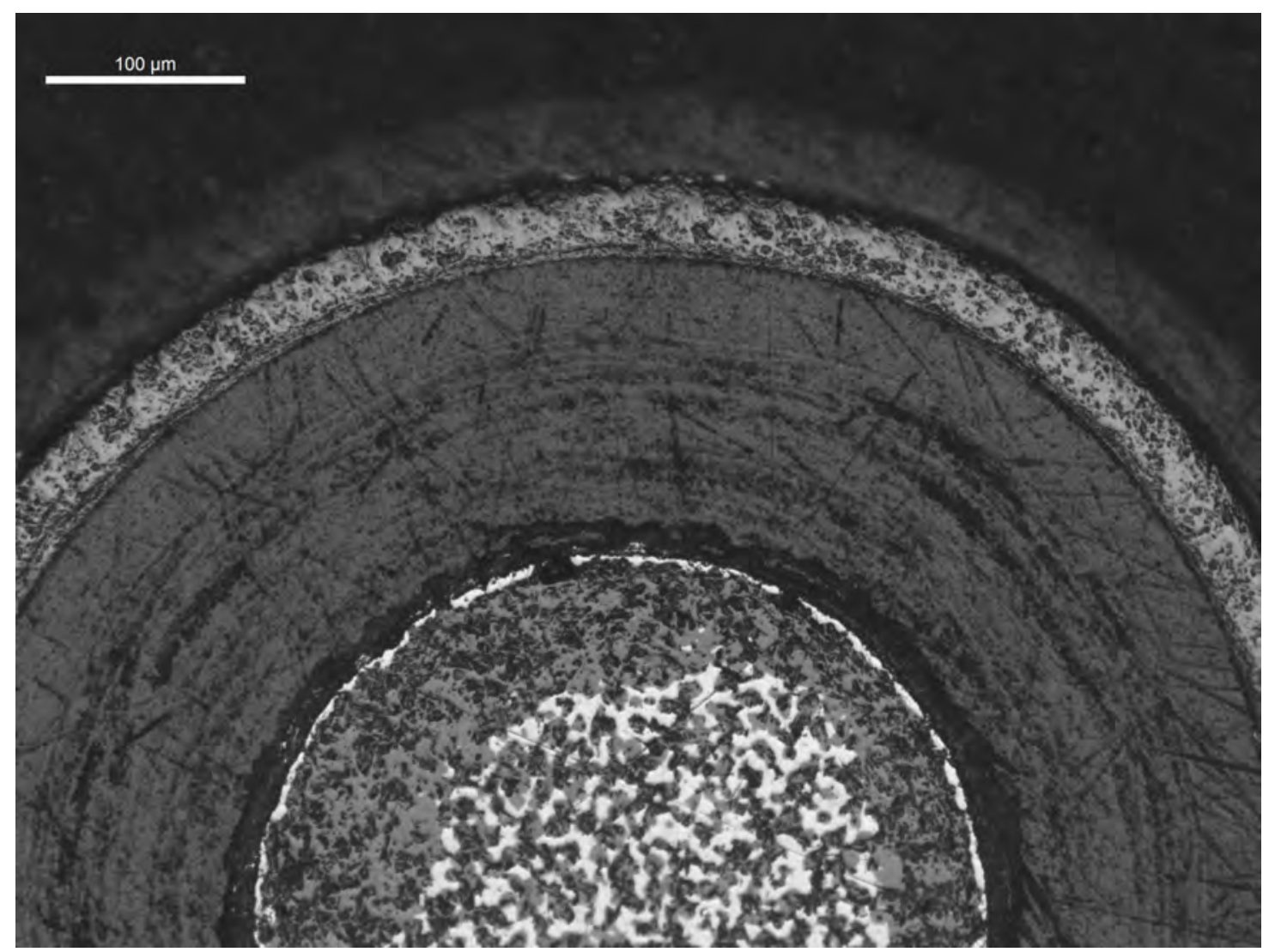

Figure 35. Rough polish of unirradiated particle mixed in with IMGA sample (Mount 6351). 


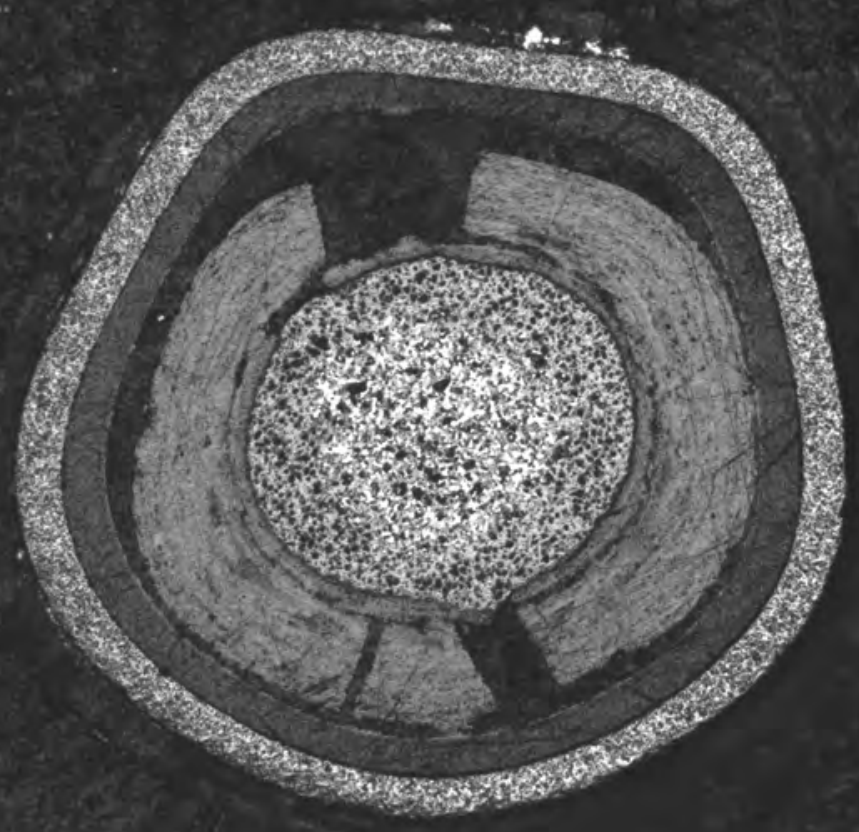

Figure 36. Rough polish of particle with low ${ }^{144} \mathrm{Ce}$, but normal ${ }^{137} \mathrm{Cs} /{ }^{144} \mathrm{Ce}$ ratio (Mount 6349).

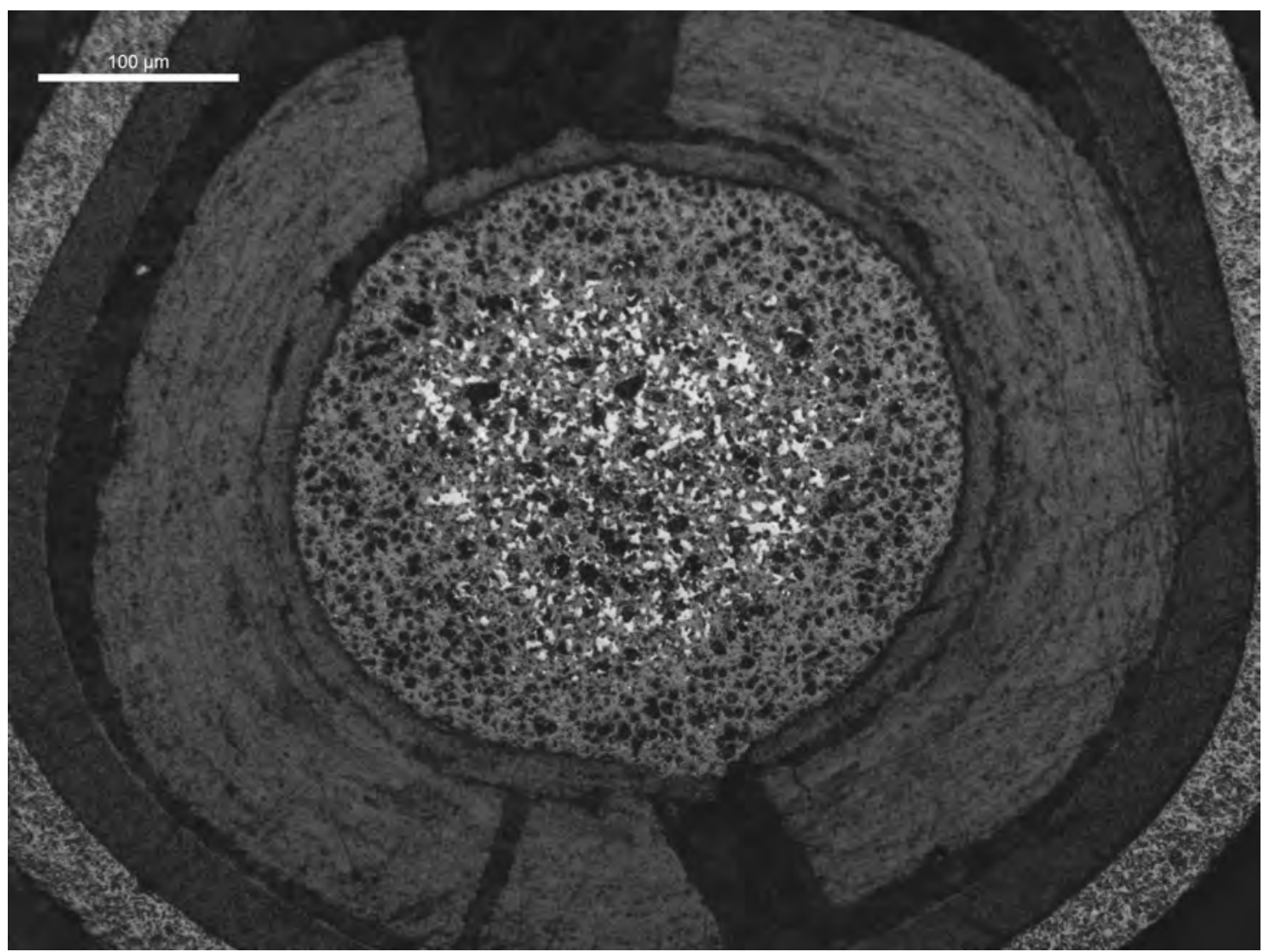

Figure 37. Rough polish of particle with low ${ }^{144} \mathrm{Ce}$, but normal ${ }^{137} \mathrm{Cs} /{ }^{144} \mathrm{Ce}$ ratio (Mount 6349). 


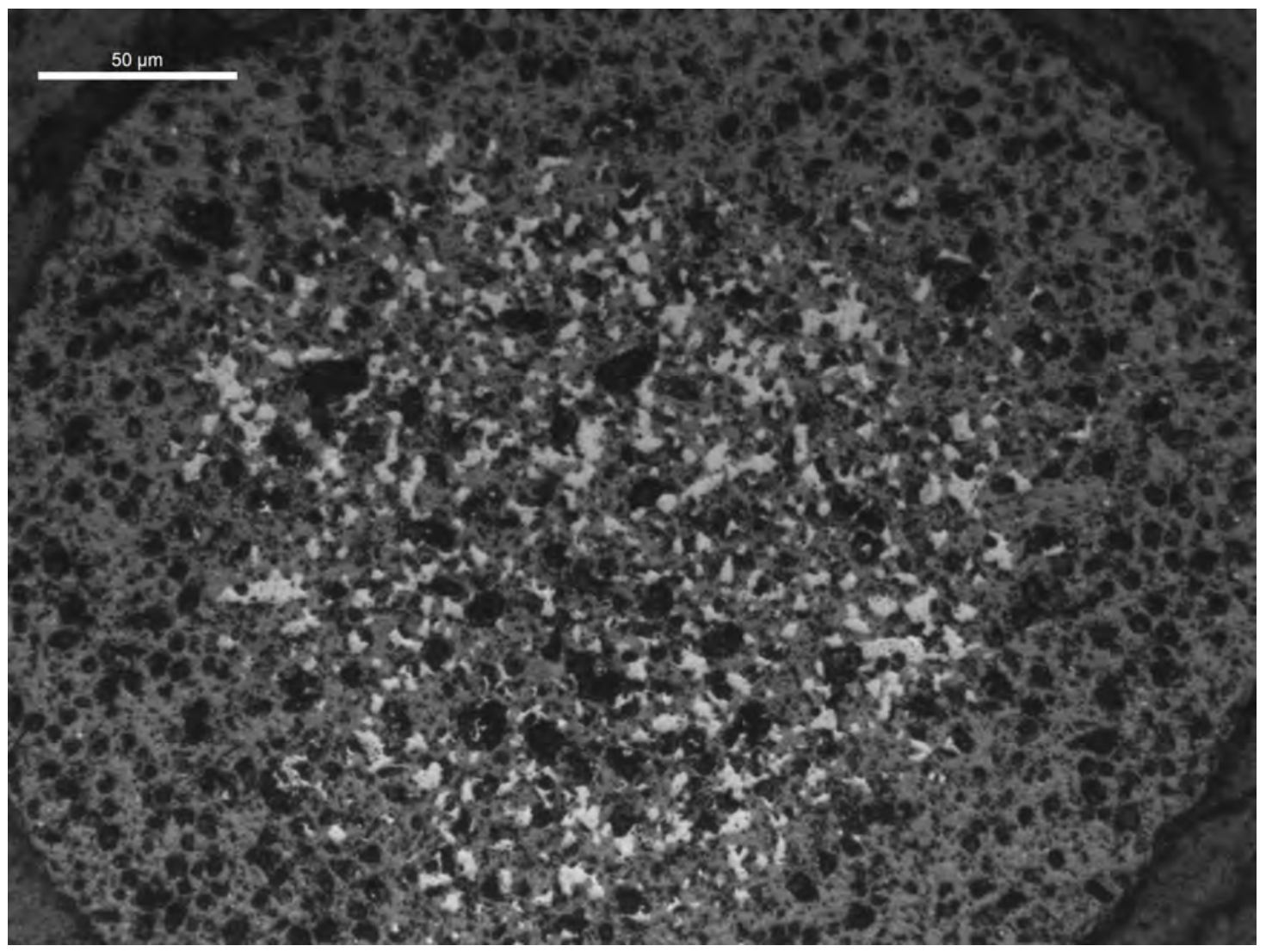

Figure 38. Rough polish of particle with low ${ }^{144} \mathrm{Ce}$, but normal ${ }^{137} \mathrm{Cs} /{ }^{144} \mathrm{Ce}$ ratio (Mount 6349).

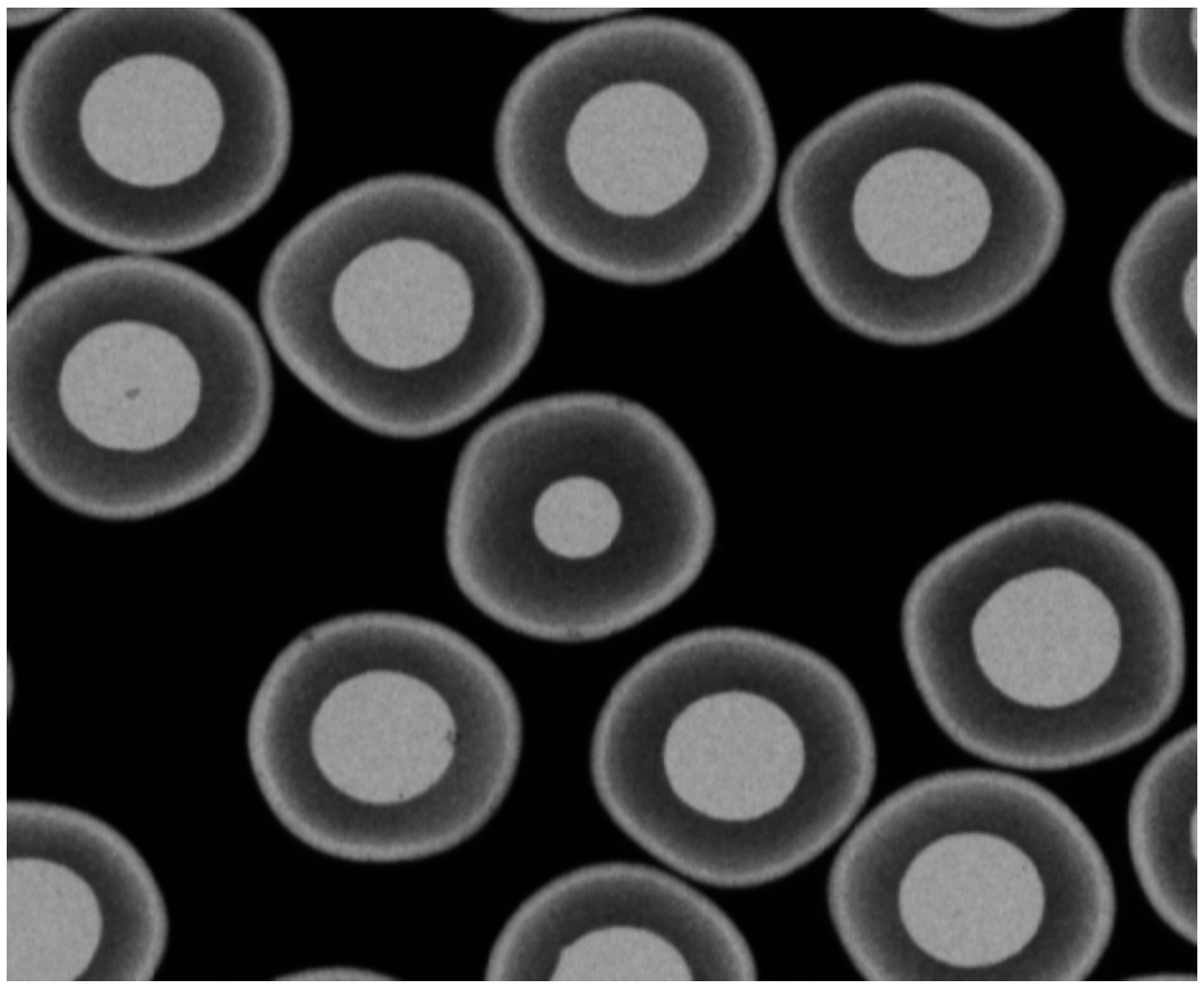

Figure 39. X-ray image of pre-irradiated fuel particles from AGR-1 Baseline compact showing small diameter kernel. 
Mounts 6352 and 6353 were two funnel mounts (Table 8), each containing 8 particles sorted by IMGA as having an average inventory of ${ }^{144} \mathrm{Ce}$ and ${ }^{137} \mathrm{Cs}$ (normalized ${ }^{137} \mathrm{Cs} /{ }^{144} \mathrm{Ce}$ ratio between 0.9 and 1.2). These particles were taken to a final polish with $3 \mu \mathrm{m}$ diamond on a Struer's Dac woven silk disk before optical imaging. All the particles exhibited buffer densification and shrinkage, with no obvious irradiation changes in the other layers, except those related to buffer fracture (Figure 40 through Figure 43). The buffer and kernel fell out of one particle (Figure 43), so this particle was not included in the analysis. In most cases (9/15), the buffer appeared completely separated away from the IPyC layer. In some cases (4/15), the buffer appeared partially separated away from the IPyC layer. For these 13 out of 15 particles, the buffer contracted around the kernel, which appeared to have limited kernel expansion.

Two particles in this set of 15 particle cross-sections exhibited a buffer that cracked during irradiation and the kernels appear to have extruded to some degree into the open space. One of these kernels had much larger pores (Figure 41), which may be related to the lack of constraint from an intact buffer. The other kernel (Figure 43), which did not swell as dramatically, showed a pore size that was slightly larger than average. The buffer in this second particle was still mostly attached to the IPyC, and this probably resulted in the observed propagation of the buffer cracks into the IPyC (Figure 44).

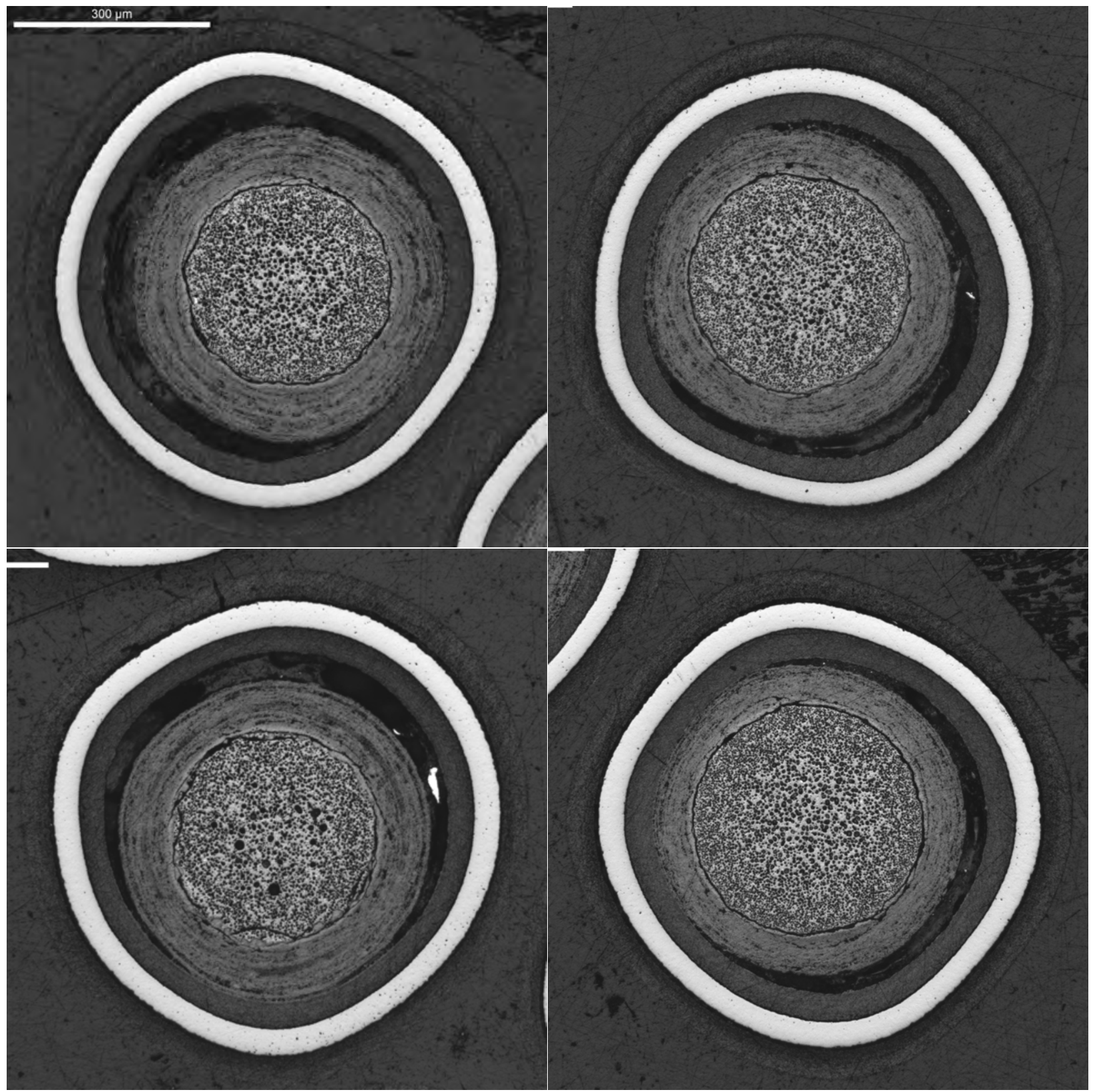

Figure 40. Four particles with normal ${ }^{137} \mathrm{Cs} /{ }^{144} \mathrm{Ce}$ ratio (Mount 6352). 


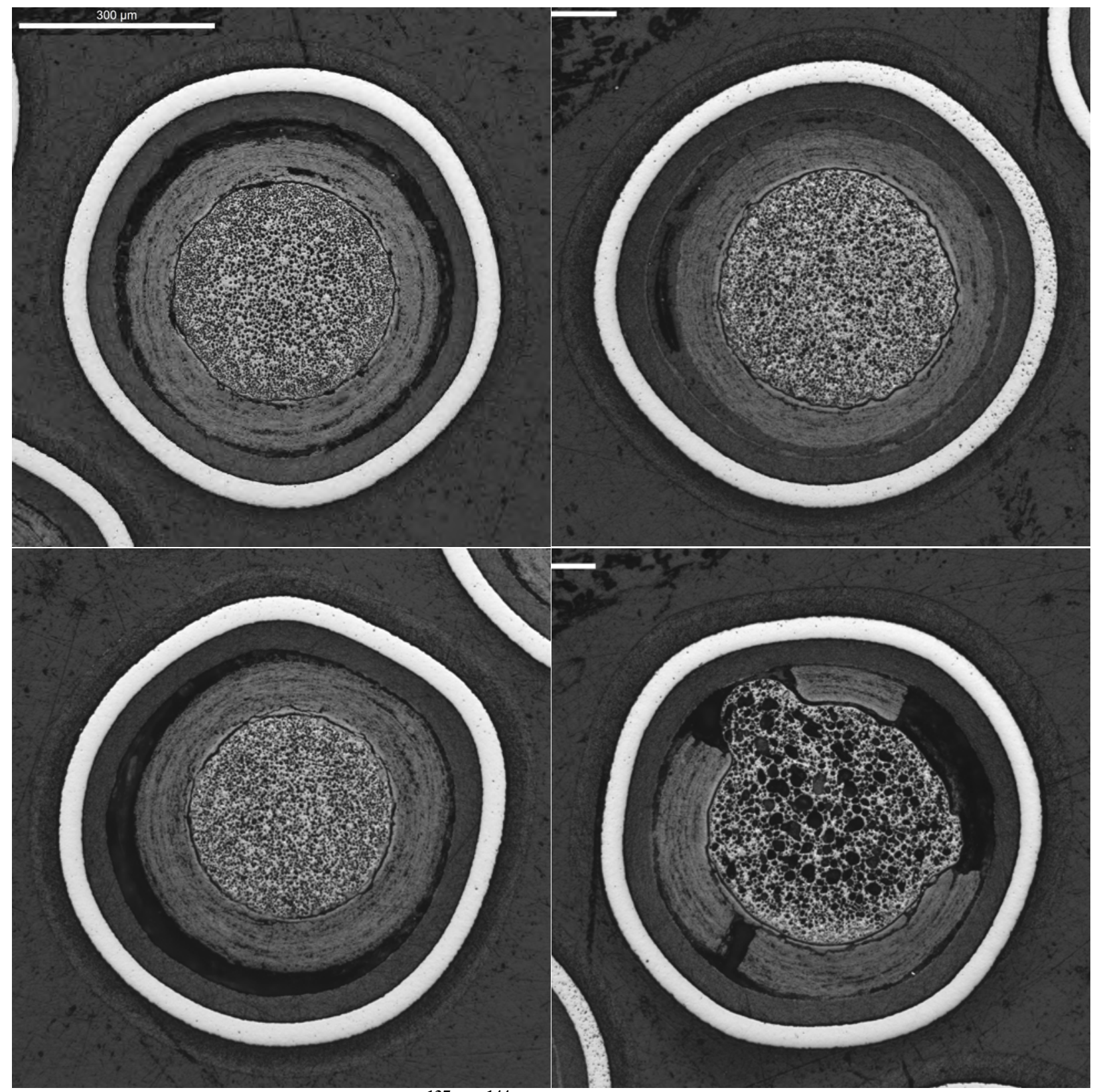

Figure 41. Four particles with normal ${ }^{137} \mathrm{Cs} /{ }^{144} \mathrm{Ce}$ ratio (Mount 6352). 


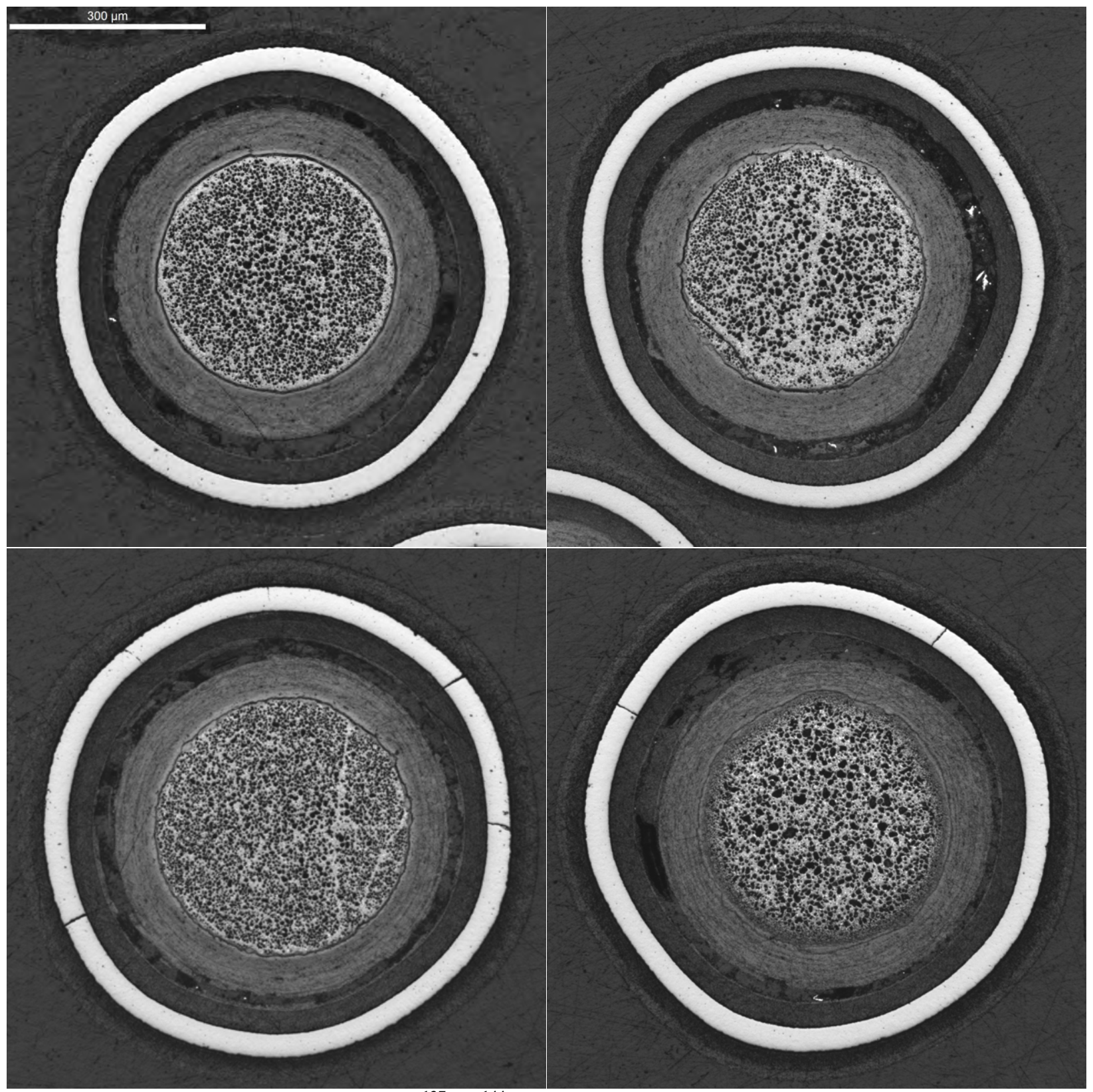

Figure 42. Four particles with normal ${ }^{137} \mathrm{Cs} /{ }^{144} \mathrm{Ce}$ ratio (Mount 6353). The radial cracks in the SiC are artifacts of a non-optimized grinding process. 


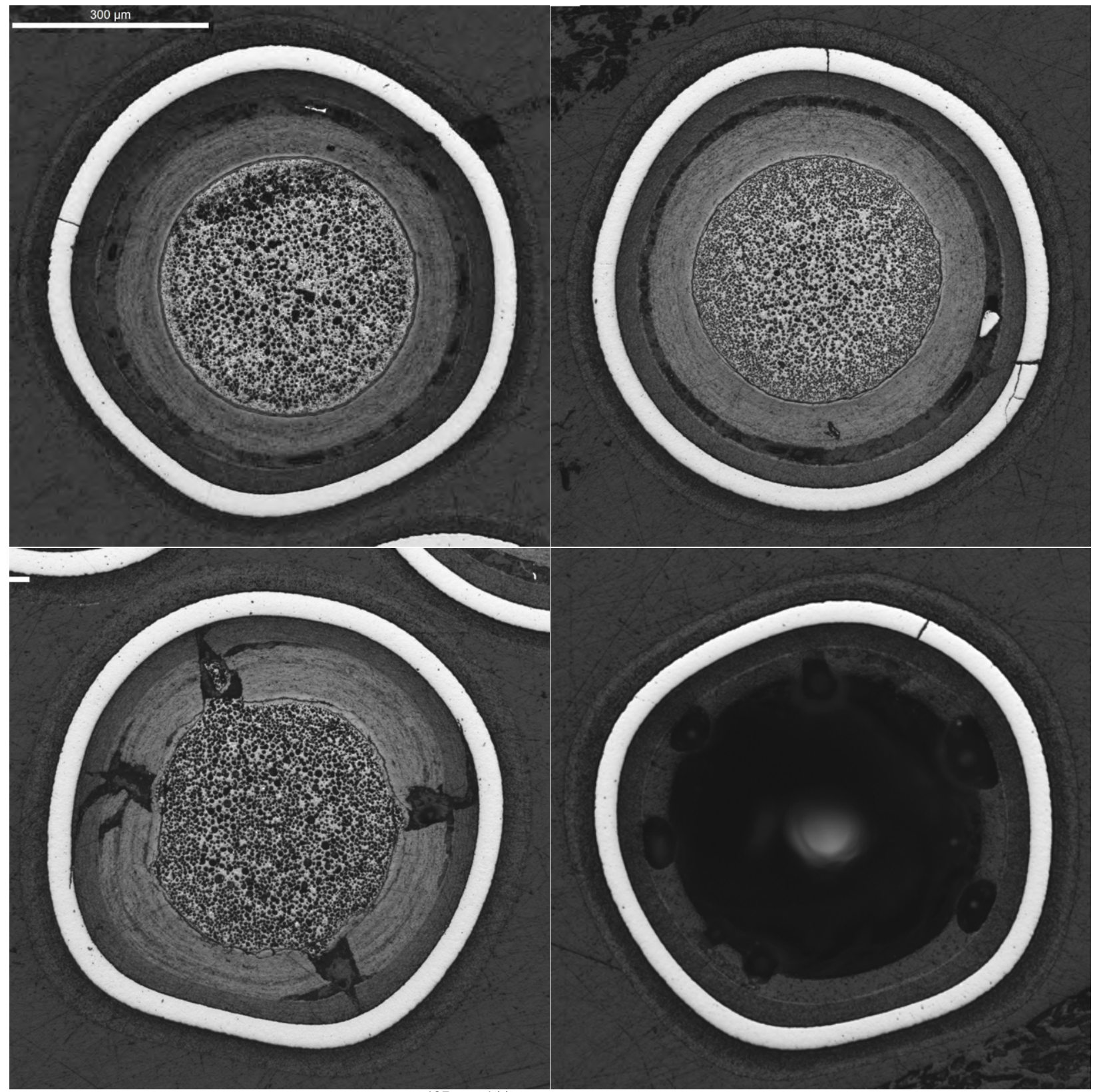

Figure 43. Four particles with normal ${ }^{137} \mathrm{Cs} /{ }^{144} \mathrm{Ce}$ ratio (Mount 6353). The radial cracks in the SiC are artifacts of a non-optimized grinding process. The buffer and kernel were pulled out of the particle in the lower right during sample preparation. 


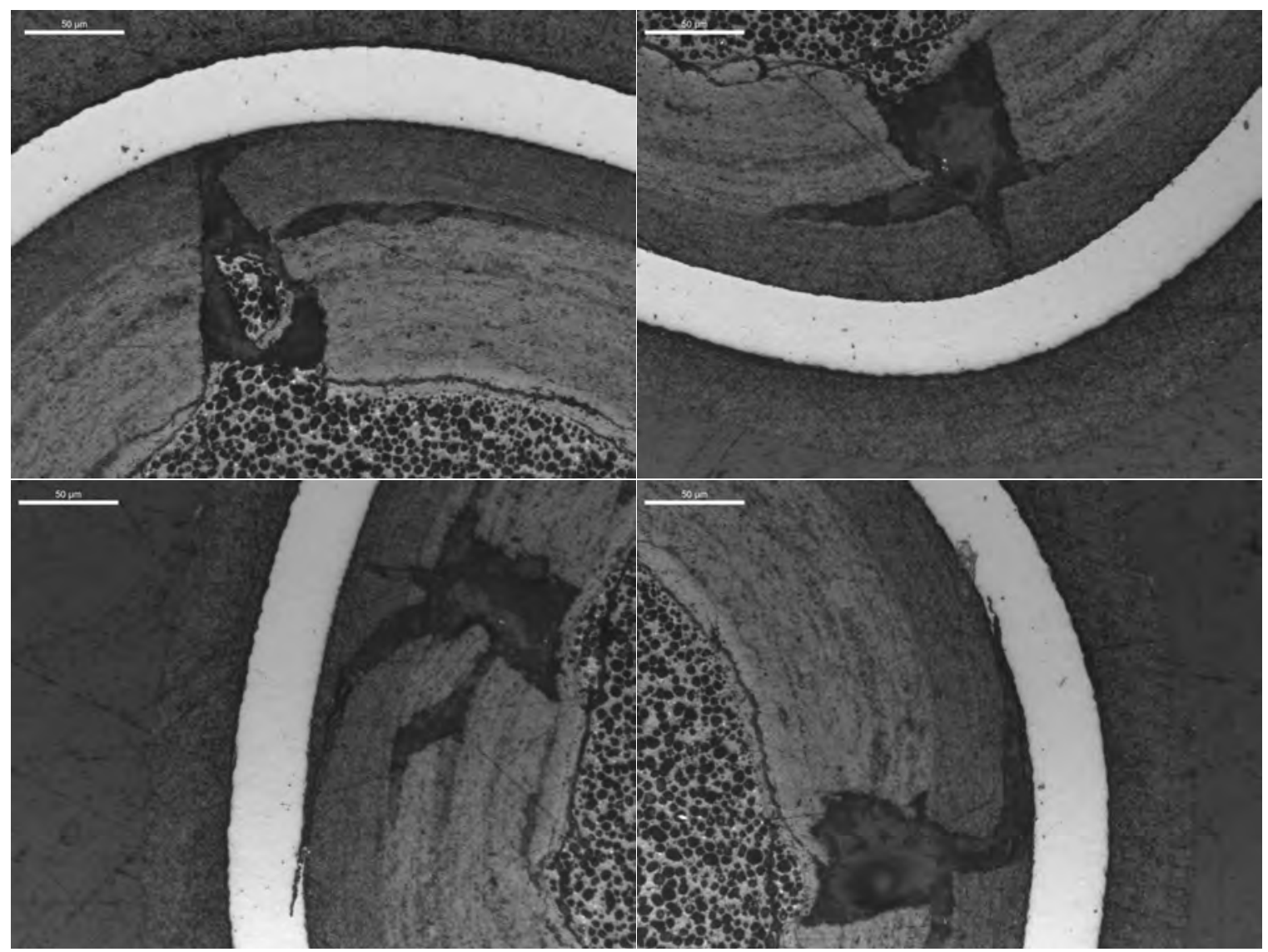

Figure 44. Particle from Mount 6353. Buffer and IPyC appear to have cracked simultaneously and separation of IPyC from SiC appears to have cracked SiC.

In the particle shown in Figure 44, some of the IPyC adjacent to the crack appears to have curled inward. This may indicate additional shrinkage of the IPyC due to a higher local exposure to fission recoils. Local IPyC densification, shrinkage, and cracking in a shape that has been compared to a "spearhead" have been previously observed in irradiated coated particles [Rose 1966]. In two areas of the particle cross-section, the IPyC crack appeared to propagate into the $\mathrm{SiC}$ at the point where the IPyC was separated from the $\mathrm{SiC}$. The crack did not continue through the $\mathrm{SiC}$, but only proceeded a short distance and appeared to be restricted to the region of fine $\mathrm{SiC}$ grain structure near the $\mathrm{IPyC} / \mathrm{SiC}$ interface.

Kernel microstructure varied for the particles shown in Figure 40 through Figure 43. Some of this variation is likely related to the pre-irradiation kernel microstructure, which also varied considerably. Optical inspection of the as-fabricated kernels [Kercher and Hunn 2005] showed four general kernel surface types (Figure 45). A brief survey of optical images of cross sectioned particles from the AGR-1 Baseline composite, obtained for coating thickness analysis [Hunn and Lowden 2006], also identified a number of general internal kernel microstructure types (Figure 46). In these images of pre-irradiated kernel cross sections, the uranium oxide phase appears gray and the uranium carbide phase appears white. Most kernels had a well-defined uranium oxide rind around a central region of mixed uranium oxide and uranium carbide (Types A, B, and D). Types B and D, where similar to Type A, but had a finer mixture of oxide and carbide and sometimes higher internal closed porosity. Some kernels had a thinner, less welldefined oxide rind and a thicker carbide skin at the kernel buffer interface (Types $\mathrm{C}$ and $\mathrm{E}$ ). This carbide skin formed on all kernels during coating, due to conversion of monocarbide to $\mathrm{UC}_{2-\mathrm{x}}$, with subsequent migration of free $U$ to the kernel surface, where it reacted with the buffer to form additional $U_{2-x}$. Type E kernels also showed internal regions of low carbide content, probably formed around large open pores through a mechanism similar to what forms the oxide rind during carbothermic reduction. Some kernels of this type appeared to have very little carbide remaining. Type F kernels were clearly not spherical (see Type 3 in Figure 45), appeared to be more friable and porous, did not have an oxide rind, and did not have a gap inside the carbide skin. 

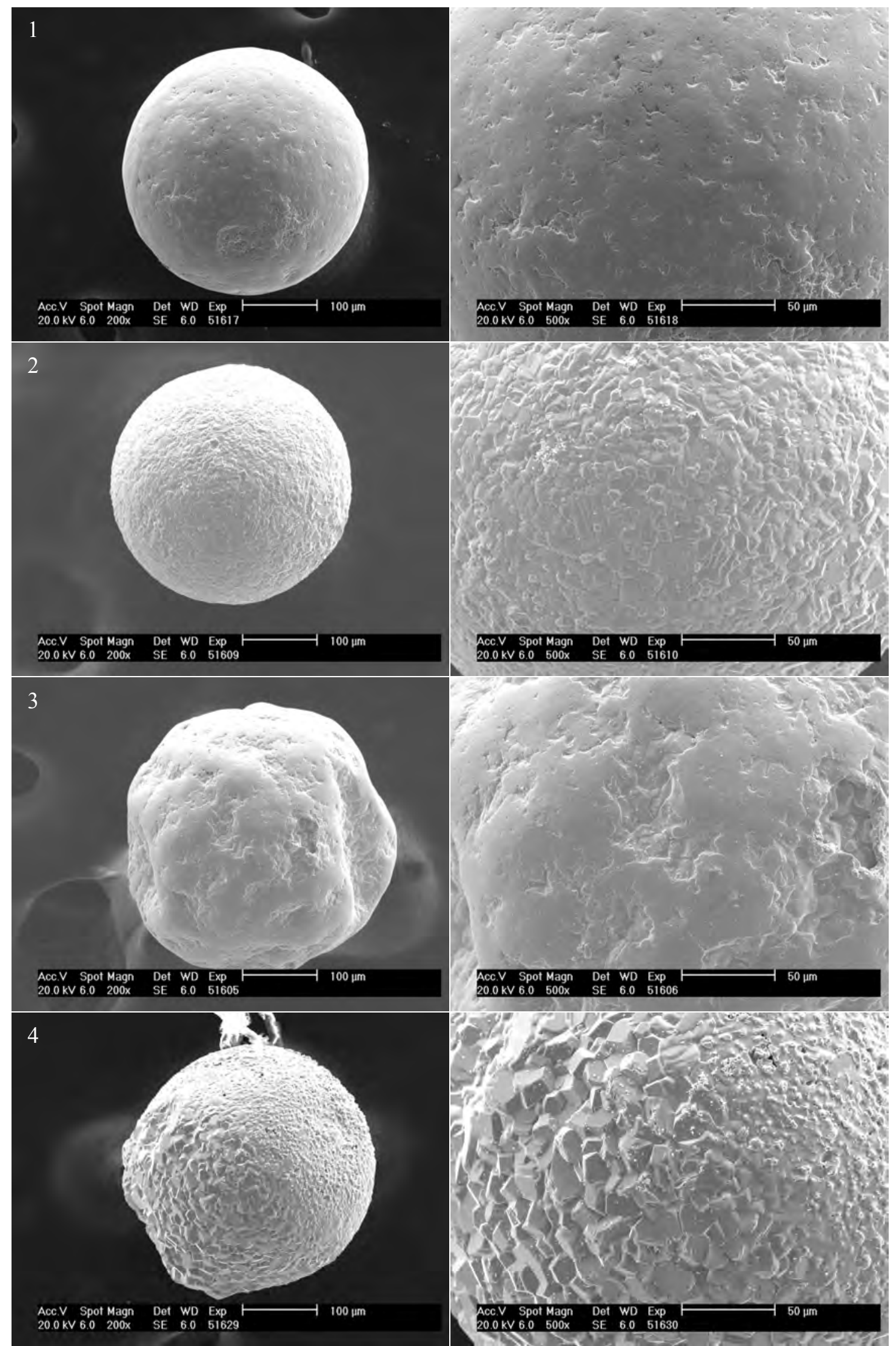

Figure 45. Four general kernel surface types observed in AGR-1 fuel particles. Relative populations of the various types was 30\% Type $1,40 \%$ Type $2,15 \%$ Type 3 , and $15 \%$ Type 4 . 

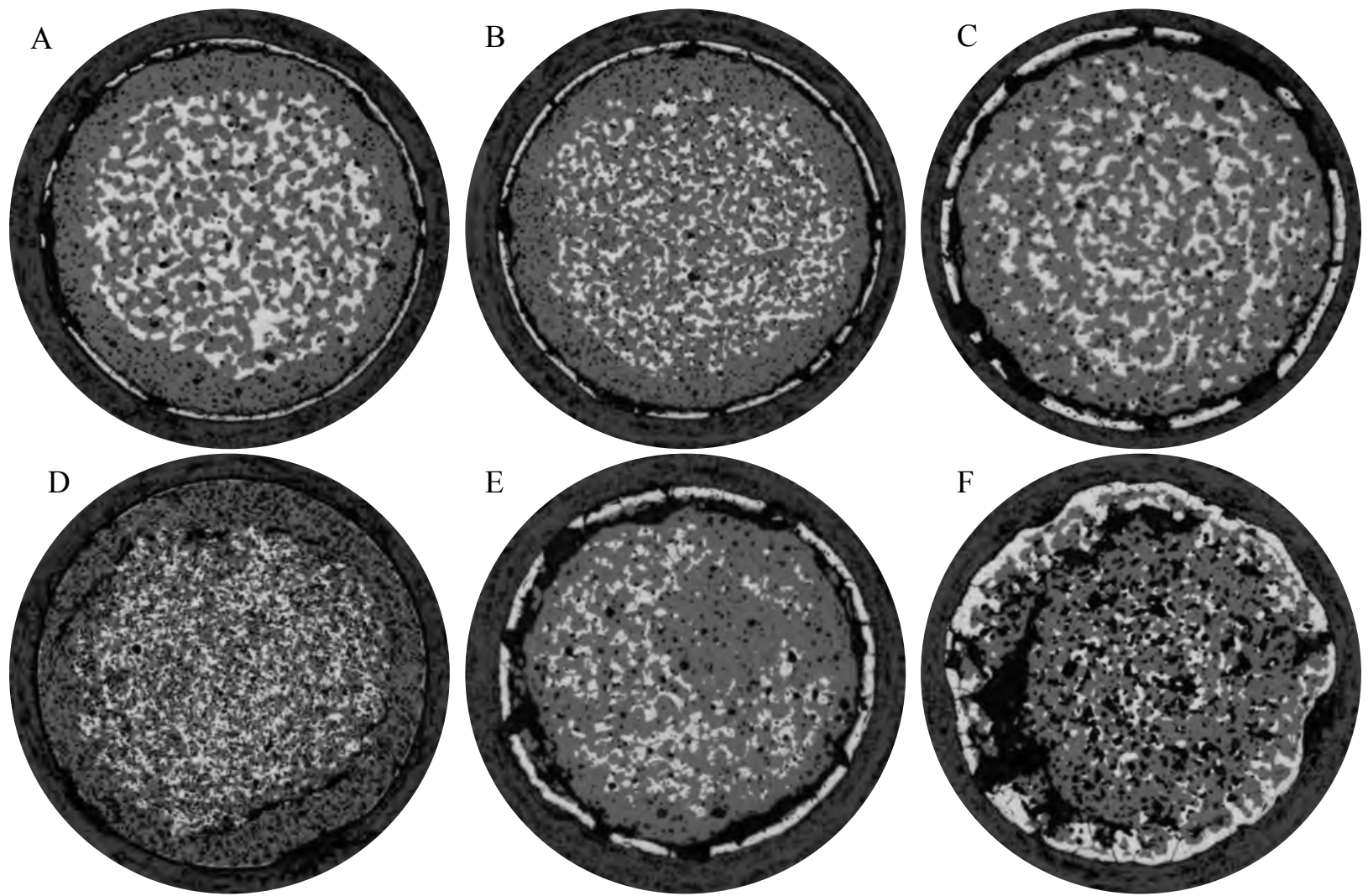

Figure 46. Six general kernel microstructure types observed in AGR-1 Baseline fuel particles. Rough estimate of relative populations of the various types was $44 \%$ Type $A, 14 \%$ Type $B, 25 \%$ Type C, $2 \%$ Type D, $10 \%$ Type E, and $5 \%$ Type F.

It is very difficult to relate the irradiated kernel microstructure for the particles shown in Figure 40 through Figure 43 to the pre-irradiated microstructures shown in Figure 46. This type of comparison could be improved by optimizing the sample preparation for better retention and visualization of the kernel microstructure. Vacuum back-potting and finer polishing of both pre- and post-irradiation cross sections would eliminate some of the uncertainty and SEM imaging may provide additional information. Given the images available for this report, some tenuous connections can be proposed. Figure 47 through Figure 50 group some of the kernels from the particles shown in Figure 40 through Figure 43 into categories possibly related to the observed pre-irradiation kernel microstructure types shown in Figure 46. Figure 47 shows irradiated kernels that have a relatively symmetric microstructure, with a porous central core surrounded by a rind of finer porosity. This two-zone pore structure could possibly be related to the structure observed in Type A or B kernels, which had a well-defined oxide rind with about the same relative thickness. Figure 48 shows irradiated kernels that have a relatively symmetric microstructure, but with less obvious demarcation between fine porosity and coarse porosity. By the same argument, these might be related to Type $\mathrm{C}$ kernels. Figure 49 shows irradiated kernels with a pore size distribution similar to those in Figure 48, but with an asymmetric microstructure. This asymmetric microstructure may be related to the asymmetric carbide content observed in Type E kernels. Firm conclusions regarding the possible relationship between the uranium oxide/uranium carbide structure in the pre-irradiated kernels and the porosity distribution in the irradiated kernels would require further investigation.

An obvious example of an irradiated non-spherical Type F kernel was not available, but the particle with a fractured buffer in Mount 6353 had a kernel that showed some indication of asphericity not obviously connected to the distortion from the unconstrained kernel growth associated with the buffer fracture (Figure 50). For the samples prepared in this series, the presence of a separate carbide skin was no longer obvious after irradiation. However, improved sample preparation methods discussed below revealed some evidence that a remnant of the carbide skin can still be seen around the inside edge of the buffer (for instance, see Figure 79 through Figure 84). 

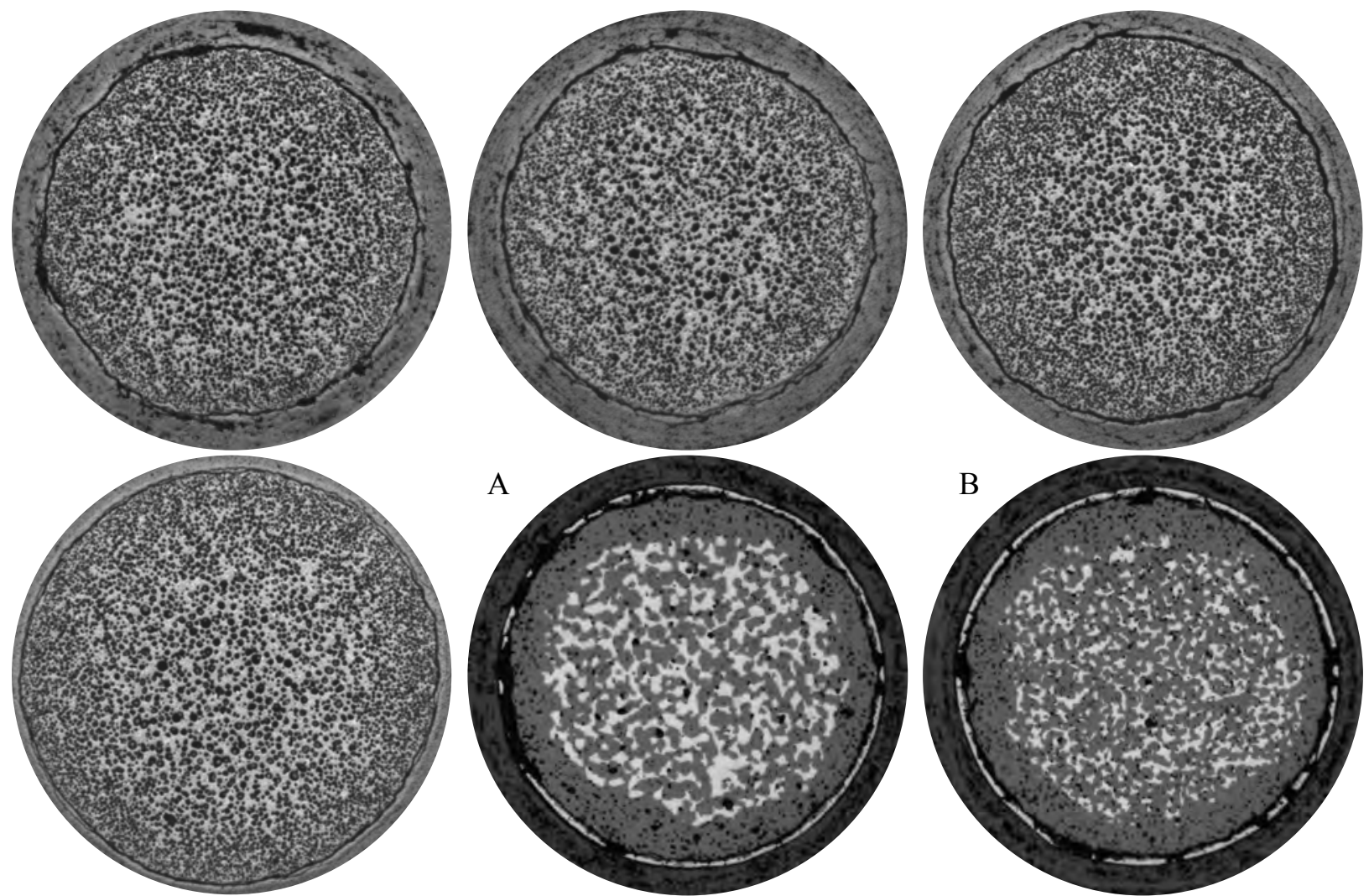

Figure 47. Irradiated kernels from Mounts 6352 and 6353 with two regions of different porosity, possibly related to kernels with a symmetric microstructure and thick, well-defined oxide rind (Types A and B).
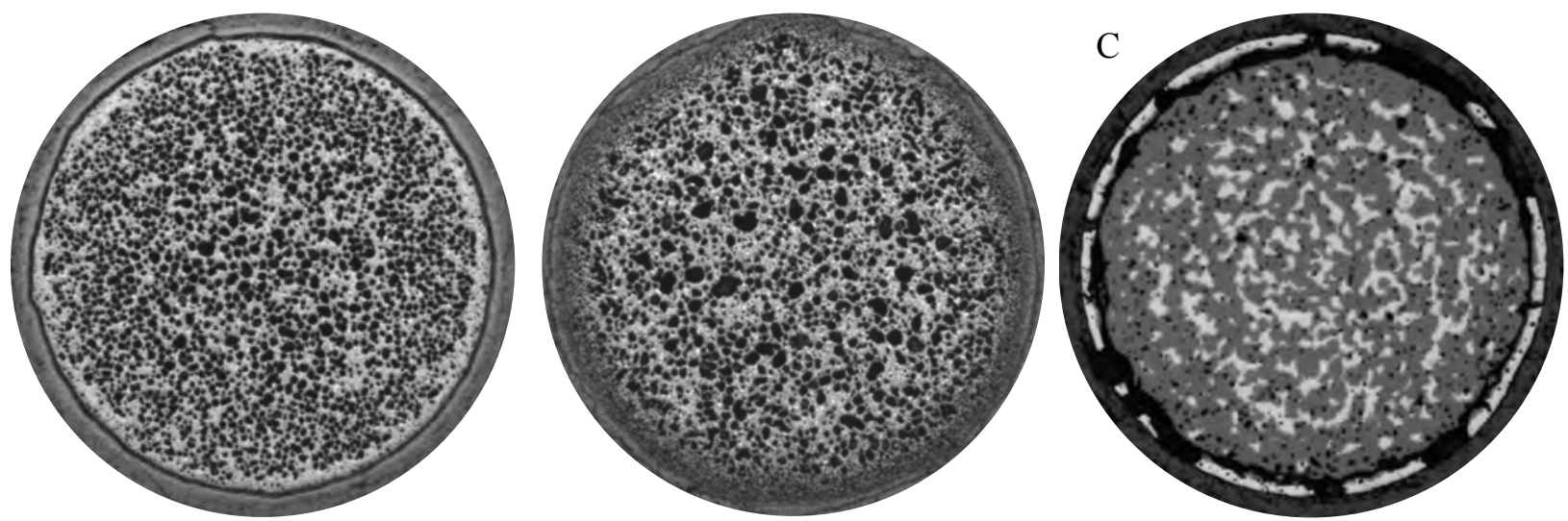

Figure 48. Irradiated kernels from Mount 6353 with less obvious demarcation between fine porosity and coarse porosity, possibly related to kernels with thin, less well-defined oxide rind (Type C). 

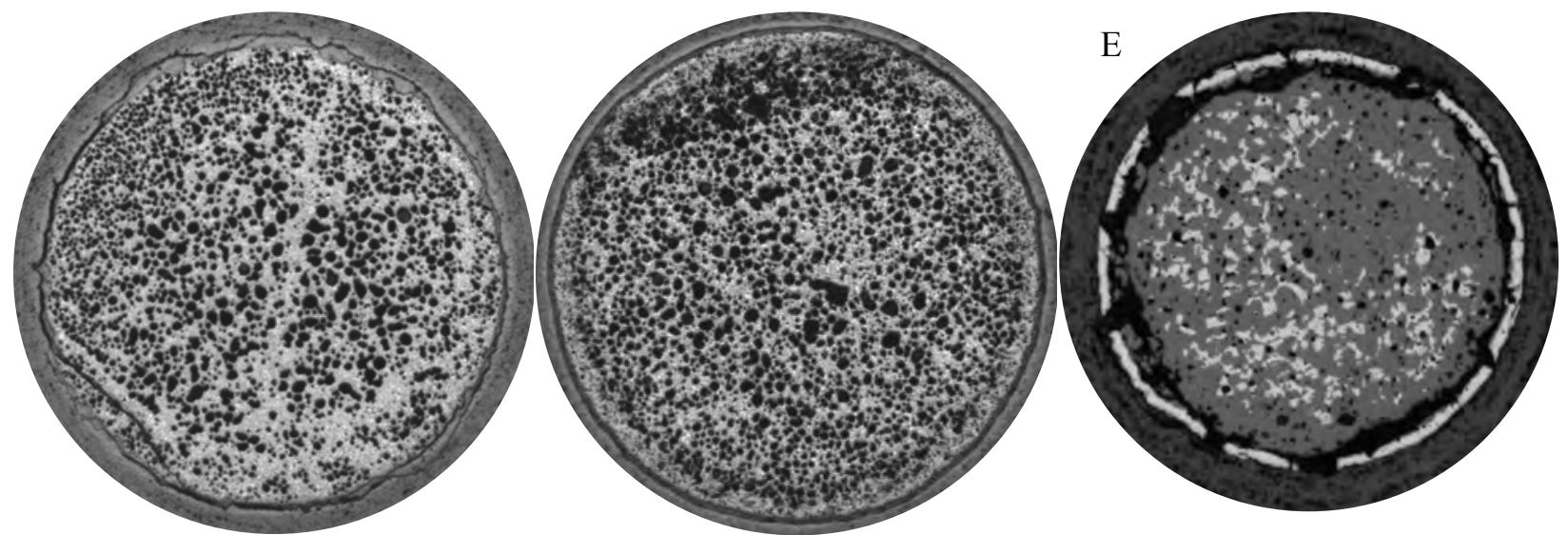

Figure 49. Irradiated kernels from Mount 6353 with asymmetric porosity, possibly related to kernels with asymmetric carbide content (Type E).
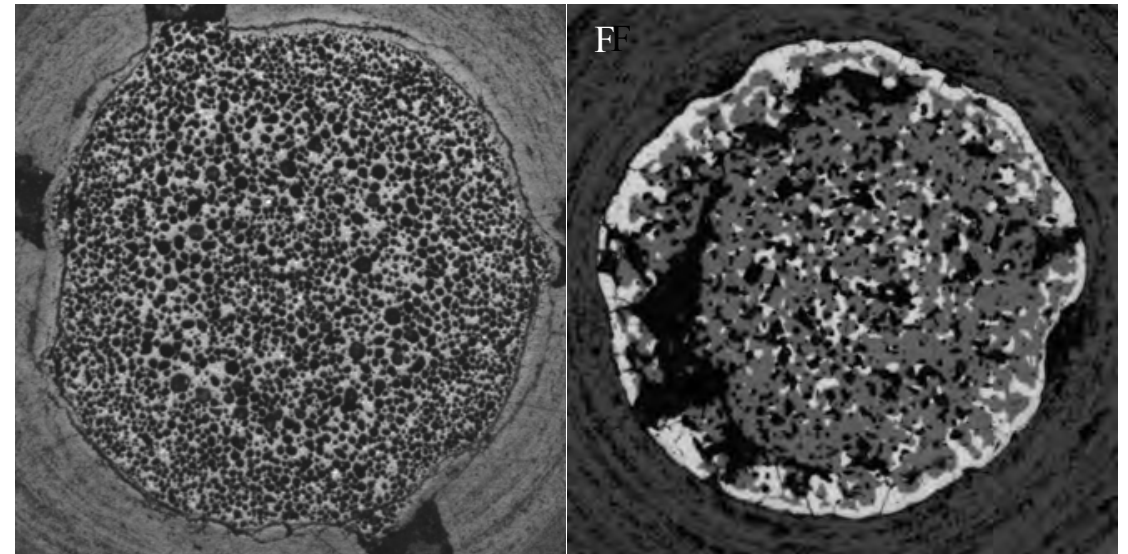

Figure 50. Irradiated kernel from Mount 6353 with possible aspherical shape, similar to Type F kernels.

Mounts 6355 and 6356 (Table 8) were funnel mounts of particles sorted by IMGA as having an average inventory of ${ }^{144} \mathrm{Ce}$ and ${ }^{137} \mathrm{Cs}$ (normalized ${ }^{137} \mathrm{Cs} /{ }^{144} \mathrm{Ce}$ ratio between 0.9 and 1.2 ), each mount containing only 1 particle. These particles were taken to a final polish with $3 \mu \mathrm{m}$ diamond on a Struer's Dac woven silk disk before obtaining the optical images shown below. Figure 51 shows the particle in Mount 6355, which is an example of an intact buffer layer shrinking away from the IPyC with a portion of the buffer/IPyC interface still intact. Figure 52 shows the particle in Mount 6356, which is an example of a fractured buffer layer with the kernel extruding into the gap between the buffer fragments. The pores in this kernel are noticeably larger, similar to previous observations of kernel with fractured buffer. 


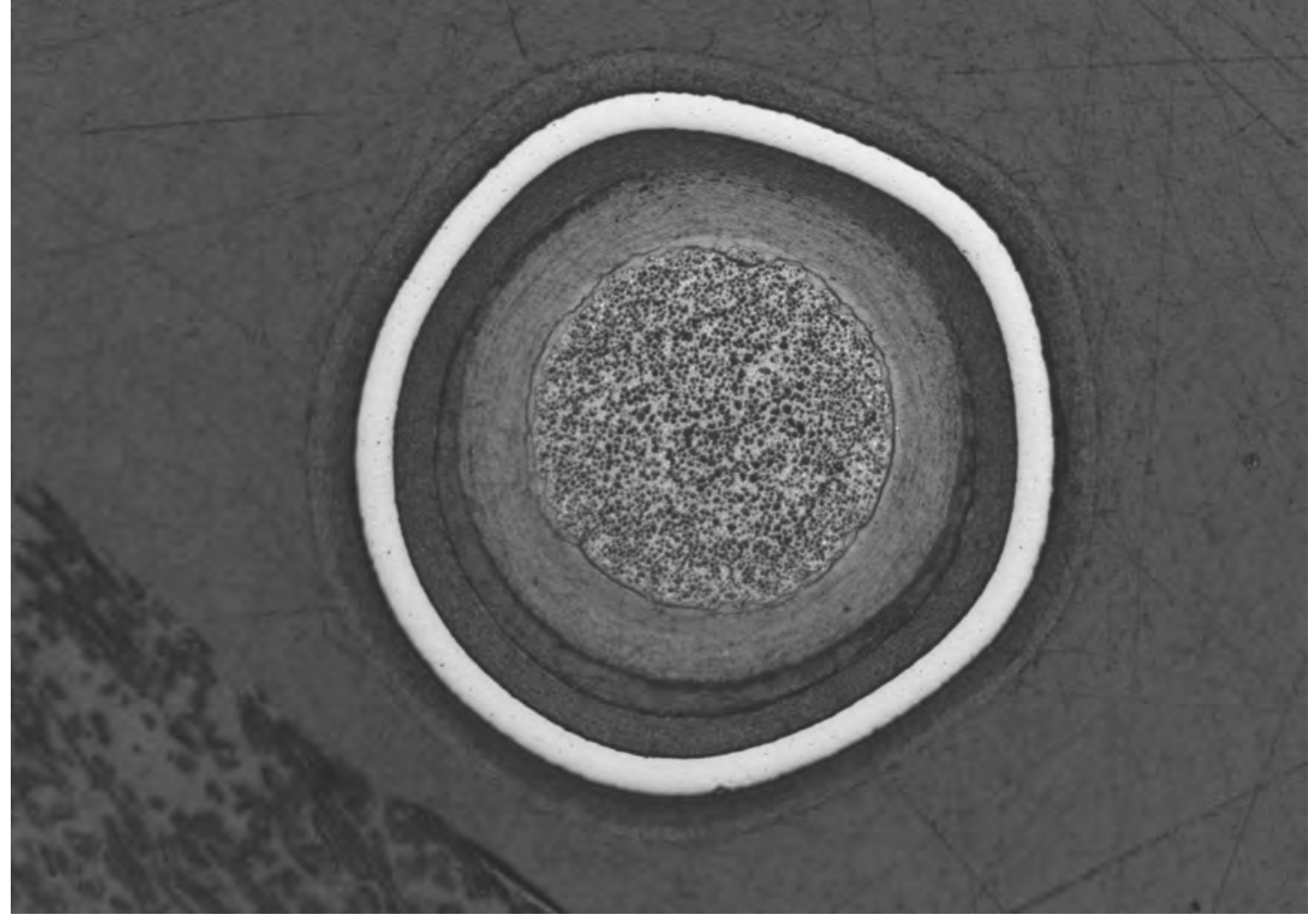

Figure 51. Particle with normal ${ }^{137} \mathrm{Cs} /{ }^{144} \mathrm{Ce}$ ratio (Mount 6355).

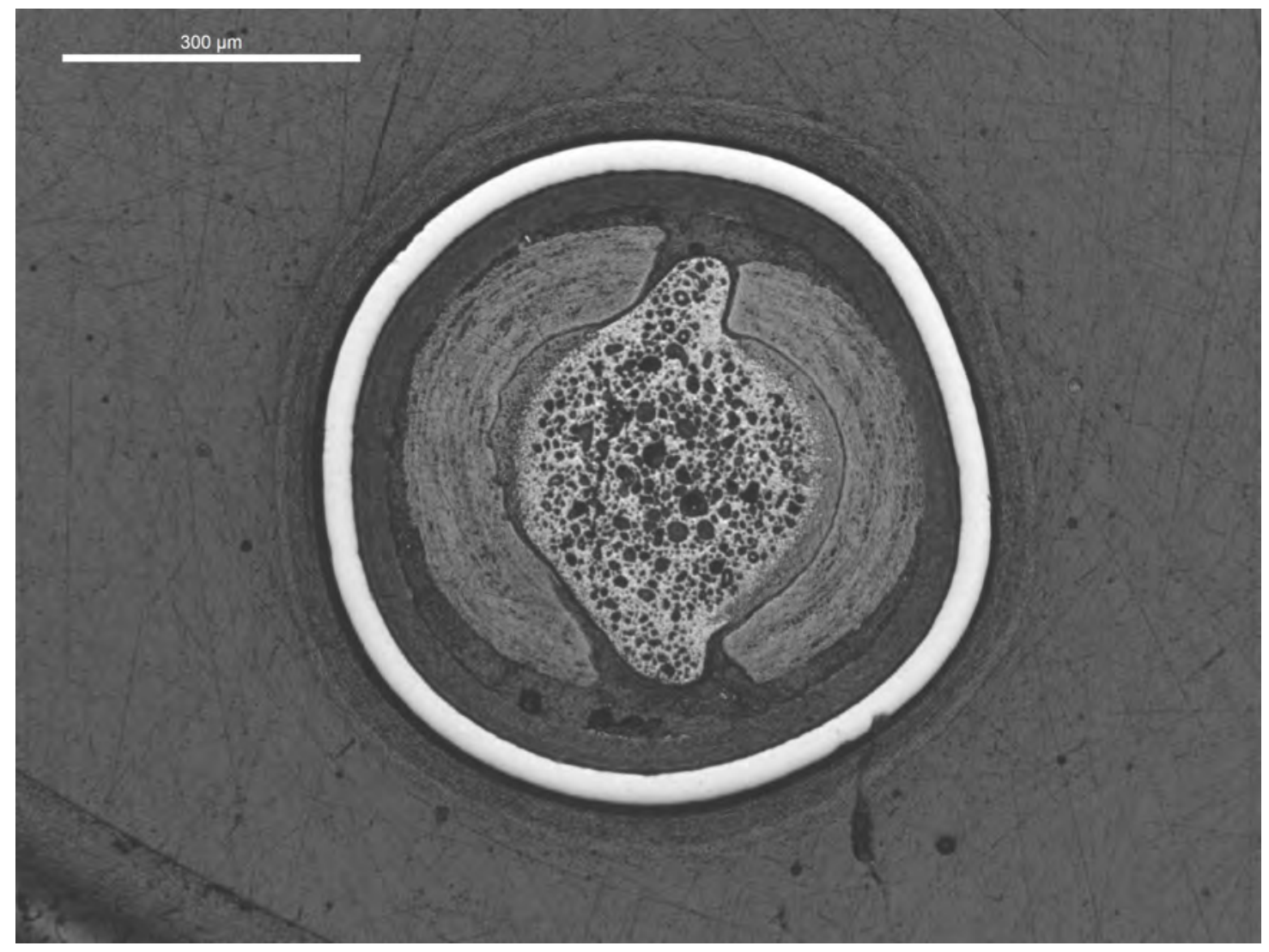

Figure 52. Particle with normal ${ }^{137} \mathrm{Cs} /{ }^{144} \mathrm{Ce}$ ratio (Mount 6356). 
Mounts 6357 and 6359 contained particles selected from the particles analyzed by IMGA using 6 hour counting times (Table 8). Mount 6357 was an array mount containing six particles determined to have above average, average, and below average ${ }^{110 \mathrm{~m}} \mathrm{Ag}$ content. Mount 6359 was a funnel mount containing one particle with a ${ }^{110 \mathrm{~m}} \mathrm{Ag}$ inventory that was undetectable with the 6 hour gamma scan. To reduce charging in the SEM, $15 \mathrm{wt} \%$ graphite powder was thoroughly mixed into to the epoxy resin to produce a conductive epoxy mount. These particles were taken to a final polish with $3 \mu \mathrm{m}$ diamond on a Struer's Dac woven silk disk before obtaining the optical images shown below. Polish at this stage was poor. The two particles with the highest silver content were not ground far enough to expose the kernel; the particle with average silver content and one with below average silver inventory had been pulled out of the epoxy by the grinding process; and some of the $\mathrm{SiC}$ layers had been fractured during grinding. Nevertheless, these particles were further polished for SEM analysis, because the remaining particles all had fractured buffer layers with extruding kernels that warranted further analysis (Figure 53 through Figure 55). However, because of the limited sampling, no conclusions should be drawn at this time regarding the relationship between the observed microstructure in these 3 particles and the silver retention.

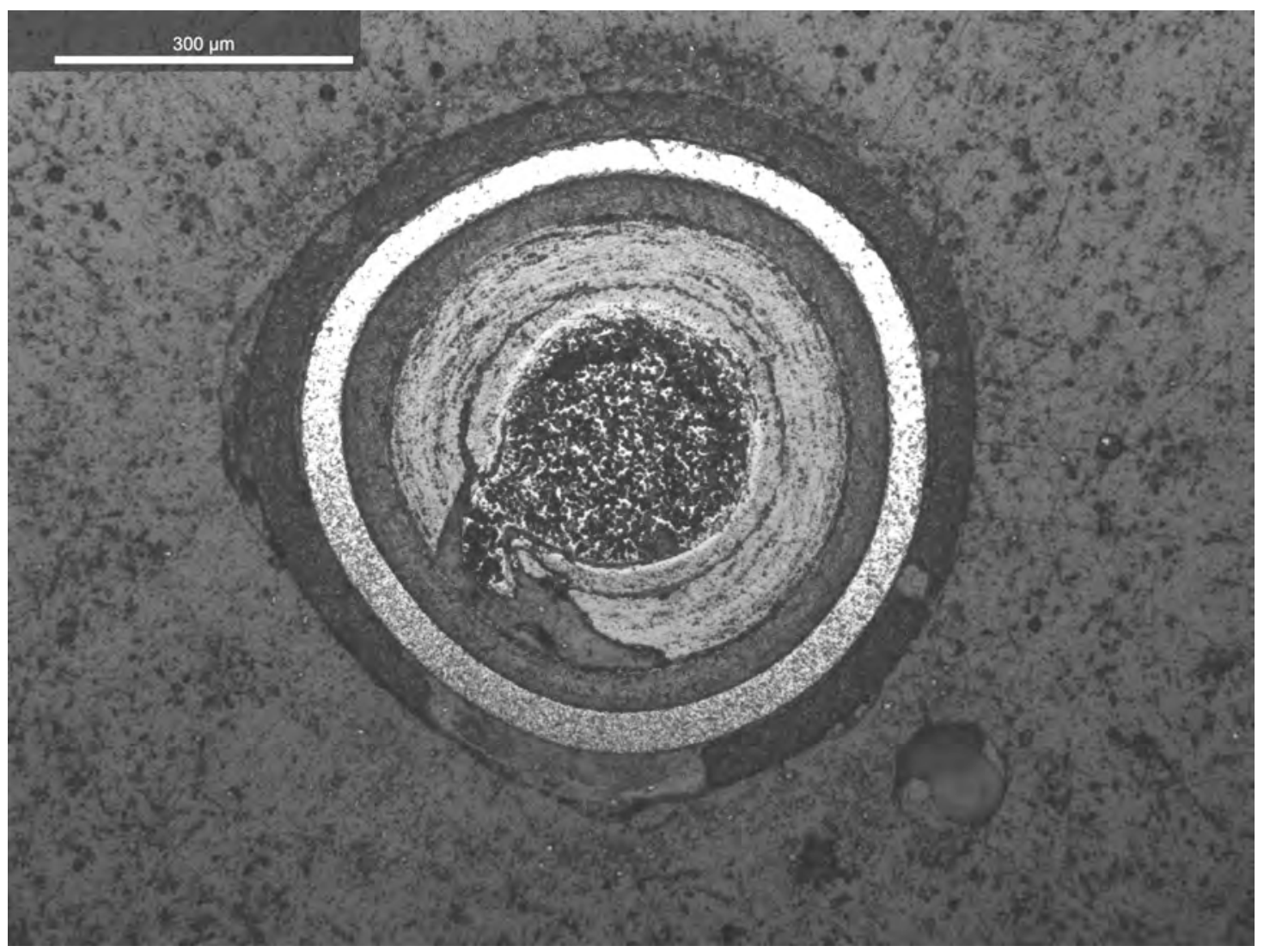

Figure 53. Particle Ag-14 with below average ${ }^{110 \mathrm{~m}} \mathrm{Ag}$ inventory (Mount 6357). 


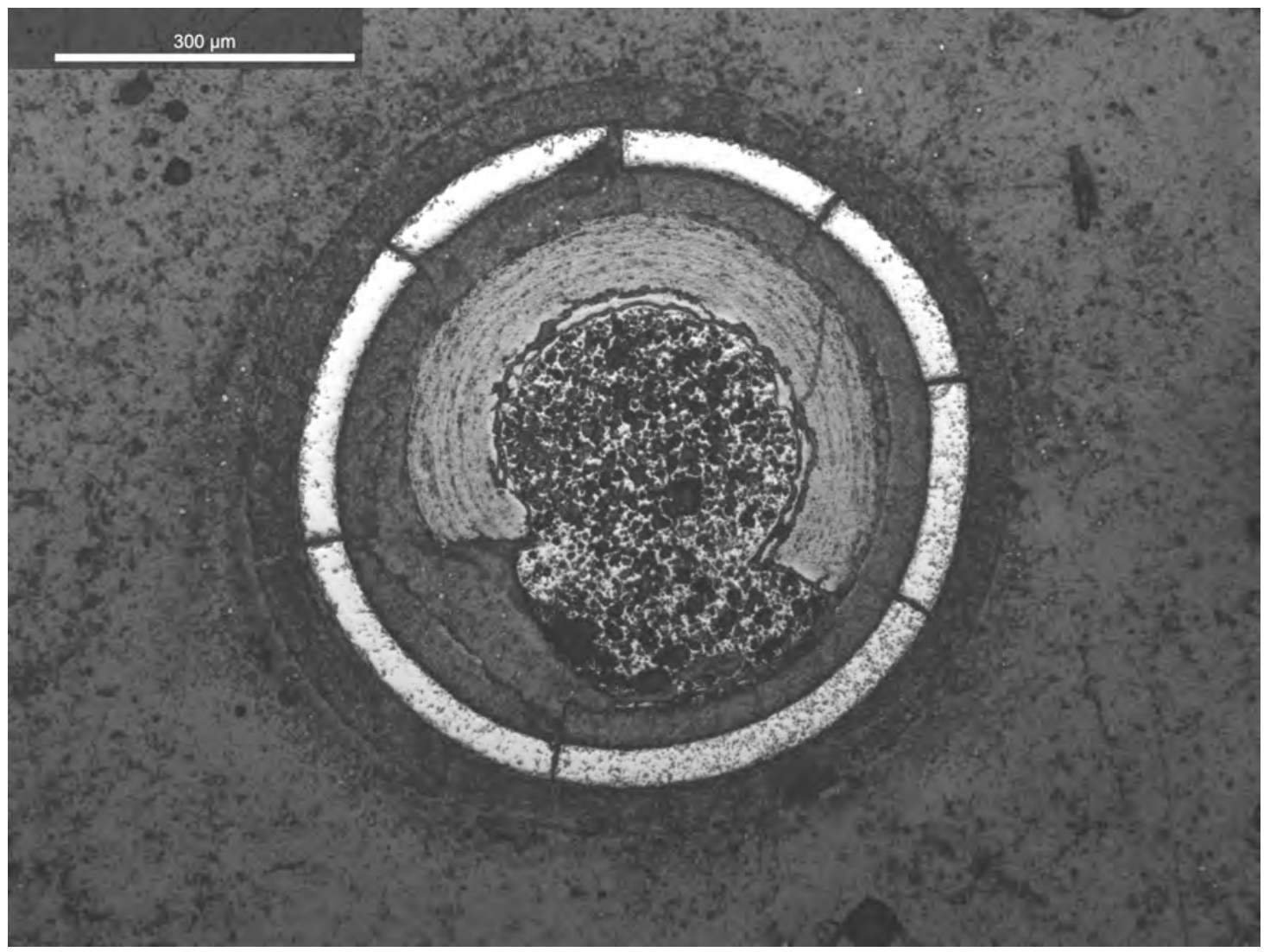

Figure 54. Particle Ag-18 with below average ${ }^{110 \mathrm{~m}}$ Ag inventory (Mount 6357).

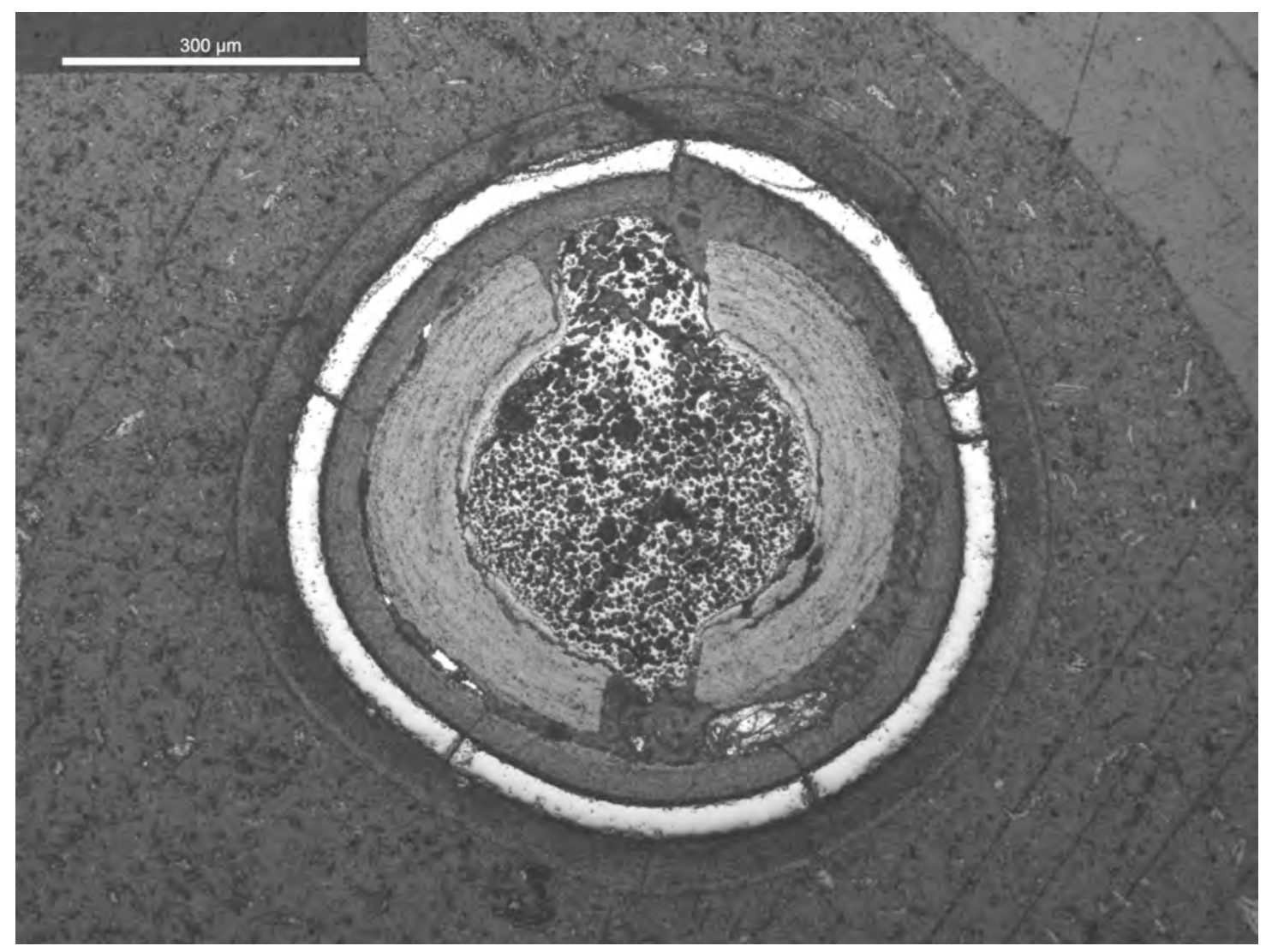

Figure 55. Particle Ag-51 with no detectable ${ }^{110 \mathrm{~m}}$ Ag inventory (Mount 6359). 


\section{Materialography on Individual Particles: SEM Analysis}

SEM imaging and WDS/EDS analysis were performed using a JEOL JSM-6390L SEM fitted with an Oxford INCA Wave 500 WDS system and an Oxford INCA Energy 250 EDS system. The SEM is designed to be operated within the same standalone hot cell used for the Core Conduction Cooldown Test Facility (CCCTF) furnace. The SEM chamber, vacuum systems, electron source, and detectors are located on a pallet that can be placed in the CCCTF hot cell cubicle (Figure 56). The control console is located just outside of the cell and connected via cabling run into the cell via an alpha-seal feedthrough.

SEM imaging of the irradiated particles was conducted using both secondary electron (SE) and backscattered electron (BSE) detectors. SE imaging is surface sensitive, allowing for the determination of surface topography. BSE imaging is an ideal method for identifying fission products distributed in the coating layers or interfaces, because the BSE signal intensity is dependent on the atomic number $(Z)$ of the scattering atom. The relatively low $\mathrm{Z}$ of the carbon and $\mathrm{SiC}$ layers strongly contrast with the presence of high $\mathrm{Z}$ fission products. When possible, parallel micrographs were obtained in both imaging modes to differentiate between actual embedded fission products versus surface structure or particulates, which can also appear with high contrast. This differentiation is important, as the sample preparation inside the hot cell is prone to surface contamination, which can be misinterpreted as fission products in the layers. EDS and WDS chemical analyses were conducted in the SEM using the following microscope conditions: $20 \mathrm{kV}, 16 \mathrm{~mm}$ working distance, and spot size setting of 76. The working distance of $16 \mathrm{~mm}$ was selected to ensure the sample was properly situated on the Rowland circle for accurate WDS analysis and a spot size setting of 76 was selected to obtain a sufficient current to achieve significant counting statistics. Imaging of select areas was conducted at $20 \mathrm{kV}, 16 \mathrm{~mm}$ working distance, and a spot size setting of 64 to improve resolution over the standard conditions used for chemical analysis. Information on the SiC microstructure was obtained by adjusting the brightness and contrast intensities in the BSE imaging mode to highlight various grain orientations. This imaging is optimized by having the highly polished samples with minimal surface damage, which were achieved by the final $0.05 \mu \mathrm{m}$ OP-S polishing step.

The mounts investigated by SEM are described in Table 8 in the previous section. Further polishing was performed in preparation for SEM imaging. Mounts 6352, 6353, 6355, 6356, 6357, and 6359 were polished with $1 \mu \mathrm{m}$ diamond suspension on a Struer's Dac followed by $0.05 \mu \mathrm{m}$ colloidal silica OP-S on a Struer's Nap. Mounts 6352, 6353, 6355, and 6356 were gold coated to reduce charging in the SEM. Mounts 6357 and 6359, which were made with conducting epoxy, were not gold coated, however samples were backpotted with non-conducting epoxy to fill gaps and secure the kernel and buffer. The presence of this non-conducting epoxy led to slight charging effects and sample drift issues discussed below.

Limited chemical analysis was conducted on the Au coated particles (Mounts 6352, 6353, 6355, 6356) because the high $\mathrm{Z}$ of Au masked the presence of fission products segregated throughout the particles. Additionally, the Au coating had been disturbed during transfer from the hot cell preparation area to the SEM in the CCCTF hot cell. During transfer the Au coating had been partially rubbed off, and this led to small agglomerations of Au decorating the sample surface producing high contrast areas on the surface that made identification of fission product clusters difficult. Analysis of the mounts produced with the conductive epoxy (Mounts 6357 and 6359) clearly showed fission products distributed in the coating layers and were the focus of the SEM investigation. However, as discussed in the previous section, the grinding process for Mounts 6357 and 6359 was not optimized and damage to the coating layers, particularly the $\mathrm{SiC}$, was introduced by the process. Fractured coating layers in any of the micrographs shown in this section were artifacts of the sample preparation. 


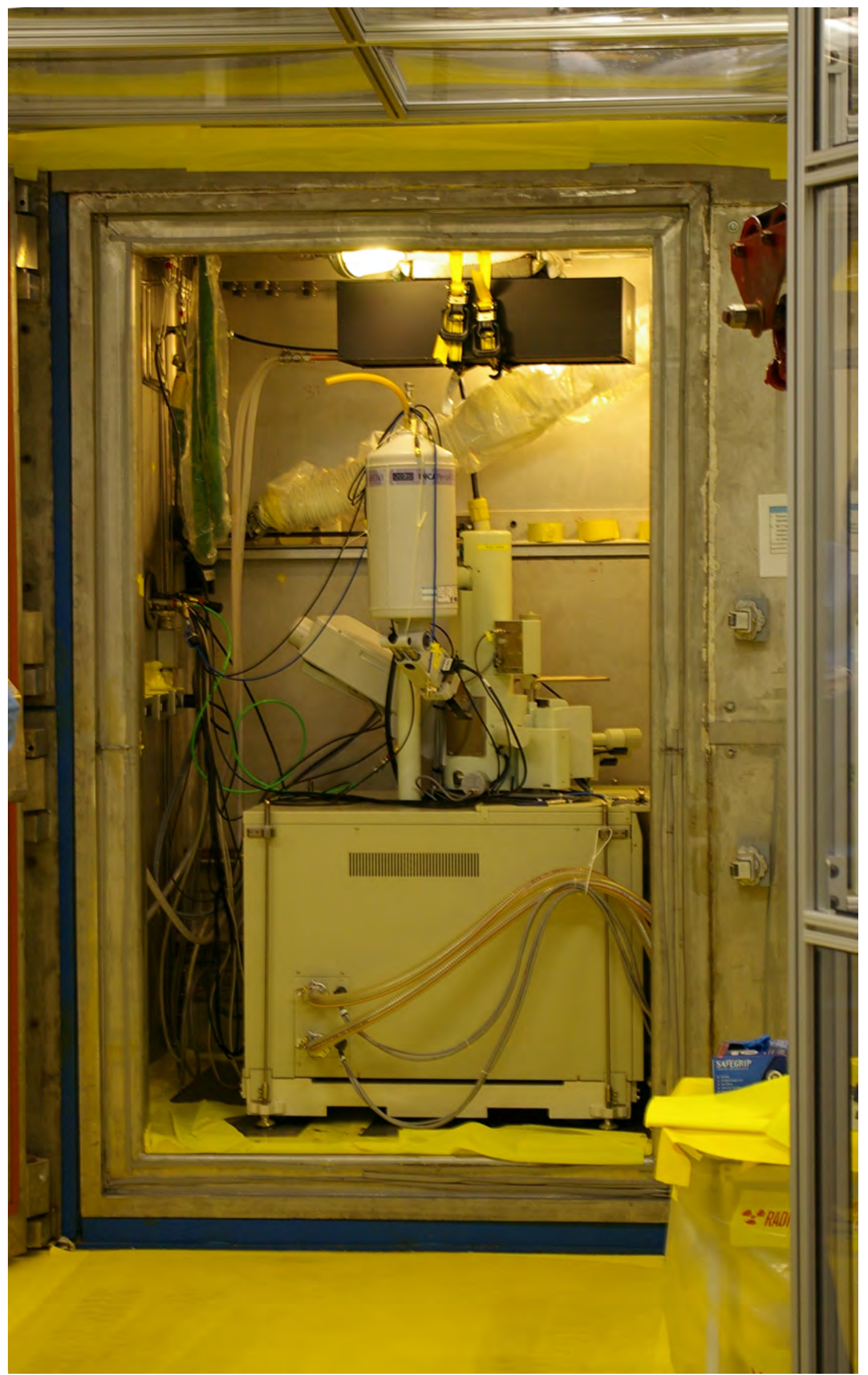

Figure 56. SEM with WDS/EDS in position in the CCCTF hot cell cubicle. 


\section{Backscattering electron imaging}

Analysis of Mounts 6357 and 6359 revealed large fission product (FP) clusters in the buffer/IPyC and $\mathrm{IPyC} / \mathrm{SiC}$ interfaces and small FP clusters embedded in the buffer, IPyC, and SiC layers. In the SEM images, the high Z FPs appear as bright spots on the darker $\mathrm{C}$ and $\mathrm{SiC}$ layers. These features were similar in all particles analyzed, and examples are shown in Figure 57 through Figure 59 for particles with below average and less than detectable ${ }^{110 \mathrm{~m}} \mathrm{Ag}$ inventories. Comparison of SE and BSE images was used to confirm that the observed FP clusters were embedded in the layers of the irradiated particles and not just surface contamination from the polishing process. Figure 60 and Figure 61 are examples of BSE and SE micrographs of the same region around the IPyC/SiC interface of Particle Ag-18. The FP clusters observed as bright spots in the SiC layer in the BSE image, which do not show shadowing in the SE image, are embedded FP clusters, while those with shadowing are FPs that have been deposited on the surface during sample preparation. Similar confirmation of fission products embedded at the interfaces or in the buffer layer could not be accomplished because of the possibility of FPs being introduced into gaps or pores during polishing. Figure 62 shows FPs clustered in the buffer that could be a result of FPs caught in open space in the layer. Recently, ultrasonic cleaning of the polished samples has been performed immediately before SEM analysis, and this greatly reduces FP inclusion from sample preparation. In some cases, elemental analysis provides additional data for distinguishing whether observed FP clusters were due to polishing artifacts, this is discussed below.

For the small number of samples analyzed in this shakedown study, the embedded FP clusters in the $\mathrm{SiC}$ were primarily contained within the first $15 \mu \mathrm{m}$ of the $\mathrm{SiC}$ layer. The circumferential distribution of the embedded FPs suggests that the trapping mechanism for these FPs may be related to abnormalities or defects in the $\mathrm{SiC}$ microstructure, which tend to appear at multiple positions at a given distance from the $\mathrm{IPyC}$, because they are related to the $\mathrm{SiC}$ deposition. The absence of FP clusters in the outer half of the $\mathrm{SiC}$ layer should not lead to the conclusion that the FPs were stopped in the $\mathrm{SiC}$, because these FPs were also detected outside the SiC by DLBL. More recent SEM analysis on particles from other compacts has revealed similar FP clusters in the outer region of the $\mathrm{SiC}$.

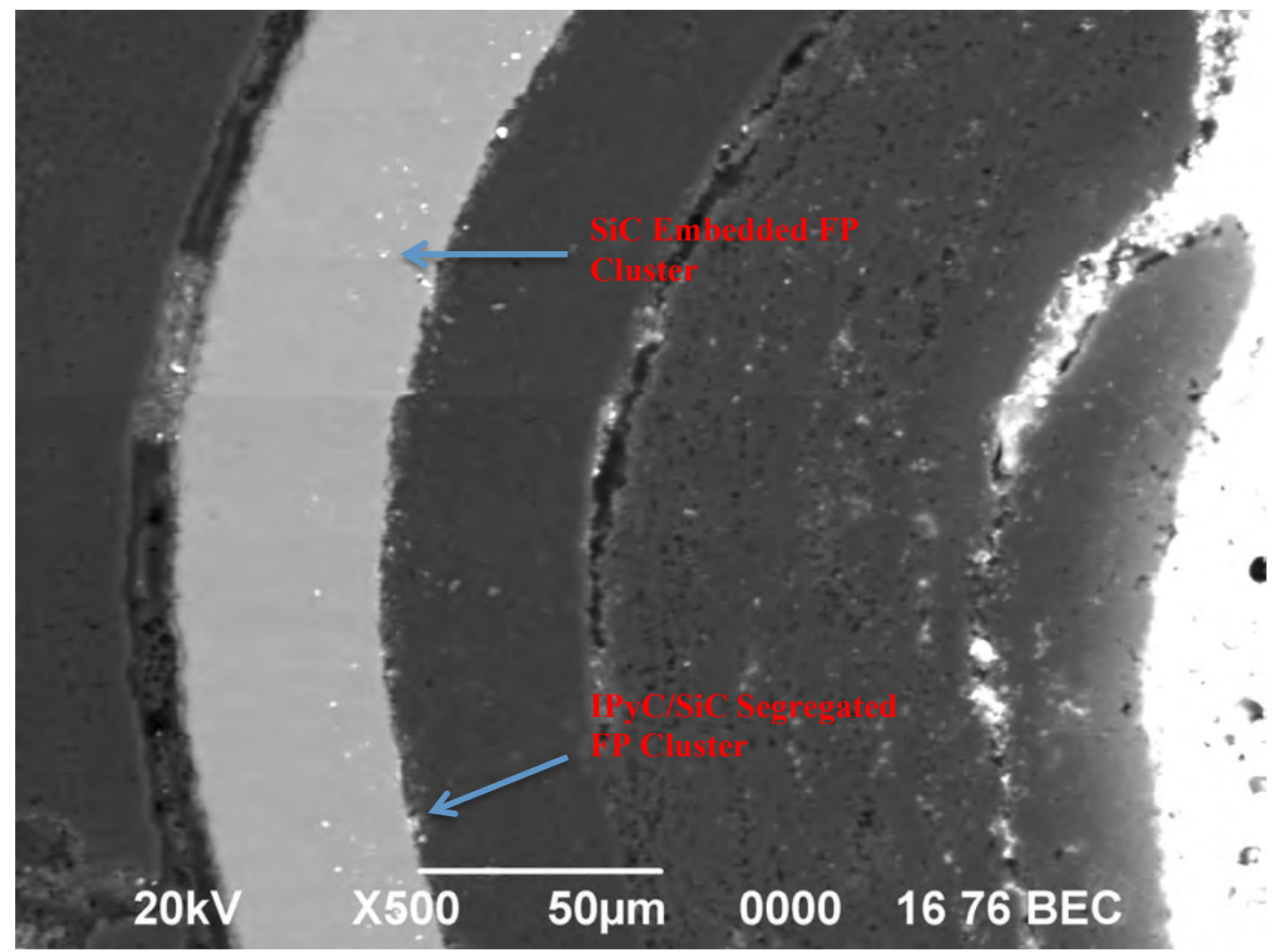

Figure 57. BSE image of Particle Ag-14 with below average ${ }^{110 \mathrm{~m}}$ Ag inventory (Mount 6357). 


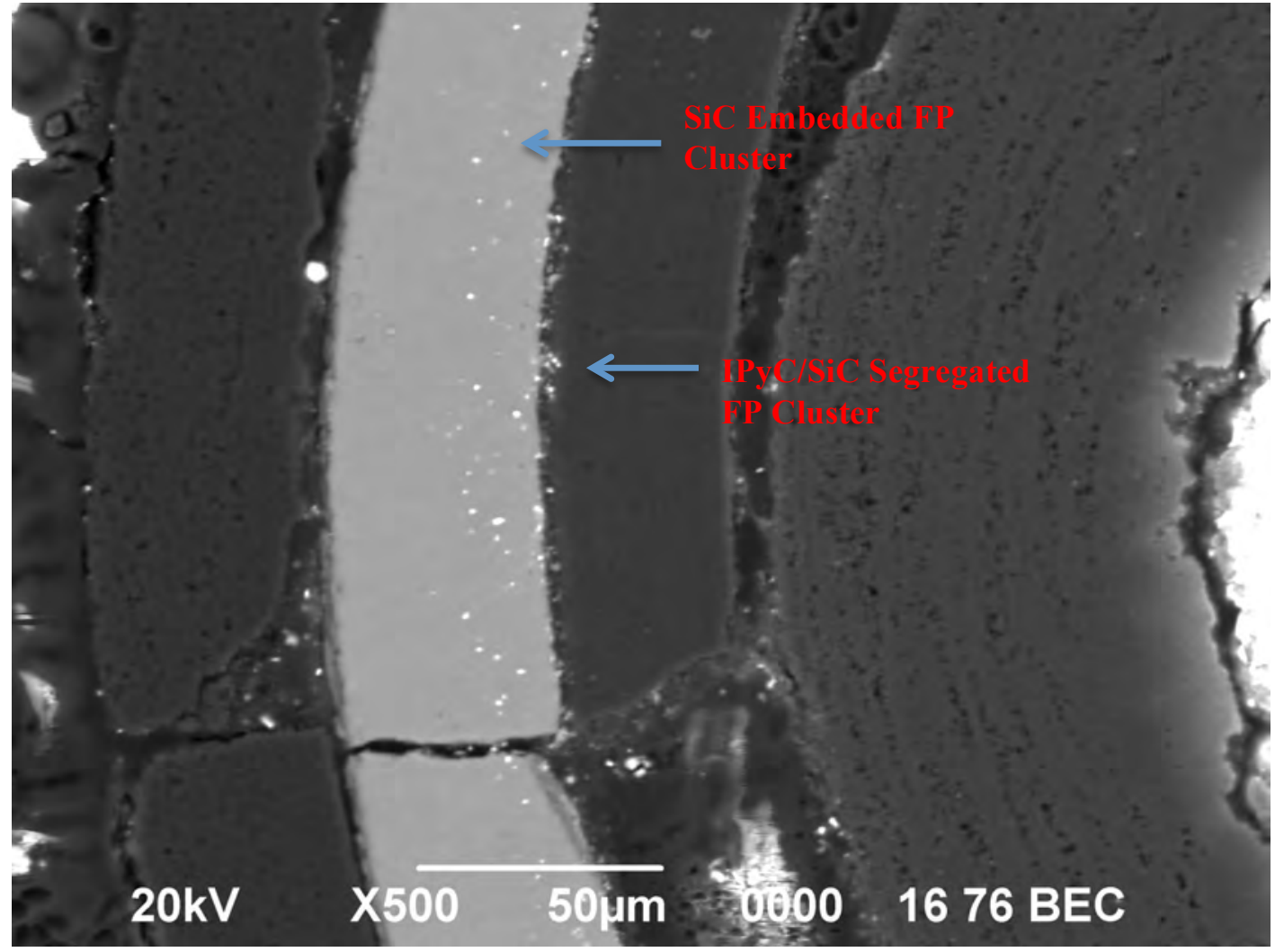

Figure 58. BSE image of Particle Ag-18 with below average ${ }^{110 \mathrm{~m}} \mathrm{Ag}$ inventory (Mount 6357).

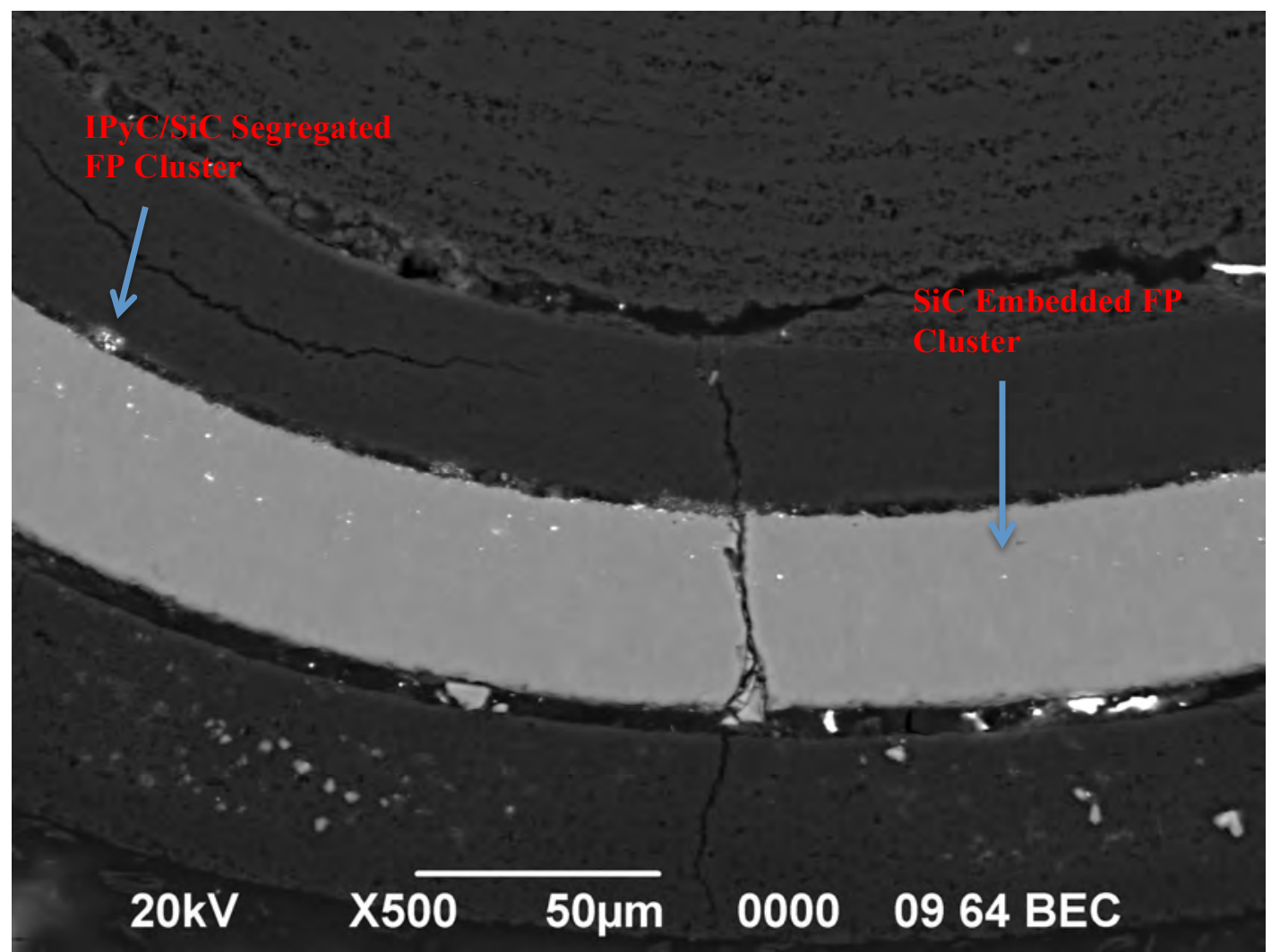

Figure 59. BSE image of Particle Ag-51 with less than detectable ${ }^{110 \mathrm{~m}} \mathrm{Ag}$ inventory (Mount 6359). 


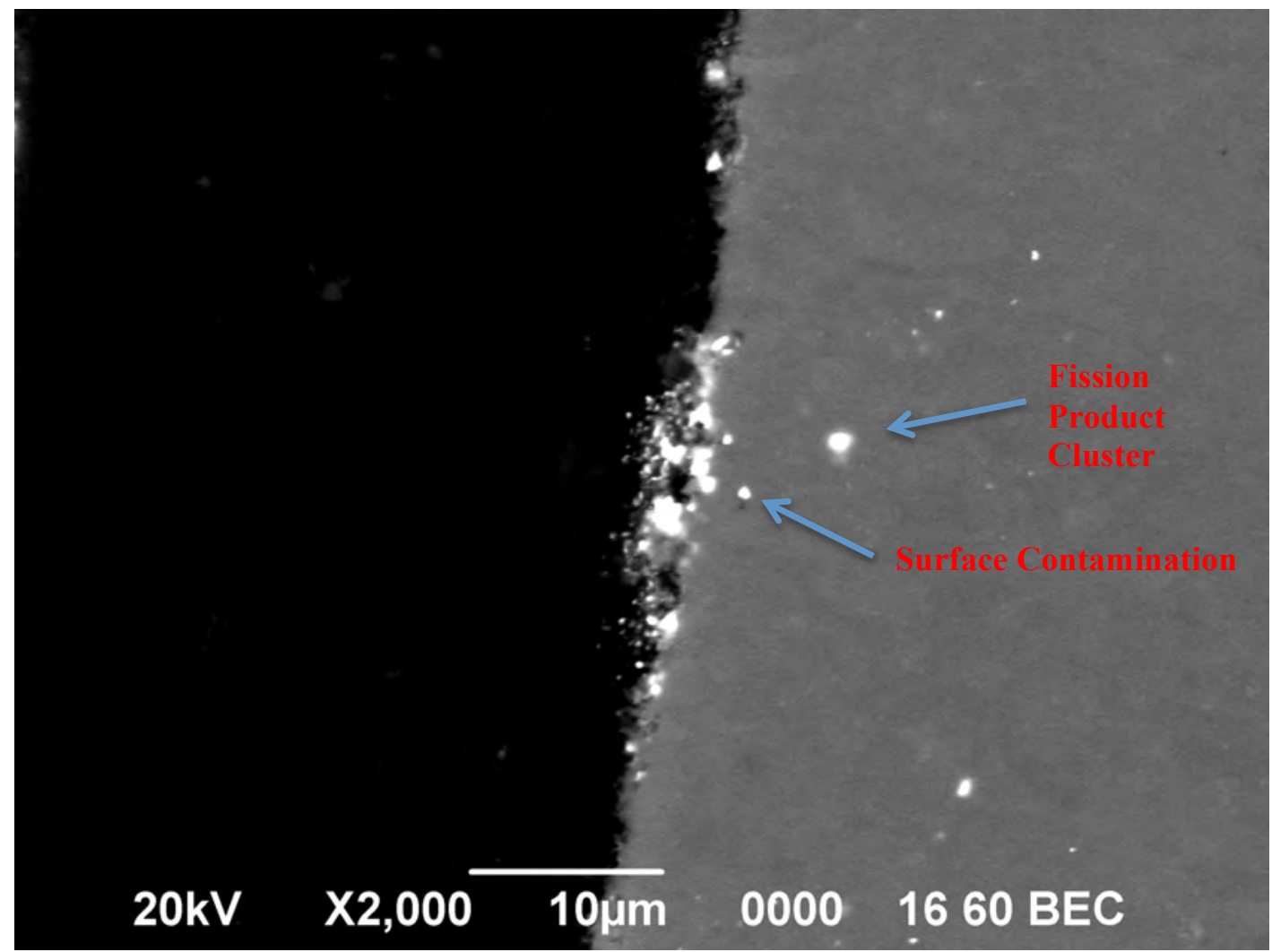

Figure 60. BSE image of Particle Ag-18 IPyC/SiC interface (Mount 6357) showing embedded FP clusters and surface contamination.

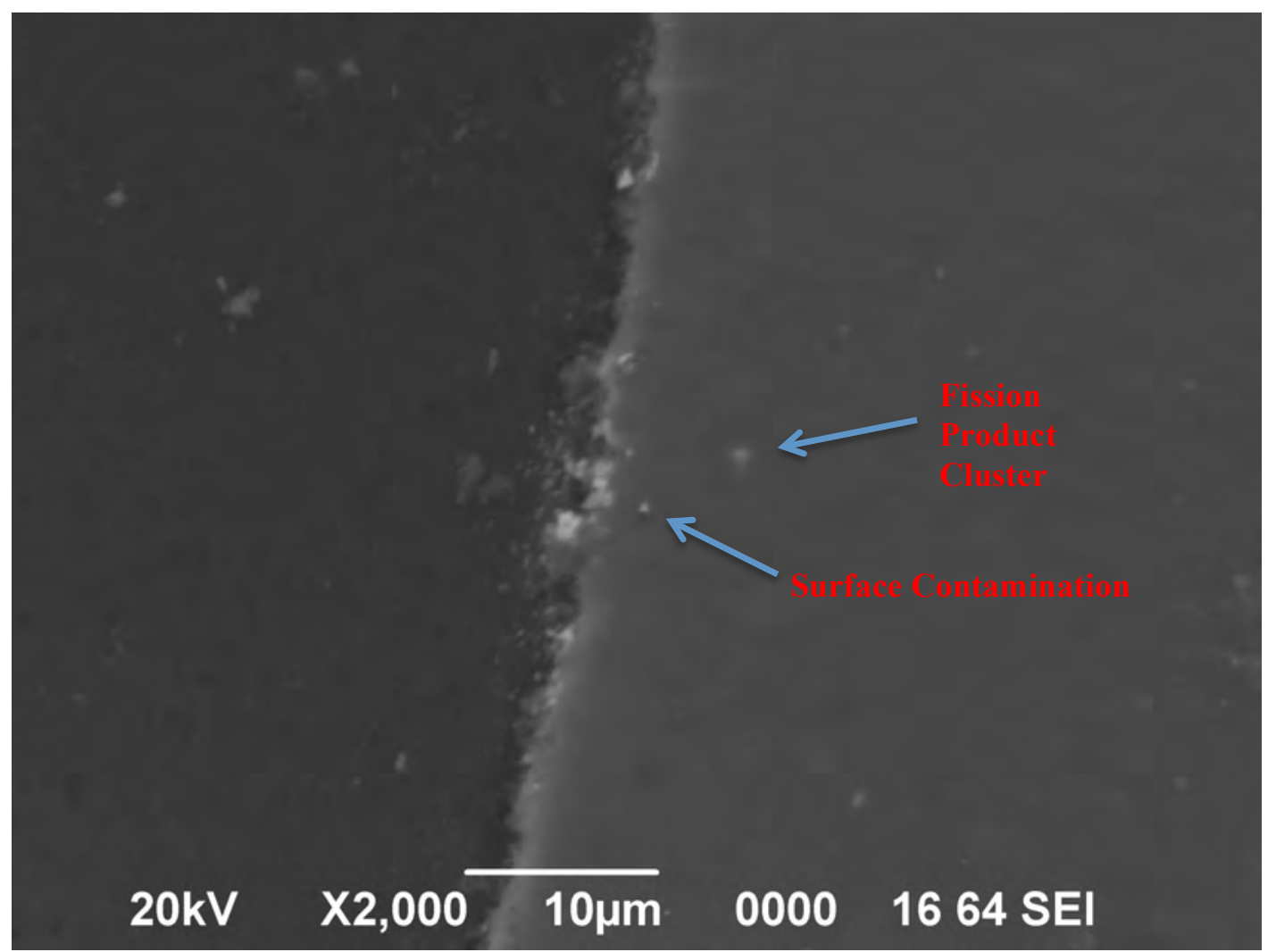

Figure 61. SE image of the same area on Particle Ag-18 shown in Figure 60 showing different appearance for embedded FP clusters and surface contamination. 


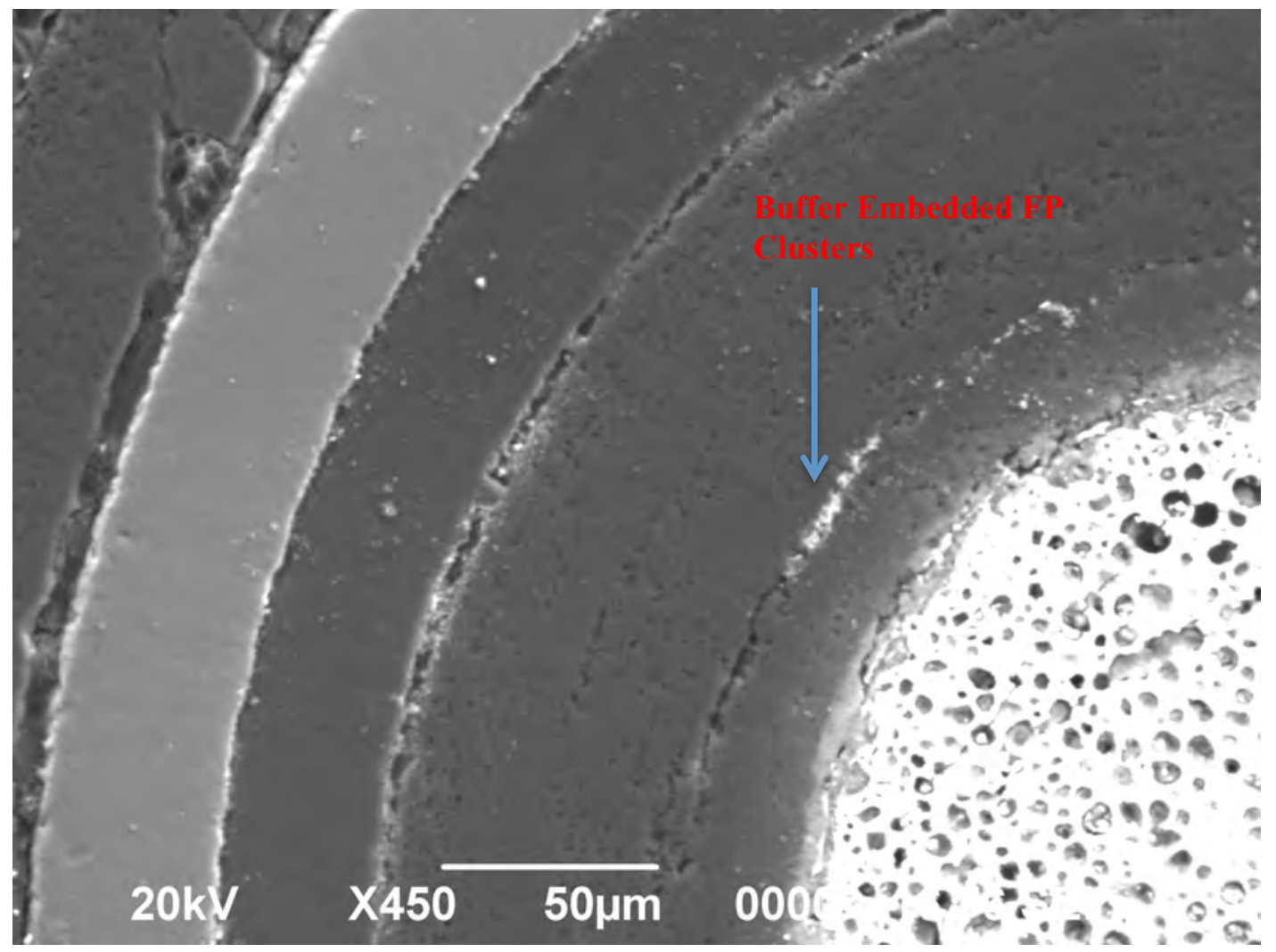

Figure 62. BSE image of Particle Ag-14 with below average ${ }^{110 \mathrm{~m}} \mathrm{Ag}$ inventory (Mount 6357) showing clustering of FPs in buffer disruptions.

\section{Chemical Analysis of Fission Product Clusters}

WDS and EDS were employed simultaneously for elemental analysis of the observed FP features at several locations of interest. The use of EDS and WDS in concert is often necessary to accurately resolve the presence of trace elements in the sample, such as was the case for the Ce analysis discussed below. Analysis was conducted on the FPs located at the buffer disruptions, IPyC/SiC interface, and $\mathrm{FP}$ clusters embedded in the $\mathrm{SiC}$. Analysis of the Cs concentration in each TRISO layer was also performed.

EDS was employed to determine the major and minor constituent elements. EDS analysis was conducted at $20 \mathrm{kV}$ with 2000 channels, $0-40 \mathrm{keV}$ range detector set-up with a $120 \mathrm{sec}$ count time, resulting in a $30-40 \%$ dead time. The $0-40 \mathrm{keV}$ range was selected to improve deadtime, as the $0-20 \mathrm{keV}$ range resulted in poor counting efficiency. Following EDS analysis, WDS was employed to differentiate between possible peak interference situations and to determine the presence of trace elements. The WDS detector was equipped with LiF, pentaerythritol (PET), and thallium acid pthalate (TAP) crystals, which allowed characteristic $x$-ray wavelengths to be collected from 1.14-23.78 $\AA$. This range allowed for most elements to be determined, with the exception of the lighter elements $(Z<8)$ with characteristic $x$-ray wavelengths greater than $23.78 \AA$. The dominant $x$-ray lines were calibrated for each element of interest using standards from Geller Microanalytical Laboratory, certified to ISO-9001 and 17025 standards. WDS analysis focused on $\mathrm{Ag}, \mathrm{Cs}, \mathrm{Pd}$, and $\mathrm{U}$ detection and trace element confirmation. WDS wavescans were performed on the features of interest in lieu of automated peak identification routines performed by the INCA software suite to confirm the presence of the elements of interest. Wavescans were acquired at two different acquisition rates depending on the abundance of the elements of interest. Scan speed $5(0.25$ seconds per $0.868 \mathrm{~m} \AA$ ) was selected for major constituent elements while scan speed 3 ( 0.5 seconds per $0.434 \mathrm{~m} \AA$ ) was selected for trace element analysis. Limited range sans for specific elements could be acquired in 0.5-2 min, wide spectrum scans could take up to $30 \mathrm{~min}$. 
Complications in EDS and WDS analysis arose from sample drift due to localized charging of the non-conductive epoxy used for backpotting. Drifting was observed on the order of 1-5 $\mu \mathrm{m}$ over the duration of the EDS and WDS wavescan acquisition. The small feature size, in combination with sample drift, resulted in the features of interest drifting out of range of the interaction volume in the standard point acquisition mode available in the INCA analysis suite. To combat this issue, EDS spectra and WDS wavescans were obtained while imaging the features at high magnifications, $30 \mathrm{kX}-100 \mathrm{kX}$, and the sample was repositioned periodically during the duration of the acquisition to ensure the feature of interest was continually probed. The observed drift, as well as the fact that many features were small compared to the probe interaction volume at $20 \mathrm{kV}\left(\sim 1 \mu \mathrm{m}^{3}\right)$, often resulted in some material surrounding the FP cluster contributing directly to the acquired spectra. Because the acquired spectra contained unknown contributions from the surrounding material, no attempts were made to provide quantitative analysis of the fission product clusters. To overcome the probe size issues, use of a transmission electron microscope (TEM) to survey the features of interested is recommended due to the nanometer spatial resolution.

EDS analysis of a buffer embedded fission product clusters (Figure 63) indicated the major constituent elements to be $\mathrm{C}, \mathrm{Cs}, \mathrm{O}, \mathrm{Si}$ and $\mathrm{U}$, with $\mathrm{Si}$ being a minor element. Trace elements of $\mathrm{Ce}, \mathrm{S}, \mathrm{Ti}$, and $\mathrm{W}$ were also identified by the INCA software suite. However, many of these trace elements were ruled out as spurious peaks or lower intensity transitions from the major constituent elements. For instance, Figure 64 shows a WDS wavescan from 2.48-2.94 $\AA$, which should show a high intensity Ce $\mathrm{L}_{\alpha 1}$ line at $2.562 \AA$ if Ce was present as indicated by the INCA EDS automatic peak analysis. In Figure 64, no counts are observed at the $2.562 \AA$ wavelength, indicating that the INCA software incorrectly identified the lower intensity Cs transition lines as Ce because of similarities in the characteristic x-ray energies. WDS possesses improved energy resolution and sensitivity over EDS, so the $\mathrm{Ce}_{\alpha 1}$ line can be distinguished from the Cs lines. Similarly, the peak identified in the EDS spectrum as Ti $\mathrm{K}_{\alpha 1}$ was actually the $\mathrm{Cs}_{\beta 3}$ line.

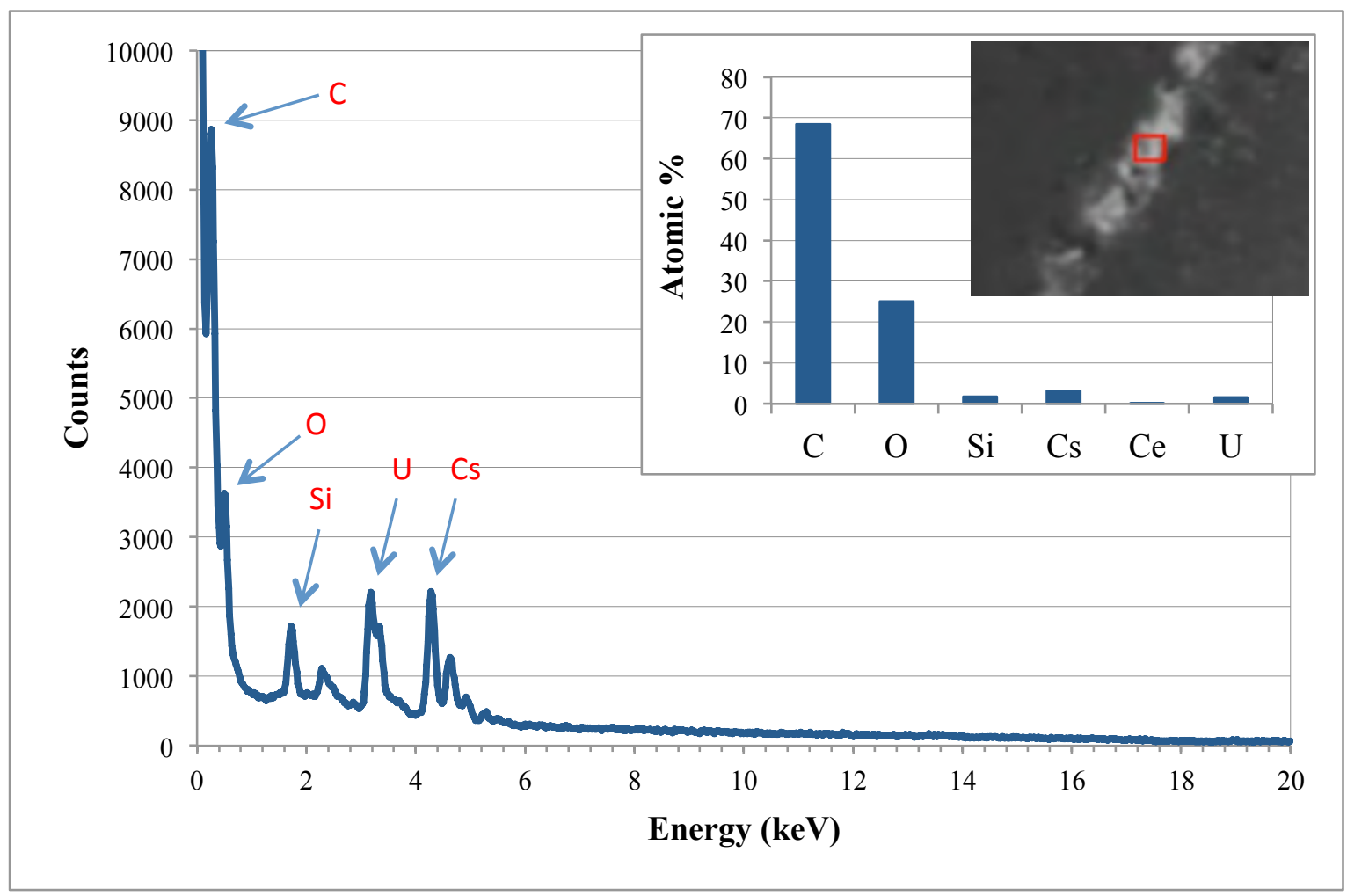

Figure 63. EDS spectrum of a buffer FP inclusion. 


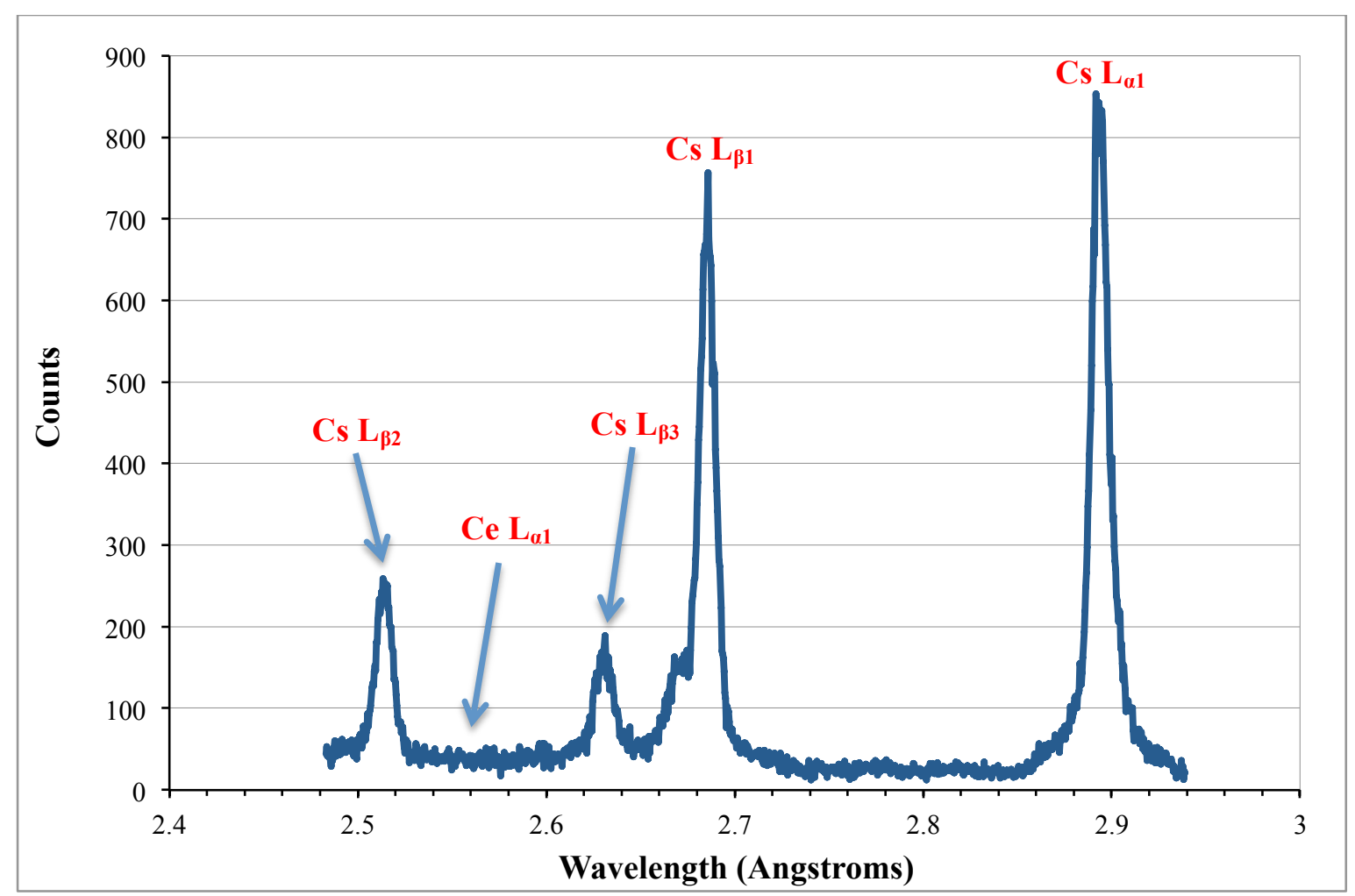

Figure 64. WDS wavescan on PET crystal from 2.48-2.94 $\AA$ indicating there was no Ce present in the buffer FP inclusion shown in Figure 63, in contrast to EDS analysis.

The distribution of $\mathrm{Cs}$ in the TRISO particle was investigated by moving radially outward across each TRISO layer. Figure 65 shows the regions of interest included in the analysis of a particle with a kernel that had extruded to the point where it was in contact with the IPyC layer (Particle Ag-18 in Figure 54). Table 9 shows the relative intensity of the major $\mathrm{Cs}_{\alpha 1}$ line at $2.892 \AA$ for each region of interest. The largest $\mathrm{Cs}_{\mathrm{L}} \mathrm{L}_{\alpha 1}$ peak was found near the kernel/IPyC interface. The $\mathrm{Cs}_{\mathrm{\alpha}} \mathrm{L}_{\alpha 1}$ intensity decreased in the IPyC interior and increased at the $\mathrm{IPyC} / \mathrm{SiC}$ interface. No detectible $\mathrm{Cs} \mathrm{L}_{\alpha 1}$ counts were observed in the $\mathrm{SiC}$ layer while a large concentration was observed at the $\mathrm{SiC} / \mathrm{OPyC}$ interface. Trace $\mathrm{Cs}_{\alpha 1}$ counts were observed in the interior of the OPyC and no detectable $\mathrm{Cs}_{\mathrm{\alpha} 1}$ intensity was observed on the epoxy away from the sample. The observation of Cs outside the $\mathrm{SiC}$ contradicts the LBL observation that Cs was retained in the particles, suggesting that the Cs observed outside the TRISO particle is a sample preparation artifact. There is a large source for Cs contamination in the IFEL hot cells. Figure 65 shows a large gap at the $\mathrm{SiC} / \mathrm{OPyC}$ interface, caused by chipping of the outer edge of the $\mathrm{SiC}$ during grinding. It is likely that debris is deposited in this gap during polishing. Debris may also be trapped in any open pores during polishing, resulting in variation in Cs intensity in the pyrocarbon layers. Some of the observed variation in Cs contamination, particularly the fact that the IPyC near the kernel extrusion contained more Cs than the more porous buffer, suggests that at least some of the Cs may be fission products from the kernel. However, the possibility for contamination makes accurate determination of Cs distribution difficult. Similar analysis for the general distribution of other FPs can present the same analysis uncertainty. As previously mentioned, ultrasonic cleaning greatly reduces FP inclusion from sample preparation and would be beneficial for reducing the uncertainty in this elemental analysis. 


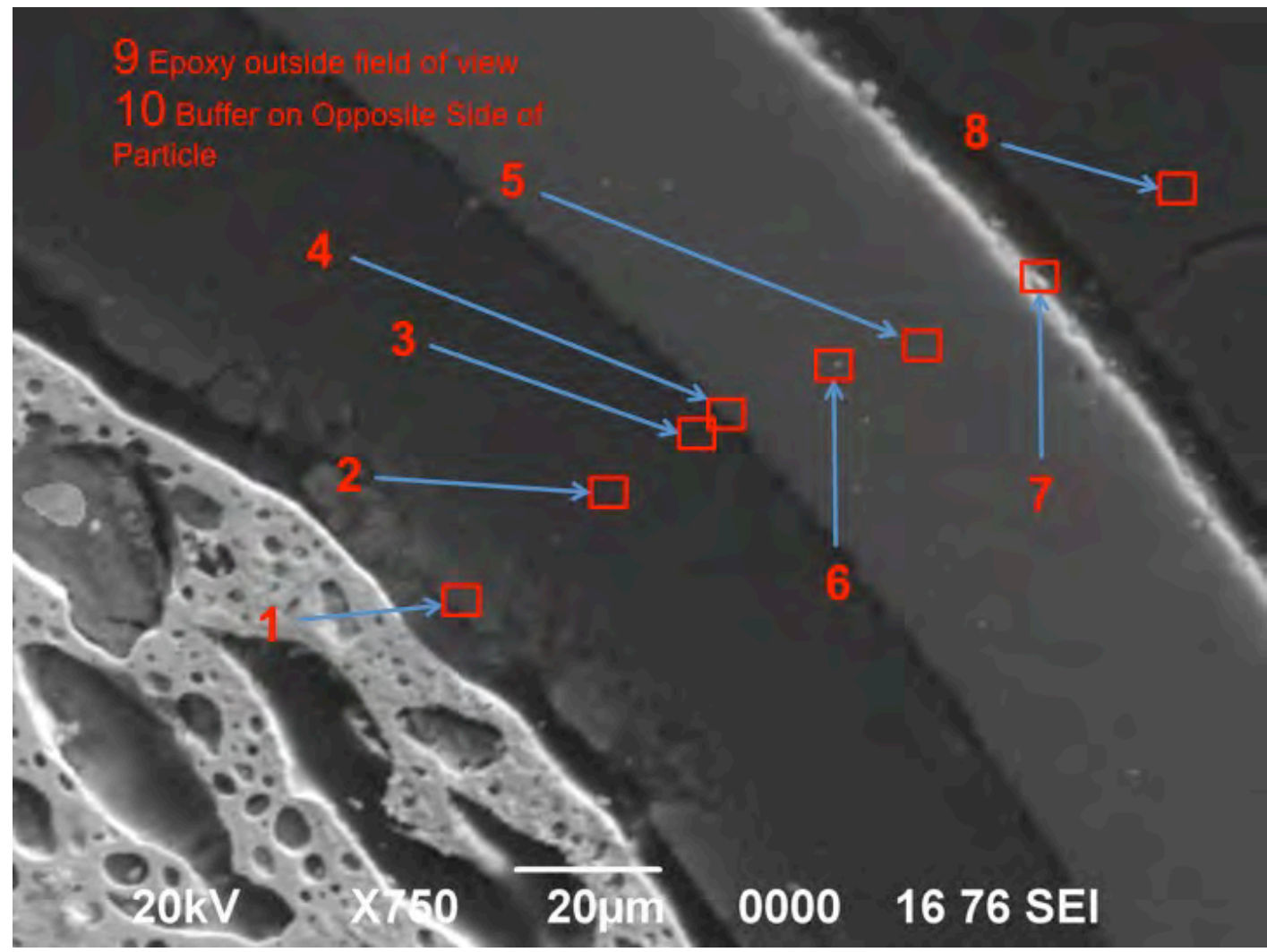

Figure 65. Regions of interest used for Cs distribution analysis, conducted on Particle Ag-18.

Table 9. Survey of Cs distribution in Particle Ag-18

\begin{tabular}{|c||c|c|}
\hline Region of Interest & Description of Region & Counts in Cs $\mathbf{L}_{\boldsymbol{\alpha} \mathbf{1}}$ Peak \\
\hline \hline 1 & Kernel/IPyC & $226 \mathrm{cts}$ \\
\hline 2 & Middle of IPyC & $41 \mathrm{cts}$ \\
\hline 3 & Near IPyC/SiC & $30 \mathrm{cts}$ \\
\hline 4 & IPyC/SiC & $50 \mathrm{cts}$ \\
\hline 5 & Embedded FP & Background \\
\hline 6 & Middle of SiC & Background \\
\hline 7 & SiC/OPyC & $80 \mathrm{cts}$ \\
\hline 8 & Middle of OPyC & $21 \mathrm{cts}$ \\
\hline 9 & Epoxy & Background \\
\hline 10 & Opposite Side Buffer & $58 \mathrm{cts}$ \\
\hline
\end{tabular}

The composition of the fission product clusters at the IPyC/SiC interface was determined to be predominantly $\mathrm{Pd}, \mathrm{Si}$, and $\mathrm{U}$. In some instances Cs concentrations were also observed, however, as discussed above, Cs is a contamination source in the hot cell and it cannot be determined if the Cs observed at the cluster locations was due to Cs migration during the irradiation test and co-trapping with the other FPs observed. The relative Cs concentration appeared to vary for individual clusters and was therefore likely due to contamination. The inclusion of the $\mathrm{SiC}$ matrix in the probe interaction volume during WDS acquisition also makes confirmation of the Si concentration in the FP cluster difficult to determine. However, the consistent presence of $\mathrm{Pd}$ and $\mathrm{U}$, in the absence of other fission products, provides strong evidence that these elements did not come from sample preparation. 
Figure 66 shows a typical IPyC/SiC FP cluster and Figure 67 shows the WDS wave scan of this FP cluster. The wavescan confirms the presence of $\mathrm{Pd}$ and $\mathrm{U}$, showing the peaks for $\mathrm{Pd}_{\alpha 1}(2.838 \mathrm{keV}$, $4.368 \AA), \mathrm{Pd} \mathrm{L}_{\beta 1}(2.990 \mathrm{keV}, 4.146 \AA), \mathrm{U} \mathrm{M}_{\alpha 1}(3.170 \mathrm{keV}, 3.91 \AA)$, and $\mathrm{U} \mathrm{M}_{\beta 1}(3.337 \mathrm{keV}, 3.716 \AA)$. The incorporation of overlapping signal from the $\mathrm{SiC}$ makes quantitative determination of the Si content in the FP cluster impossible, as the contribution of the $\mathrm{SiC}$ to the $\mathrm{Si} \mathrm{K}_{\alpha 1}$ intensity varied depending on the amount of $\mathrm{SiC}$ included in the probe area. However, a comparison of the $\mathrm{Pd} \mathrm{L}_{\alpha 1}$ and $\mathrm{U} \mathrm{M}_{\alpha 1}$ intensities from EDS and WDS gives insight into the Pd-U stoichiometry. Table 10 presents WDS and EDS analysis of IPyC/SiC FP clusters from multiple particles for the dominant Pd and U x-ray intensities. WDS analysis suggests a $\mathrm{Pd}: \mathrm{U}$ count ratio near 1 , while ESD analysis suggests $[\mathrm{Pd}]:[\mathrm{U}]$ ratio of 2.4-3.4:1. The consistency of the WDS count ratio suggests a constant FP concentration, while the variation in the reported EDS concentration ratios were likely due to variations in Si and $\mathrm{C}$ intensities from the surrounding material ( $\mathrm{SiC}$ and $\mathrm{IPyC}$ ) leading to error in calculated concentrations, as well as the limitations of EDS in the determination of light elements such a C. In addition, one IPyC/SiC FP cluster, in Mount 6355 with the $\mathrm{Au}$ coating, showed trace concentrations of $\mathrm{Nd}$ and $\mathrm{Ce}$. The wavescans confirming the presence of trace $\mathrm{Ce}_{\alpha 1}$ and $\mathrm{Nd} \mathrm{L}_{\alpha 1}$ peaks are shown in Figure 68.

Table 10. Pd:U ratio in several IPyC/SiC fission product clusters

\begin{tabular}{|c|c||c|c|c|c|c|c|}
\hline \multirow{2}{*}{ Mount } & \multirow{2}{*}{ Particle } & \multicolumn{3}{|c|}{ WDS (counts) } & \multicolumn{3}{c|}{ EDS (at\%) } \\
\cline { 2 - 8 } & & $\mathrm{Pd} \mathrm{L}_{\alpha 1}$ & $\mathrm{U} \mathrm{M}_{\alpha 1}$ & Ratio & {$[\mathrm{Pd}]$} & {$[\mathrm{U}]$} & Ratio \\
\hline \hline 6357 & Ag-18 & 35 & 31 & 1.13 & Trace & Trace & - \\
\hline 6355 & Typical & 58 & 68 & 0.85 & 33.0 & 9.8 & 3.37 \\
\hline 6357 & Ag-14 & 150 & 135 & 1.11 & 13.7 & 5.7 & 2.40 \\
\hline
\end{tabular}

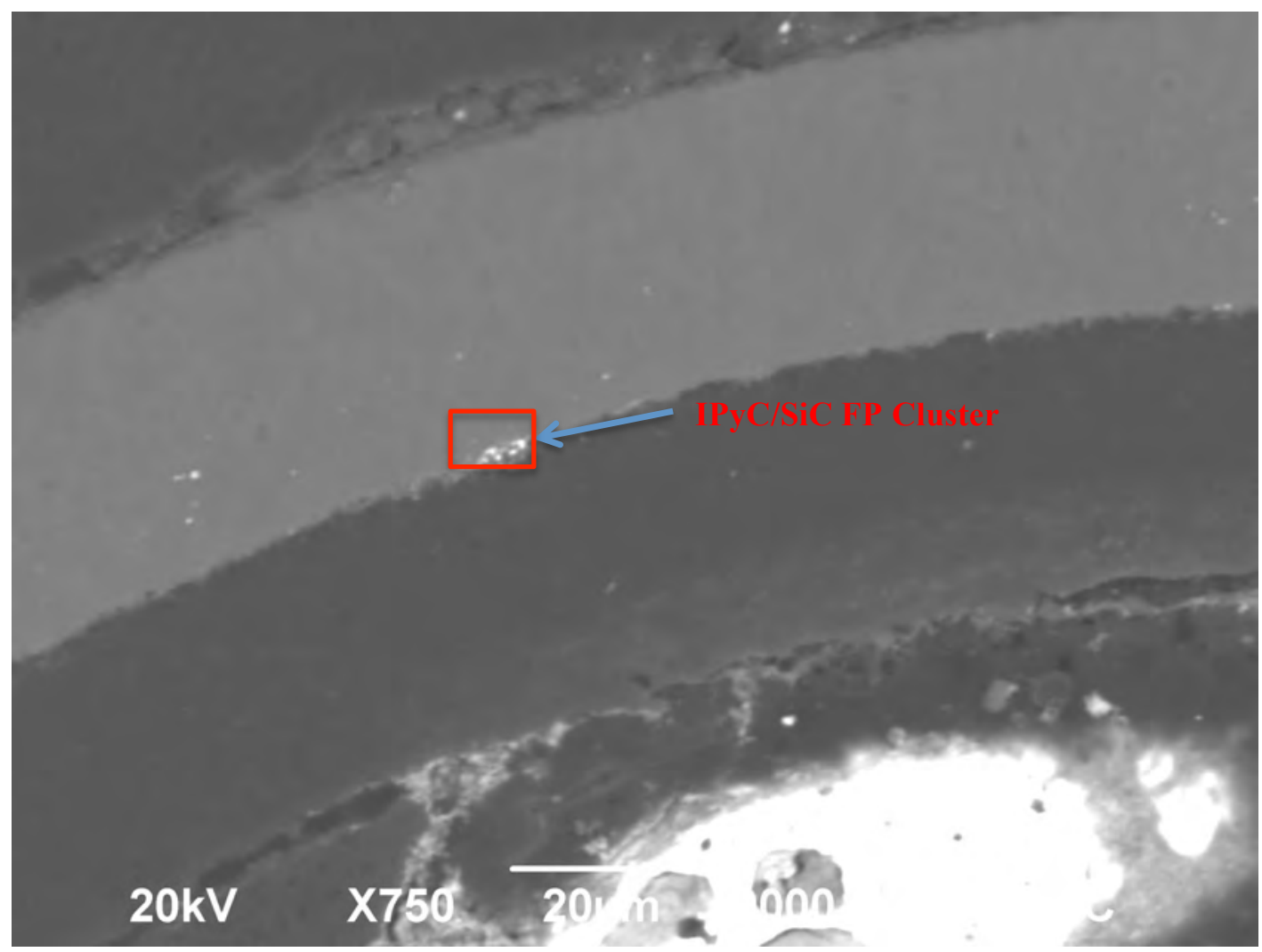

Figure 66. BSE image indicating embedded FP cluster at IPyC/SiC interface in Particle Ag-14, analyzed by WDS (wavescan in Figure 62). 


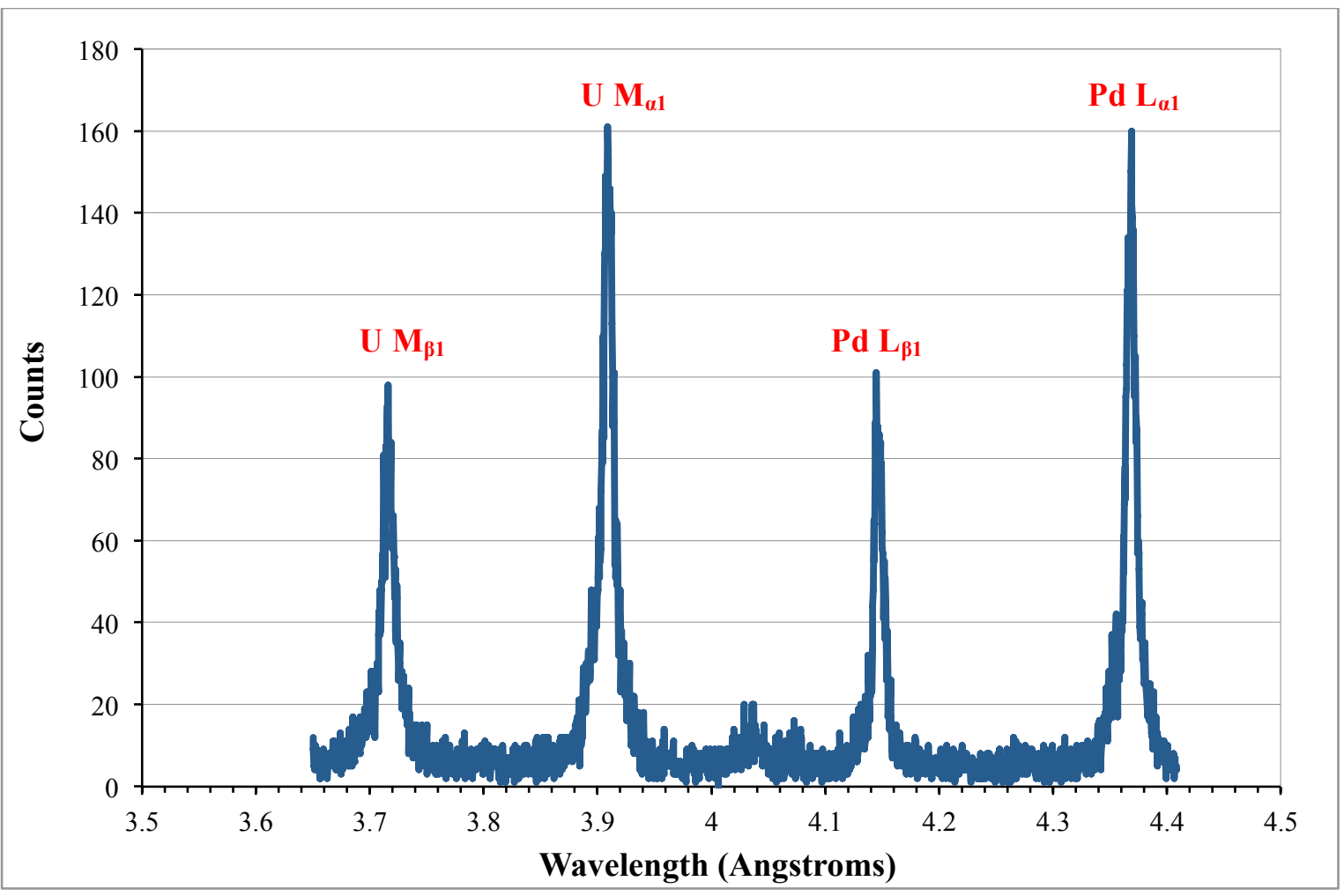

Figure 67. WDS wavescan on PET crystal from 3.65-4.41 ̊̊ of Particle Ag-14 indicating Pd and U in the FP cluster at IPyC/SiC interface.

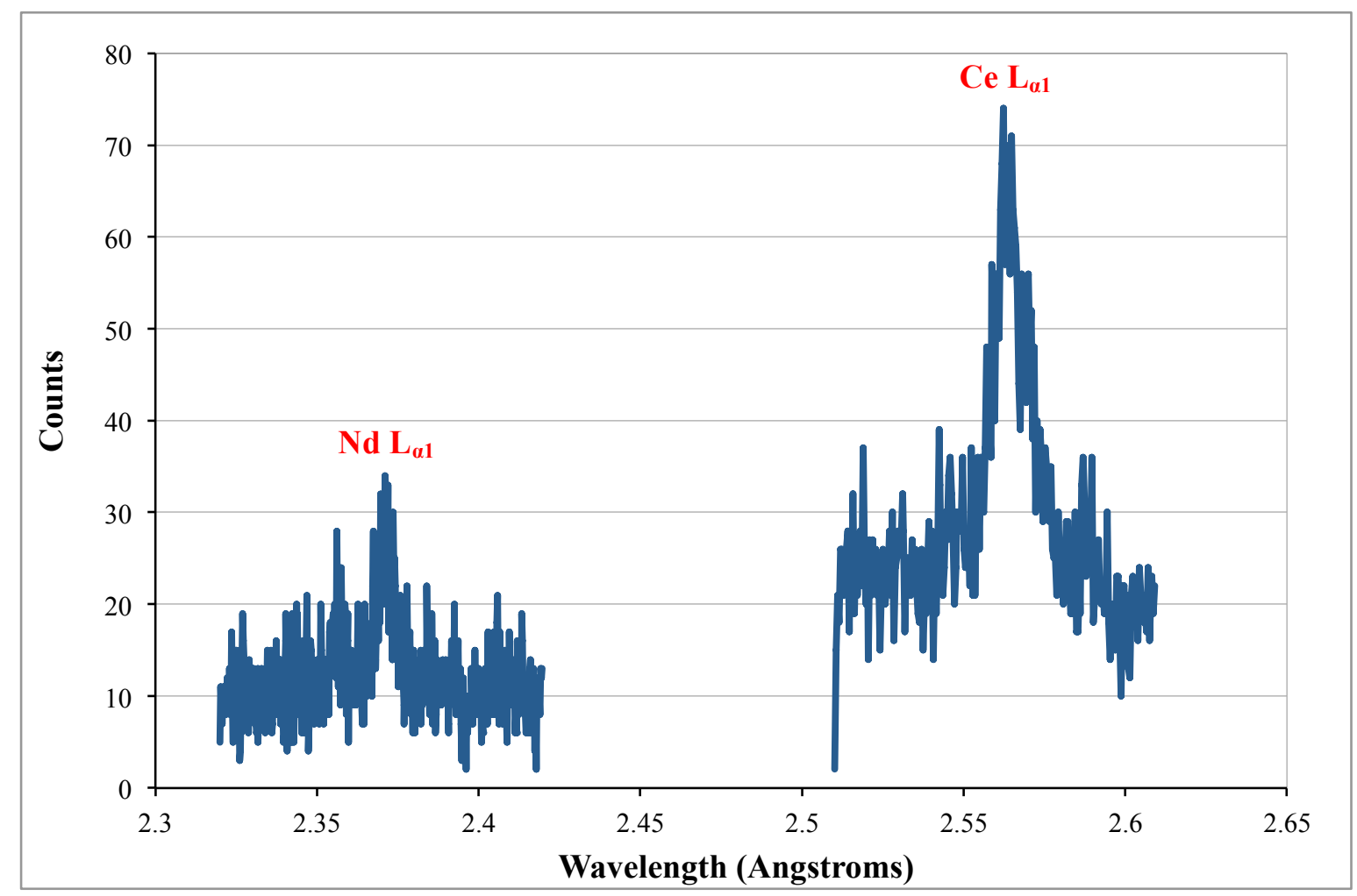

Figure 68. WDS wavescans on LiF crystal from 2.32-2.42 $\AA$ and PET crystal from 2.51-2.61 $\AA$ of the normal particle in Mount 6355 indicating $\mathrm{Ce}$ and $\mathrm{Nd}$. 
EDS and WDS analysis of the FPs embedded in the SiC layer was also performed. Again, the specific composition could not be determined due to the small particle size compared to the interaction volume resulting in contributions from the surrounding $\mathrm{SiC}$, but all $\mathrm{FP}$ clusters found in the $\mathrm{SiC}$ layer and analyzed by WDS indicated the presence of Pd-Si-U, with no other major constituents. Figure 69 shows the embedded FP of interest for the WDS wavescan presented in Figure 70, which shows the embedded FP particle contained Pd and U. As was done in Table 10 for the FP clusters at the IPyC/SiC interface, the ratios of the X-ray intensities were compared to gain insight on the $\mathrm{Pd}$ and $\mathrm{U}$ concentrations in the $\mathrm{SiC}$ embedded FP cluster in Figure 69. The EDS concentrations and WDS count ratios suggest the composition of the embedded FP cluster and IPyC/SiC fission product clusters are similar. The WDS count ratios observed in the embedded FP cluster coincided with the observed 1:1, $\mathrm{Pd} \mathrm{L}_{\alpha 1}: \mathrm{U} \mathrm{M}_{\alpha 1}$ intensity from the IPyC/SiC FP clusters. The EDS analysis again suggested an $\sim 3: 1$, Pd:U concentration, presumably owing to the same difficulties in the EDS analysis.

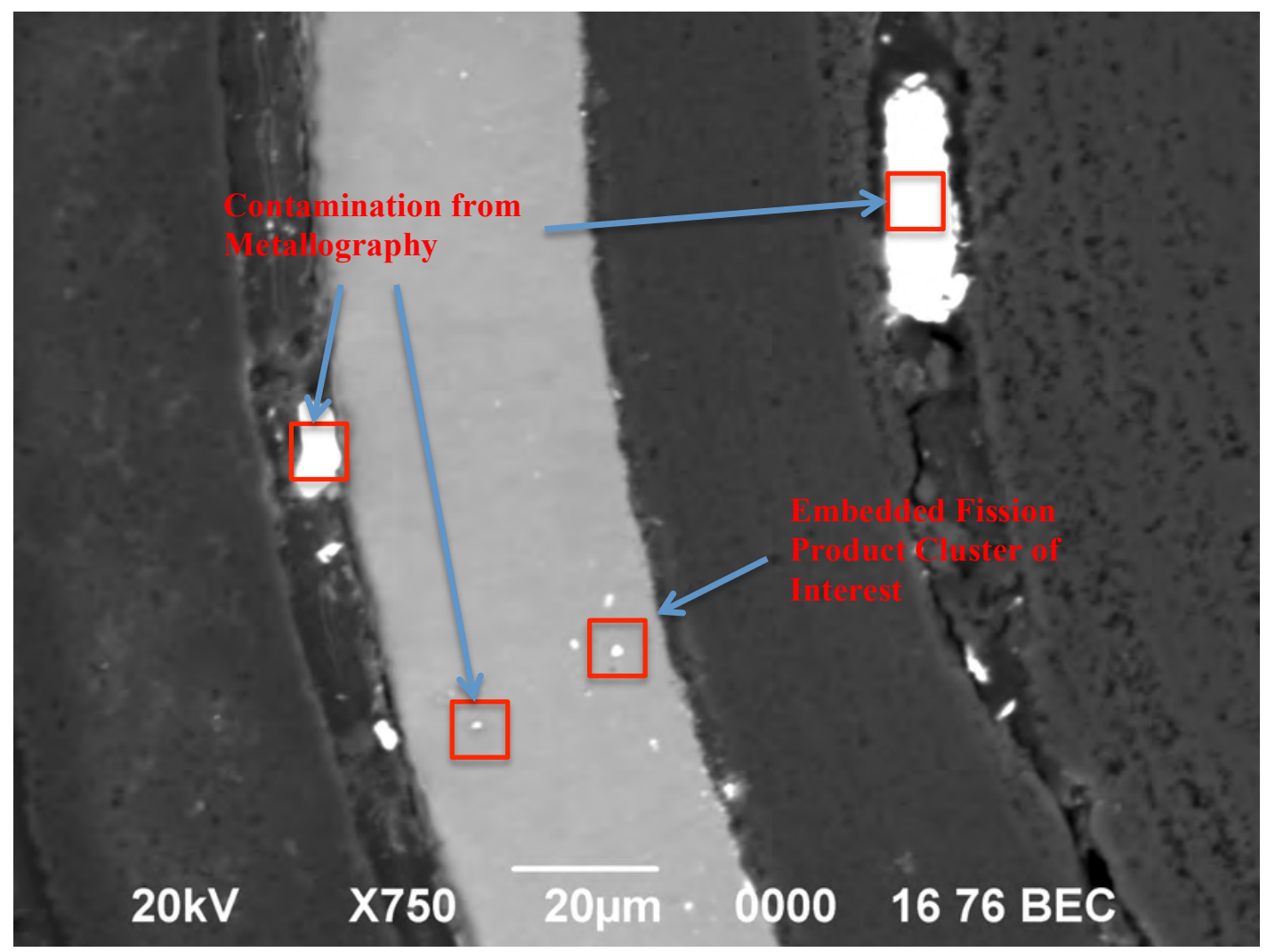

Figure 69. BSE image indicating embedded FP cluster in Particle Ag-51 analyzed by WDS (wavescan in Figure 65).

Figure 69 shows contamination on the sample surface and embedded at the SiC/OPyC interface. This contamination was confirmed to be iron oxide, calcium oxide, and $\mathrm{Cu}$ by EDS analysis of the features marked in the figure. This contamination was commonly found in the particles analyzed. The contamination was mostly distributed randomly on the surface, with $\mathrm{Cu}$ preferentially located at the $\mathrm{IPyC} / \mathrm{SiC}$ and $\mathrm{OPyC} / \mathrm{SiC}$ interfaces. The source of contamination was likely from the water used during the sample preparation and contamination picked up during metallographic preparation (Struer's Allegro discs contain soft iron). This contamination complicates the identification of FP clusters and needs to be addressed during analysis. Ultrasonic cleaning with distilled water and isopropanol should remove this type of surface contamination. 


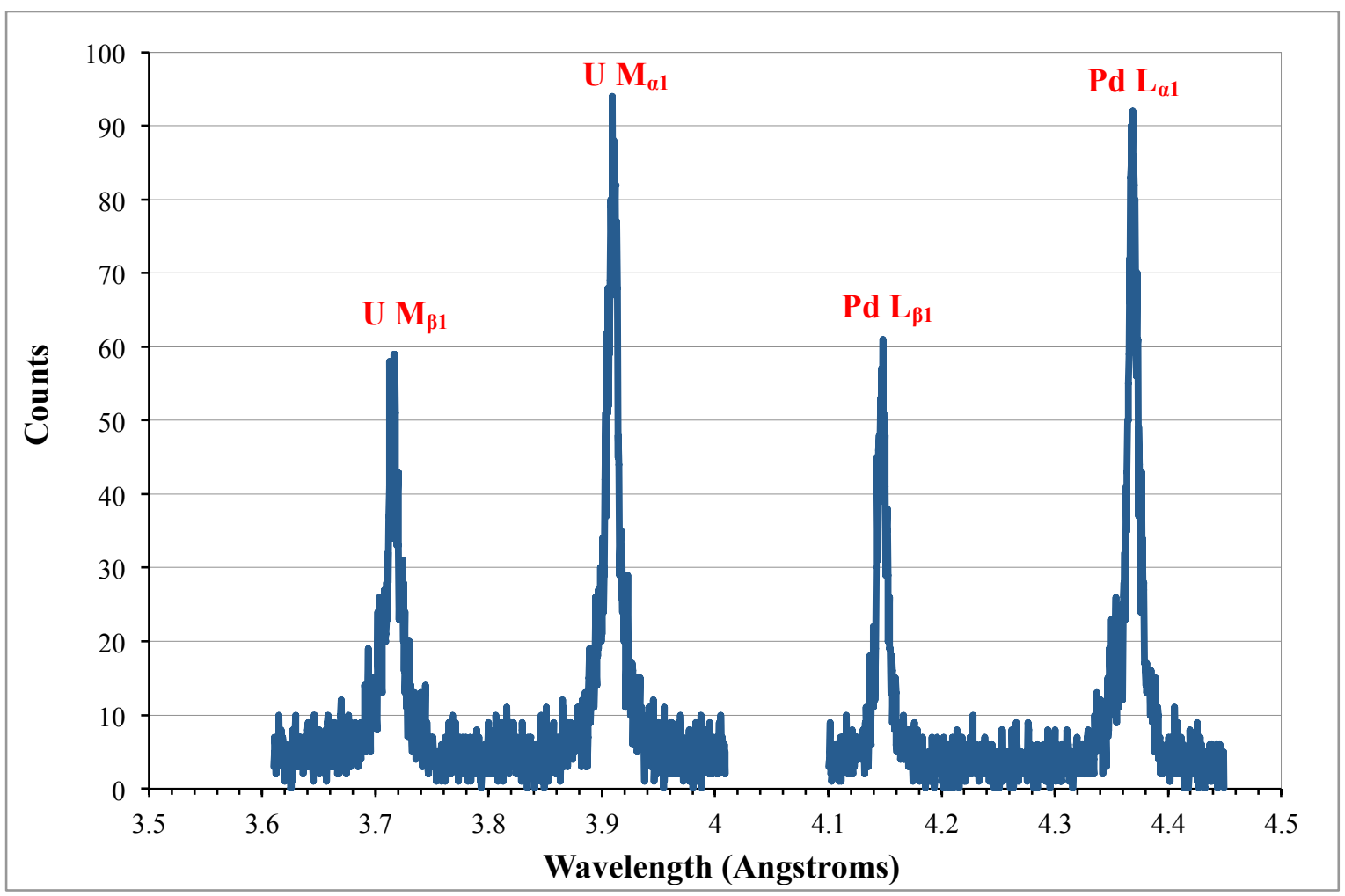

Figure 70. WDS wavescans on PET crystal from 3.65-4.01 $\AA$ and 4.10-4.41 $\AA$ of Particle Ag-51 indicating $P d$ and $U$ in the FP cluster.

Because it has shown the greatest release fraction in the DLBL and IMGA analysis, detection of silver in the SEM analysis of the TRISO particles is of primary importance and analysis may give rise to a greater understanding of the release mechanism. However, in the current analysis, no $\mathrm{Ag}$ has been confirmed in the IPyC/SiC or $\mathrm{SiC}$ embedded fission product clusters. The presence of $\mathrm{Pd}$ and $\mathrm{U}$ presents a unique challenge to the confirmation of $\mathrm{Ag}$ in the observed fission product clusters due to $\mathrm{x}$-ray overlap. The high intensity $A g \mathrm{~L}_{\alpha 1}$ and $\mathrm{Ag} \mathrm{L}_{\beta 1}$ lines exist at $2.984 \mathrm{keV}(4.154 \AA)$ and $3.150 \mathrm{keV}(3.935 \AA)$, respectively. In the Ag-Pd-U system, the $\mathrm{Pd} \mathrm{L}_{\beta 1}$ line $(2.990 \mathrm{keV}, 4.146 \AA)$ interferes with the $\mathrm{Ag} \mathrm{L}_{\alpha 1}$ and the $\mathrm{U} \mathrm{M}_{\alpha 1}$ line $(3.170 \mathrm{keV}, 3.91 \AA)$ interferes with $\mathrm{Ag} \mathrm{L}_{\beta 1}$. The similarities in the energies challenge the detector resolution for both detection of the $\mathrm{Ag} \mathrm{L}_{\alpha 1}$ and $\mathrm{Ag} \mathrm{L}_{\beta 1}$ lines. As previously discussed, Figure 67 and Figure 70 show WDS wavescans spanning these characteristic X-ray wavelengths for FP clusters at the $\mathrm{IPyC} / \mathrm{SiC}$ interface and in the $\mathrm{SiC}$, respectively. The silver peaks cannot be resolved, neither the $\mathrm{Ag} \mathrm{L}_{\alpha 1}$ next to the $\mathrm{Pd} \mathrm{L}_{\beta 1}$ line nor the $\mathrm{Ag} \mathrm{L}_{\beta 1}$ next to the $\mathrm{U} \mathrm{M}_{\alpha 1}$ line.

The Ag to Pd calculated inventories at end of irradiation for Compact 6-1-1 [Sterbentz 2011] are in a $\mathrm{Ag}: \mathrm{Pd}$ ratio of $\sim 0.05$, considering the abundance of the ${ }^{109} \mathrm{Ag}$ and ${ }^{110 \mathrm{~m}} \mathrm{Ag}$ isotopes versus the ${ }^{104} \mathrm{Pd}$ through ${ }^{108} \mathrm{Pd}$ isotopes. This could impact the resolution of the $\mathrm{Ag} \mathrm{L}_{\alpha 1}$ line versus the $\mathrm{Pd} \mathrm{L}_{\beta 1}$ line. Given the intensity of the observed $\mathrm{Pd} \mathrm{L}_{\alpha 1}$ lines at $4.368 \AA$, at this ratio, the $\mathrm{Ag} \mathrm{L}_{\alpha 1}$ line would not be detected above the background spectrum for the acquisition conditions employed. However, the DLBL analysis (Table 2 and Table 3) indicated that the fraction of the calculated inventory of silver in the compact outside the SiC layer was a factor of 10 higher than the compact fraction for palladium. In addition, survey of the capsule 6 components indicated $38 \%$ of the calculated ${ }^{110 \mathrm{~m}} \mathrm{Ag}$ inventory was released from the 12 compacts in the capsule. This corresponds to a molar ratio of $\mathrm{Ag}: \mathrm{Pd}$ of close to 1. Therefore, it is not clear that the Pd would dominate the WDS spectra, if these two elements were released in conjunction.

To attempt to overcome the issues of $\mathrm{Ag}$ detection, EDS analysis using a $30 \mathrm{kV}$ accelerating voltage and $0-40 \mathrm{keV}, 20 \mathrm{eV}$ per channel detector setup will be employed in future analysis. The higher energy range should allow for the $\mathrm{Ag} \mathrm{K} \mathrm{K}_{\alpha 1}$ line at $22.163 \mathrm{keV}$ to be investigated, as the accelerating voltage will exceed the critical excitation energy for that line. The $\mathrm{Ag} \mathrm{K}_{\alpha 1}$ is isolated and has no expected interference lines from Pd or U. The detection limits of EDS are near 1 at\%, suggesting that even a small amount of 
silver colocated with the palladium may be detected under these conditions. The sensitivity of the analysis can also be increased in future analysis by utilizing longer acquisition times to increase the peak counts above background.

\section{SiC Microstructure}

High contrast BSE imaging can be used to observe the $\mathrm{SiC}$ microstructure. The crystal orientation dependence in the electron stopping power and backscattering cross section results in contrast between $\mathrm{SiC}$ grains of different orientation. Figure 71 and Figure 72 show examples of BSE imaging of the $\mathrm{SiC}$ grain structure in two unirradiated AGR-1 Baseline particles. Grain boundaries and twinning within individual grains are readily discernable. The AGR-1 Baseline fuel was made from a composite of four coating batches. One of the batches exhibited a finer average grain structure than the other three, examples of each are shown. To observe the $\mathrm{SiC}$ microstructure a clean, well polished, and damage free surface is important. A final polishing step using $0.05 \mu \mathrm{m}$ OP-S solution is very beneficial in achieving the surface quality needed to image the $\mathrm{SiC}$ microstructure. For observation of $\mathrm{SiC}$ microstructure in the irradiated fuel samples, the imaging conditions used for the high contrast BSE imaging were $20 \mathrm{kV}, 64$ spot size setting, and 9-10 mm working distance, with low brightness and excess contrast on the detector. $\mathrm{SiC}$ microstructure was imaged on Particles Ag-14 and Ag-18 (below average ${ }^{110 \mathrm{~m}} \mathrm{Ag}$ inventory) and Particle Ag-51 (no detectable ${ }^{110 \mathrm{~m}} \mathrm{Ag}$ inventory). None of these particles were Au coated. Au coating scatters the electrons, which interferes with the imaging and does not allow clear microstructural analysis. Figure 73, Figure 74, and Figure 75 show the high contrast BSE micrographs of Particles Ag-14, Ag-18, and Ag-51, respectively. Additional effort will be required to optimize the sample preparation and imaging conditions on the hot cell SEM, but these initial attempts show promise for the method. With additional optimization, the location of embedded fission products can be correlated to the $\mathrm{SiC}$ microstructure and the possible relationship between grain structure and silver retention can be analyzed.

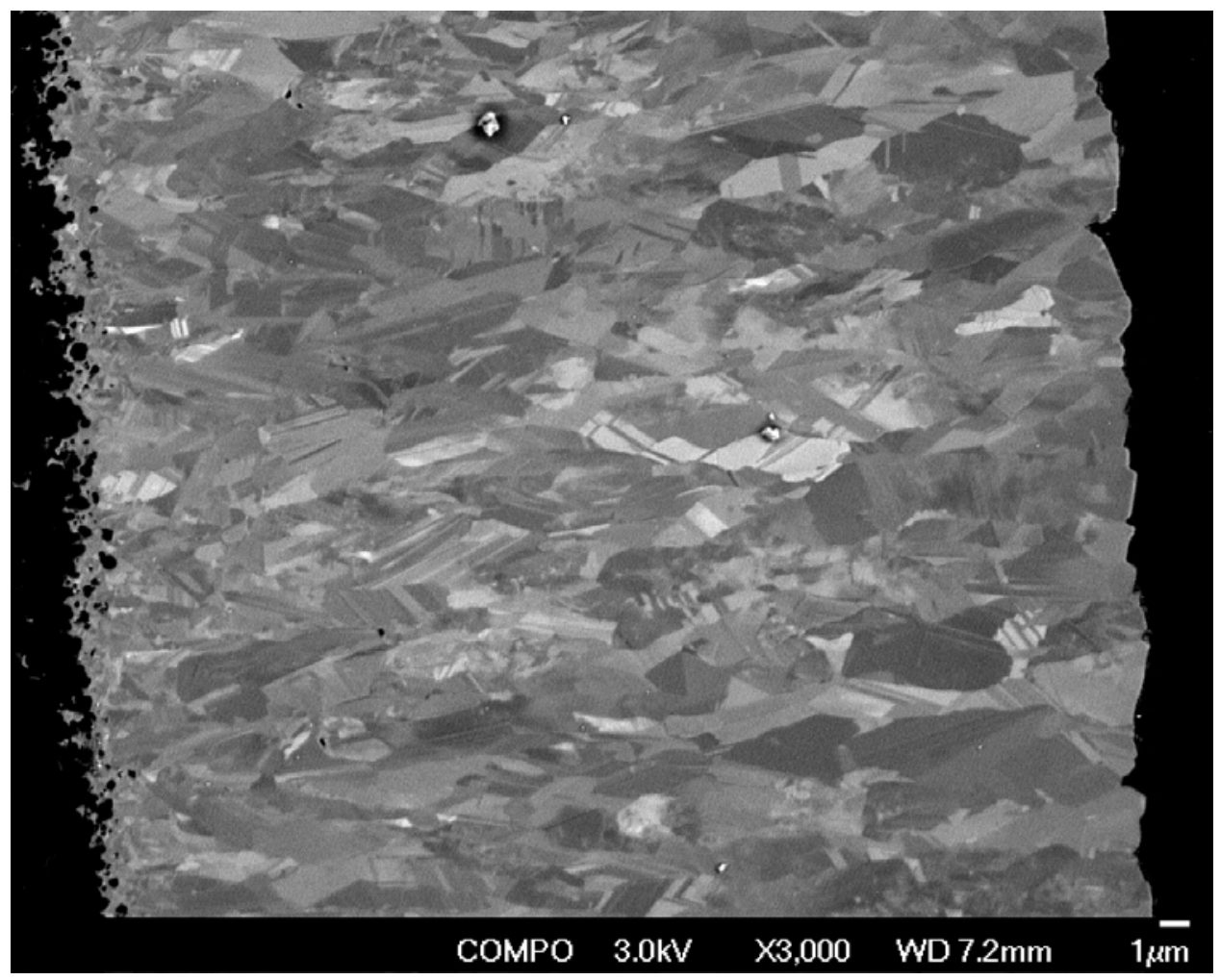

Figure 71. Example of unirradiated SiC microstructure from LEU01-27T representative of three of the four coater batches in the AGR-1 Baseline fuel composite ( $71 \%$ of the composite). 


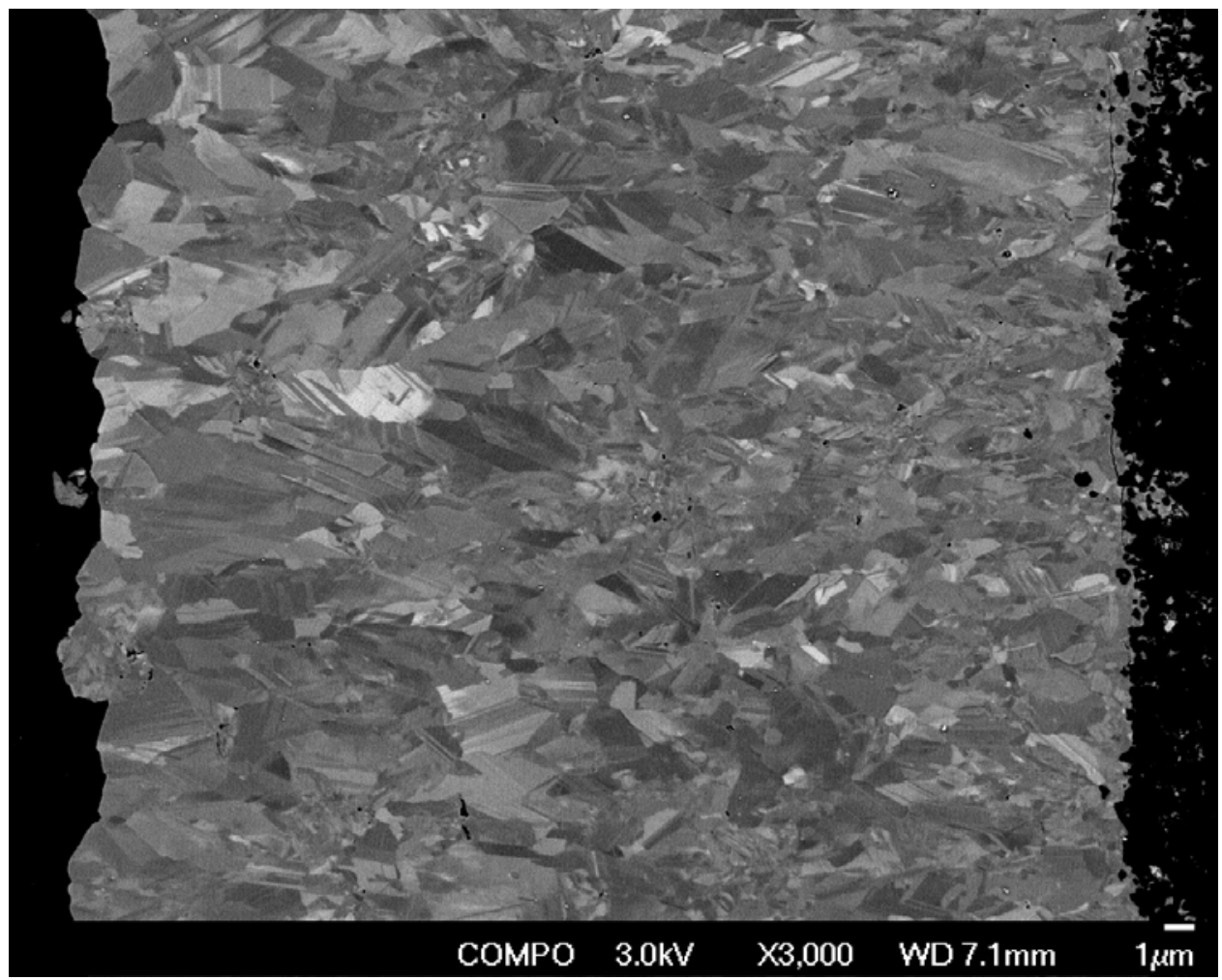

Figure 72. Example of unirradiated SiC microstructure from LEU01-45T representative of one of the four coater batches in the AGR-1 Baseline fuel composite ( 29\% of the composite).

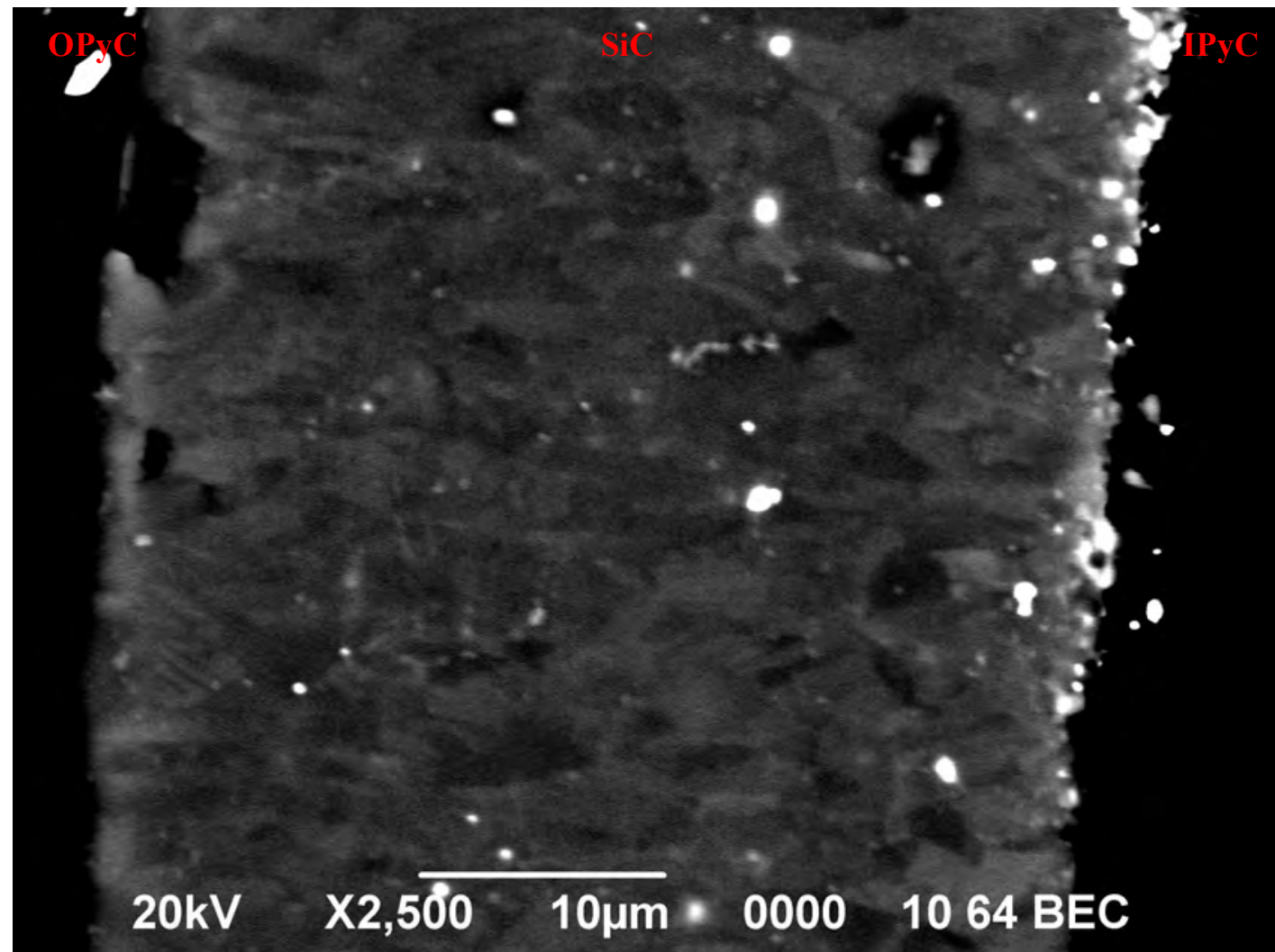

Figure 73. High contrast BSE image of Particle Ag-14 with below average ${ }^{110 \mathrm{~m}}$ Ag inventory (Mount 6357). 


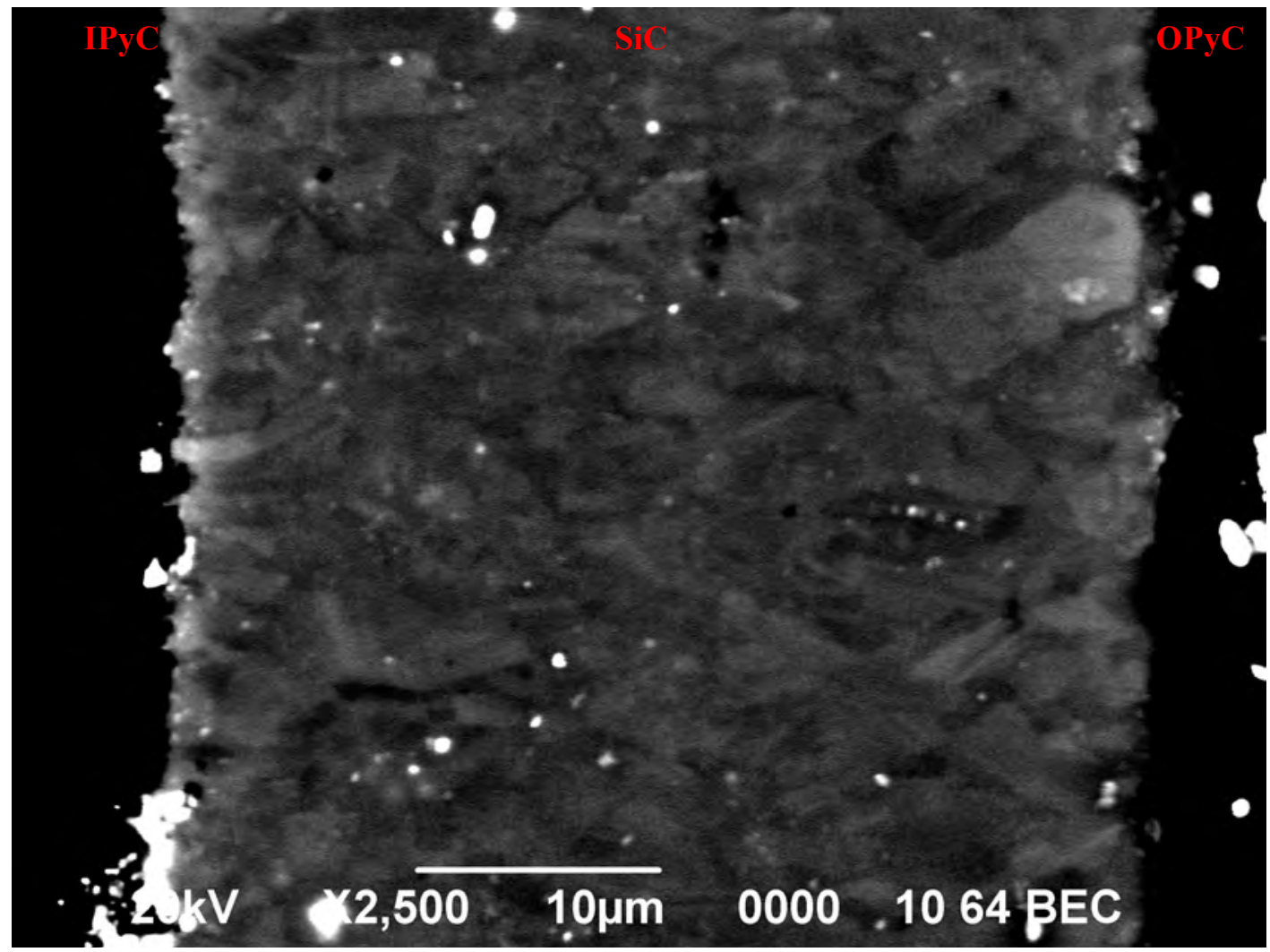

Figure 74. High contrast BSE image of Particle Ag-18 with below average ${ }^{110 \mathrm{~m}} \mathrm{Ag}$ inventory (Mount 6357).

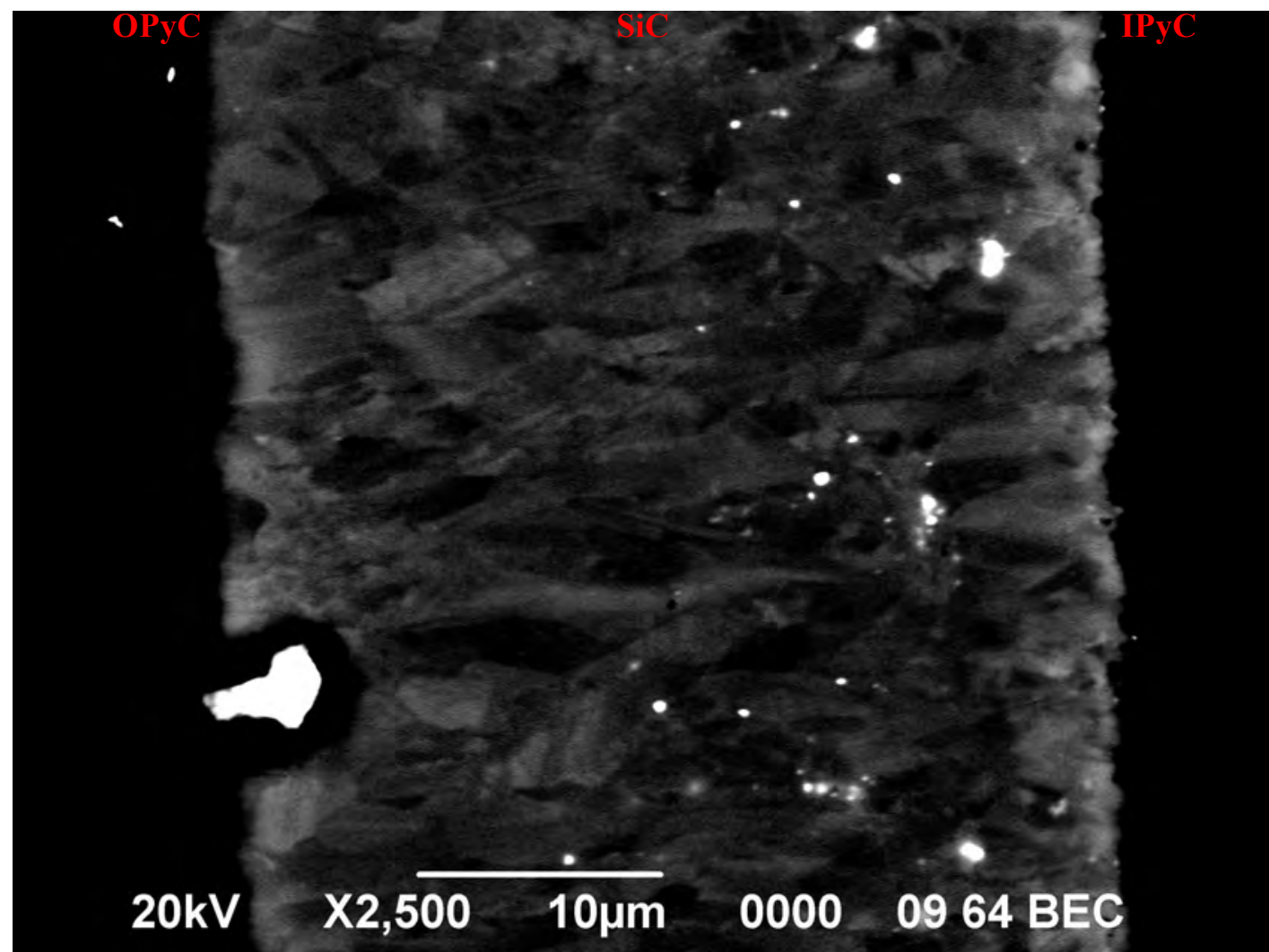

Figure 75. High contrast BSE image of Particle Ag-51 with no detectable ${ }^{110 \mathrm{~m}}$ Ag inventory (Mount 6359). 
A qualitative comparison of the grain size of Particles Ag-14, Ag-18, and Ag-51 shows that Particle Ag-14 appears to possess a slightly smaller average grain size than Particles Ag-18 and Ag-51, with Particles Ag-18 and Ag-51 having larger grains at the SiC/OPyC interface, compared to Ag-14. This is likely related to the observed batch to batch variation in SiC grain size for the AGR-1 Baseline fuel. There was no obvious correlation of this varied $\mathrm{SiC}$ grain size to the silver retention, but it would be premature to draw conclusions from this current set of images, given the non-optimized image quality and the limited number of particles analyzed. A second observation concerns the distribution of embedded FPs in the SiC layer. In all particles, high Z FP clusters were confirmed in the first 15 microns of the SiC layer, moving out from the IPyC/SiC interface. In the particles with measurable ${ }^{110 \mathrm{~m}} \mathrm{Ag}$ inventories, $\mathrm{Ag}-14$ and Ag-18, small faint bright spots indicative of additional high Z FP clusters, were observed in the 2nd half of the SiC layer, moving out toward the OPyC layer. These features were not analyzed by EDS and WDS, because they were not observed during standard BSE imaging of the SiC layer prior to that analysis. Further analysis should be performed to examine if this lower frequency of high $\mathrm{Z}$ clusters observed in the outer region of the $\mathrm{SiC}$ might be related to the difference in the grain size and structure in this region.

An additional phenomenon was observed in the SiC layer of Particle Ag-14 near the extruded kernel area where the buffer has been removed and the kernel was adjacent to the IPyC (see Figure 53 and Figure 66). Figure 76 shows the high contrast BSE image of the $\mathrm{SiC}$ layer near the kernel extrusion. At this location, the high contrast BSE brings out numerous regions throughout the SiC layer that appear darker. These area are not voids, and they do not appear in the secondary electron images or backscattered electron images at lower contrast. The low contrast suggests these areas have a lower average atomic number and/or density than the surrounding material, possibly being carbon rich zones where the silicon has been partially depleted. Additional analysis is needed to determine the cause of this phenomena.

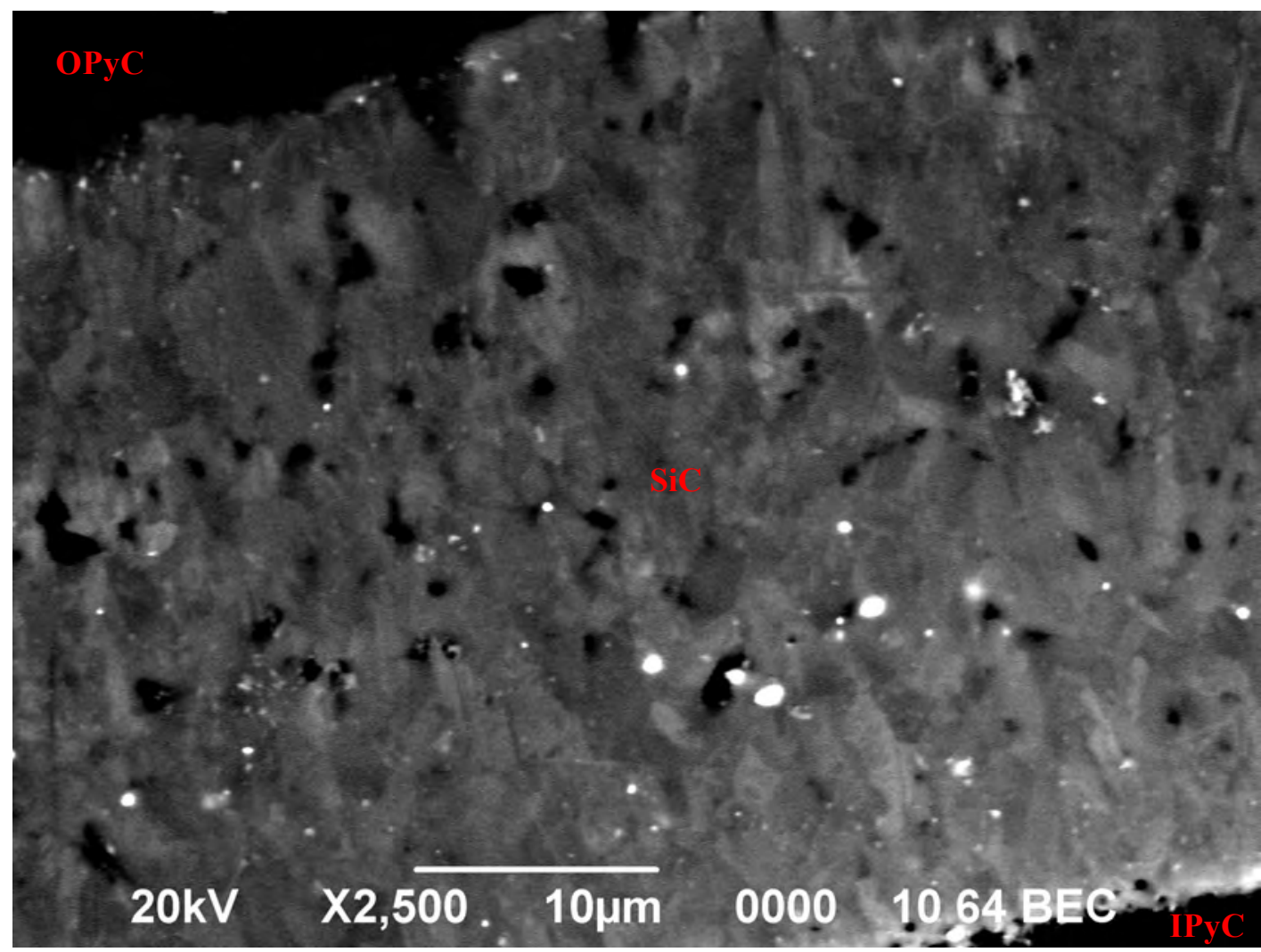

Figure 76. High contrast BSE image of SiC layer near kernel extrusion of Particle Ag-14 (Mount 6357). 


\section{Materialography on Individual Particles: Introduction of the Minimet}

Because of the difficulties encountered with the materialographic grinding and polishing processes discussed thus far, a significantly different process was developed and demonstrated using particles from AGR-1 Compact 6-1-1. A Buehler Minimet 1000 grinder/polisher was installed in the small 2nd floor cubicle at IFEL, which also houses the remote operation optical metallograph described above (Figure 32 and Figure 33). This system provides an alternative to sample preparation in 1-1/4" diameter epoxy mounts using the Struer's RotoPol system. While the Rotopol system is a good choice for polishing compact sections or multiple coated particles, the Buehler Minimet 1000 (typically used for TEM sample preparation) is suitable for polishing smaller specimens (1-10 particles) and offers several advantages over the Struer's system. Because of the smaller scale of operation, the Minimet produces less waste and samples can be prepared more rapidly, especially given the fact that the polisher is located in the same cubicle as the optical microscope so that periodic inspection of the sample during polishing is much more efficient. The Buehler Minimet 1000 is equipped with the optional precision thinning attachment shown in Figure 77. The head that holds the particle mount rides on a series of precision ball bearings and an adjustable dial in the center of the head can precisely adjust the position of the mount above the grindingpolishing surface. The ball-bearing suspended fixture helps to maintain a planar polish without need for a large contact area.
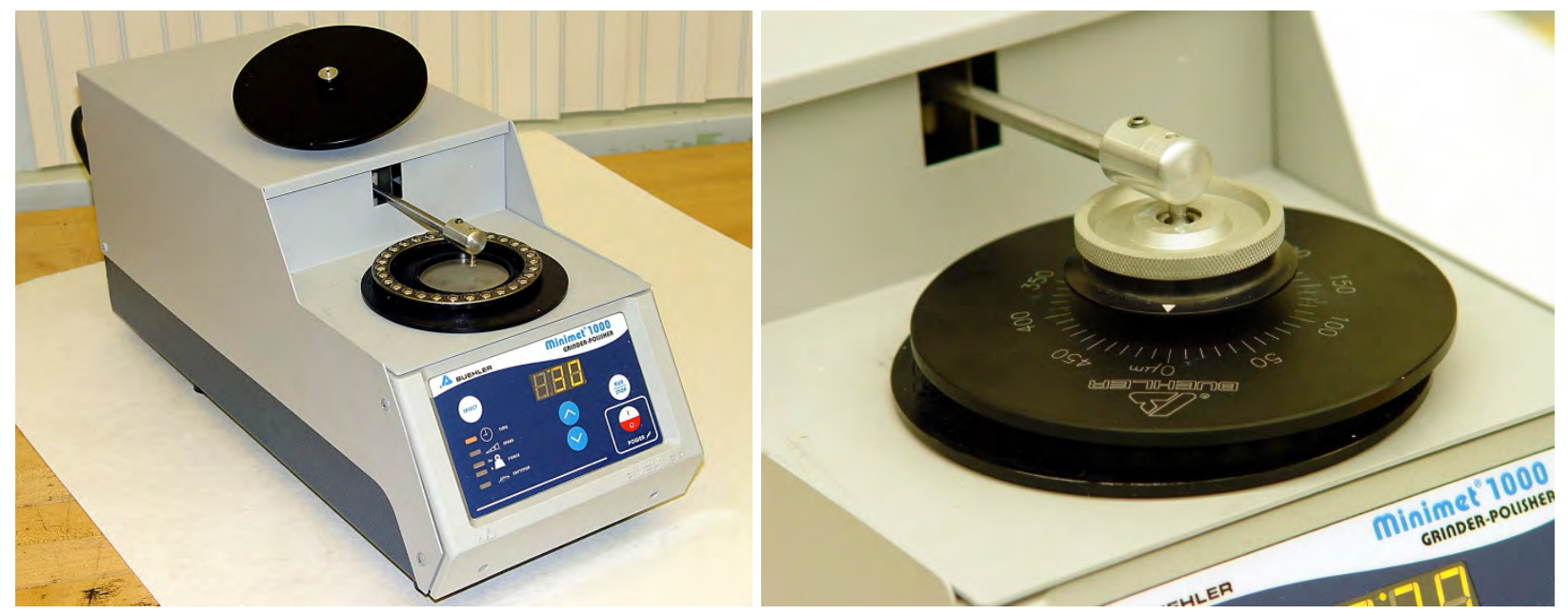

Figure 77. Buehler Minimet 1000 with precision thinning attachment.

A special mount for the particle was designed for this work that minimizes the contact area during grinding and polishing. Figure 78 shows 2 types of mounts that have been used to successfully polish irradiated particles. They are dimensionally similar consisting of a 0.50 " diameter section that fits into the head of the Buehler thinning attachment with a 0.125 " diameter section that projects outward and holds the particle and epoxy. In one design the projection forms a cup that is filled with epoxy and the particle settles to the bottom before the epoxy sets. After the epoxy is set, the 0.125 " diameter stub is ground down to expose the particle. In the other design a tapered hole goes through the entire mount. A piece of tape is placed over the tip of the stub and the particle is loaded from the back by sticking it to the tape. Epoxy is then added from the back and a vacuum is pulled on the sample several times to remove air bubbles before the epoxy sets. One advantage of the second method is that multiple particles can be mounted in the same plane and they remain in their relative positions when the epoxy is added. This system also does not require initial grinding to expose the tip of the particle. Two materials have been used of the mounts, Garolite XX phenolic rod and aluminum. The red Garolite material is commonly used at IFEL as a form for mounting irradiated materials in epoxy. It exhibits good properties for grinding and has a good shelf life in the hot cell environment. The aluminum was chosen for enhanced charge dissipation in the SEM. All Compact 6-1-1 particle samples were mounted in Garolite cup-type mounts. 

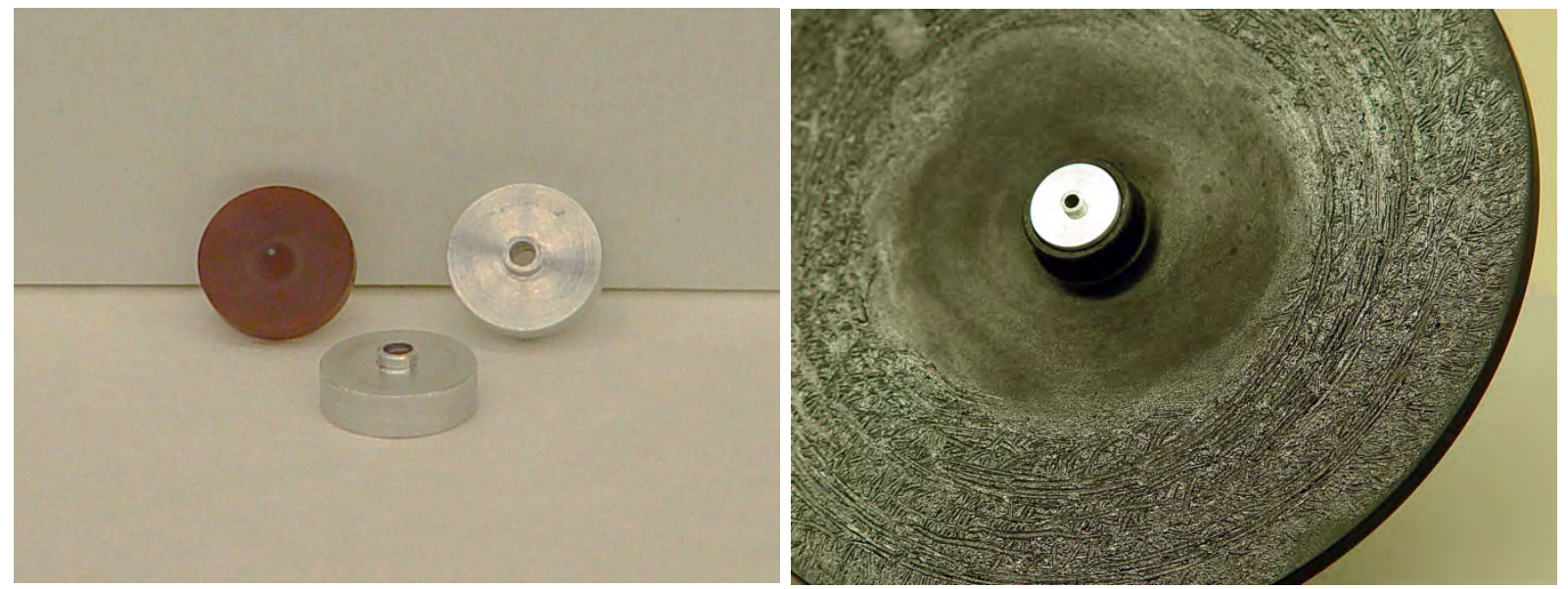

Figure 78. Mounts for polishing particles have been made using Garolite and aluminum (left). Image at right shows an aluminum mount loaded on the underside of the thinning attachment.

Initial demonstration of polishing irradiated particles with the Minimet was demonstrated using the following procedure. First a $30 \mu \mathrm{m}$ metal bonded diamond grinding disk was used with water to rough grind the particle until the void region between the buffer and IPyC or between the buffer and kernel was exposed. The particles were then back-potted under vacuum to stabilize the internal structure. The $30 \mu \mathrm{m}$ diamond disk with water was then used to continue grinding until the surface was near mid-plane. A $15 \mu \mathrm{m}$ metal bonded diamond disk was used with water to remove some of the $30 \mu \mathrm{m}$ grinding damage, then the particle was again back-potted to fill any remaining voids. After the second back-pot, the $15 \mu \mathrm{m}$ grinding disk was used to remove excess back-pot and re-exposed the particle, then a $6 \mu \mathrm{m}$ metal bonded diamond grinding disk was used with Buehler IsoCut fluid to remove the rough grinding scratches and prepare the particle for polishing. This fine polishing step removed most of the chipping around the edges of the SiC layer. Planar polishing was accomplished with a series of diamond lapping films that were stuck to a flat brass base plate using only the surface tension provided by a thin coating of IsoCut fluid. A $3 \mu \mathrm{m}$ diamond film lubricated with IsoCut fluid was used to remove the grinding marks and clean up the rough edges in the SiC. Normally it required 2 of the $3 \mu \mathrm{m}$ films to prepare the surface for the final polish. The final polish was achieved with $1 \mu \mathrm{m}$ and $0.5 \mu \mathrm{m}$ diamond films lubricated with IsoCut fluid. Depending on the particle, 2 or 3 fresh films were required to obtain the desired finish. Polishing with the $0.5 \mu \mathrm{m}$ film without introducing new scratches or pits was problematic, possibly due to the fact that these films had an adhesive backing or due to some regions of incomplete back-potting. However, the $0.5 \mu \mathrm{m}$ film provided the best final polish when successfully applied (Particle Ag-16). Recent sample polishing on particles from other compacts has included final polishing using $0.05 \mu \mathrm{m}$ Struer's OP-S colloidal silica on a woven silk Struer's DAC. This fine polish/chemical etch successfully removed residual damage from the diamond lapping films, but did not maintain the planar finish.

Table 11 lists the four particles from Compact 6-1-1 mounted and polished using the Minimet system. Samples were chosen based on the ${ }^{110 \mathrm{~m}} \mathrm{Ag}$ inventory determined by the 1 hour IMGA scans and were intended to span the range of highest silver retention down to undetectable silver retention. However, the 6 hour IMGA scan determined that the ${ }^{110 \mathrm{~m}} \mathrm{Ag}$ inventory was not as expected from the 1 hour sorting, with the result that the lowest silver retaining particles were not sampled.

Table 11. List of Minimet mounts of particles from Compact 6-1-1

\begin{tabular}{|c||l|c|}
\hline \multirow{2}{*}{ Mount ID } & Particle Description & $\begin{array}{c}\text { 110m Ag Activity } \\
\text { Ag/particle at } \\
\text { (Bq } \\
\text { EOL+1 day) }\end{array}$ \\
\hline \hline MM-A & High ${ }^{110 \mathrm{~m}}$ Ag inventory in 6 hour IMGA scan (Ag-02 from Table 7) & $4.48 \mathrm{E}+04$ \\
\hline MM-B & Low ${ }^{110 \mathrm{~m}} \mathrm{Ag}$ inventory in 6 hour IMGA scan (Ag-15 from Table 7) & $1.50 \mathrm{E}+04$ \\
\hline MM-C & High ${ }^{110 \mathrm{~m}} \mathrm{Ag}$ inventory in 6 hour IMGA scan (Ag-16 from Table 7) & $4.66 \mathrm{E}+04$ \\
MM-D & Medium ${ }^{110 \mathrm{~m}}$ Ag inventory in 6 hour IMGA scan (Ag-54 from Table 7) & $2.60 \mathrm{E}+04$ \\
\hline
\end{tabular}


Mount MM-C (Particle Ag-16), which had a successful final polish on the $0.5 \mu \mathrm{m}$ film, was the best Compact 6-1-1 shakedown example of a single particle mounted and polished using the new Minimet (Figure 79 through Figure 85). Notice that the interlayer stitching between the IPyC and the SiC is well preserved (Figure 85). This is a good measure of the quality of the planar polish. Grinding damage is often prevalent at the edge of the $\mathrm{SiC}$. This damage can be difficult to remove without rounding the edge of the $\mathrm{SiC}$ and removing the detailed microstructure present at that interface. In addition to preserving the interface structure, the high quality planar polish achieved with the Minimet makes it possible to see fine detail in the microstructure of the kernel and coating layers. Kernel porosity is well defined (Figure 80). Porosity and variation in density is also evident in the pyrocarbon layers. For this particle, it is apparent that the separation of buffer from IPyC occurred in the buffer, with a thin layer of buffer left adhered to the IPyC (see, for example, Figure 84 and Figure 85). There is also evidence of a reaction layer in the buffer at the kernel surface. Figure 83 and Figure 84 show that this reaction layer is separated from the kernel, and, in some places, a thin fracture can be seen where it transitions into more normal appearing buffer. This reaction layer may be what remains of the kernel's uranium carbide skin. Figure 83 shows two small bright spots at the $\mathrm{IPyC} / \mathrm{SiC}$ interface. It is not clear whether these are metallic fission products segregated at the interface or simply debris pressed into the surface during sample preparation.

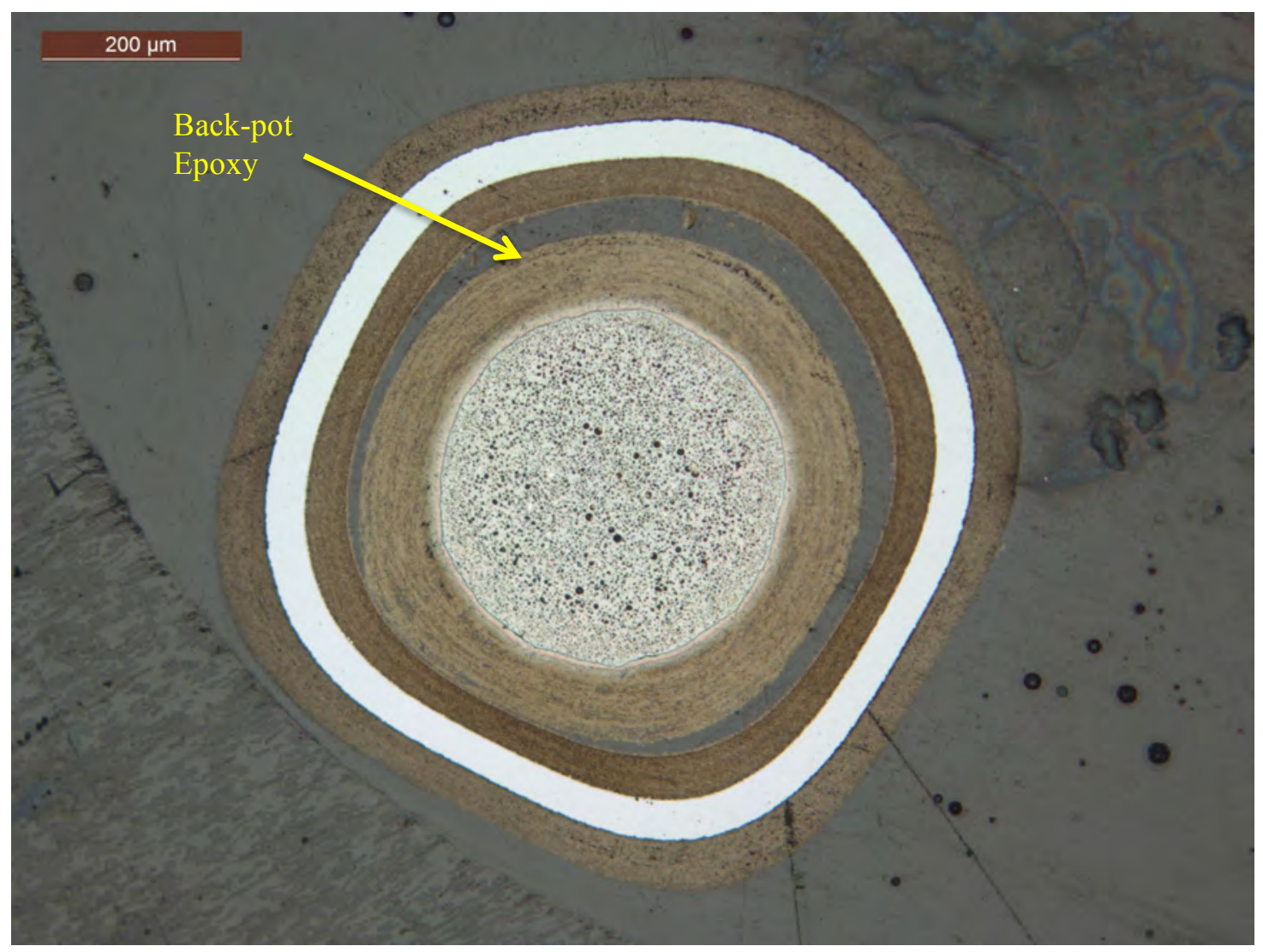

Figure 79. Particle Ag-16 from Compact 6-1-1 (Mount MM-C) polished on Minimet. 


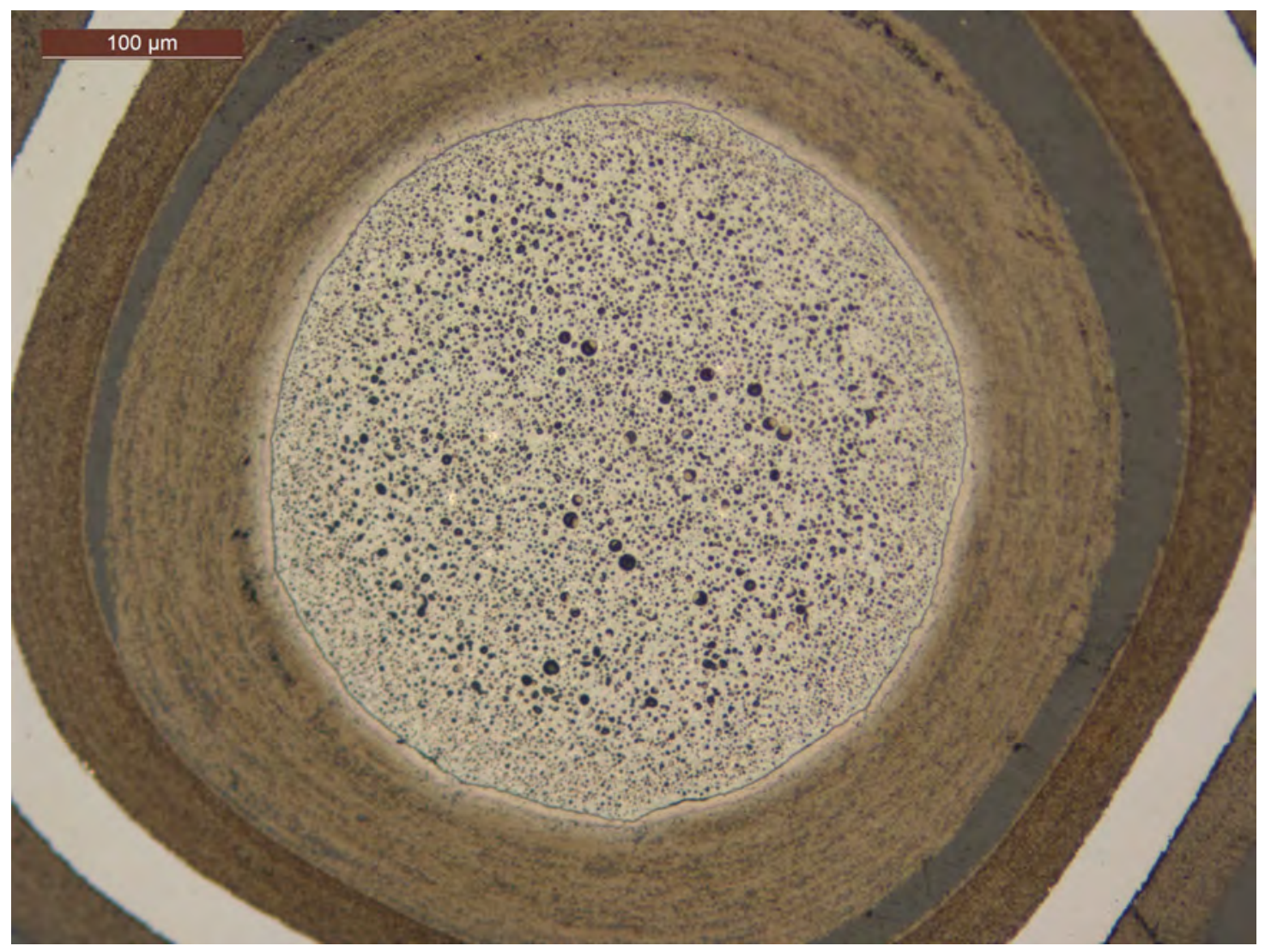

Figure 80. Higher magnification image of particle from Figure 79 (Particle Ag-16).

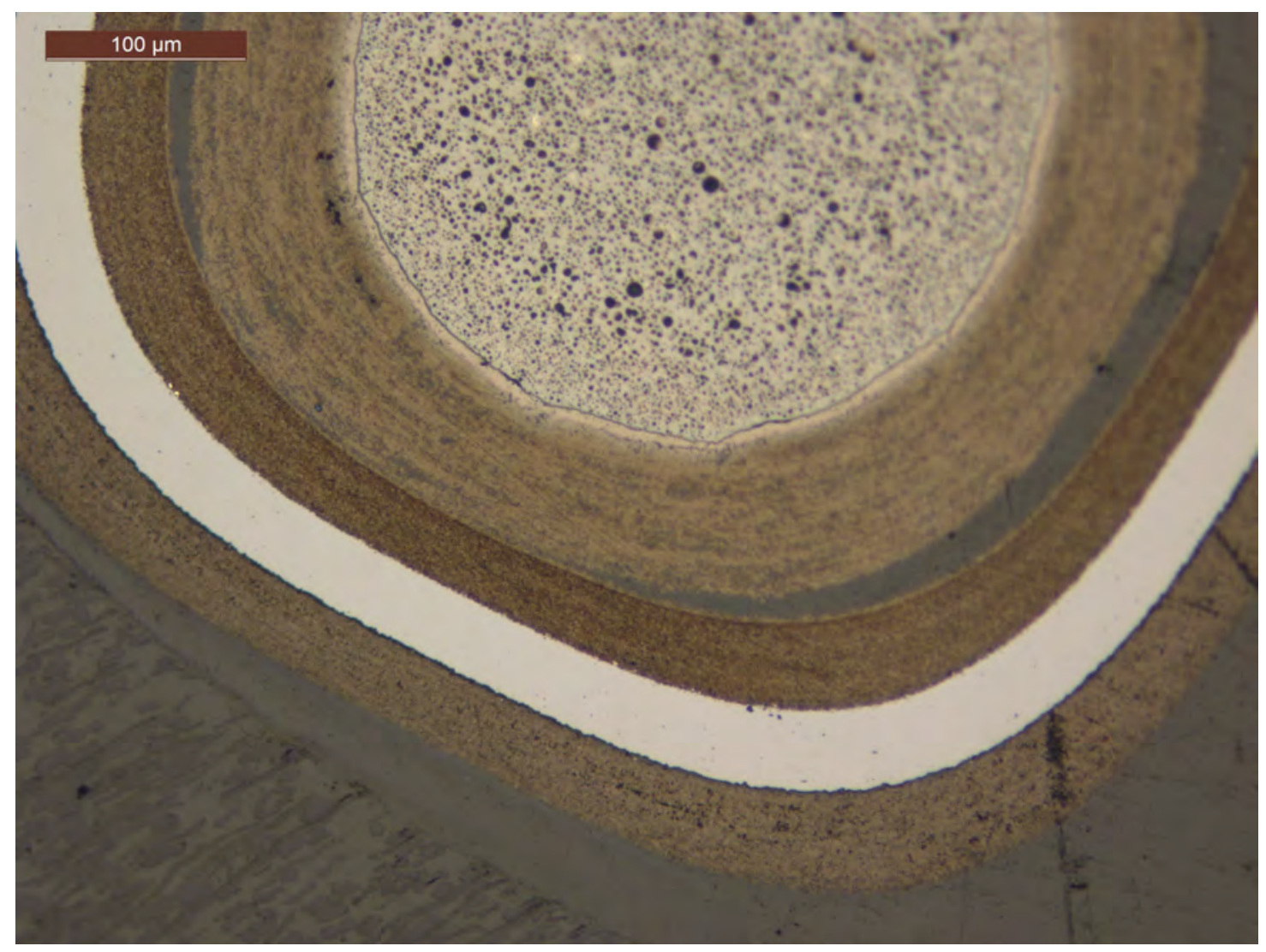

Figure 81. Higher magnification image of particle from Figure 79 (Particle Ag-16). 


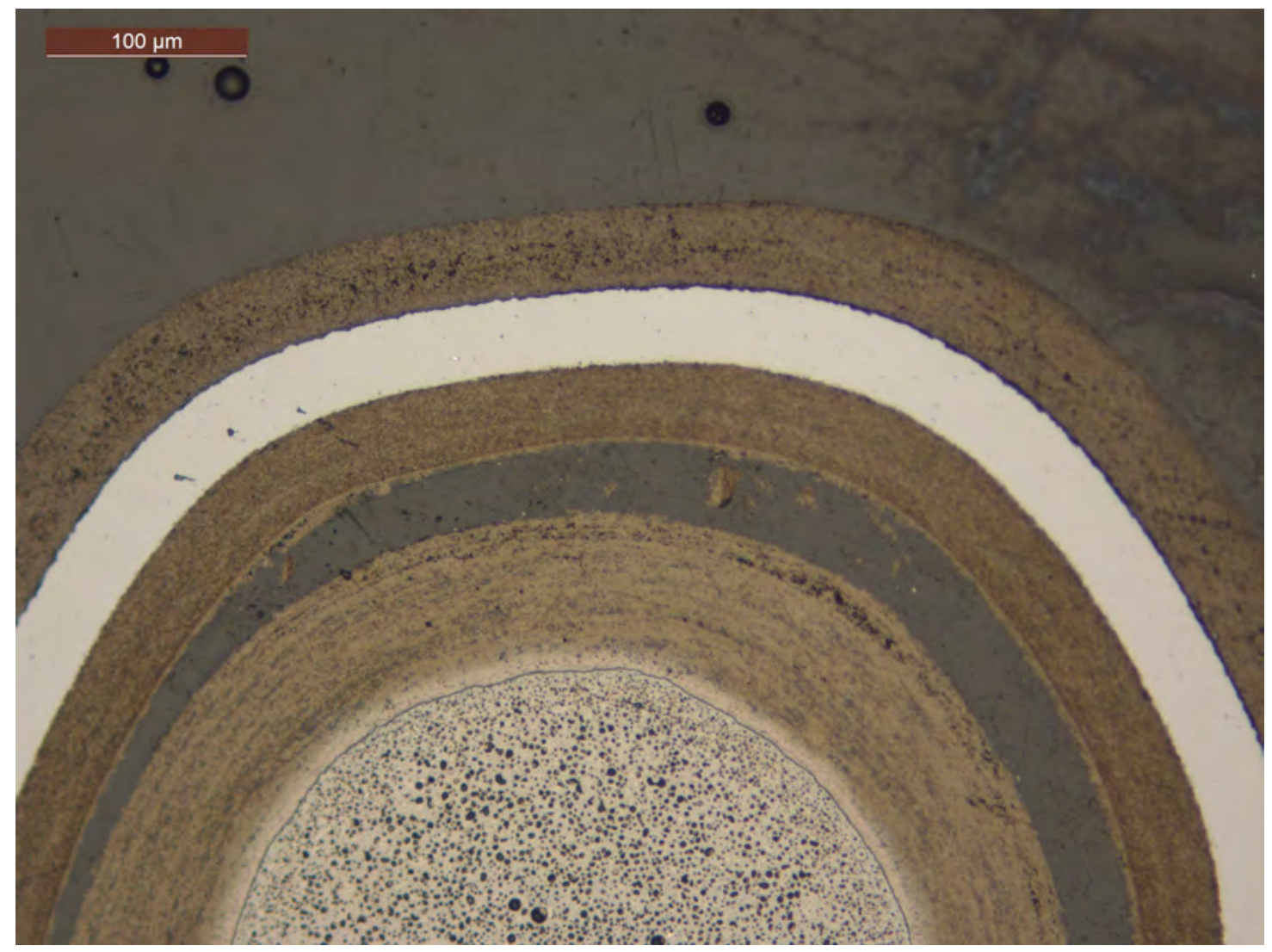

Figure 82. Higher magnification image of particle from Figure 79 (Particle Ag-16).

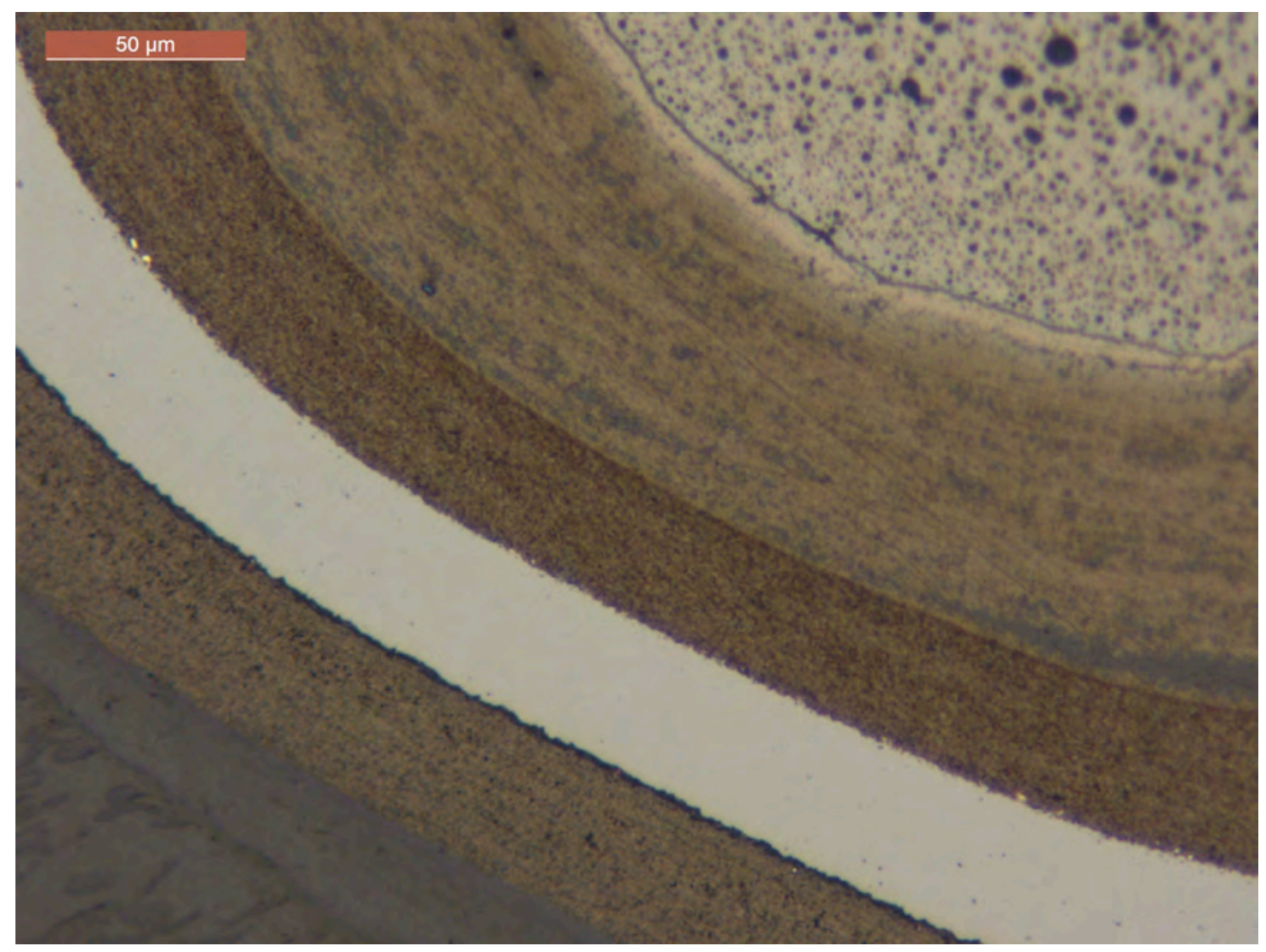

Figure 83. Higher magnification image of particle from Figure 79 (Particle Ag-16). 


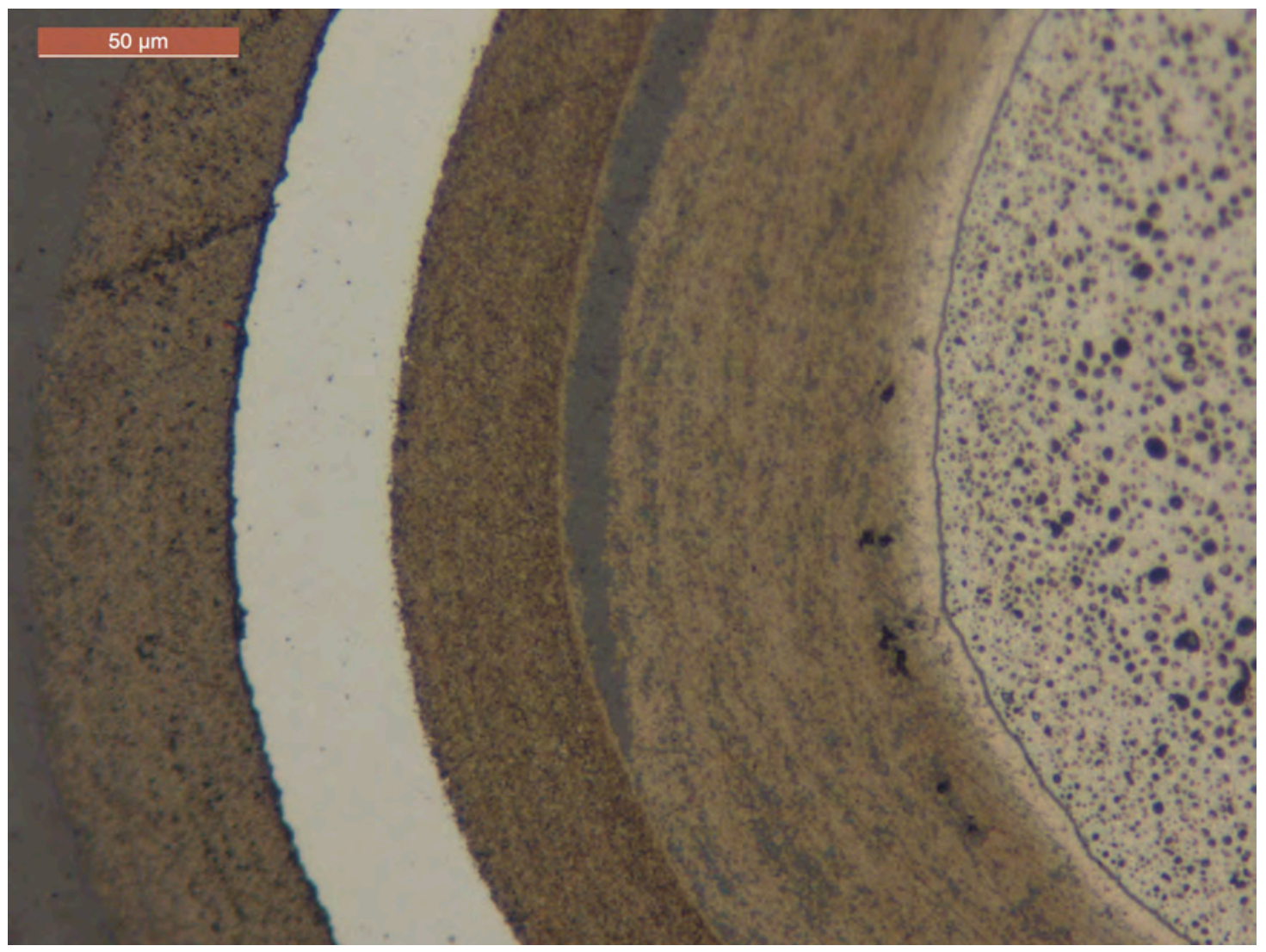

Figure 84. Higher magnification image of particle from Figure 79 (Particle Ag-16).

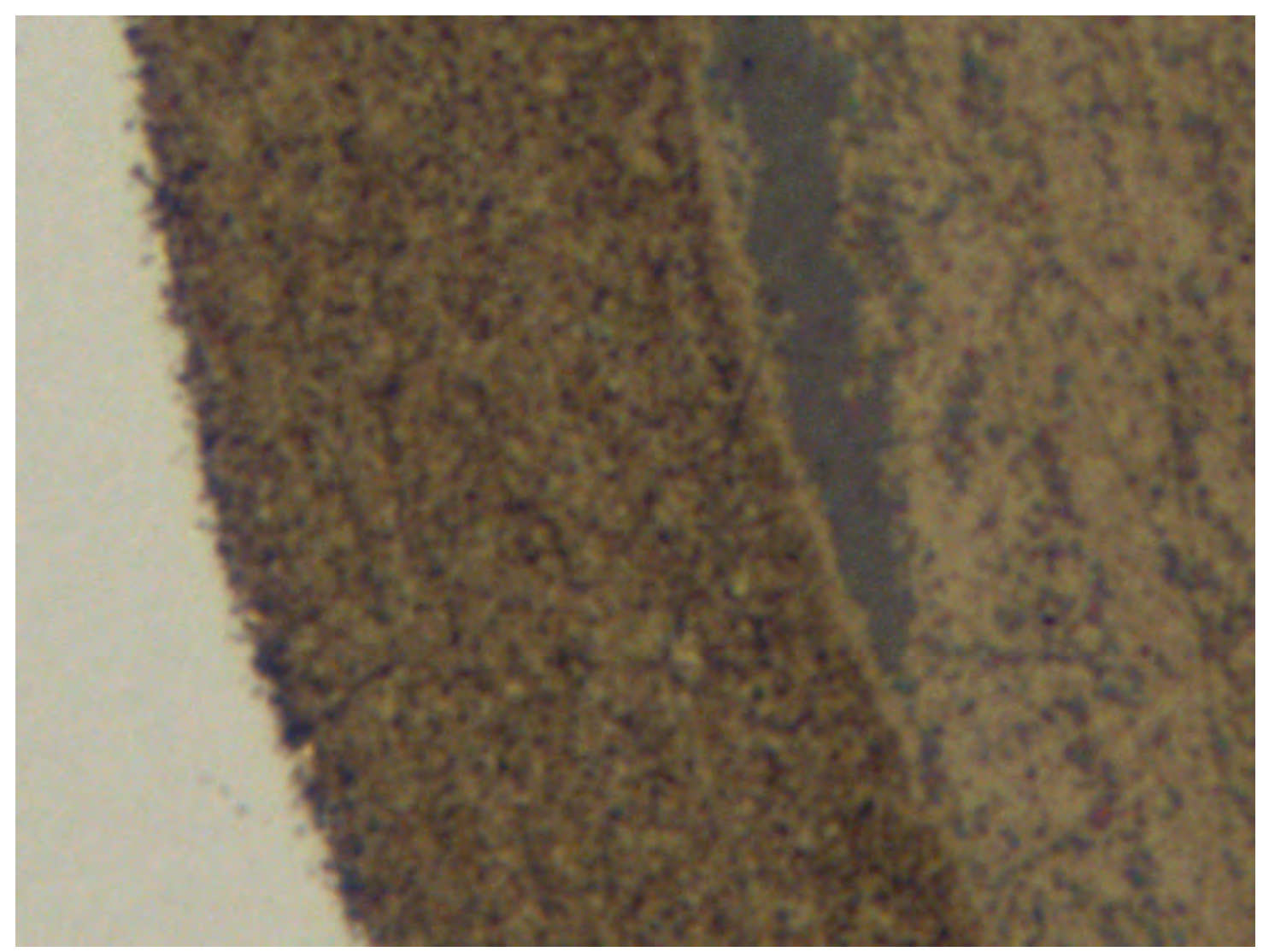

Figure 85. Digital zoom of image in Figure 84 (Particle Ag-16). 
The other three Minimet sample mounts listed in Table 11 were imaged after a final polish on $1 \mu \mathrm{m}$ diamond film. Particles in these mounts showed similar features to those discussed above, but there tended to be more fine scratches in the carbon layers and the SiC layers still showed some surface damage from the sample preparation. Figure 86 through Figure 89 show Particle Ag-02. Note that this particle does not have an $\mathrm{OPyC}$ layer. The OPyC layer was probably lost during handling after electrolytic deconsolidation and leaching. There is evidence that the sieving process used to separate particles from the matrix debris prior to transfer to the IMGA may break off some of the OPyC layers. Contact with the vacuum needle in the IMGA can also break off OPyC layers. Both of these scenarios would indicate that the OPyC layers were not as rugged as they are in the pre-irradiated state. This particle also shows a chip in the $\mathrm{SiC}$ layer (Figure 86). The fact that there is no epoxy infiltrated in underneath this chip indicates that it was caused during sample preparation.

Figure 90 through Figure 93 show Particle Ag-54 and Figure 94 through Figure 97 show Particle Ag15. There is a gap visible between the $\mathrm{SiC}$ and OPyC in Particle Ag-15 (Figure 96), but this may be an artifact of the grinding and polishing process, indicating that additional polishing of this sample was needed to get past the grinding damage at the $\mathrm{SiC} / \mathrm{OPyC}$ interface. Although Particle Ag-15 retained the least amount of ${ }^{110 \mathrm{~m}} \mathrm{Ag}$ in this group of 4 particles surveyed using the Minimet, there is no obvious microstructural feature visible, which would account for the additional silver loss.

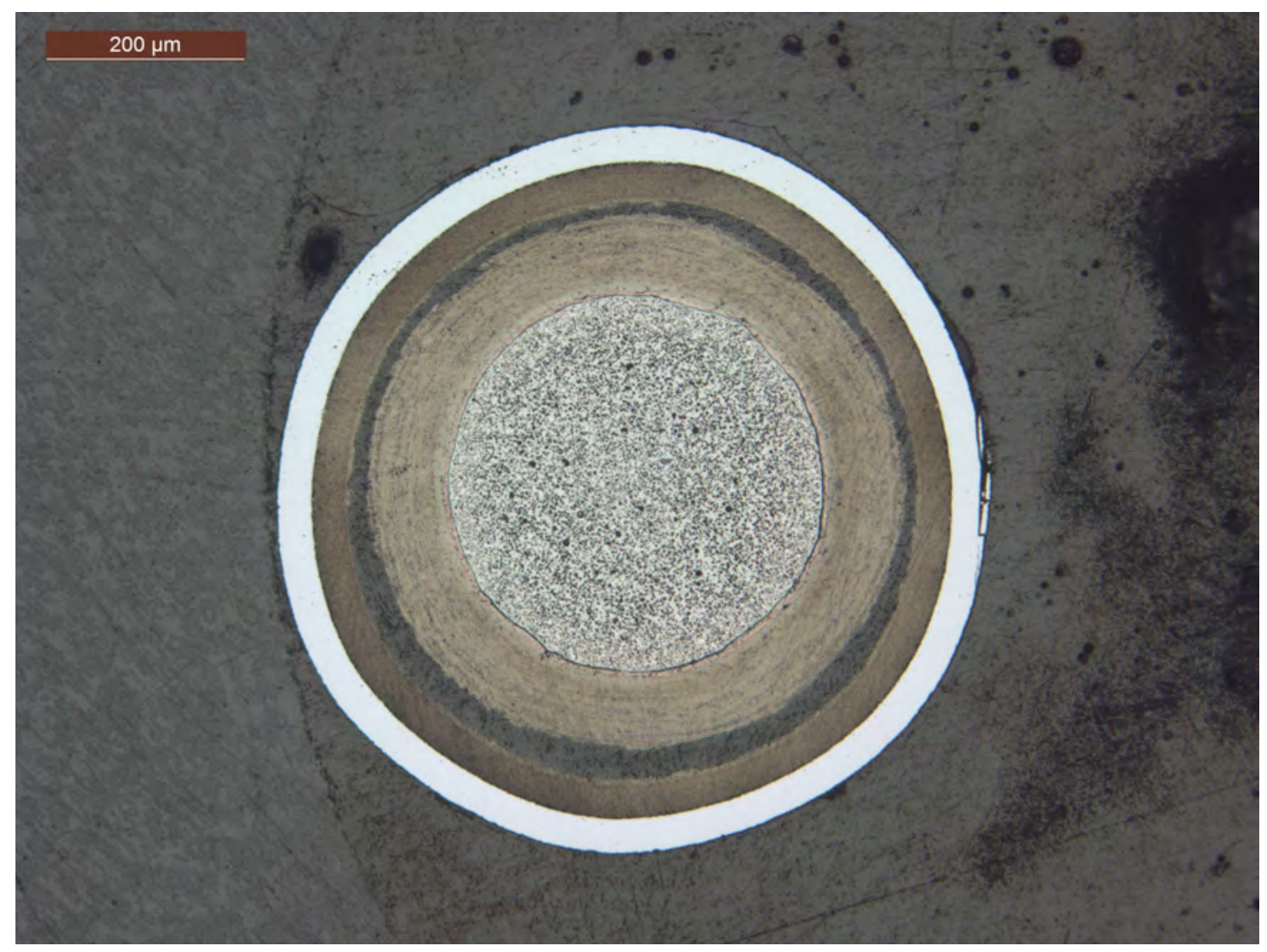

Figure 86. Particle Ag-02 from Compact 6-1-1 (Mount MM-A) polished on Minimet. 


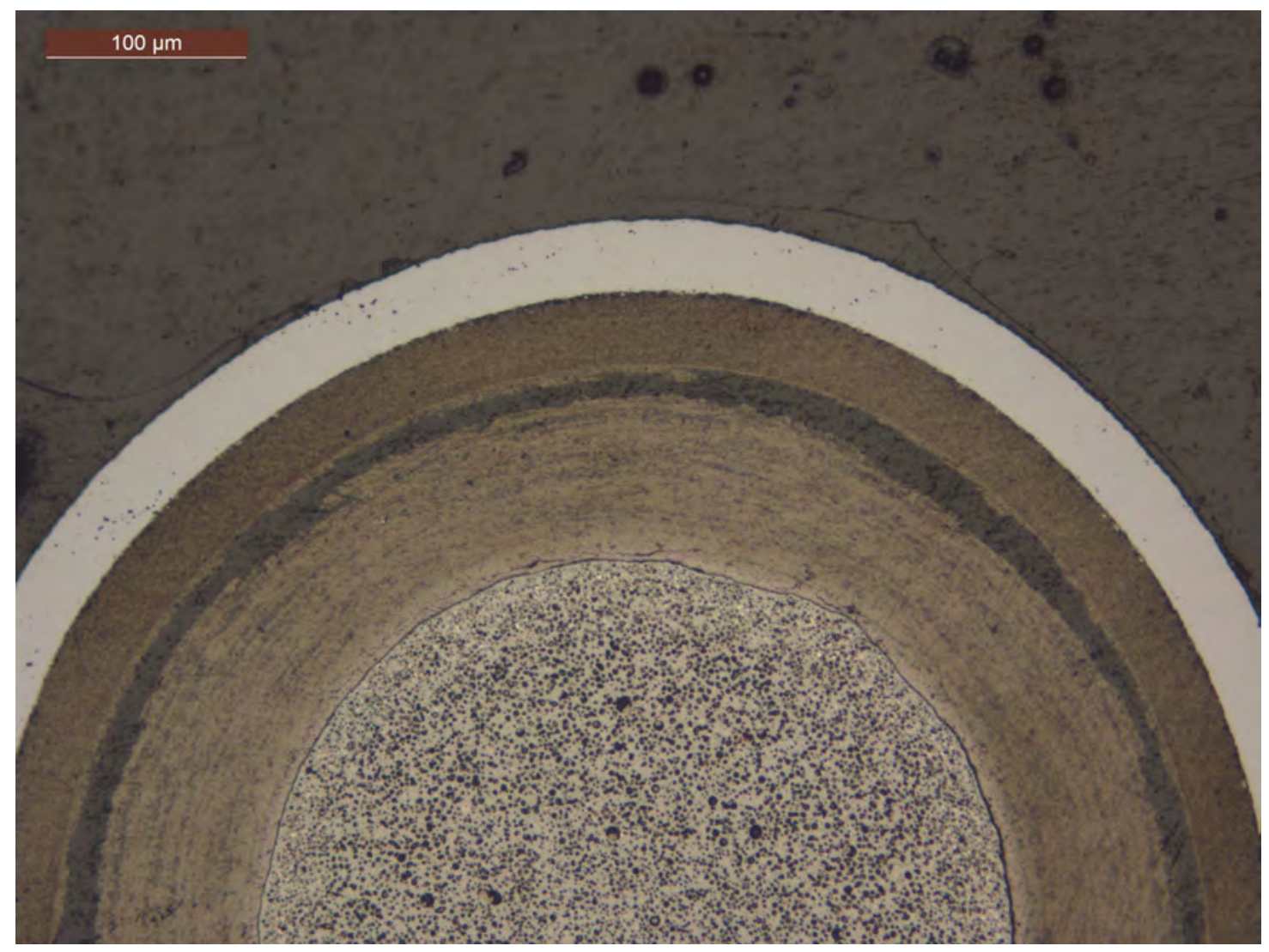

Figure 87. Higher magnification image of particle from Figure 86 (Particle Ag-02).

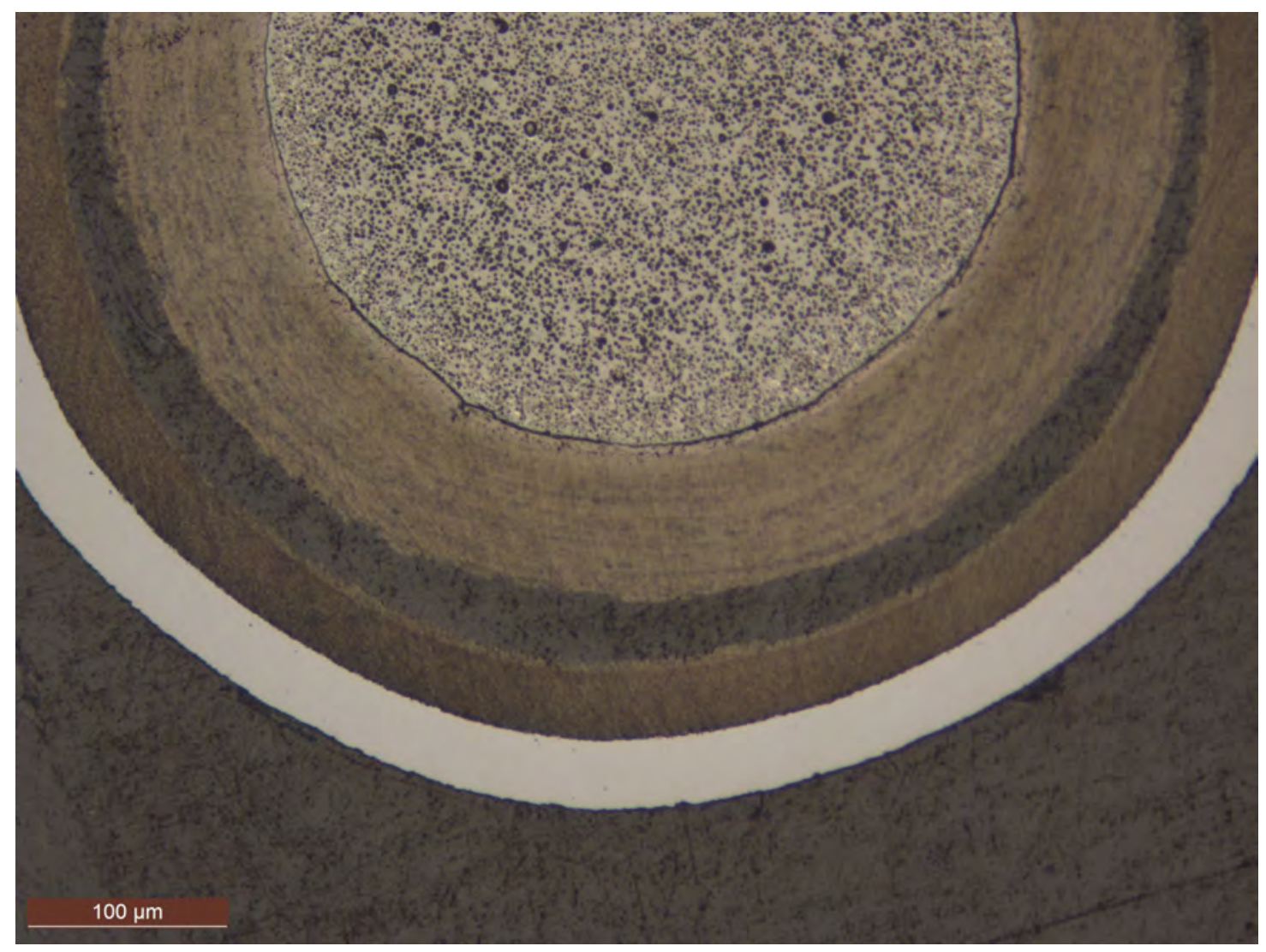

Figure 88. Higher magnification image of particle from Figure 86 (Particle Ag-02). 


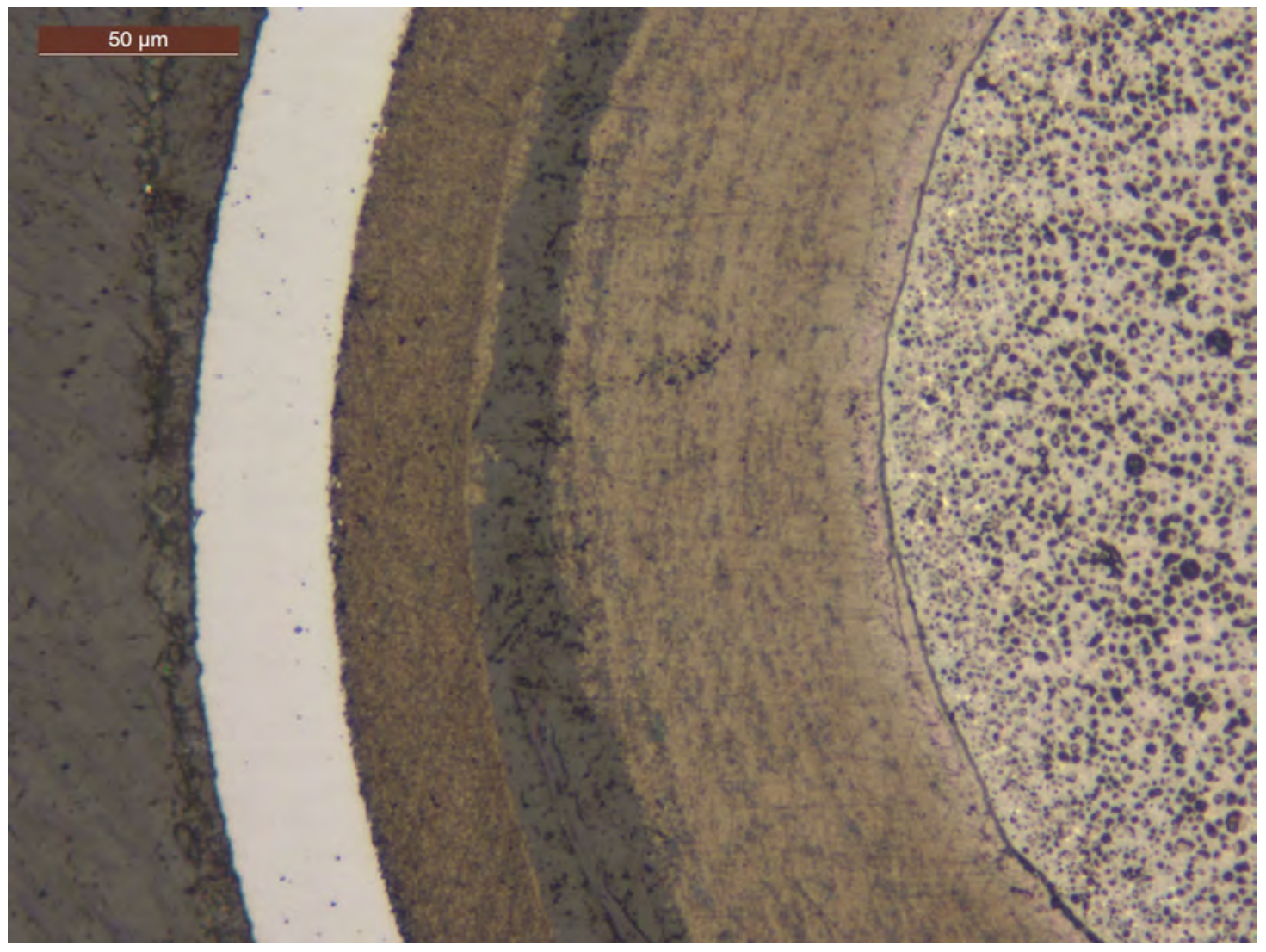

Figure 89. Higher magnification image of particle from Figure 86 (Particle Ag-02).

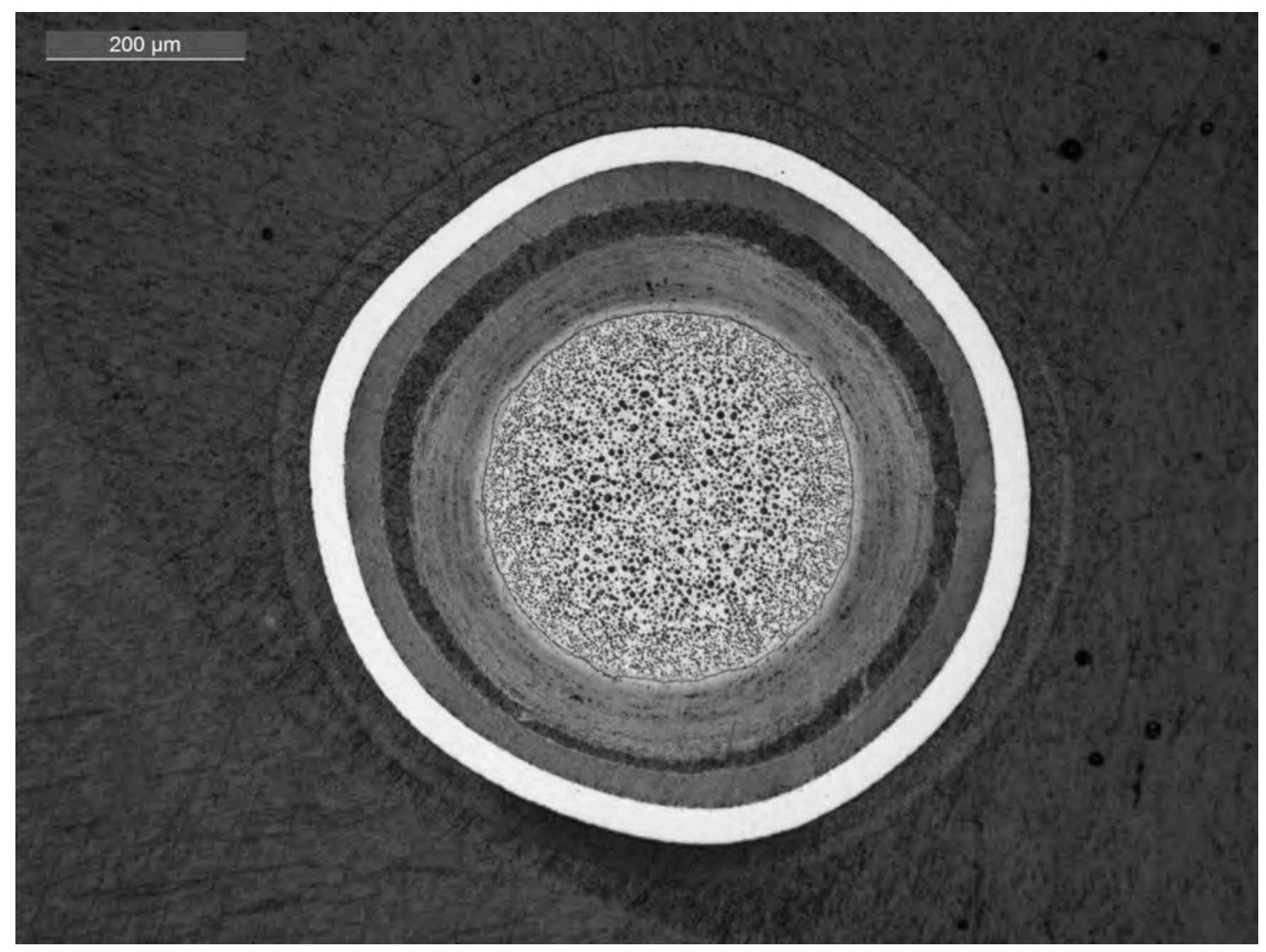

Figure 90. Particle Ag-54 from Compact 6-1-1 (Mount MM-D) polished on Minimet. 


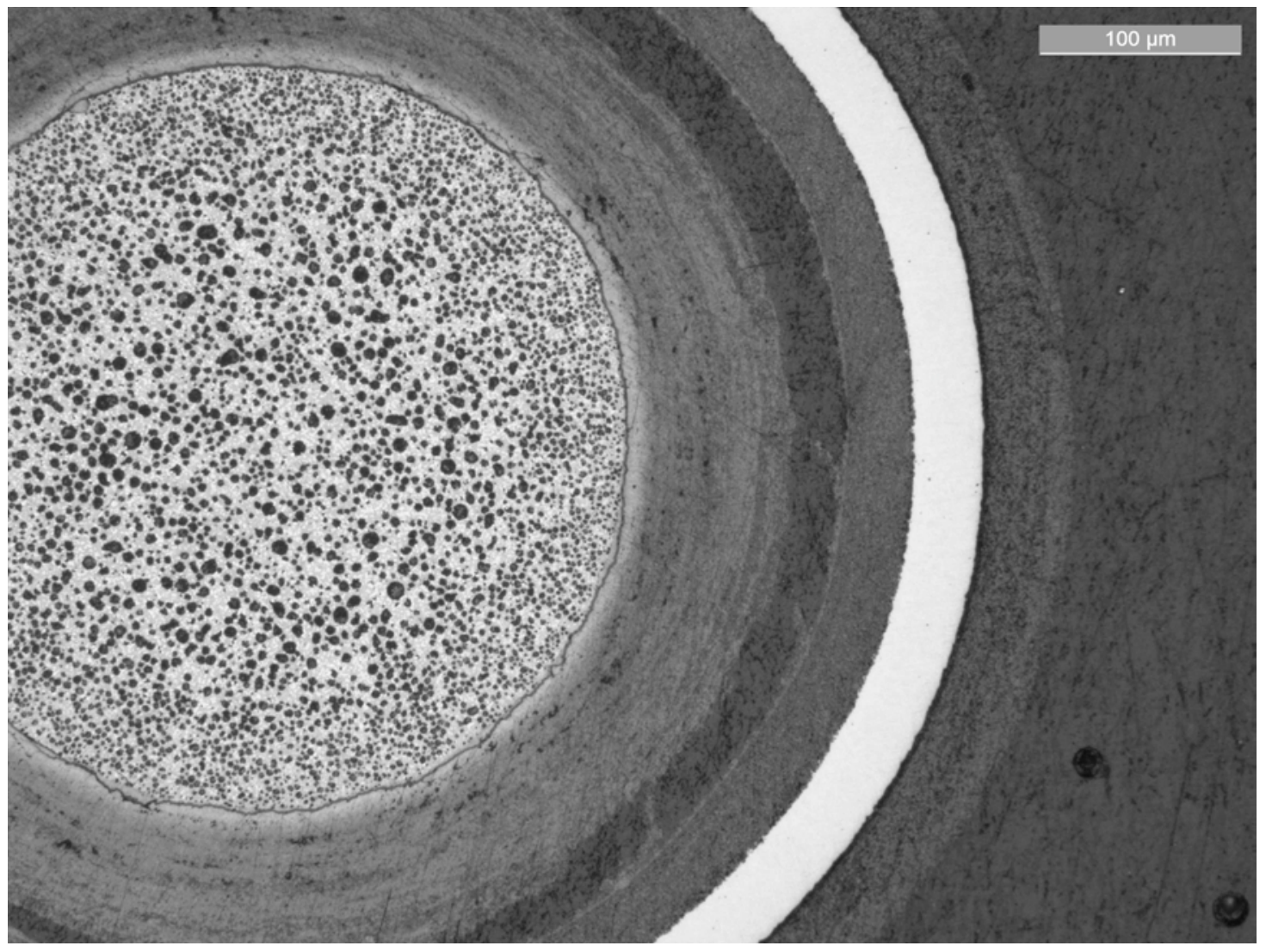

Figure 91. Higher magnification image of particle from Figure 90 (Particle Ag-54).

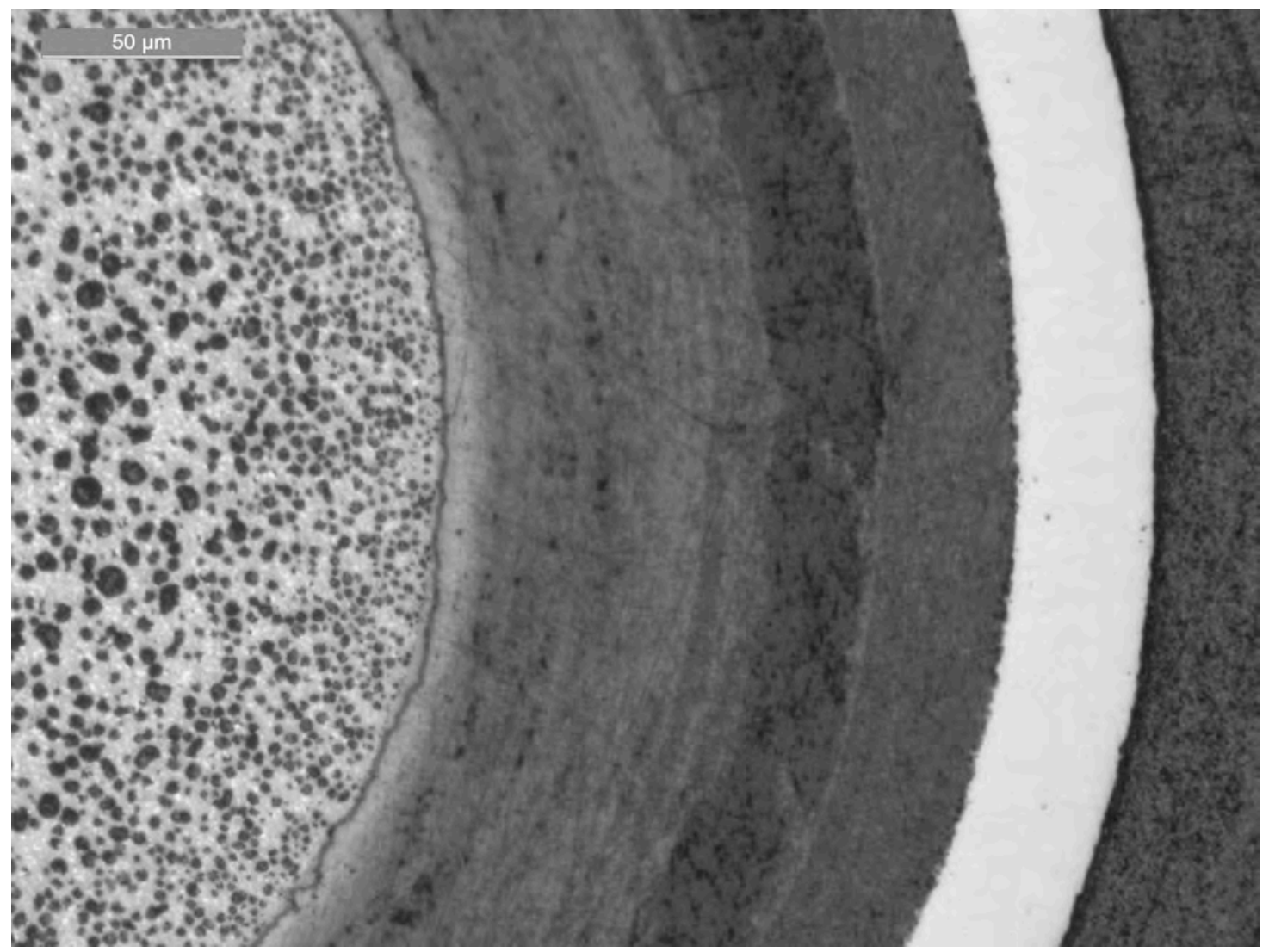

Figure 92. Higher magnification image of particle from Figure 90 (Particle Ag-54). 


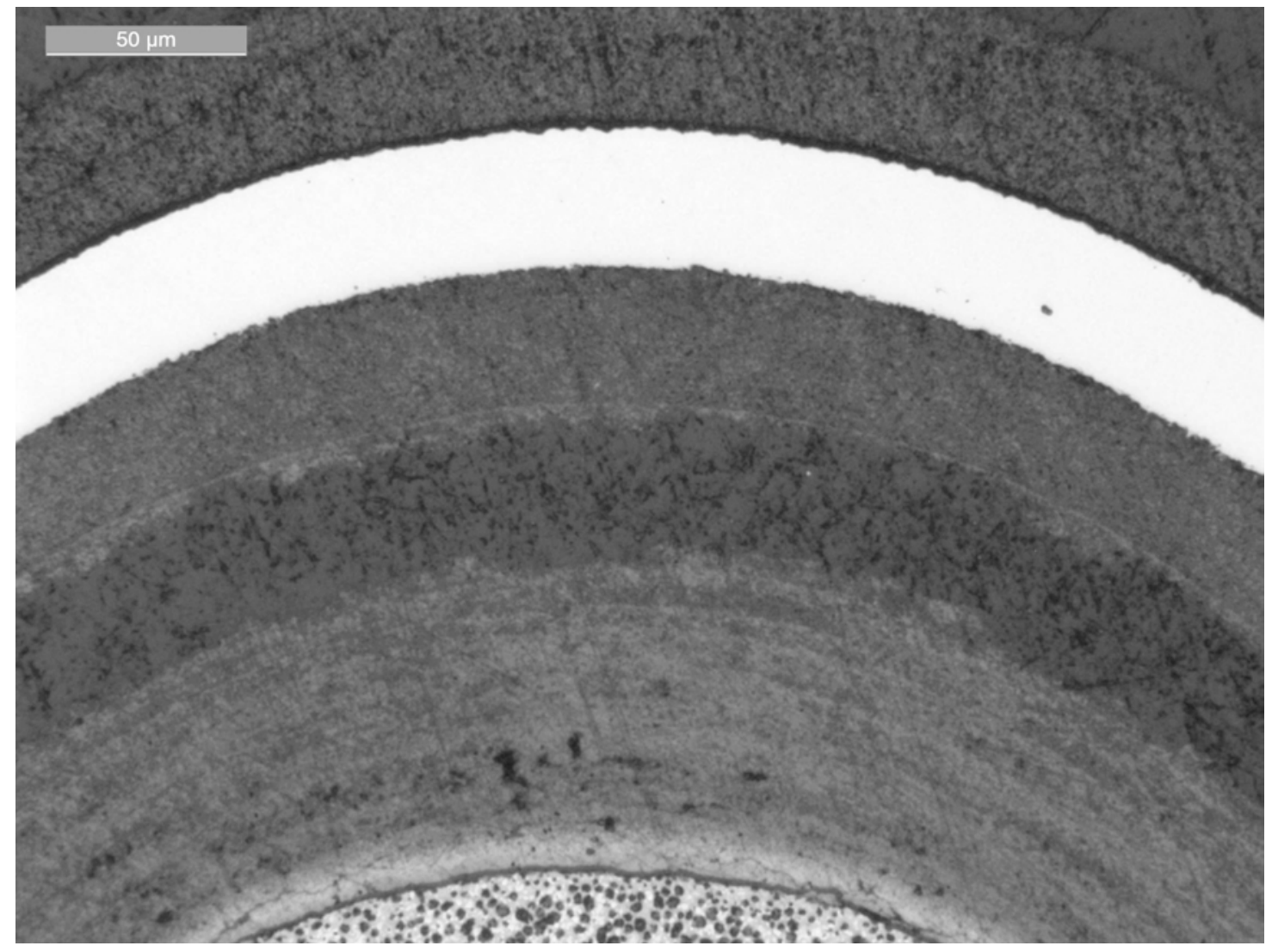

Figure 93. Higher magnification image of particle from Figure 90 (Particle Ag-54).

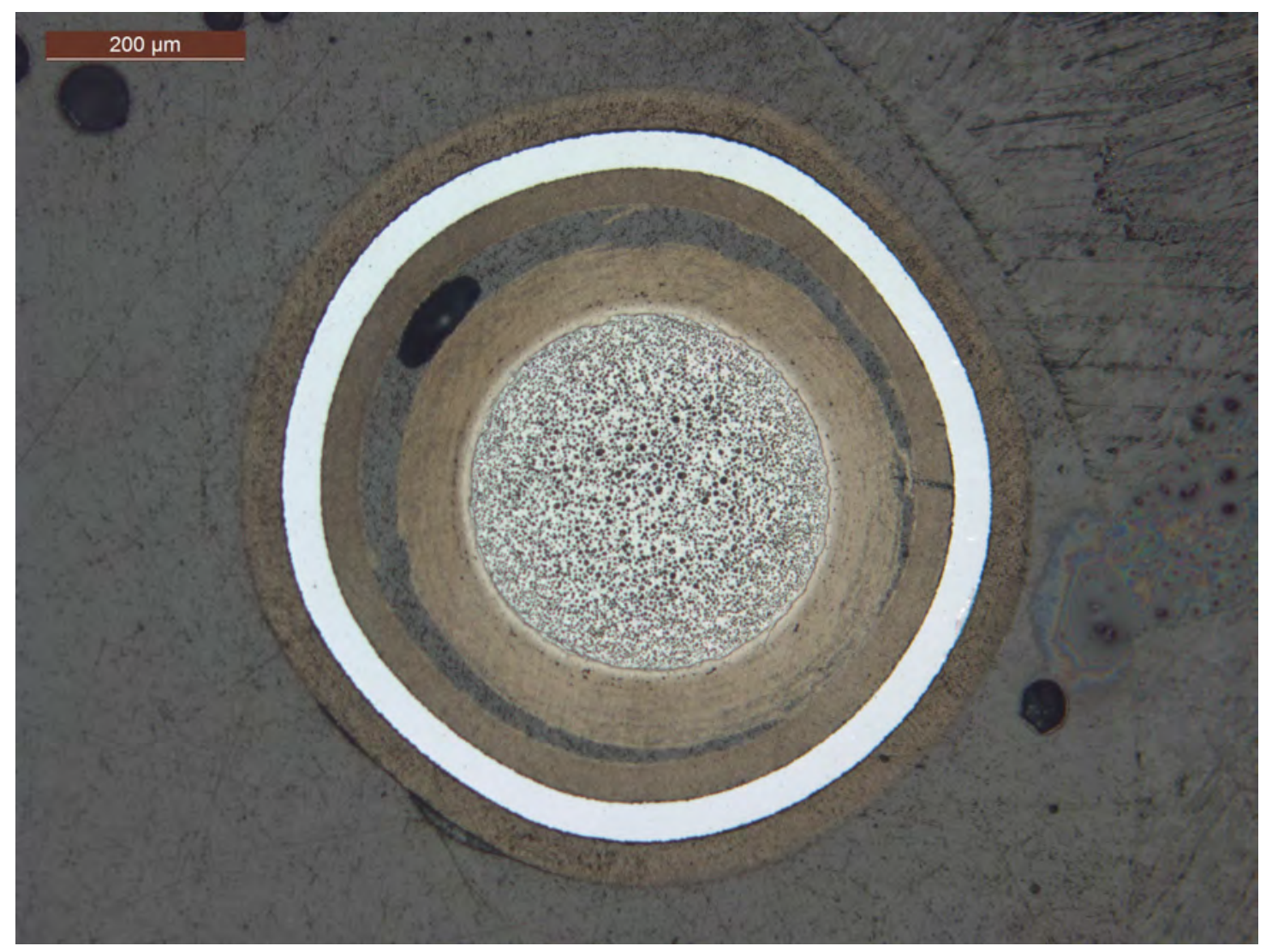

Figure 94. Particle Ag-15 from Compact 6-1-1 (Mount MM-B) polished on Minimet. 


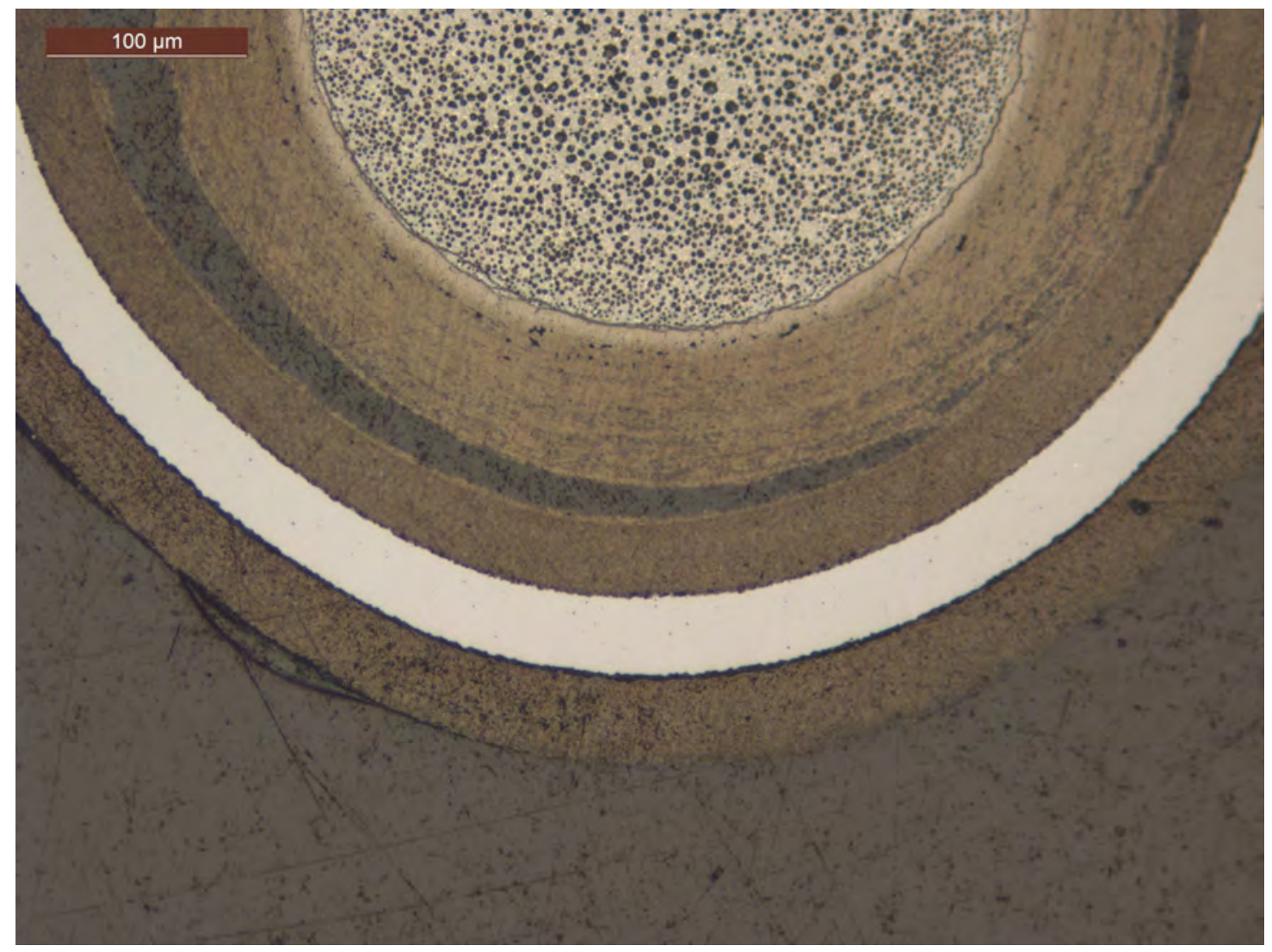

Figure 95. Higher magnification image of particle from Figure 94 (Particle Ag-15).

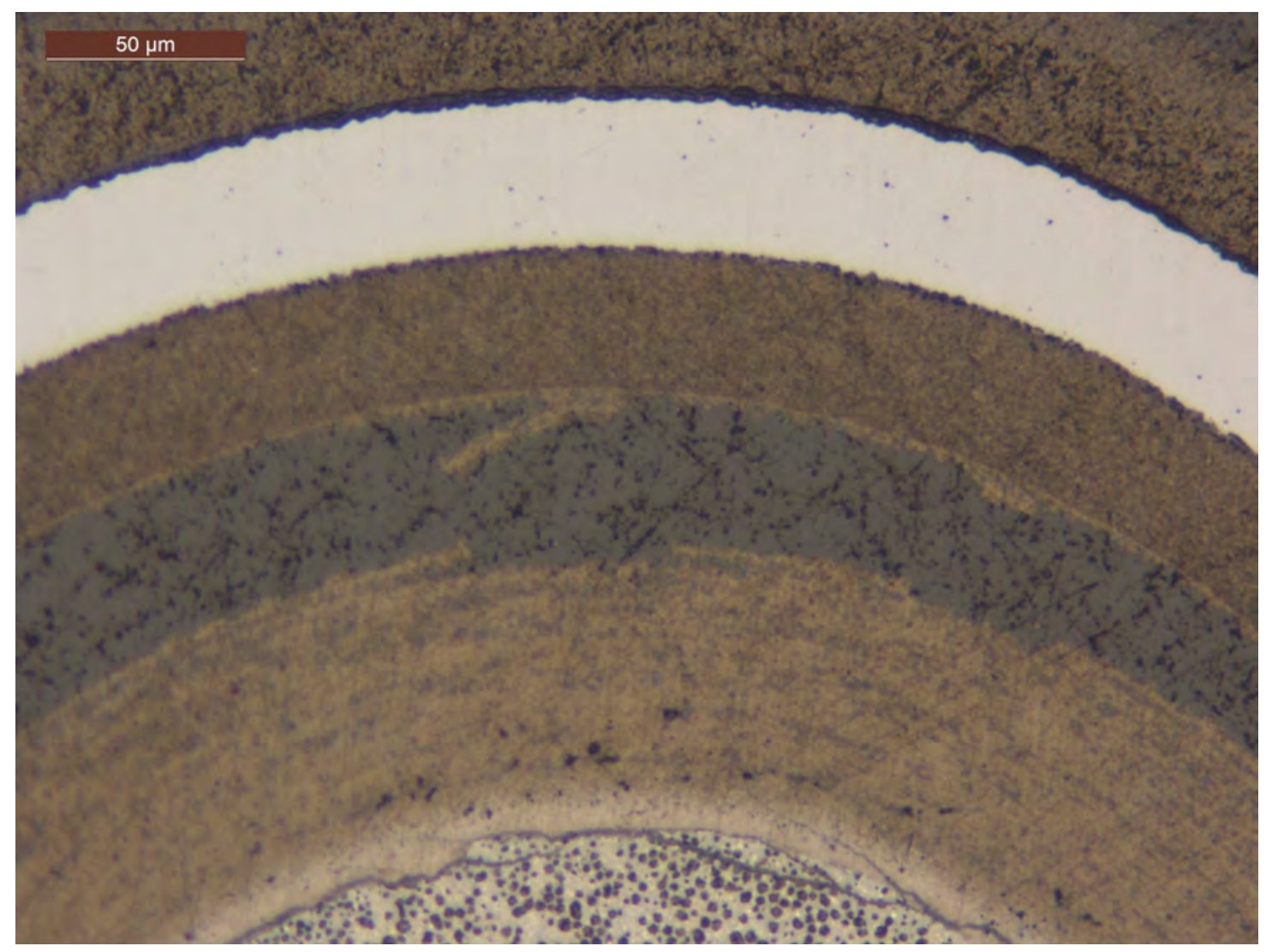

Figure 96. Higher magnification image of particle from Figure 94 (Particle Ag-15). 


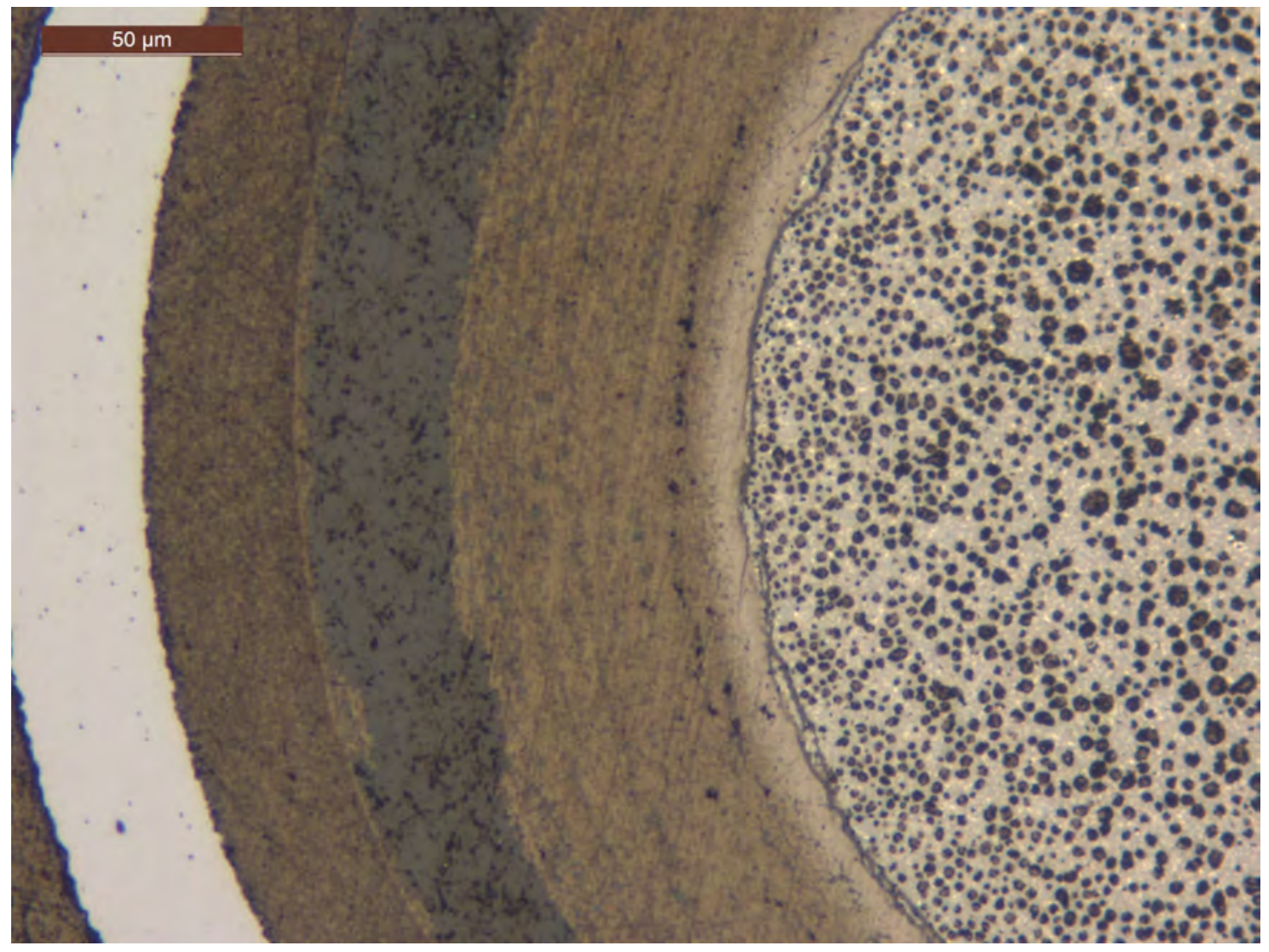

Figure 97. Higher magnification image of particle from Figure 94 (Particle Ag-15). 


\section{X-ray Tomography on Individual Particles}

X-ray tomography is a non-destructive analysis tool that can provide valuable characterization of coated particle fuel. Images of coated particles cross-sections can be obtained without the need for grinding or polishing. This represents a considerable benefit in terms of analysis time, cost and waste reduction, which can be particularly desirable for analysis of irradiated particles. In addition, mechanical grinding and polishing can introduce artifacts in the sectioned surface, and this often adds uncertainty to the analysis. Imaging of 2-dimensional planar sections and 3-dimensional visualization, without disturbing the internal microstructure of the particle, can be particularly valuable in correctly interpreting observed features and anomalies.

$\mathrm{X}$-ray tomography is performed by placing the particle in an x-ray beam and obtaining a radiograph, where the variation in intensity in the image is related to the relative $\mathrm{x}$-ray density along the transmission path of the x-rays striking that area of the detector. The particle is rotated perpendicular to the x-ray beam, and radiographs are obtained at multiple angles of rotation. Tomographic reconstruction is performed to determine the x-ray density of each minimum resolvable volume element (voxel) in the cylindrical volume of rotation. From this data, 2-dimensional tomographs can be produced for any planar section. In addition to tomographs, 3-dimensional representations can be produced using various 3-dimensional visualization software.

A high resolution x-ray tomography instrument, with spatial resolution around $1 \mu \mathrm{m}$, was designed for coated particle fuel characterization by ORNL and Xradia, based on the Xradia MicroXCT-400. This system uses a $100 \mathrm{kV}$ tungsten microfocus $\mathrm{x}$-ray source operated at $40 \mathrm{kV}$ and located $\sim 100 \mathrm{~mm}$ from the sample to provide a high intensity, collimated beam. High resolution is obtained by capturing a digital image of the x-ray scintillation on a polished Tl-doped CsI crystal located 10-40 $\mathrm{mm}$ from the sample and at the focal point of a $20 \mathrm{x}$ microscope objective, which projects the image onto a $2048 \mathrm{x} 2048$ pixel CCD array. Digital images are captured at $0.6 \mu \mathrm{m} / \mathrm{pixel}$, allowing resolutions of $1-2 \mu \mathrm{m}$. This instrument has been used successfully for fuel development under the AGR program, and has been very beneficial for analysis and elimination of coated particle defects. For the first time, this equipment has now been utilized to image irradiated TRISO fuel particles

To use this system with irradiated particles, a lead lined stainless steel shielding enclosure was designed to hold a single particle on a kinematic mount, which couples to the MicroXCT sample stage. Two small ports allow x-rays to enter and exit the shielding enclosure when shutters are retracted. This shielded enclosure allows irradiated particles that measure $\sim 10 \mathrm{Rem} / \mathrm{hr}$ at contact and $240 \mathrm{mRem} / \mathrm{hr}$ at $30 \mathrm{~cm}$ to be reduced to a dose rate of $<2.1 \mathrm{mRem} / \mathrm{hr}$ at contact and $<0.5 \mathrm{mRem} / \mathrm{hr}$ at $30 \mathrm{~cm}$. While in the hot cell, the particle is glued to a plastic Luer-Lok needle and mounted on the sample holder. The sample holder is then loaded into its shielded container (Figure 98). Once transferred to the x-ray tomography instrument and coupled to the stage, the window apertures can be raised to allow line of sight exposure between the x-ray source and the detector (Figure 99). Initially, the irradiated particle is located below the imaging ports. After retracting the shutters, the doors of the large lead-lined enclosure (Figure 100) that surround the entire $x$-ray system are closed before raising the particle up to the open windows. Gamma rays that reach the scintillation crystal yield minimal interference during $\mathrm{x}$-ray imaging.

X-ray radiographs are typically acquired with about $15 \mathrm{sec}$ exposure time. For tomography, radiographic image sets are acquired by rotating the particle about the vertical axis. Depending on the desired image quality, up to 3200 particle positions may be imaged, so image acquisition for each particle can take from 2 to 17 hours. Tomographic reconstruction is done using Xradia Reconstructor software and 3 dimensional visualization of the tomographic data sets is achieved using Kitware's VolView 2.0 software. 


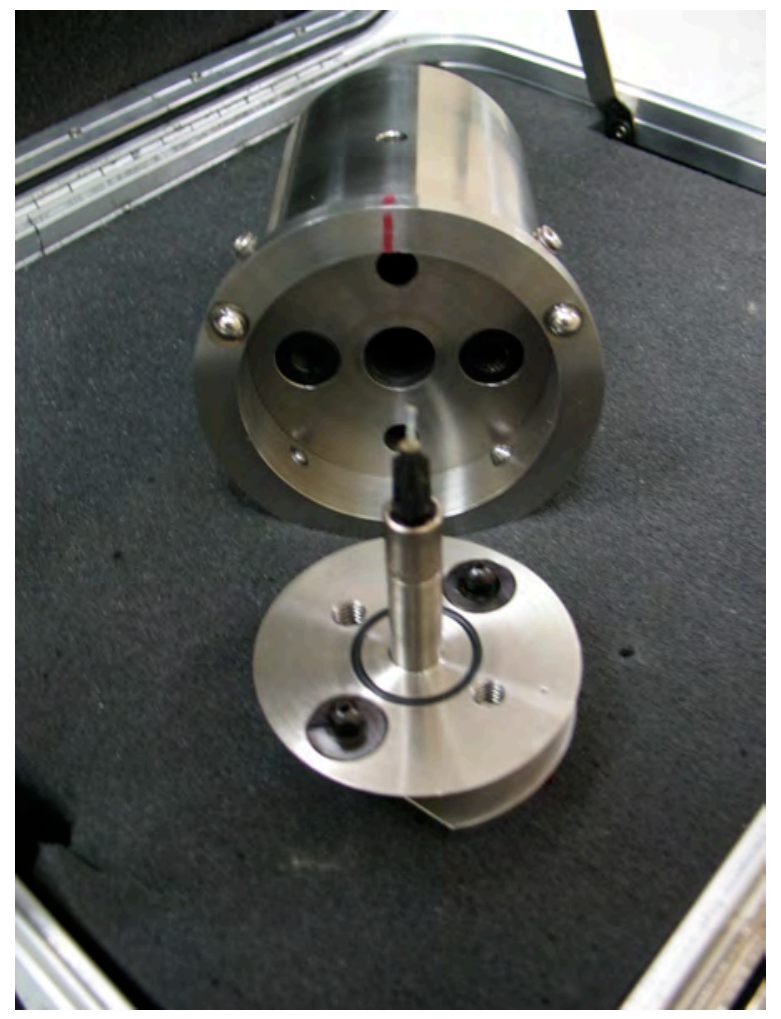

Figure 98. Shielded enclosure for x-ray tomography of irradiated fuel particles.

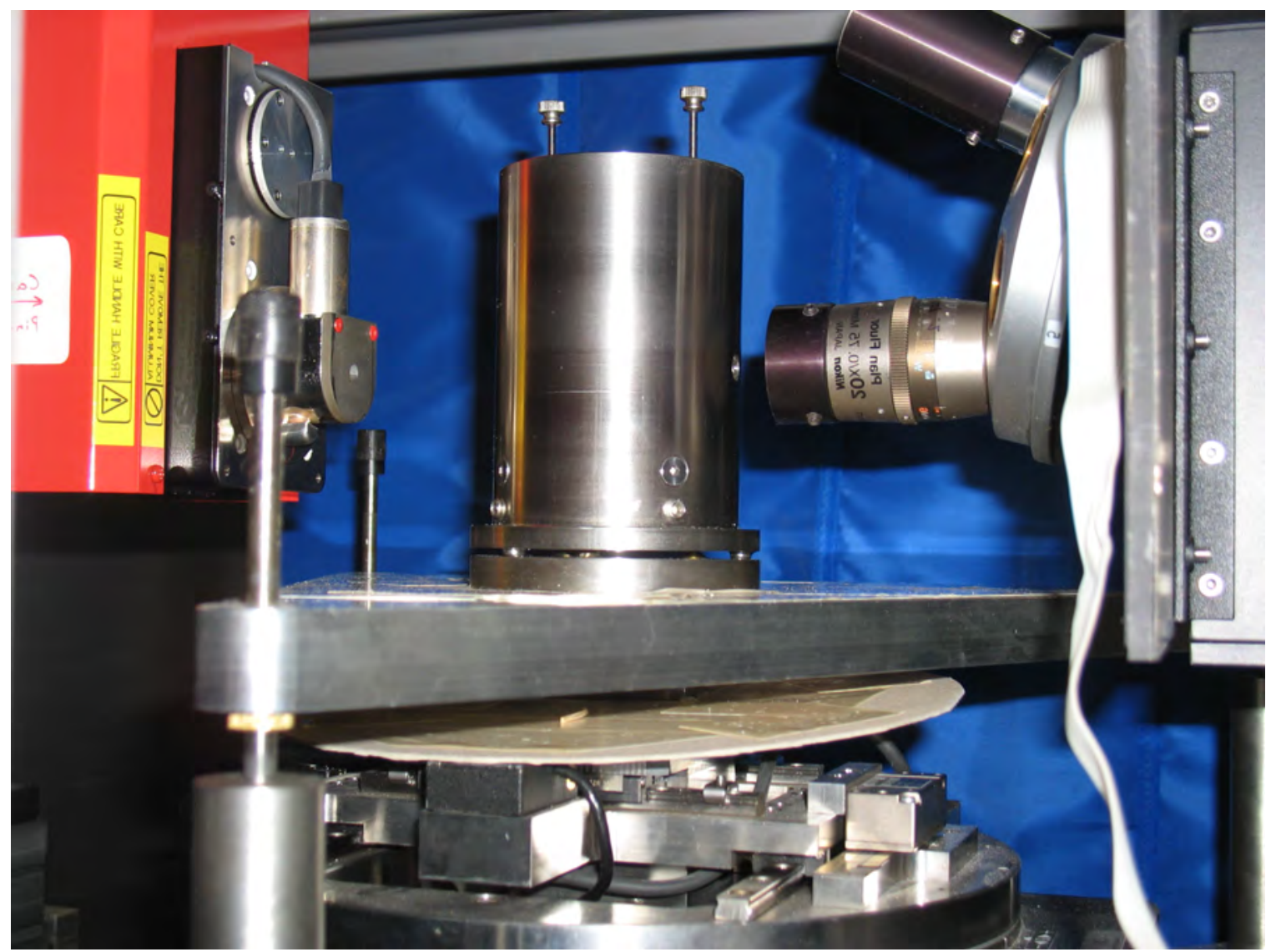

Figure 99. Shielded enclosure in position in x-ray tomography instrument. The x-ray source is shown on the left and the detector on the right of the shield enclosure. 


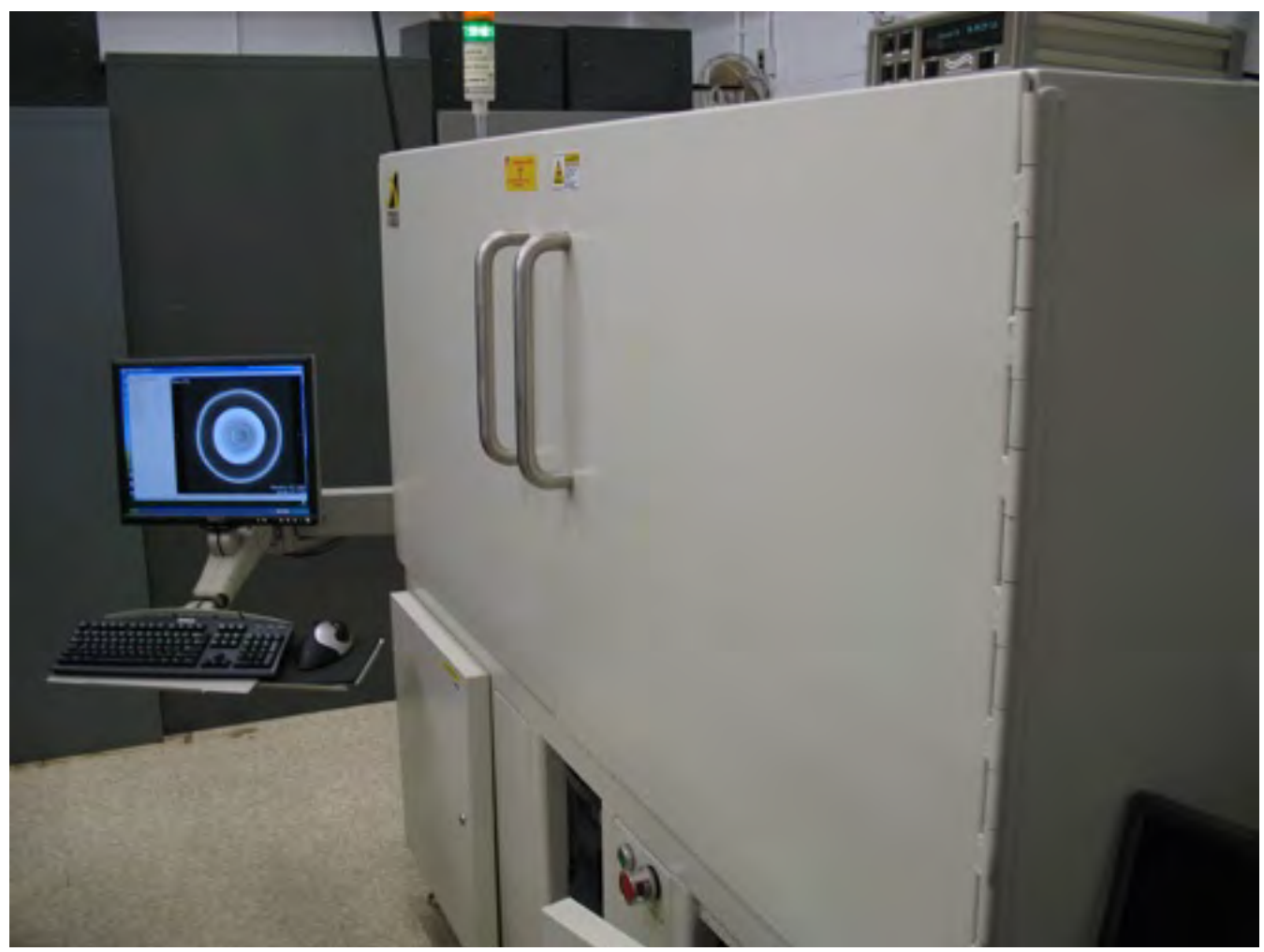

Figure 100. Xradia $x$-ray tomography system for coated particle imaging.

Three particles deconsolidated from Compact 6-1-1 were imaged by x-ray tomography as part of the PIE shakedown. These particles were selected based on results of the IMGA analysis (Table 12). Mount XR-01 held one of the particles discussed in the IMGA section that exhibited abnormally low inventory for both ${ }^{144} \mathrm{Ce}$ and ${ }^{137} \mathrm{Cs}$ (Figure 14 and Figure 15). However, the ${ }^{137} \mathrm{Cs} /{ }^{144} \mathrm{Ce}$ ratio (Figure 16) fell within the distribution band for the whole compact, indicating that the particle had less fissionable material at the start of irradiation, as opposed to loss of cerium or cesium. Cross-sectioning and optical imaging of the other particle with low ${ }^{144} \mathrm{Ce}$ and ${ }^{137} \mathrm{Cs}$ (Figure 36 through Figure 38) showed that the kernel was undersized. Figure 101 and Figure 102 are x-ray tomographs of two orthogonal planes through the approximate center of the particle in Mount XR-01. The kernel appeared to be slightly smaller than normal, although it is difficult to be certain due to the aspherical shape and radiation-induced swelling. This particle exhibited shrinkage and fracture of the buffer layer. However, the buffer fracture was somewhat unusual in that the fracture apparently initiated tangential to the kernel surface. This behavior seems to have prevented the normal kernel extrusion into the large buffer gap, and kernel swelling was limited to only a slight extension beyond a spherical shape. The outer three layers of the particle appear to be intact. Bright spots at the IPyC/SiC interface are probably fission product clusters, as seen in the SEM analysis of polished cross sections. A low density layer (dark ring) at the outer edge of the $\mathrm{SiC}$ can be seen in the upper half of the particle. Figure 103 provides a higher resolution tomograph of this region. This is a soot inclusion, and may be associated with over-fluidization of a particle that would have been lighter than average if the kernel was undersized. The features within the kernel are artifacts of the reconstruction caused by the fact that the $40 \mathrm{keV}$ x-rays cannot penetrate this region.

Table 12. Particles from Compact 6-1-1 imaged by $x$-ray tomography

\begin{tabular}{|c||l|c|}
\hline \multirow{2}{*}{ Mount ID } & Particle Description & $\begin{array}{c}\mathbf{1 1 0 m} \text { Ag Activity } \\
\text { (Bq/particle at } \\
\text { EOL+1 day) }\end{array}$ \\
\hline \hline XR-01 & Low Ce inventory, normal Cs/Ce ratio & not measured \\
\hline XR-02 & Average ${ }^{110 \mathrm{~m}} \mathrm{Ag}$ inventory in 6 hour IMGA scan (Ag-19 from Table 6) & $3.29 \mathrm{E}+04$ \\
\hline XR-03 & Undetectable ${ }^{110 \mathrm{~m}} \mathrm{Ag}$ in 6 hour IMGA scan (Ag-52 from Table 6) & $<0.5 \mathrm{E}+04$ \\
\hline
\end{tabular}




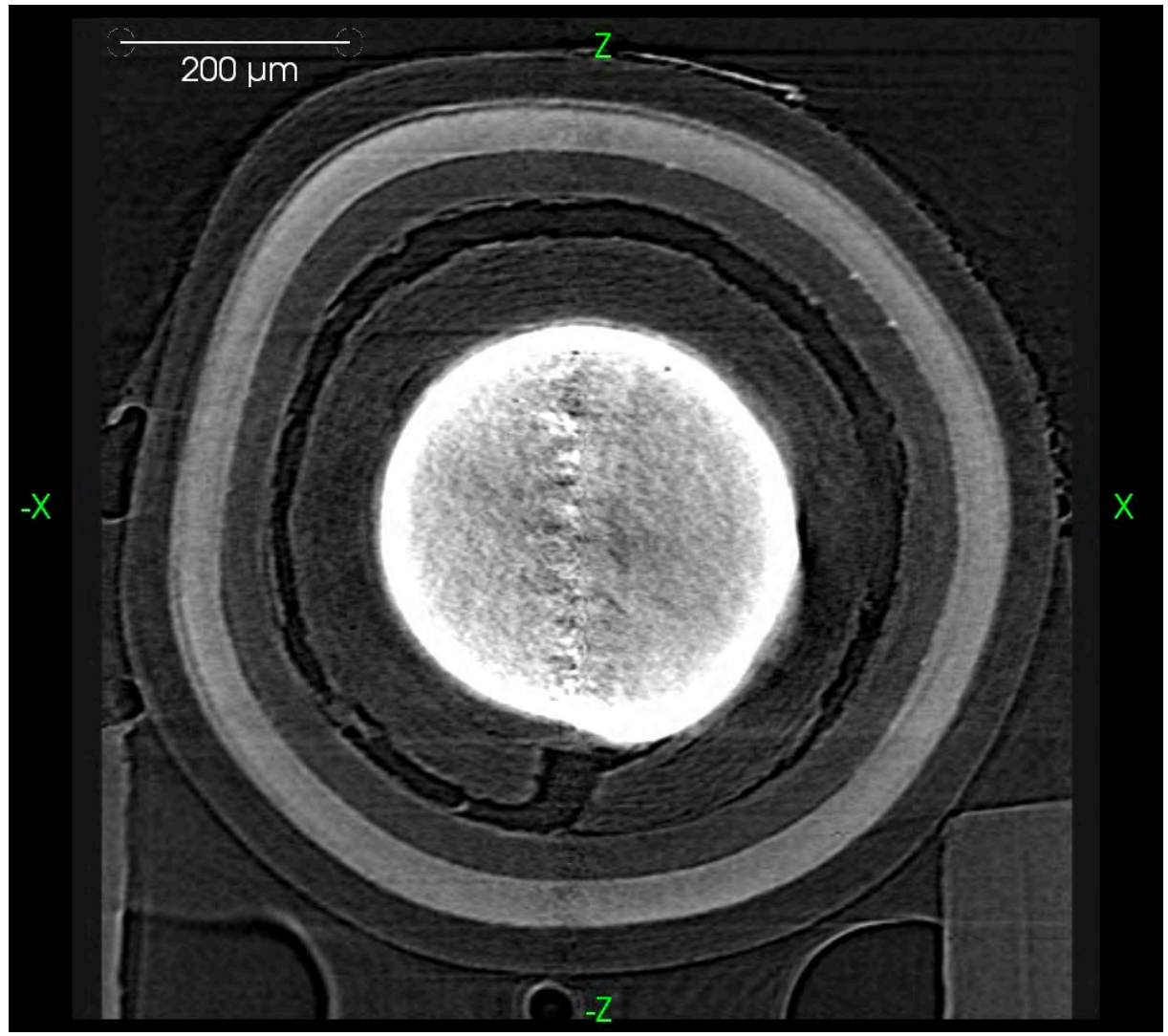

Figure 101. X-ray tomograph near mid-plane of particle in Mount XR-1.

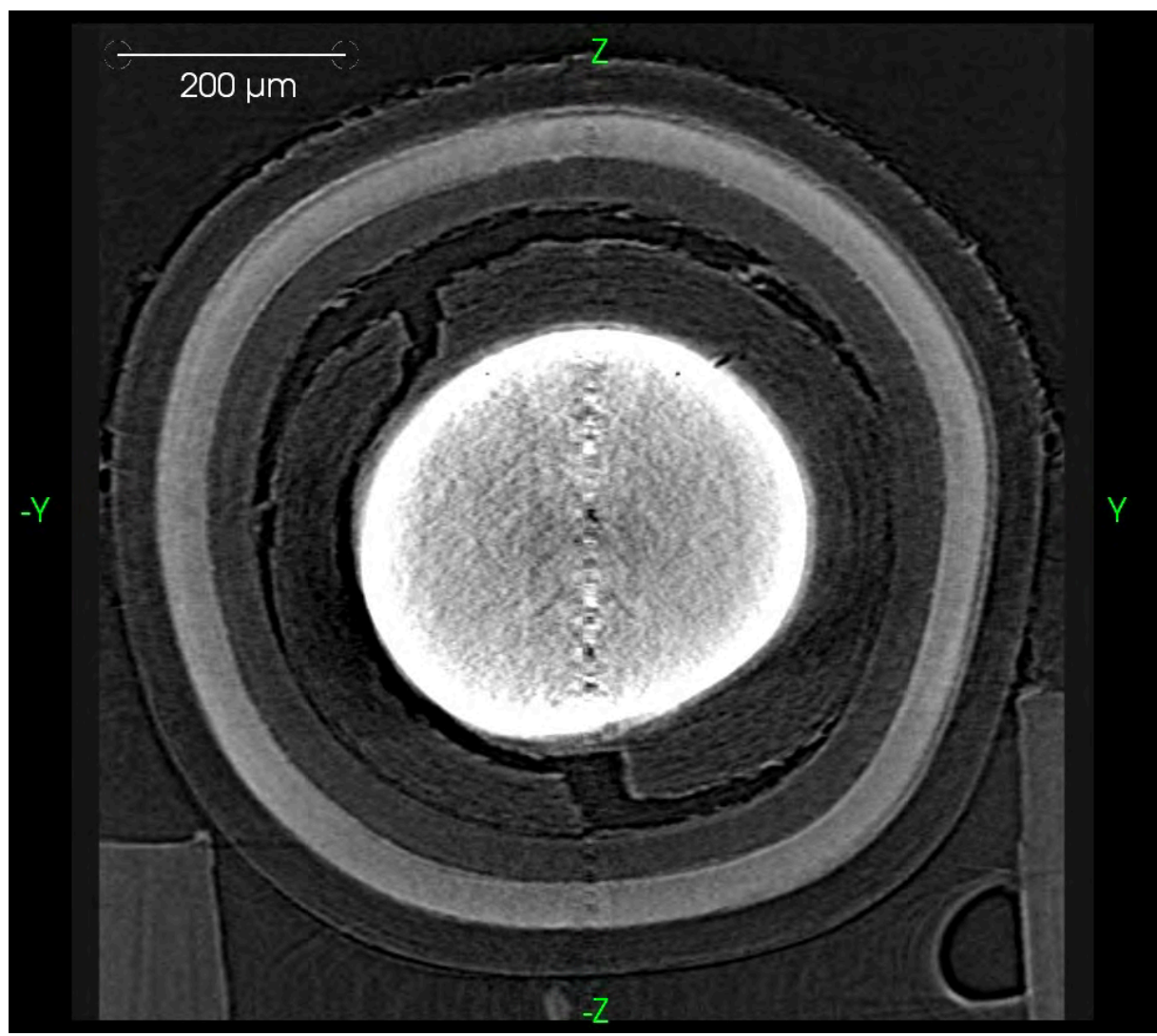

Figure 102. X-ray tomograph near mid-plane of particle in Mount XR-1 (orthogonal to tomograph plane in Figure 101). 


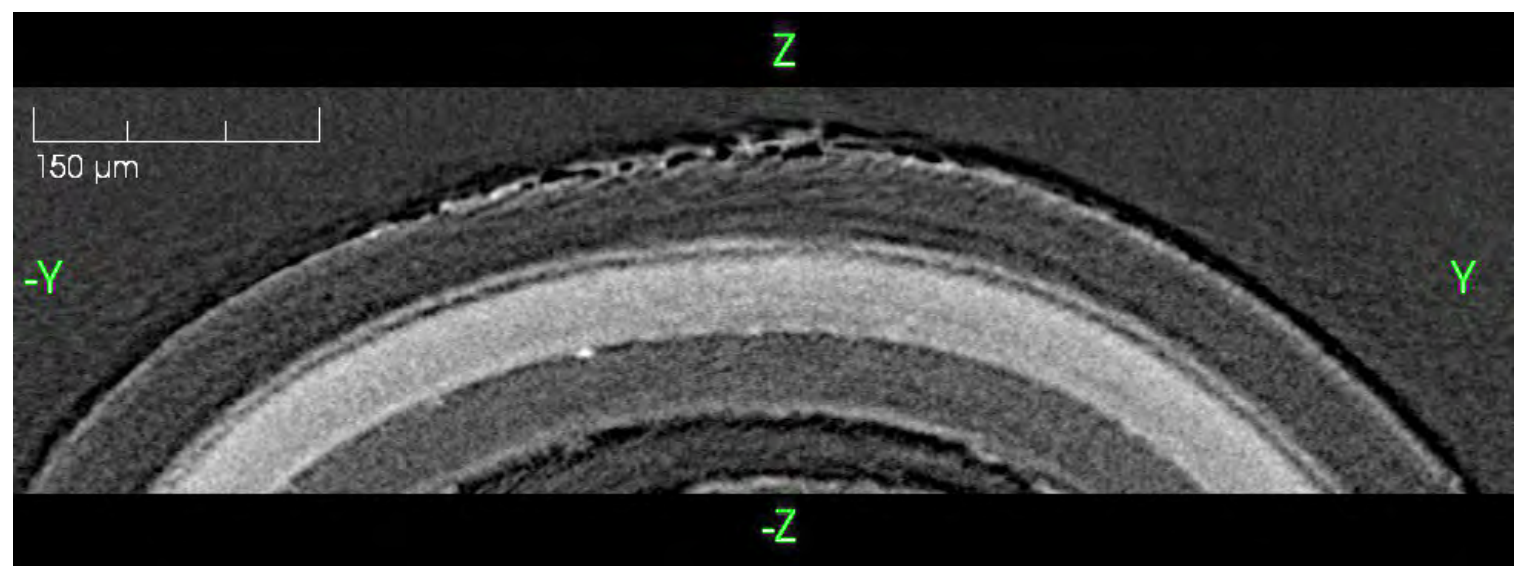

Figure 103. Enhanced resolution tomographic reconstruction of upper region of particle in Mount XR-1 showing soot inclusion in SiC layer.

Figure 104 and Figure 105 show x-ray tomographs of Particle Ag-19 (Mount XR-2). IMGA analysis determined that this particle had a typical fission product inventory. All layers and interfaces were clearly imaged except for the $\mathrm{OPyC}$ at the top of the particle, which was cut off slightly by the shielding enclosure aperture. The IPyC and $\mathrm{SiC}$ layers appear to be intact and defect free. High density spots, indicating fission products, were observed at the IPyC/SiC boundary (Figure 105). Shrinkage and cracking of the buffer is evident, as has been seen in mechanically cross-sectioned particles. The kernel extruded into the open space between the buffer fragments and can be seen in contact with the IPyC layer. Figure 106 is a rendering of the kernel surface obtained using the 3-dimensional visualization software. The regions of kernel extrusion can be seen as raised ridges. The highest of these ridges appears to have completely filled the buffer gap in some regions, and was flush with the inner surface of the IPyC.

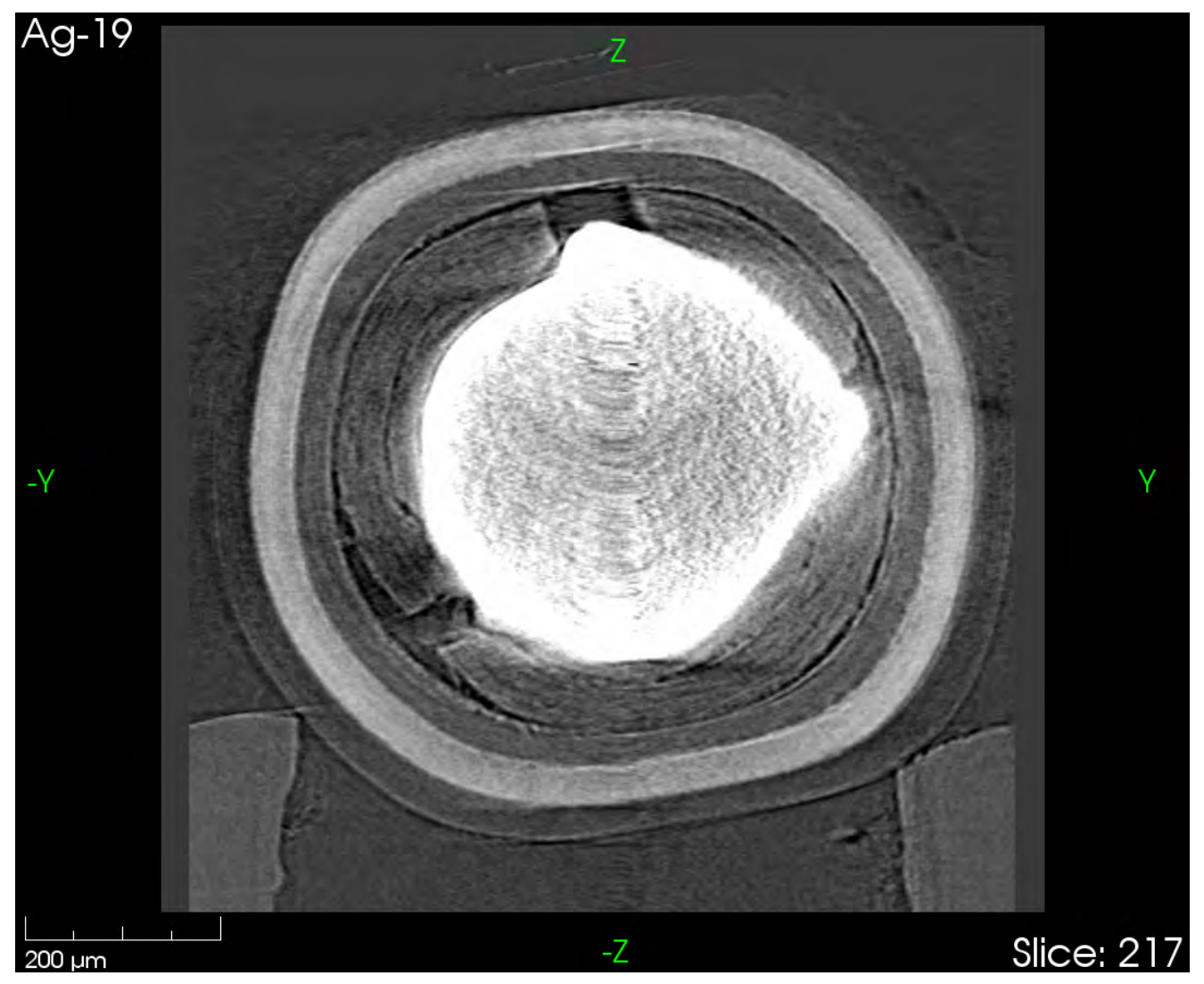

Figure 104. X-ray tomograph of an irradiated TRISO particle showing cracking in the buffer layer and kernel extrusion. 


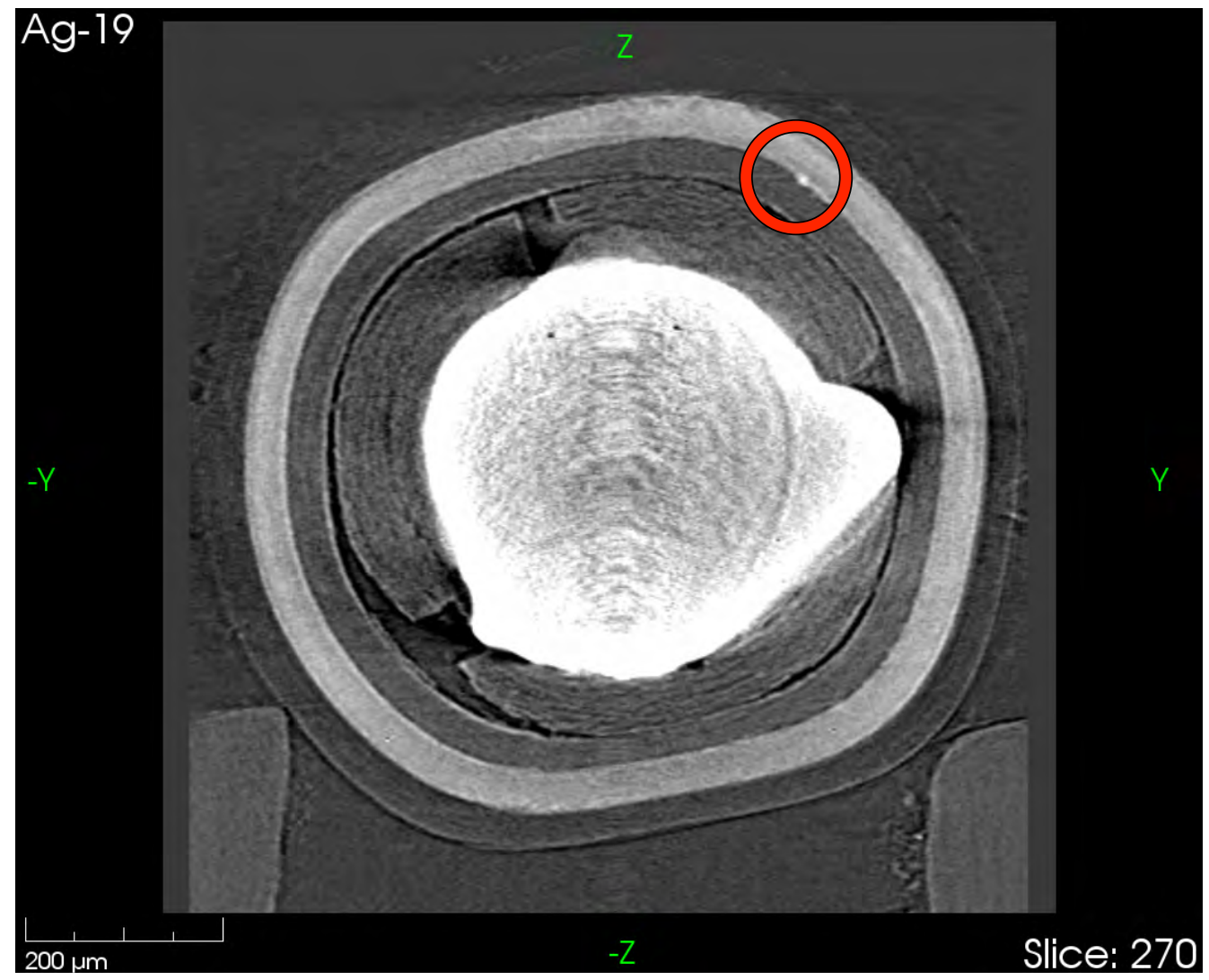

Figure 105. X-ray tomograph of an irradiated TRISO particle showing fission products coalesced at the IPyC/SiC interface (as indicated by the red circle).

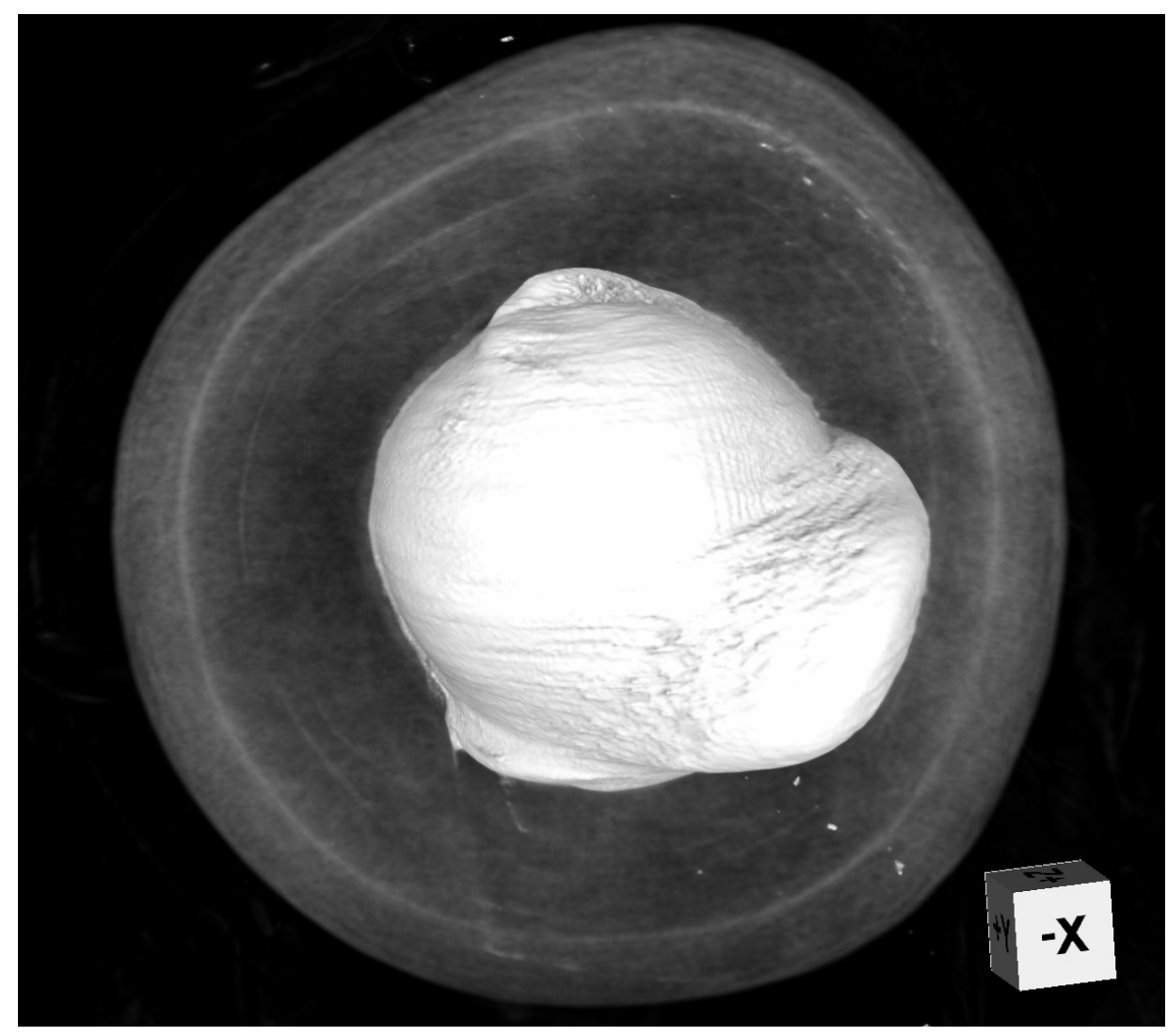

Figure 106. Three dimensional visualization of the extruded kernel from Particle Ag-19. 
In contrast to Particle Ag-19, Particle Ag-52, which had an atypical ${ }^{110 \mathrm{~m}} \mathrm{Ag}$ inventory below the 6 hour IMGA detection threshold, appeared to have the most typical post-irradiation microstructure (Figure 107). The buffer was detached from the IPyC and shrank down to about $60 \mu \mathrm{m}$ thickness. The kernel swelled to a diameter of about $380 \mu \mathrm{m}$. Assuming a $350 \mu \mathrm{m}$ initial kernel diameter, this would correspond to $\sim 28 \%$ kernel swelling and $\sim 43 \%$ buffer shrinkage. The x-ray imaging was able to discern some buffer material still adhering to the inner surface of the IPyC, as expected from the analysis of Minimet cross sections.

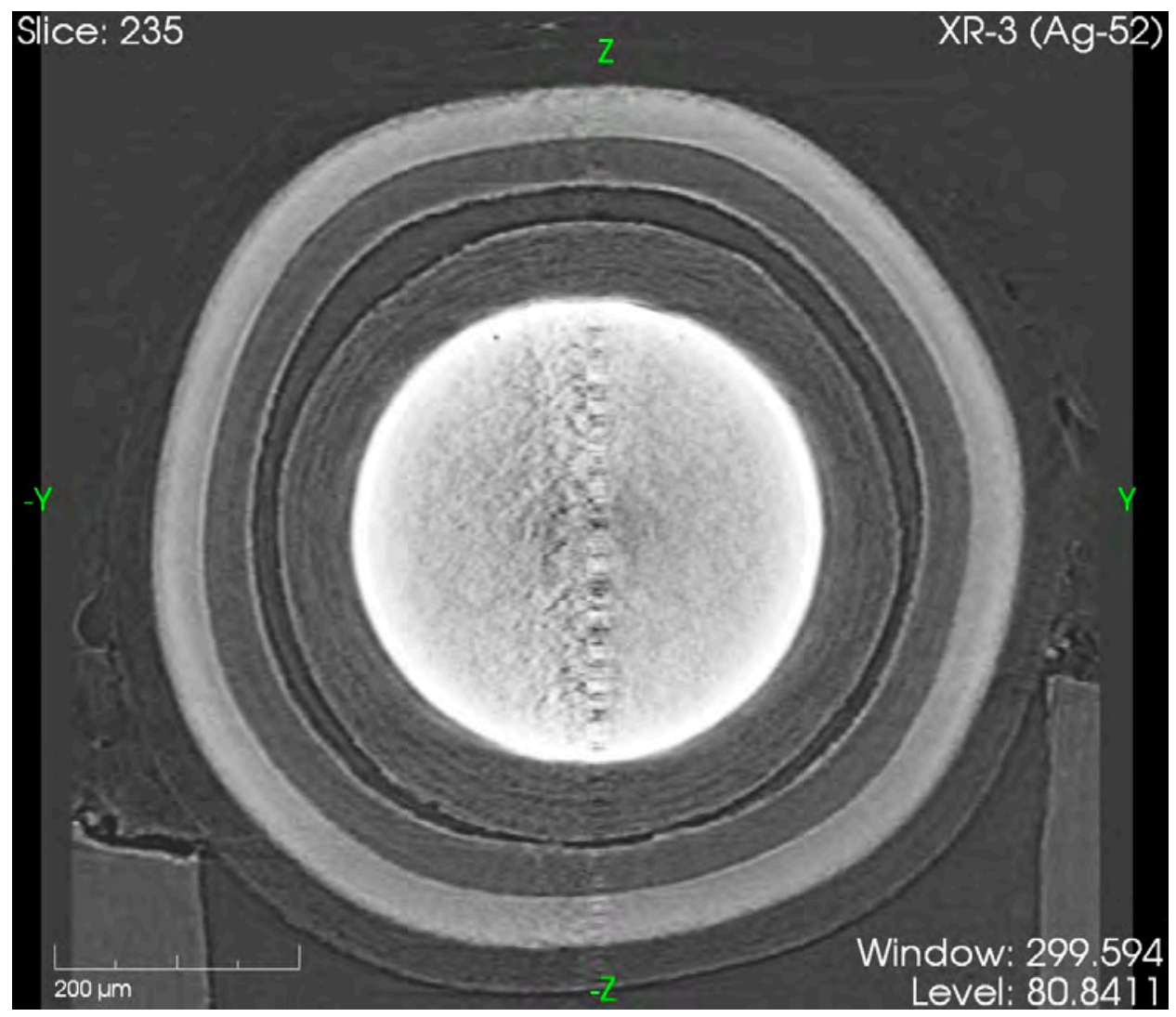

Figure 107. Particle Ag-52 (Mount XR-3) near mid-plane. 


\section{Summary}

AGR-1 irradiation test Compact 6-1-1 was subjected to detailed post-irradiation examination. PIE included analysis by LBL and IMGA, preparation of polished particle cross sections, followed by optical and scanning electron microscopy, and non-destructive $\mathrm{x}$-ray tomography of the irradiated particles. All planned PIE [Demkowicz 2010-2] was completed, except for single particle furnace tests, which were not performed due to limited funding and higher prioritization for whole compact furnace tests. AGR-1 Compact 6-1-1 PIE was also designed to be a shakedown of the PIE methods and procedures. As part of this process, procedures for analysis and data reporting were refined.

The hot cell equipment designed for electrolytic deconsolidation and LBL by Soxhlet extraction performed well. Special effort to reduce pick-up of hot cell contamination was identified as an important practice. Leachant analysis was initially performed for a broad spectrum of fission products. Analysis of beta/gamma emitting isotopes was generally found to be more reliable than analysis by mass spectrometry for the stable isotopes, because of lower background contamination levels and better analysis sensitivity for the radioactive isotopes. There was little value gained by performing mass spectrometry to measure the concentration of elements with available beta/gamma emitting isotopes. This essentially redundant mass spectrometry will be deleted from future analysis, and for the remaining stable isotopes, only those that are present in measurable concentrations will be measured quantitatively. Based on results from Compact 6-1-1, this reduced ICP-MS analysis list should include ${ }^{105} \mathrm{Pd}$ and ${ }^{152} \mathrm{Sm}$, and possibly some of the lanthanides. ICP-MS was also used to measure actinide concentration, and the same issues affected these results. It was possible to determine that no kernels were exposed in Compact 6-1-1, either before or after the burn, but measurement of low concentrations of uranium and plutonium (less than a few tenths of a single kernel's inventory) was limited by analysis accuracy and hot cell contamination.

Several conclusions can be drawn from the deconsolidation leach-burn-leach analysis of AGR-1 irradiated Compact 6-1-1. Low values for uranium indicated that there were no exposed kernels, either due to total failure of the TRISO coating layers or due to defective SiC. However, retention of silver, europium, and palladium by the intact $\mathrm{SiC}$ shells was relatively poor. More than $10 \%$ of the expected

${ }^{110 \mathrm{~m}} \mathrm{Ag}$ generated during irradiation was detected outside of the $\mathrm{SiC}$ and this represents an unknown fraction of the total silver release because it is known that silver diffused out into the graphite holder during irradiation. Europium and palladium were detected at about $1 \%$ of the predicted compact inventory. A similar amount of gadolinium was also detected outside of the $\mathrm{SiC}$, but it is unclear if the detected ${ }^{156} \mathrm{Gd}$ passed through the $\mathrm{SiC}$ as gadolinium or as ${ }^{156} \mathrm{Eu}$ prior to beta decay. At less than $0.1 \%$ of expected fission product inventories, smaller, but apparently measurable releases of ${ }^{90} \mathrm{Sr},{ }^{144} \mathrm{Ce}$, and ${ }^{152} \mathrm{Sm}$ were also detected by the LBL analysis. Like europium, these elements may diffuse out as carbides. Several other elements (e.g., technetium, lanthanum, praseodymium, and neodymium) were detected by the ICP-MS, but the results were inconclusive because of the possible levels of background contamination.

Electrolytic deconsolidation, Soxhlet extraction, and a final 24 hour boil in nitric acid was successful in removing the compact matrix material from the surface of the TRISO particles prior to IMGA analysis. It is desirable to perform IMGA analysis prior to burn-leach of the particles, because this allows for detection and microstructural analysis of particles with defective SiC. Otherwise, the burn-leach process would destroy the carbon layers, kernel, and probably the defective SiC layer. Bench testing also determined that the IMGA particle handling worked best on the larger, OPyC coated material. However, even with clean full TRISO particles, some multiple particle pick up still occurred during analysis of the particles from Compact 6-1-1. Adjustments to the IMGA control software have been made to reduce the likelihood for multiple particle pick up in the future.

A standardized method for presenting the IMGA data was derived to report the ratio of the measured particle inventory for each gamma emitting isotope versus the calculated inventory (assuming no fission product release). The calculated single particle inventory for each particle was estimated by first dividing the calculated inventory for the relevant compact [Sterbentz 2011] by the average number of particles in the compact (4145). This average calculated single particle inventory was then adjusted for the variation in fissile content and burnup in each particle by multiplying by the ratio of the measured ${ }^{137} \mathrm{Cs}$ activity for 
that particle to the average measured ${ }^{137} \mathrm{Cs}$ activity. The resulting normalized measured to calculated inventory ratio is given by,

$$
\frac{A_{i}^{X}}{A_{\text {calc }}^{X} \times\left(A_{i}^{C S-137} /\left(\frac{1}{n}\right) \sum_{j=1}^{n} A_{j}^{C S-137}\right)},
$$

where $\mathrm{A}_{\mathrm{i}}^{\mathrm{X}}$ is the decay-corrected measured activity of particle $i$ for isotope $X, \mathrm{~A}_{\text {calc }}^{\mathrm{X}}$ is the average calculated activity for a single particle, $A_{i}^{\mathrm{Cs}-137}$ is the decay-corrected measured ${ }^{137} \mathrm{Cs}$ activity for particle $i$, and $n$ is the total number particles counted. For the case where the isotope of interest is ${ }^{137} \mathrm{Cs}$, ${ }^{144} \mathrm{Ce}$ is used to adjust for the variation in fissile content and burnup. The use of ${ }^{144} \mathrm{Ce}$ was considered for normalizing all the measured inventory data (as has been done in the past), but correlations to the ${ }^{137} \mathrm{Cs}$ data appeared to be stronger and produced narrower distributions. Cesium also appears to be retained better than cerium in non-defective AGR-1 particles and ${ }^{137} \mathrm{Cs}$ is a more stable indicator of burn-up for particles with intact $\mathrm{SiC}$.

A short scan $(100 \mathrm{sec})$ IMGA analysis was performed on 4079 of the expected $\sim 4145$ particles in Compact 6-1-1. Some particles dropped off the IMGA vacuum needle due to multiple particle pick up and were not recovered for analysis due to concerns with cross contamination of the sample. The short IMGA scan for ${ }^{137} \mathrm{Cs}$ and ${ }^{144} \mathrm{Ce}$ determined that no particles had preferentially lost cesium, which would occur if a particle had defective SiC. This result was in agreement with the LBL. The average ${ }^{137} \mathrm{Cs}$ inventory was also very close to what had been calculated. Two abnormal particles were found that had only $20 \%$ of the expected inventory of both ${ }^{137} \mathrm{Cs}$ and ${ }^{144} \mathrm{Ce}$, but a normal ${ }^{137} \mathrm{Cs} /{ }^{144} \mathrm{Ce}$ ratio. These particle had undersized kernels (as determined by materialography and x-ray) and may also have had a lower than average fraction of ${ }^{235} \mathrm{U}$, but there was no indication that cerium or cesium had been released from these particles. Further analysis is planned to determine the source of these abnormal particles, which have also been observed in other compacts.

A longer scan (1 hour) IMGA analysis was completed on 120 randomly selected particles. A bimodal distribution in the retained inventory of ${ }^{110 \mathrm{~m}} \mathrm{Ag}$ was observed, with some particles retaining most of their silver and some releasing almost all of it. The ${ }^{154} \mathrm{Eu}$ inventory was also examined. The average ratio of the measured versus calculated ${ }^{154} \mathrm{Eu}$ inventory was 0.84 . This was lower than expected. The measured ${ }^{154} \mathrm{Eu}$ in the compact matrix and capsule components indicate a europium retention above $98 \%$. This discrepancy is most likely an indication of error in the calculated values for europium production. The distribution in the ${ }^{154} \mathrm{Eu}$ inventory was slightly broader than ${ }^{137} \mathrm{Cs}$ and two particles in the 120 particle random sample had a measurably lower ${ }^{154} \mathrm{Eu}$ inventory. Unfortunately, these two particles were not found when additional particles were surveyed in individual vials for 6 hours, as discussed below. Additional IMGA analysis would be required to identify these low europium retention particles for further analysis.

Sixty particles were re-analyzed with 6 hour scanning. This re-analysis included all 47 particles that indicated a measurable inventory in the 1 hour scan, 2 particles that had been set aside because they were picked up and measured together, and 11 particles whose inventory could not be measured with the 1 hour scan. Of the 11 particles with undetectable ${ }^{110 \mathrm{~m}} \mathrm{Ag}$ in the 1 hour scan, 6 retained insufficient silver to be detected in the 6 hour scan. The sensitivity threshold for this 6 hour gamma scan was estimated to be $\sim 0.5 \cdot 10^{4} \mathrm{~Bq}\left(\sim 15 \%\right.$ of the calculated inventory). Four particles exhibited low ${ }^{110 \mathrm{~m}} \mathrm{Ag}$ activity between 0.5 $1.3 \cdot 10^{4} \mathrm{~Bq}$. One particle had a measured ${ }^{110 \mathrm{~m}} \mathrm{Ag}$ activity of $2.6 \cdot 10^{4} \mathrm{~Bq}$, which should have been detectable with 1 hour of counting, but might possibly have been improperly sorted if it was part of a multiple particle pick-up. The 1 hour gamma scan was apparently insufficient to resolve the variation in silver content for particles with less than $\sim 40 \%$ of the calculated ${ }^{110 \mathrm{~m}} \mathrm{Ag}$ inventory, but a bimodal distribution in the silver retention was still indicated. Future IMGA analysis should be performed using count times sufficient to measure the full range of silver inventory, and if count times are extended, all particles in a random sample should be re-analyzed.

Particles were selected for materialographic and x-ray examination based on IMGA analysis. Production of polished particle cross sections using 1.25" diameter mounts was complicated by the lack of immediate feedback by optical inspection of the surface during grinding. There was also an increased likelihood for damage from particle debris when mounts contained multiple particles. Production of 
polished particle cross sections using a 0.125" diameter mounting area and a Buehler Minimet installed in the same hot cell cubicle as the remote metallograph was much more successful.

The kernel and buffer layer were impacted the most by the irradiation. Buffer densification occurred, with the buffer usually separating near the buffer/IPyC interface. In some cases, the buffer fractured as it was shrinking. This fracture may be related to instances where the buffer did not detach from the IPyC. Kernels increased in volume, with a large variation in degree of swelling and internal porosity that appeared to be related to both the amount of constraint to expansion supplied by the buffer and the asfabricated kernel microstructure. Buffer fracture resulted in a lack of constraint on kernel swelling, resulting in larger internal pores and preferential swelling into the open space between the buffer fragments. One particle showed propagation of the buffer fracture into the adjacent IPyC layer. This resulted in local delamination of the IPyC from the $\mathrm{SiC}$, which produced small fractures in the $\mathrm{SiC}$ that did not penetrate through the layer. The $\mathrm{SiC}$ fractures appeared to be directed tangential to the $\mathrm{IPyC} / \mathrm{SiC}$ interface and confined to the region of smaller grain structure near the inside of the $\mathrm{SiC}$ shell. This grain structure may have been beneficial in preventing the cracks from propagating through the layer. Further away from the $\mathrm{IPyC} / \mathrm{SiC}$ interface, $\mathrm{SiC}$ grains are larger and elongated in the radial direction. This grain structure might be more prone to radial cracking.

Scanning electron microscopy with EDS and WDS analysis was useful in further studying the coating layer microstructure and identifying clusters of fission products that had migrated out of the kernel. The use of EDS and WDS in concert was necessary to identify the fission products accurately. Without the implementation of WDS, many minor elements would not be properly identified due to peak overlap issues. The added chemical sensitivity was also of importance for trace element analysis.

The major fission product features of interest were Pd-U-Si clusters at both the IPyC/SiC interface and embedded in the SiC layer. WDS analysis on this limited sample set suggested a relatively constant $\mathrm{Pd}: \mathrm{U}$ concentration ratio close to unity. The relationship between silver migration through $\mathrm{SiC}$ and palladium silicide formation remains an unanswered question. Silver could not be detected in the Pd-rich fission product clusters observed in this study, but sensitivity to silver in the WDS spectrum was limited by peak overlap issues. Additional analysis using higher excitation energy will be attempted in the future to increase silver detection sensitivity. In a single case, trace cerium and neodymium concentrations were also observed at the IPyC/SiC interface. Based on this observation and LBL results, further analysis for lanthanides is warranted. Analysis for cesium outside of the kernel was complicated by hot cell contamination and inclusion of cesium in pores or gaps between the layers. Ultrasonic cleaning will be used in the future to reduce this contamination effect.

A custom designed shielded closure was successfully used for x-ray tomography of intact irradiated particles. X-ray tomography proved to be very useful for viewing changes in the buffer layer and extrusion of the kernel in particles with fractured buffer. Because of their relatively higher density, fission products clustered outside of the kernel could also be easily located. The three dimensional data provided by the tomography provides the opportunity for quantification of the kernel swelling and buffer shrinkage without the inherent uncertainties involved in two dimensional analysis of polished cross sections.

Defects in the outer three coating layers can also be detected, but none were seen in the samples that were imaged.

Future PIE is expected to build on the methods and techniques used to study AGR-1 compact 6-1-1. Some lessons learned from this initial shakedown have already been applied to the analysis of other compacts. Given the limited number of samples examined by materialography and x-ray, it would be premature to draw conclusions from the observations presented in this report. However, suggested trends in the irradiation behavior are being examined further and conclusions can eventually be supported as sufficient data becomes available. Variation in behavior from particle to particle and from compact to compact is already becoming evident as PIE progresses. Understanding of this variation is complicated by the combined effects from variation in initial as-fabricated properties (e.g., kernel stoichiometry and SiC microstructure) and time and spatial dependent variation in burn-up and temperature within the irradiation test train. Deconvoluting these variations may be complicated and will require additional effort to improve calculation of irradiation conditions, in addition to acquisition of sufficient PIE data. 


\section{References}

Demkowicz, P.A., “AGR-1 Post-Irradiation Examination Plan,” INL/PLN-2828, Rev. 1, March 2010.

Demkowicz, P.A., L.T. Cole, S.A. Ploger, and P.L. Winston, "AGR-1 Irradiated Test Train Preliminary Inspection and Disassembly First Look," INL/EXT-10-20722, January 2011.

Demkowicz, P.A., "Irradiated AGR-1 Compact 6-1-1 Examination Plan," INL/PLN-3624, September 2010 .

Harp, J.M., "Analysis of Individual Compact Fission Product Inventory and Burnup of the AGR-1 TRISO Experiment Using Gamma Spectrometry," INL/ECAR-1682, September 2011.

Harp, J.M., P.A. Demkowicz, and S.A. Ploger, "Post-Irradiation Examination and Fission Product Inventory Analysis of AGR-1 Irradiation Capsules," HTR2012-3-006, Proceedings of the 6th International Topical Meeting on High Temperature Reactor Technology, Tokyo, Japan, October 28 November 1, 2012.

Hawkes, G.L., “AGR-1 Daily As-Run Thermal Analyses,” INL/ECAR-968, Rev. 2, January 2012.

Hunn, J.D. and R.A. Lowden, "Data Compilation for AGR-1 Baseline Coated Particle Composite LEU01-46T,” ORNL/TM-2006/019, April 2006.

Hunn, J.D., F.C. Montgomery, and P.J. Pappano, "Data Compilation for AGR-1 Baseline Compact Lot LEU01-46T-Z,” ORNL/TM-2006/507, August 2006.

Kercher, A.K. and J.D. Hunn, "Results from ORNL Characterization of Nominal $350 \mu \mathrm{m}$ LEUCO Kernels from the BWXT G73D-20-69302 Composite," ORNL/TM-2005/517, August 2005.

Kocher, D.C., "Radioactive Decay Data Tables, A Handbook of Decay Data for Application to Radiation Dosimetry and Radiological Assessments," DOE/TIC-11026, 1981.

Parry, J.R., "Estimate of the AGR-1 End of Irradiation Radiological Source Term," INL/ECAR-719, Rev. 0, September 2009.

Pope, M.A., “AGR-1 Irradiation Test Final As-Run Report,” INL/EXT-10-18097, April 2010.

Sterbentz, J.W., "JMOCUP As-Run Daily Depletion Calculation for the AGR-1 Experiment in the ATR B-10 Position,” INL/ECAR-958, Rev. 1, August 2011.

Rose, K.S.B., B.J. Symes, and J.B. Sayers, "Structural Changes in Coated Particles Irradiated Over a Wide Range of Burn-Up and Temperature," Harwell, Atomic Energy Research Establishment AERER5159 (also Dragon Project Report 412), 1966.

Roussin, R.W., J. R. Knight, J.H. Hubbell, and R.J. Howerton, "Description of the DLC-99/Hugo Package of Photon Interaction Data in ENDF/B-V Format, ORNL/RSIC-46 (ENDF-335), December 1983.

Valentine, K.H. and M.J. Kania, "IMGA Operating Manual," ORNL/TM-6576, August 1979. 